\title{
FALLACIES IN JUDICIAL INTERPRETATION
}

BY

ANDREW GEOFFREY HUTCHISON

\begin{abstract}
A thesis
submitted to the Victoria University of Wellington

in fulfilment of the requirements for the degree of

Doctor of Philosophy in Law
\end{abstract}

Victoria University of Wellington

2012 


\section{ACKNOWLEDGEMENTS}

I thank my supervisors Tony Angelo, Gordon Stewart and Grant Morris for their careful, attentive reading of this thesis, their many detailed and helpful suggestions and comments, their tolerance with my shifting and developing ideas, and for their flexibility during my mother's illness.

I thank Joy Christine Franz for reading many drafts and for her insightful and encouraging comments. I am thankful to Shaun Broadley for carefully reading a late draft and making many helpful observations. I also thank John Garratt for reading draft chapters and Richard Hutchison for his willingness to discuss the ideas in this thesis with me.

I am very grateful to my father for all his support during my research and writing. It would have been impossible for me to complete this thesis without this support. I had the privilege of caring for my mother while working on this thesis. I was deeply impressed and supplied during this time by the pattern she provided of a faithful lover of Christ expressing Him in the midst of sufferings and limitation.

Most importantly, for His mercy, grace and timely help, I thank the Great High Priest, Jesus, the Son of God. 


\begin{abstract}
This thesis concerns fallacies in judicial interpretation. The central contention of this thesis is that judges commit certain fallacies when interpreting language and that it is possible to detect such fallacies and arrive at alternative, non-fallacious interpretations when they occur.

An instance of judicial interpretation is fallacious when it takes into account an irrelevant consideration and it is most likely that a different result would have been reached if that consideration had been omitted, or when it omits a relevant consideration and it is most likely that a different result would have been reached if that relevant consideration had been taken into account.
\end{abstract}

The thesis identifies two specific fallacies which involve judges introducing an irrelevant consideration and usually involve judges omitting relevant considerations. These two fallacies are errors of categorisation, and occur when judges make an interpretive decision on the basis of the irrelevant consideration of the verbal category to which an item can be assigned rather than the relevant considerations which determine the legal category to which it should be assigned.

These two fallacies are detected by assessing whether an instance of interpretation is merely based on the verbal category to which an item can be assigned or whether it is justified by relevant considerations. Alternative, non-fallacious interpretations are arrived at by introducing any relevant considerations and omitting any irrelevant considerations. 


\section{TABLE OF CONTENTS}

ABSTRACT ...................................................................................... 3

TABLE OF CONTENTS......................................................................... 4

DIAGRAMS AND CHARTS................................................................ 7

\section{CHAPTER ONE}

INTRODUCTION

\section{CHAPTER TWO}

LANGUAGE, LAW AND JUDICIAL INTERPRETATION ................................................ 12
A Introduction 12
B Language. 12
C Law and Language ..... 14
D Judicial Interpretation.... 16
E Questions for this Thesis 20

\section{CHAPTER THREE}

LANGUAGE AND INTERPRETATION FALLACIES ................................................. 22

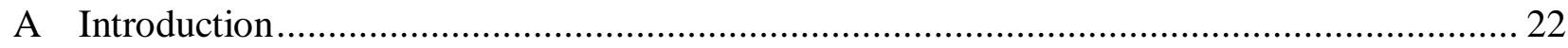

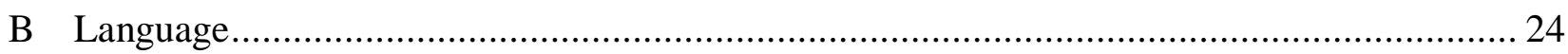

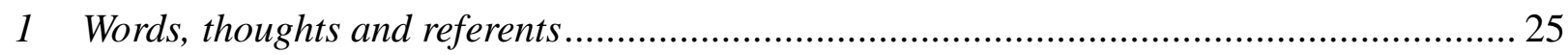

(a) Approach to language and interpretation........................................................... 33

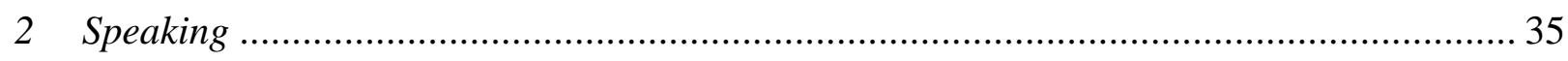

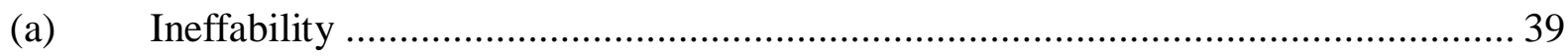

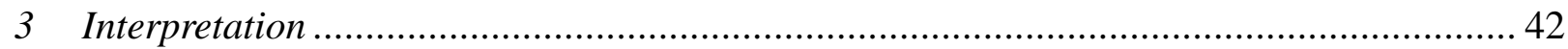

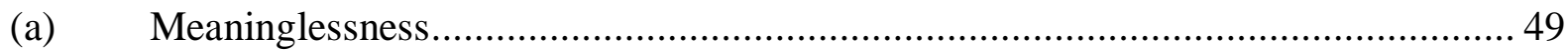

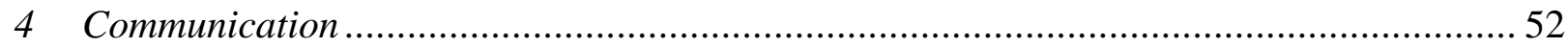

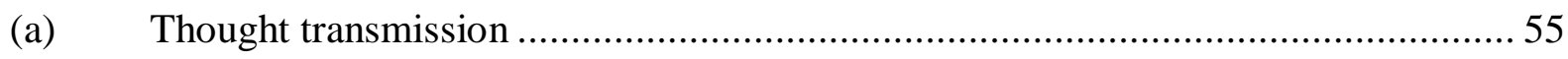

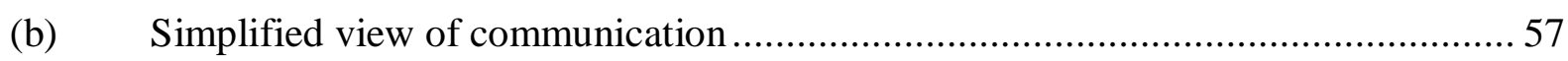

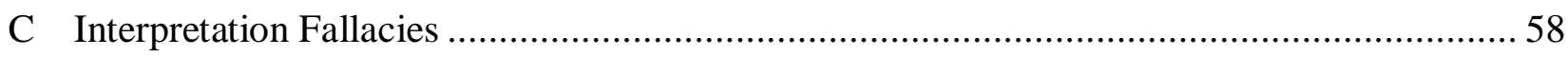

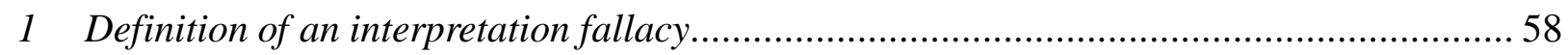

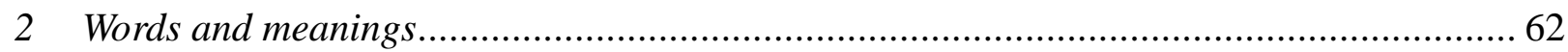

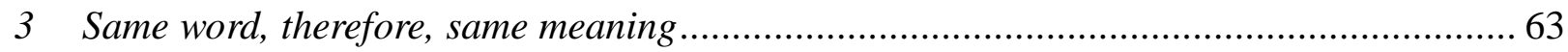


4 Different word, therefore, different meaning ............................................................. 68

5 Discussion of 'same word' fallacy and 'different word' fallacy...................................... 71

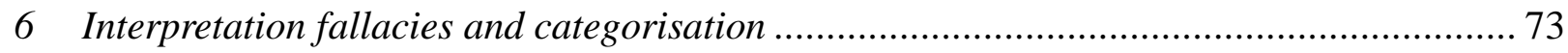

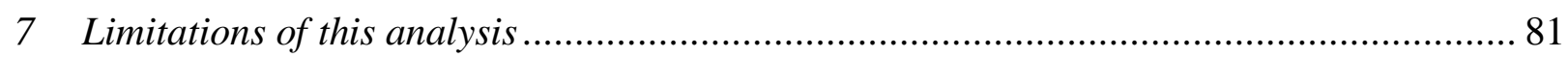

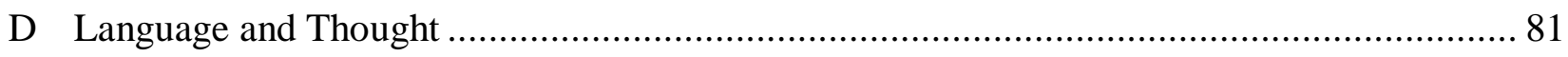

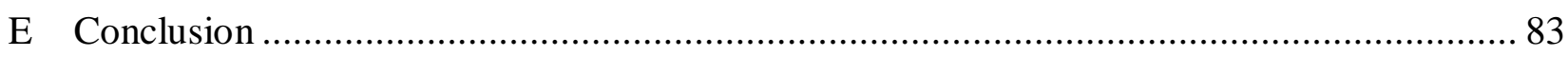

\section{CHAPTER FOUR}

LANGUAGE IN THE LAW AND JUDICIAL FALLACIES ................................................. 87

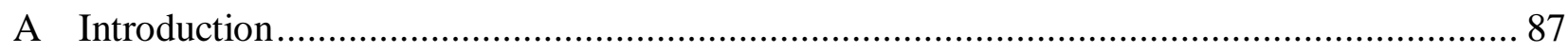

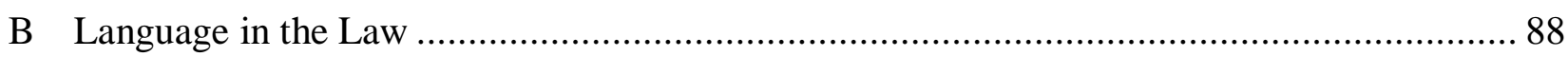

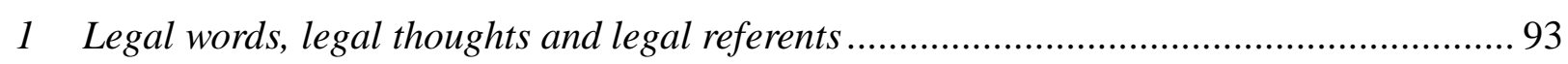

(a) Approach to language in the law and judicial interpretation: categorisation ............ 96

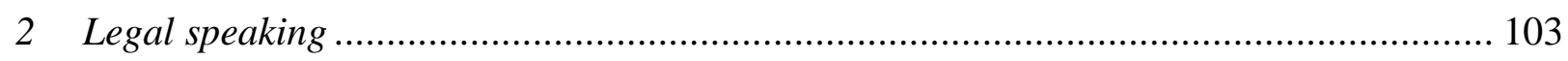

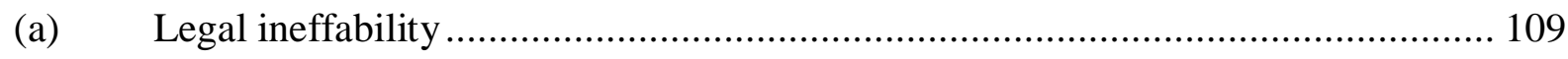

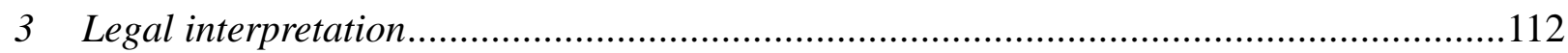

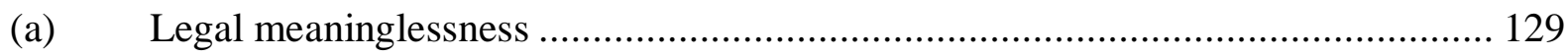

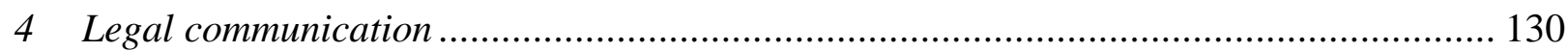

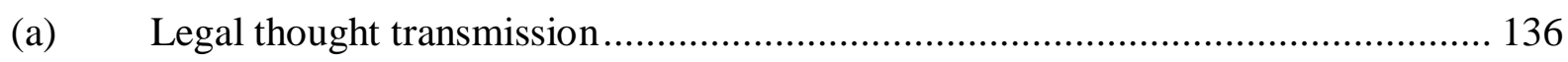

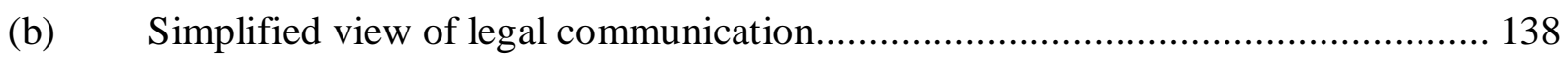

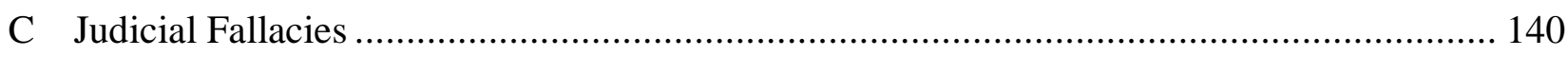

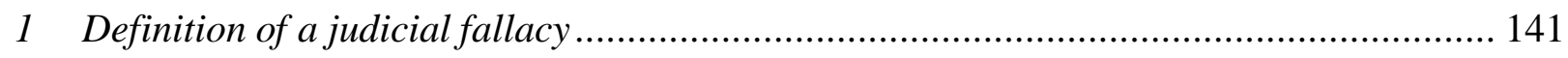

2 Verbal categories and legal categories .................................................................. 143

3 Same verbal category, therefore, within legal category ............................................ 146

4 Different verbal category, therefore, outside legal category ......................................... 161

5 Discussion of 'same verbal category' fallacy and 'different verbal category' fallacy....... 173

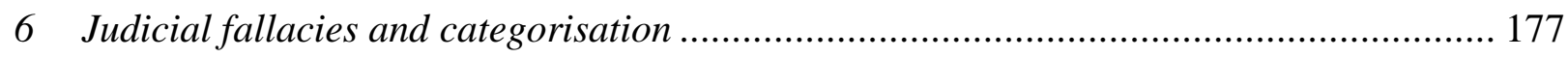

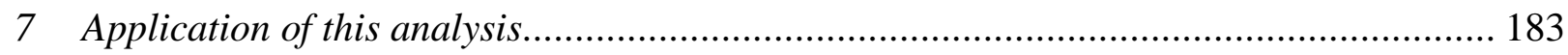

8 Detecting fallacies and providing alternative, non-fallacious interpretations................. 186

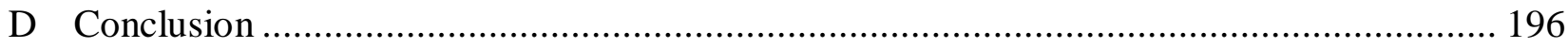




\section{CHAPTER FIVE}

LAW, LANGUAGE, AND CATEGORISATION......................................................... 202

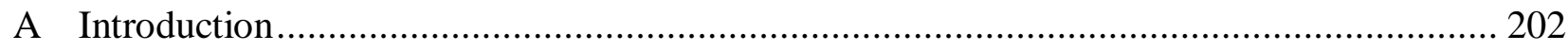

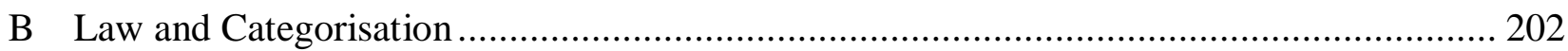

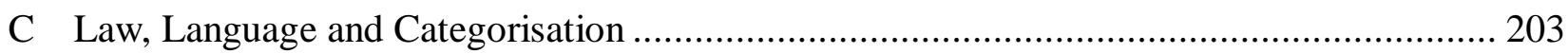

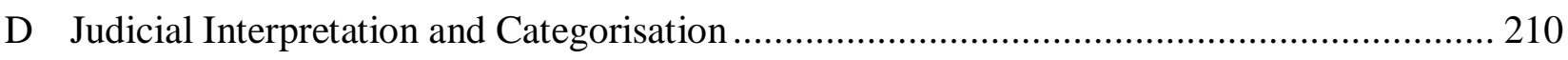

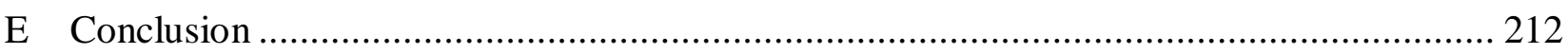

\section{CHAPTER SIX}

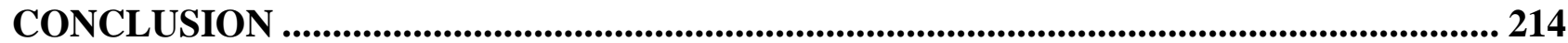

\begin{tabular}{|c|c|}
\hline APPENDIX ONE & GLOSSARY \\
\hline APPENDIX TWO & DIAGRAMS........ \\
\hline
\end{tabular}

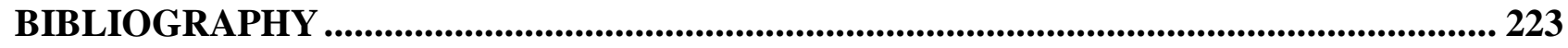

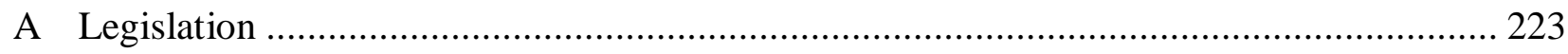

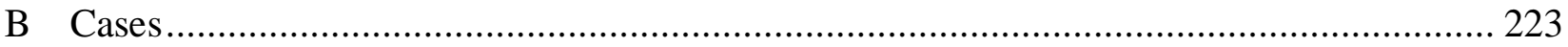

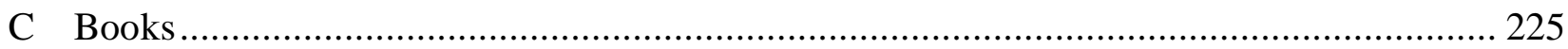

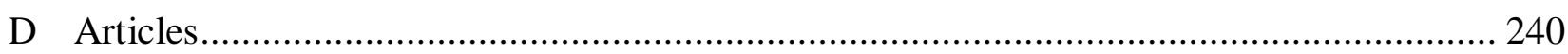

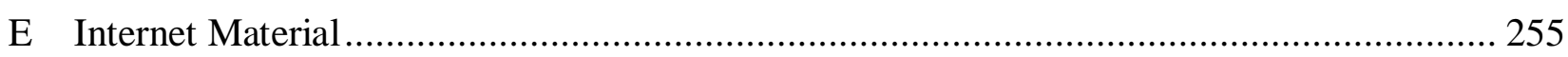




\section{DIAGRAMS AND CHARTS}

\section{Diagrams}

Diagram 2.1 The Relationship between Law and Language................................18

Diagram 3.1 Word, Thought and Referent.............................................. 26

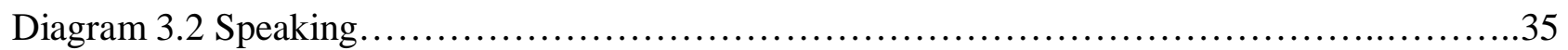

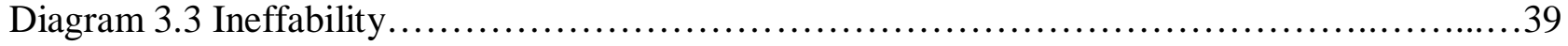

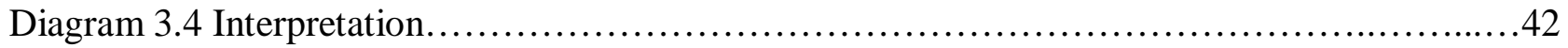

Diagram 3.5 Meaninglessness......................................................... 49

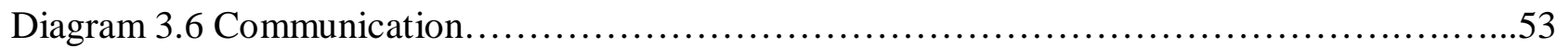

Diagram 3.7 Thought Transmission.................................................. 55

Diagram 3.8 Simplified View of Communication.......................................... 57

Diagram 3.9 Two Possibilities with Categorisation.......................................... 76

Diagram 3.10 Possible Categorisations in the Abstract.....................................77

Diagram 3.11 'Same Category’ Fallacy and 'Different Category’ Fallacy.......................78

Diagram 4.1 Legal Word, Legal Thought and Legal Referent...............................93

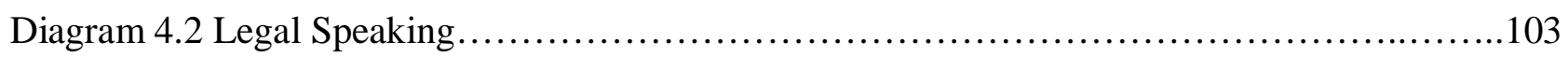

Diagram 4.3 Legal Ineffability.........................................................

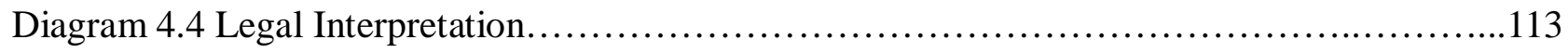

Diagram 4.5 Legal Meaninglessness.................................................... 129

Diagram 4.6 Legal Communication.......................................................131

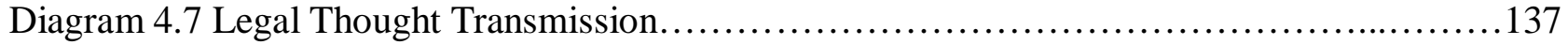

Diagram 4.8 Simplified View of Legal Communication..................................138

Diagram 4.9 Two Possibilities with Legal Categorisation.................................178

Diagram 4.10 Possible Legal Categorisations in the Abstract...................................179

Diagram 4.11 ‘Same Verbal Category’ Fallacy and ‘Different Verbal Category’ Fallacy............180

Diagram 5.1 The Relationship between the Law and Language...............................207

Diagram 5.2 The Role of Judicial Interpretation in the Law.................................211

\section{Charts}

Chart 3.1 Relevant Considerations for Interpreters.......................................... 48

Chart 3.2 'Same Category’ Fallacy and 'Different Category’ Fallacy...........................80

Chart 3.3 'Same Word' Fallacy and 'Different Word' Fallacy................................8

Chart 4.1 Relevant Legal Considerations for Judges.........................................124

Chart 4.2 'Same Verbal Category’ Fallacy and 'Different Verbal Category’ Fallacy...............183

Chart 4.3 Detecting Fallacies and Providing Alternative Interpretations.........................188 
The sabbath was made for man, and not man for the sabbath. ${ }^{1}$

1 Mark 2:28 The Holy Bible (King James Version). 


\section{CHAPTER ONE}

\section{INTRODUCTION}

This thesis ${ }^{2}$ investigates fallacies in judicial interpretation. Fallacies in judicial interpretation are instances of the judicial interpretation of language that are not legally justified and reach the wrong ${ }^{3}$ result. The primary aim of this thesis is to provide a way to critique instances of judicial interpretation and determine whether certain fallacies have been committed. ${ }^{4}$ It also provides a way for judges to avoid these fallacies.

The central contention of this thesis is that judges commit certain fallacies when interpreting language and that it is possible to detect such fallacies and arrive at alternative, non-fallacious interpretations when they occur.

To prove this contention, there are three things this thesis does: first, it provides a general definition of when an instance of judicial interpretation is fallacious; second, it identifies specific fallacies that have been committed by judges, and provides a method by which such fallacies can be detected; and third, it provides a method by which alternative, non-fallacious interpretations can be reached for the specific fallacies identified.

This thesis has six chapters. Following this introductory chapter, Chapter Two introduces the topic of judicial interpretation by briefly discussing some basic issues related to language, law and judicial interpretation. Chapter Two concludes with two groups of questions which are addressed in the remainder of this thesis: first, general questions regarding the relationship between law and language, and second, specific questions regarding fallacies in judicial interpretation.

Chapter Three analyses the ordinary interpretation of language ${ }^{5}$ and discusses some fallacies in such interpretation to provide a foundation from which to analyse judicial interpretation.

2 The word 'thesis' is ambiguous, and can be used to refer to both a complete research dissertation and to the specific proposition that is proven in such a dissertation. In this paper, the word 'thesis' will be used to refer to this entire dissertation and the word 'contention' will be used to refer to the proposition that is proven in this thesis.

3 What it means for a result to be 'wrong' will be discussed at Chapter Four C.1.

4 The word 'commit' will be used in relation to fallacies because this is the common word used with reference to fallacies. This word should not be taken to have any legal connotation.

5 The ordinary interpretation of language means the interpretation of language outside the law. It is in contrast to the interpretation of language by the judiciary. 
Chapter Four analyses judicial interpretation. It provides a general definition of fallacious interpretation and identifies two specific fallacies. Following this, it analyses some instances of judicial interpretation, detects these two fallacies, and provides alternative, non-fallacious interpretations. It concludes by addressing the specific questions raised in Chapter Two regarding fallacies in judicial interpretation.

Chapter Five addresses the general questions raised in Chapter Two regarding the relationship between law and language.

Chapter Six provides a conclusion to the thesis showing how the central contention has been proven.

This thesis deals with the judicial interpretation of legal documents such as statutes, regulations, contracts, and wills, and focuses on instances of judicial interpretation that involve categorisation. ${ }^{6}$ Two specific fallacies are identified which occur when judges make interpretive decisions on the basis of the verbal category to which an item can be assigned rather than the relevant legal considerations which determine the legal category to which it should be assigned.

The analysis in this thesis applies to judicial interpretation under the Common Law legal system, but is not limited to any specific jurisdiction ${ }^{7}$ or to any particular area of the law. This analysis, therefore, applies very broadly. This means that detailed considerations concerning interpretation in particular areas of the law are not introduced unless they are relevant to the specific cases being discussed. Therefore, this thesis does not provide a descriptive analysis of the current process of interpretation in any specific area of the law, but rather provides an analysis of judicial interpretation in the abstract.

References to places within this thesis are given by the heading level (for instance, Chapter Three B.2.(a).) if an entire section is being referred to. More specific references are given by referring to

6 For a detailed discussion of the instances of judicial interpretation on which this thesis focuses, see Chapter Four B.1.(a).

7 Legal terminology sometimes differs between jurisdictions, with either the same words being used with different meanings or different words being used with similar meanings. In the general discussion in the thesis, the terminology that applies all jurisdictions has been adopted, for instance, the phrase 'the legislature' has been used rather than 'Parliament' or 'Congress'. When discussing specific judicial decisions, however, the terminology from the jurisdiction under discussion has been adopted. 
the footnote number, or the text or paragraph accompanying a certain footnote. ${ }^{8}$

8 When referring to a specific sentence or quotation, there is a reference the text accompanying a footnote. When referring to a specific paragraph, there is a reference to the paragraph accompanying a footnote. This is not to highlight that particular footnote, but is just a convenient way to refer to that specific paragraph. 


\section{CHAPTER TWO}

\section{LANGUAGE, LAW AND JUDICIAL INTERPRETATION}

\section{A Introduction}

Much has been written on the topic of judicial interpretation from many different points of view and many issues have been raised regarding the relationship between law and language and the nature of judicial interpretation. In order to provide an introduction to this topic, this chapter briefly sets out some basic issues and viewpoints related to language, law and judicial interpretation. Specifically, it looks at the importance of language to the law, the relationship between law and language, and the role of judicial interpretation in the law. The chapter concludes with two groups of questions which will be addressed in the remainder of this thesis.

\section{B Language}

One of the distinguishing characteristics of human beings is the ability to use language. ${ }^{9}$ At first blush, it may seem that language is primarily used to communicate thoughts and feelings. ${ }^{10}$ Even more basic than this, however, is the constitutive role of language in relation to thought itself. In many cases, it is language that enables abstract or complex thought. Language is also the primary means people use to conceptually categorise the various items in the world. ${ }^{11}$ Language, therefore, on the one hand, is an internal medium ${ }^{12}$ of thoughts and feelings and, on the other hand, enables people to conceptualise the external world. Language plays a crucial role both in comprehending

9 This has been frequently noted by theorists. Possessing languages and dialects has been described as "a uniquely human characteristic.” Laurie Bauer \& Peter Trudgill Language Myths (Penguin Books Limited, London, 1998) at xviii; S Morris Engel claimed that “[h]uman beings can be defined as talking animals." Fallacies and Pitfalls of Language (Dover Publications, Inc, New York, 1994) at 1; Steven Pinker noted that "[i]n any natural history of the human species, language would stand out as the preeminent trait.” The Language Instinct (Penguin Books Limited, London, 1994) at 16. Various definitions that have been given to 'language' are discussed at Chapter Three (B).

10 A C Gimson starts an article by stating: "We use language primarily as a means of communication with other human beings.” “The Transmission of Language” in Randolph Quirk The Use of English (Longmans, Green and Company Limited, 1962) 259 at 259.

11 See John M Ellis Language, Thought, and Logic (Northwestern University Press, Evanston (IL), 1993) at ch 3.

12 See Lera Boroditsky and Jesse Prinz "What Thoughts Are Made Of” in Gün R Semin and Eliot R Smith (eds) Embodied Grounding (Cambridge University Press, Cambridge, 2008) 98. The authors argue that "the acquisition of knowledge ... is simultaneously grounded in perceptual experience and enmeshed within a linguistic system.” (at 112). 
things in the world and in engaging in thought. As will be seen, it is important to clearly grasp the relationship between words, thoughts and things.

Having said this, communication is also a crucial function of language. Language helps people to understand each other and cooperate with each other. Furthermore, language enables people to pass information on to subsequent generations. ${ }^{13}$ For these reasons, societies are able to advance by means of language.

Language, however, can be dangerous. Language not only creates the possibility for understanding, but also for misunderstanding. Francis Bacon noted: "Men imagine that their minds have command of language, but it often happens that language bears rule over their minds.” ${ }^{14}$ Similar sentiments have frequently been expressed. S Morris Engel remarked: “Although language seems the oldest, the easiest, and the most natural of our gifts, it is in reality one of the most difficult, subtle, and treacherous of them.”15 Anatol Rapoport claimed that: ${ }^{16}$

[I]t is symbolic language that generates the tremendous excess baggage of false knowledge cluttering up our existence ... It is symbolic language that makes possible the manipulation of the many by the few.

Such scepticism ${ }^{17}$ concerning language may be justified. On the one hand, language can be used by speakers to deliberately misinform and manipulate hearers. On the other hand, and perhaps more dangerously, language can unconsciously mislead both speakers and hearers. ${ }^{18}$

13 This function of language was an important part of what Alfred Korzybski called 'time-binding', which he defined as "a capacity to collect all known experiences of different individuals.” Alfred Korzybski Science and Sanity (5th ed, Institute of General Semantics, New Jersey, 1994) at 376.

14 Quoted by Simeon Potter in Language in the Modern World (Penguin Books Limited, Harmondsworth, 1960) at 19.

15 Engel, above n 9, at 1.

16 Anatol Rapoport Semantics (Thomas Y Crowell Company, New York, 1975) at 16.

17 A fear of language has been given the name 'logophobia' (Peter Farb Word Play (Coronet Books, London, 1973) at 158). Compare n 20.

18 There have been a number of books written on the dangers of language. These include: Stuart Chase The Tyranny of Words (6th ed, Methuen \& Company Limited, Great Britain, 1947); Engel, above n 9; and CK Ogden and IA Richards The Meaning of Meaning (10 ed, Routledge \& Kegan Paul Limited, London, 1949). 
It is possible to draw various parallels between law ${ }^{19}$ and language. Just as having a language is a distinctive human characteristic, having a system of laws or rules may be a universal characteristic of human societies. Just as language is necessary to communicate thoughts and feelings, law is necessary to communicate the legislature's intention. Just as language is essential for the advance of society, law is also an important factor in such advancement. Just as people can be fearful of being misled by language, people are often sceptical about law. ${ }^{20}$ Theorists have also noted other parallels between law and language. ${ }^{21}$

Furthermore, language is essential to the operation of the law. Statutes, regulations and other legal documents are drafted in language. Judicial decisions are given in language and often involve the interpretation of language. Lawyers advise clients, prepare briefs, and plead cases using language. Words have often been considered the tools of the lawyer's and judge's trade. ${ }^{22}$ To be a successful lawyer or judge, therefore, requires the skilful use of language. ${ }^{23}$

A number of theorists have gone further to claim that law is language ${ }^{24}$ or have made related

19 The meaning of 'law' in this context refers to a legal system generally, and includes both oral and written law.

20 Interestingly, Christopher Hutton noted: "Fear and mistrust of language frequently go together with fear and mistrust of law ('jurisphobia')” Christopher Hutton Language, Meaning and the Law (Edinburgh University Press, Edinburgh, 2009) at 4. Just as there have been books written on the dangers of language, there have been sceptical books written about the law. For instance, two sceptical books written by American legal realists are Fred Rodell Woe Unto You, Lawyers (Pageant Press, New York, 1957) and Jerome Frank Courts on Trial (Princeton University Press, Princeton, 1950) [Courts].

21 "Language, like law, is a living thing. It grows and changes. It both reflects and shapes the communities that use it." Terrill Pollman and Judith M Stinson "IRLAFARC! Surveying the Language of Legal Writing” (2004) 56 Me L Rev 239 at 240; "Law and language are structurally similar. They are generated through social practices, resulting in organized and more or less formalized communication systems, in the sense that they are both governed by their own rules of creation and reproduction.” Edgardo Rotman "The Inherent Problems of Legal Translation: Theoretical Aspects” (1995) 6 Ind Int'l \& Comp L Rev 187 at 188; "With both language and law, theorists have ... tried to locate a single source of order, regularity, coherence, authority or sovereignty.” Hutton, above n 20, at 5.

22 See Zechariah Chafee "The Disorderly Conduct of Words” (1941) 41 Colum L Rev 381 at 382; Glanville Williams "Language and the Law” (1945) 61 Law Q Rev 71 at 71; JJ Spigelman "Words, Words, Words” (2007) 81 Australian Law Journal 601 at 601; and Richard V Barndt "Language and Logic in the Law” (1964) 43 Tex L Rev 86 at 86.

23 "A facility with words is a desirable attribute for a good lawyer." Gerard McMeel "Language and the Law Revisited: An Intellectual History of Contractual Interpretation” (2005) 34 Comm L World Rev 256 at 256.

24 "The relation between language and the law is so intimate that it is not far-fetched to say that law is essentially language.” Rotman, above $n$ 21, at 187; "The specific purpose of this study has been to develop the theoretical basis for an interdisciplinary approach to law and legal texts as language or as linguistic practice.” Peter Goodrich Legal Discourse (St Martin's Press, New York, 1987) at ix. See also the slightly different claims: "Law is in a full sense a language” James Boyd White "Law as Language: Reading Law and Reading Literature” (1982) 60 Tex L Rev 415 at 415, and "Our law is a law of words." Peter M Tiersma "The Ambiguity of Interpretation: Distinguishing Interpretation from Construction” (1995) 73 Wash U L Q 1095 at 1095 [“Ambiguity”]. 
claims. $^{25}$ It is difficult to draw any definite conclusions from such claims, and they need to be assessed on their own merits. Such claims, however, do show that a close relationship has been recognised between law and language.

Rather than considering whether law should be regarded as language, it is more useful at this stage to consider some specific claims that have been made concerning the relationship between law and language. First, it has been said that laws are expressed in language. ${ }^{26}$ The term 'laws' in such a claim refers to specific legal rules. Such rules are expressed in language, for instance, in the text of statutes. Second, statutes, judicial decisions and various other items (most of which consist of language) have been described as sources of law. ${ }^{27}$ This means that such items function as the origins of law. The term 'law' in such a claim is more general than the term 'laws', and is an abstraction referring to the whole system of rules, conventions, and principles that are recognised as law. ${ }^{28}$ Third, language has been described as the medium of the law. ${ }^{29}$ The phrase 'the law' in this claim is also an abstraction and probably refers to an entire legal system. The practical operation of such a system is conducted in language, for instance, the language of statutes, private legal documents and judicial decisions. Thus, language functions as the medium of the law. ${ }^{30}$

Therefore, at an abstract level, language functions as the medium within which a legal system operates. More concretely, the language of certain documents functions as the source of law. Furthermore, specific legal rules are expressed in language. Thus, language functions as the medium of the law, the source of law, and the means for laws to be expressed. These three aspects

25 It has also been claimed that law is communication (Mark Van Hoecke Law as Communication (Hart Publishing, Oxford, 2002)), law is rhetoric (James Boyd White "Law As Rhetoric, Rhetoric As Law: The Arts of Cultural and Communal Life” (1985) 52 U Chi L Rev 684), and that law is a code (Goodrich, above n 24, at 65).

26 "Laws are expressed in language.” Lawrence M Solan "Why Laws Work Pretty Well, but Not Great: Words and Rules in Legal Interpretation” (2001) 26 Law \& Soc Inquiry 243 at 267.

27 "[M] ost of what we call law consists of words, whether in the form of statutes, judicial opinions, or the myriad other sources of law.” Tiersma “Ambiguity”, above n 24, at 1095.

28 J C Gray's notes that statutes are "to be dealt with as sources of Law, and not as part of the Law itself” The Nature and Sources of the Law (The Columbia University Press, New York, 1909) at s 276. Other sources of law that Gray gives include: "judicial precedents, opinions of experts, customs, and principles of morality (using morality as including public policy).” (at s 274). Regardless of whether such sources are viewed as part of the law or merely as sources of law, it can be said that they are origins of law. Most of these sources consist of language, and even though customs and principles may not initially be expressed in language, for them to function as sources of law they need to be recognised and this recognition requires their expression in language.

29 "Language is the medium through which law acts.” Brian Bix Law, Language, and Legal Determinacy (Oxford University Press, Oxford, 1993) at 1.

30 This distinction between 'laws', 'law' and 'the law' is useful for making sense of these claims regarding the relationship between law and language, but should not be applied to every use of these words. It is worth noting that not only is the meaning of 'law' slightly different in each of these uses, but the language referred to may also be different. Thus, it can be misleading to compare statements about the relationship between law and language, since the meanings of both 'law' and 'language' may be different in each statement. 
of the relationship between law and language can be summarised by saying that law is embodied in language.

\section{Judicial Interpretation}

For the successful operation of a legal system, however, the law does not merely need to be embodied, but needs to be applied to concrete situations. The law is applied to situations by judicial decisions, which often involve the interpretation of the language in which the law is embodied.

Judicial interpretation has, on the one hand, been viewed as being limited to ascertaining the meaning of the law by interpretation rather than creating the law. ${ }^{31}$ Proponents of this view may hold a declaratory view of law: that "judges find (or declare) law rather than make law." ${ }^{32}$ This is the view that the judges' task is "not ... to pronounce a new law, but to maintain and expound the old one.” 33 On the other hand, judicial interpretation has been viewed as a form of legislating. ${ }^{34}$ On this view, judicial interpretation involves creating the law, not merely expounding it. Judicial interpretation itself has even been viewed as 'the law'. ${ }^{35}$ Conversely, law has been viewed as interpretation. $^{36}$

Before comparing such claims it is important to ascertain whether they are referring to the same kind of interpretation. In relation to the interpretation of statutes, one theorist may argue that a court's job is limited to interpreting the law (that is, the rules embodied in the text of statutes). In

31 "A court does not legislate and it does not enforce the law, it can only interpret and apply the law." Margaret O’Toole "Lawyer's response to language constructing law” in John Gibbons (ed) Language and the Law (Longman Group UK Limited, Harlow, 1994) 188 at 189.

32 William S Brewbaker III "Found Law, Made Law and Creation: Reconsidering Blackstone's Declaratory Theory" (2006-2007) 22 J L \& Religion 255 at 256.

33 William Blackstone The Commentaries on the Laws of England (Robert Malcolm Kerr (ed)) (4th ed, John Murray, London, 1876) vol 1 at 47, quoted in Brewbaker, above n 32, at 256. Compare Matthew Krygier's remark that "even in hard cases the law governs judicial decisions." "Julius Stone: Leeways of Choice, Legal Tradition and the Declaratory Theory of Law” (1986) 9 UNSWLJ 26 at 26.

34 For example, Jerome Frank stated: "Legislative legislation ... often calls for interpretation which compels judicial legislation necessary to carry out the legislature’s purpose.” Frank Courts, above n 20, at 294.

35 J C Gray stated: "It has sometimes been said that the Law is composed of two parts, - legislative law and judgemade law, but in truth all the Law is judge-made law. The shape in which a statute is imposed on the community as a guide for conduct is that statute as interpreted by the courts. The courts put life into the dead words of the statute.” Gray, above n 28, at s 276. A similar point was made by Karl N Llewellyn when he referred to "judges or sheriffs or clerks or jailers or lawyers" as "officials of the law" and stated: "What these officials do about disputes is, to my mind, the law itself.” The Bramble Bush (Oxford University Press, New York, 2008) at 5 (italics in original). Compare Oliver Wendell Holmes' remark: "The prophecies of what the courts will do in fact, and nothing more pretentious, are what I mean by the law." “The Path of the Law” (1897) 1 Boston L School Mag 1 at 4.

36 Ronald Dworkin “Law as Interpretation” (1982) 60 Tex L Rev 527. 
relation to the common law, another theorist may claim that a judge's role is to create the law, rather than interpret it. ${ }^{37}$ It is misleading to contrast such claims and suggest that they show different ways of viewing judicial interpretation when they are really describing different kinds of judicial interpretation. Furthermore, it is important to draw a distinction between judicial interpretation of language and judicial interpretation of the law. ${ }^{38}$ Although the judicial interpretation of language involves the interpretation of the law embodied in that language, statements solely related to the judicial interpretation of law should not be applied to the judicial interpretation of language. ${ }^{39}$

Having said this, it is still possible to discern two basic views regarding the judicial interpretation of language. On the one hand, the judicial interpretation of language can be viewed as ascertaining the meaning of the law, and, on the other hand, such interpretation can be viewed as creating the law. ${ }^{40}$ There is much involved in this dispute about the role of the judicial interpretation of language in the law, but, on any view, it is clear that the law is applied to concrete situations by such interpretation. $^{41}$ This includes not merely statutory interpretation, but judicial interpretation generally. For instance, a judicial decision regarding the interpretation of a will or a contract is the application of the law to the situation at issue in the sense that it is a legally recognised binding interpretation. $^{42}$

The relationship between law and language, therefore, involves both embodiment and application. The law needs to be embodied in language, and this embodied law needs to be applied by the interpretation of the language in which it is embodied.

37 For instance, Glanville Williams defined the common law as "the power of judges to create new law under the guise of interpreting it.” Learning the Law (10th ed, Stevens \& Sons, London, 1978) at 26.

38 This thesis is looking at the judicial interpretation of language rather than merely judicial interpretation of the law, which may not involve any explicit interpretation of language.

39 For instance, see Glanville Williams’ statement regarding the common law, quoted in n 37.

40 On both views, judicial interpretation involves ascertaining the meaning of language.

41 This does not, however, mean that the law is only applied to situations by the interpretation of language. Even judicial decisions that do not explicitly involve interpretation involve the application of the law.

42 For a further discussion of this, see the paragraph accompanying n 238. 
This relationship between law and language is depicted by Diagram 2.1, below.

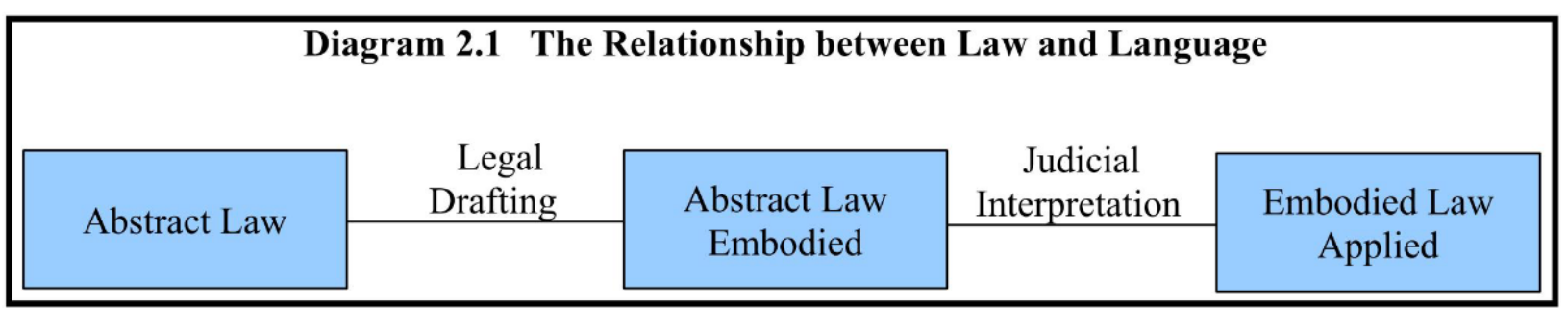

This diagram ${ }^{43}$ depicts the relationship between law and language in a simple way. It also shows the role of judicial interpretation in the law. Although useful as a starting point, this diagram has its shortcomings. First, the 'legal drafting' referred to is limited to statutory drafting, since it is not usually claimed that the drafting of contracts or other legal documents involves the embodiment of law. ${ }^{44}$ Thus, this diagram omits some legally significant uses of language. Second, the concept of 'abstract law' is questionable, and this concept may create confusion. ${ }^{45}$ Third, this diagram does not show what the processes of legal drafting or judicial interpretation involve, or how they are related to one another. ${ }^{46}$ Diagram 2.1, therefore, is not sufficient to adequately explain the relationship between law and language and the role of judicial interpretation in the law. There is the need to examine the use of language in the law in more detail to understand the relationship between law and language and the role of judicial interpretation clearly.

The next section of this chapter will raise some questions to be addressed in this thesis regarding the relationship between language and the law and fallacies in judicial interpretation. Before doing this, however, it is important to address the issue of whether an instance of judicial interpretation can ever be fallacious.

At the beginning of Chapter One, fallacies in judicial interpretation were defined as instances of

43 The processes depicted here - the embodiment of law and the application of law - are returned to in more detail in Chapter Four. That chapter discusses 'legal speaking' and 'legal interpretation', which are similar to these two processes.

44 Although such documents are legally significant, they are not usually viewed as involving the embodiment of law. For instance, a contract can be seen as the embodiment of a legally enforceable promise. The law recognises such a promise, but the promise is not generally viewed as part of the law itself.

45 Oliver Wendell Holmes belittled the view of the law as an abstraction by stating: "The common law is not a brooding omnipresence in the sky, but the articulate voice of some sovereign or quasi sovereign that can be identified” Southern Pacific Co v Jensen (1917) 244 US 205 (SC) at 222.

46 A more detailed depiction of two similar processes is given in Diagram 4.6. A different view of the relationship between law and language is depicted in Diagram 5.1 (which depicts the relationship between the law and language). 
judicial interpretation that are not legally justified and reach the wrong result. There are difficulties, however, with claiming that an instance of judicial interpretation is wrong. In most situations, judges have the discretion to make whatever decision they want to make. ${ }^{47}$ Furthermore, once language has been judicially interpreted, it means what the judge says it means. ${ }^{48}$ In this sense, it is not a question of a right or wrong interpretation, but a question of who has the authority to make the decision on meaning. Apart from a decision being reversed on appeal or overturned by legislative action, ${ }^{49}$ an instance of interpretation cannot be legally challenged. Thus, it cannot be said that the decisions are legally wrong merely because they appear to be unjustified.

Having said this, although an interpretive decision may be legally valid in that it is a legally authoritative interpretation, it may still be unjustified in that the reasons given for the decision do not support the decision reached. This thesis will use the word 'fallacy' to describe an instance of interpretation that reaches a result that is not legally justified because the reasons given for the decision do not support the decision reached. Such fallacious decisions will also sometimes be referred to as 'wrong' decisions. This does not mean that are not legally valid, but it means that they have not been legally justified. ${ }^{50}$

There are also difficulties with describing an instance of fallacious interpretation as a mistaken interpretation. It is not possible to claim definitively that a judge has made a mistake in interpretation. Because of the subjective nature of interpretation, it may be impossible to know whether an unjustifiable interpretive decision was deliberate, or whether it was caused by an oversight on the part of the judge. A judge may deliberately interpret a provision in an unjustifiable way. In such a situation, although the judge may not have been mistaken, the interpretation is still fallacious. Therefore, this thesis will refer to 'fallacies', rather than 'mistakes'.

47 In practice, judicial decisions may be constrained in certain ways, for instance, by binding precedent. The point being made here is that within the limits of their authority, judges are not constrained to interpret a provision in a specific way.

48 "Once a decision has been made, the meaning of the words of the statute is what the judge says it is." Yon Mayley "The language of the law" in John Gibbons (ed) Language and the Law (Longman Group UK Limited, Harlow, 1994) 11 at 31.

49 The legal principle established in a case can also be overruled by a subsequent decision of a higher court, but this does not mean that this specific instance of interpretation is changed for the parties involved. It does mean, however, that it is no longer good law.

50 This point about wrong decisions is discussed in more detail at Chapter Four C.1. 
This chapter has briefly discussed various views regarding law, language and judicial interpretation. Based on this discussion some general questions can be raised:

1. What is a useful way to describe the nature of the relationship between law and language?

2. Why is language important to the law?

3. To what extent does the nature of language determine the nature of the law?

4. Is the law merely contained in language, or is this language itself the law?

5. If a distinction is drawn between the words of the law and the law, what is the law as opposed to the words of the law?

6. Does changing the words of statutes or other legal documents change the law?

7. When judges determine the meaning of language, do they create the law or do they merely interpret the meaning of the law?

Questions raised at this level of generality can be answered in many ways. Furthermore, such questions may rely on unsubstantiated assumptions. It is clearer if more specific questions about the nature of judicial interpretation are addressed before an attempt is made to address these general questions.

A more specific question that this thesis needs to address is: 'What causes an instance of judicial interpretation to be legally justified?' Once this question has been addressed, a more detailed definition of judicial fallacies can be given. ${ }^{51}$ The method of addressing this question in this thesis is to compare judicial interpretation with ordinary interpretation. This thesis will investigate specific fallacies in judicial interpretation similar to certain fallacies committed in ordinary interpretation. This question can therefore be expanded into a group of questions related to the comparison between legal interpretation ${ }^{52}$ and ordinary interpretation and to fallacies in judicial interpretation:

51 This question is addressed at Chapter Four B.3 and a definition of judicial fallacies is given at Chapter Four C.1.

52 The phrases 'legal interpretation' and 'judicial interpretation' are used interchangeably in this thesis, both referring to interpretation by the judiciary, with the choice of phrase depending on what is being emphasised in the specific context. 'Judicial interpretation' emphasises the role of the judiciary in interpretation and 'legal interpretation' is in contrast to ordinary interpretation and emphasises the difference between these kinds of interpretation. 
1. What are the differences between legal interpretation and ordinary interpretation?

2. Should legal interpretation be approached differently from ordinary interpretation? If so, in what way?

3. Are fallacies committed in the interpretation of language ordinarily relevant to legal interpretation?

4. What is the goal of judicial interpretation?

5. What makes an instance of judicial interpretation fallacious?

6. What kinds of fallacies are committed in judicial interpretation?

7. Why are these fallacies committed in judicial interpretation?

8. What is the consequence of these fallacies?

9. How should an instance of interpretation be analysed to see whether it is fallacious?

10. How can judges avoid fallacies?

11. What is the way to arrive at alternative, non-fallacious interpretations when judicial fallacies have been committed?

The central contention of this thesis is that judges commit certain fallacies and that it is possible to detect such fallacies and arrive at alternative, non-fallacious interpretations when they occur. The answers to these questions will show in detail how this contention has been proven.

These questions, although more specific than the general questions which have been raised, can also be answered in many ways. Without an understanding of the way language functions ordinarily, however, it is difficult to address such questions adequately. This thesis, therefore, will address these questions by comparing legal interpretation with ordinary interpretation and determining whether there are fallacies that can be committed in legal interpretation which correspond to fallacies which can be committed in ordinary interpretation. For this reason, Chapter Three will analyse the interpretation of language ordinarily and identify some fallacies in such interpretation. 


\section{CHAPTER THREE}

\section{LANGUAGE AND INTERPRETATION FALLACIES}

\section{A Introduction}

This chapter will analyse the use of language ordinarily and fallacies that can be committed in the ordinary interpretation of language. ${ }^{53}$ The ordinary interpretation of language refers to the interpretation of language outside the law. At the beginning of this analysis, it is helpful to raise some questions regarding interpretation in ordinary language and fallacies in such interpretation which will be addressed in this chapter. These questions correspond to some of the questions raised regarding judicial interpretation at the end of Chapter Two:

1. What is the goal of interpretation?

2. Is it always unjustifiable for an interpreter to arrive at a different meaning from a speaker?

3. What makes an instance of interpretation fallacious?

4. What kinds of fallacies are possible with interpretation?

5. Why are these fallacies committed?

6. What is the consequence of these fallacies?

7. How should an instance of interpretation be analysed to see whether it is fallacious?

8. How can interpreters avoid fallacies?

9. What is the way to arrive at alternative, non-fallacious interpretations when fallacies have been committed?

The aim of this chapter is to provide a general sketch of ordinary interpretation with which legal interpretation can be compared. Therefore, these questions will not be answered exhaustively, but will be addressed in sufficient detail to provide a foundation from which legal interpretation can be analysed. Furthermore, this chapter will not discuss every kind of fallacy possible in ordinary language, but only certain fallacies which correspond to fallacies that can be committed in legal interpretation.

53 The focus of this chapter is on the ordinary interpretation of language, not the interpretation of ordinary language. It is a focus on a kind of interpretation, not a kind of language that is being interpreted. 
This chapter will look at the principles that generally govern ordinary interpretation. Distinctive aspects of specialist kinds of interpretation (for instance, literary criticism and biblical hermeneutics) will not be covered in detail since these kinds of interpretation are not representative of the way language is ordinarily interpreted. Because this thesis investigates the judicial interpretation of written language, ${ }^{54}$ this chapter will not focus on aspects of interpretation relevant only to spoken language. Furthermore, other aspects of ordinary interpretation that are not relevant to legal interpretation will not be covered.

There are various academic disciplines ${ }^{55}$ that deal with language and interpretation, including linguistics, the philosophy of language, semiotics, and literary criticism. ${ }^{56}$ This chapter draws insights from a number of these disciplines. ${ }^{57}$ There are also various conflicts between these disciplines. This chapter does not enter into a detailed investigation of any of these conflicts. ${ }^{58}$

This chapter has three main parts. The first part of this chapter (Chapter Three B, Language) analyses the processes of speaking and interpretation. The second part (Chapter Three C, Interpretation Fallacies) identifies fallacies in interpretation. The third part (Chapter Three D, Language and Thought) briefly discusses the relationship between language and thought.

54 This thesis focuses on the judicial interpretation of legal documents such as statutes, regulations, contracts and wills.

55 In this chapter certain words have been given definitions to distinguish them from the technical way they have been used by writers in these various disciplines or to clarify their meaning for the purpose of this thesis. Important words that are defined in this chapter include: 'arbitrary', 'convention', 'referent', 'meaning', 'speaking', 'ineffable', 'interpretation', 'meaningless', and 'fallacy'. The definitions are given when these words are first used and are collected in Appendix One, Glossary.

56 The topics of language and interpretation are also dealt with in a number of other areas. These topics are dealt with in the discipline of general semantics developed by Alfred Korzybski, which is outside mainline academia (see Korzybski, above $n$ 13). Much attention was also paid to language in the twentieth century by two (now defunct) schools of philosophy - logical positivism and ordinary language philosophy - both influenced by Ludwig Wittgenstein. Furthermore, there are many popular books dealing with language and communication, for instance, John Gray Men are from Mars, Women are from Venus (Thorsons, New York, 1993). Such sources occasionally contain useful insights and have also been consulted in the writing of this chapter.

57 This thesis, however, is not interdisciplinary, in that it does not adopt a methodology from a specific discipline and apply it to the interpretation of language in the law. Rather, it draws relevant insights from various disciplines to provide a general description of the process of ordinary interpretation. This chapter does not presume any background knowledge of any of these language disciplines.

58 Most of the points of conflict between these disciplines are not relevant to this thesis either because it is not concerned with the matters in dispute or because it does not need to investigate the disputed topic at the level of depth at which the conflicts appear. Controversial points include the origin of language, whether humans think in words or images (or in some other medium), and whether the ability to use language is innate or acquired. These issues do not need to be addressed. The only controversial point that needs to be addressed is the nature of meaning. Even in relation to meaning, however, the different views held by various theorists are not discussed in detail. Rather, a definition of meaning is adopted that works for the purposes of this thesis. 
Language has been defined in various ways. It is often defined by comparing it to something else. ${ }^{59}$ An outdated view is to compare language to human inventions by calling it an invention. ${ }^{60}$ This view is not currently popular. ${ }^{61}$ Language has also been compared to an instrument ${ }^{62}$ and words have been compared to tools. ${ }^{63}$ Under this view, language is something that is used to achieve a certain purpose. ${ }^{64}$ Another view of language is that it is an aspect of human behaviour, comparable to other kinds of human behaviour. ${ }^{65}$ A popular current view is that language is an innate biological capacity. Steven Pinker views language as an instinct, comparing the ability to talk to a spider's ability to spin webs. ${ }^{66}$ In a similar vein, Noam Chomsky compares the "growth of language" in humans to "the development of a bodily organ." ${ }^{67}$ Finally, semioticians view language as a system of signs, ${ }^{68}$ similar to other sign systems. ${ }^{69}$

Each one of these views can be problematic if it is pressed too far. It may be better just to look at language directly, rather than comparing it to something else. There are, however, some useful insights to be gained from these various ways of looking at language. The following section of this chapter will therefore begin by looking at words as signs.

59 Most theorists, however, do not present their definitions of language as comparisons, but as comprehensive descriptions of what language is. The danger with presenting such definitions in this way is that they usually only highlight one aspect of language.

60 “[S]ymbolic language, like all human inventions, is a mixed blessing.” Rapoport, above n 16, at 16.

61 This view has fallen out of fashion because it conflicts with the currently popular view of language as an innate biological capacity. The view of language as an invention did influence the law. Glanville Williams began an influential legal article with the sentence: "Language is perhaps the greatest of all human inventions." "Language and the Law” (1945) 61 Law Q Rev 71 at 71. In a legal article in 2005, Gerard McMeel quoted this sentence and remarked: "Nowadays the cognitive scientists and evolutionary biologists would immediately quarrel with that. Human language is now understood as a species attribute or a genetically determined innate metal ability.” McMeel, above n 23, at 257.

62 L Susan Stebbing Thinking to Some Purpose (Penguin Books, Harmondsworth, 1939) at 57.

63 Ludwig Wittgenstein (GEM Anscombe trans) Philosophical Investigations (2nd ed, Blackwell Publishers Limited, Oxford, 1958) at [11] [Investigations]; William Empson Seven Types of Ambiguity (2 ed, Chatto and Windus, London, 1949) at 5-6.

64 Stebbing, above n 62, at 57-58.

65 BF Skinner Verbal Behavior (Appleton-Century-Crofts, Inc, New York, 1957).

66 Pinker, above n 9, at 18. Although currently popular, this view of language is not new. For instance, in a book first published in 1851, Richard Trench expressed a similar view: "Man makes his own language, but he makes it as the bee makes its cells, as the bird its nest” On the Study of Words \& English, Past and Present (JM Dent \& Sons Limited, London, 1927) at 18. This view is not without opposition (see Geoffrey Sampson The 'Language Instinct' Debate (Continuum, London, 2005)).

67 Noam Chomsky Reflections on Language (Fontana Books, Glasgow, 1976) at 11.

68 Jonathan Bignell Media Semiotics (2ed, Manchester University Press, Manchester, 2002) at 6.

69 These different views concerning language determine the way language is studied, and these ways may conflict. For instance, the view of language as an innate capacity directly conflicts with the view of language as an acquired behaviour (see Noam Chomsky “Review of BF Skinner Verbal Behavior” (1959) 35 Language 26). 
This section will introduce some important ideas about language. It will discuss the relationship between words, thoughts and referents, the arbitrariness and conventionality of language, and the notion of meaning. This section will also define some important words that will be used in this analysis of language in this chapter.

It is useful to begin this analysis of language by viewing words as signs. There is no argument with the fact that words are signs, ${ }^{70}$ but the semiotic view of language can be taken too far. It can lead to the extreme view that: ${ }^{71}$

Rather than thinking of signs and media as channels which translate pre-existing thought and reality into communicable form, signs and media are the only means of access to thought or reality which we have.

Such a statement, taken at face value, is easily disproved by looking at children who have not yet learned to speak, but who have access to thought and reality without signs. ${ }^{72}$ Having heeded this warning against taking the semiotic approach to language too far or drawing unwarranted conclusions from it, it is still useful to view words as signs. Once words are defined as signs, it is necessary to consider what they signify. On the one hand, words seem to signify ideas, ${ }^{73}$ thoughts. $^{74}$ On the other hand, words also seem to signify things. ${ }^{75}$ The relationship between words, thoughts and things needs to be seen clearly.

70 It is more accurate to say that words are symbols, and to define symbols as signs which are deliberately used for communication: Stephen Ullmann Words and their Use (Frederick Muller Limited, London, 1951) at 13. This distinction between signs and symbols, however, is not needed for this thesis as it is only looking at signs which are symbols (specifically, words).

71 Bignell, above n 68, at 7.

72 Perhaps Bignell would argue that children still use signs to access thought and reality, but not words. Since such signs cannot be equated directly with thought (they are, in his words, the "means of access to thought"), it is difficult to see what such signs could be. Alternatively, viewing this statement charitably it could be taken to mean that once a person has learned the name of something, this person no longer has direct, unmediated knowledge of it, and now the name provides the "means of access to reality".

73 John Locke states that "words, as they are used by men, can properly and immediately signify nothing but the ideas that are in the mind of the speaker” John Locke (John W Yolton (ed)) An Essay Concerning Human Understanding (JM Dent, London, 1993) at 229 (italics in original).

74 It is more accurate to say that the spoken word is a sign of the thought and the written word is a sign of the spoken word (Potter, above n 14, at 48). Because this thesis is dealing with the interpretation of written language, the step of spoken language will be omitted, and written words will be treated as signs of thoughts directly.

75 In a famous book on linguistics, Leonard Bloomfield stated: "We can define the names of minerals ... in terms of chemistry and mineralogy, as when we say that the ordinary meaning of the English word salt is 'sodium chloride (NaCl)'” Leonard Bloomfield Language (Henry Holt and Company, New York, 1933) at 139. If meaning can be equated with signifying, this claim that 'salt' means $\mathrm{NaCl}$ suggests that a word signifies the object to which it relates. Modern theorists do not generally agree with Bloomfield's view (see David Bellos Is That a Fish in Your Ear? (Penguin Books Limited, London, 2011) at 83-84). 
Words are associated with things, but it is the idea of the thing, the thought about the thing, that establishes this connection. Words directly signify thoughts that refer to things. This makes it possible for words to stand for things. A convenient label for the thing for which a word stands is 'referent' ${ }^{76}$ The relationship between words, thoughts and referents was illustrated helpfully in an early book on semantics by C K Ogden and I A Richards, The Meaning of Meaning, ${ }^{77}$ by a diagram commonly referred to as the semantic triangle. Diagram 3.1, below, is a simplified and slightly modified version of this semantic triangle.

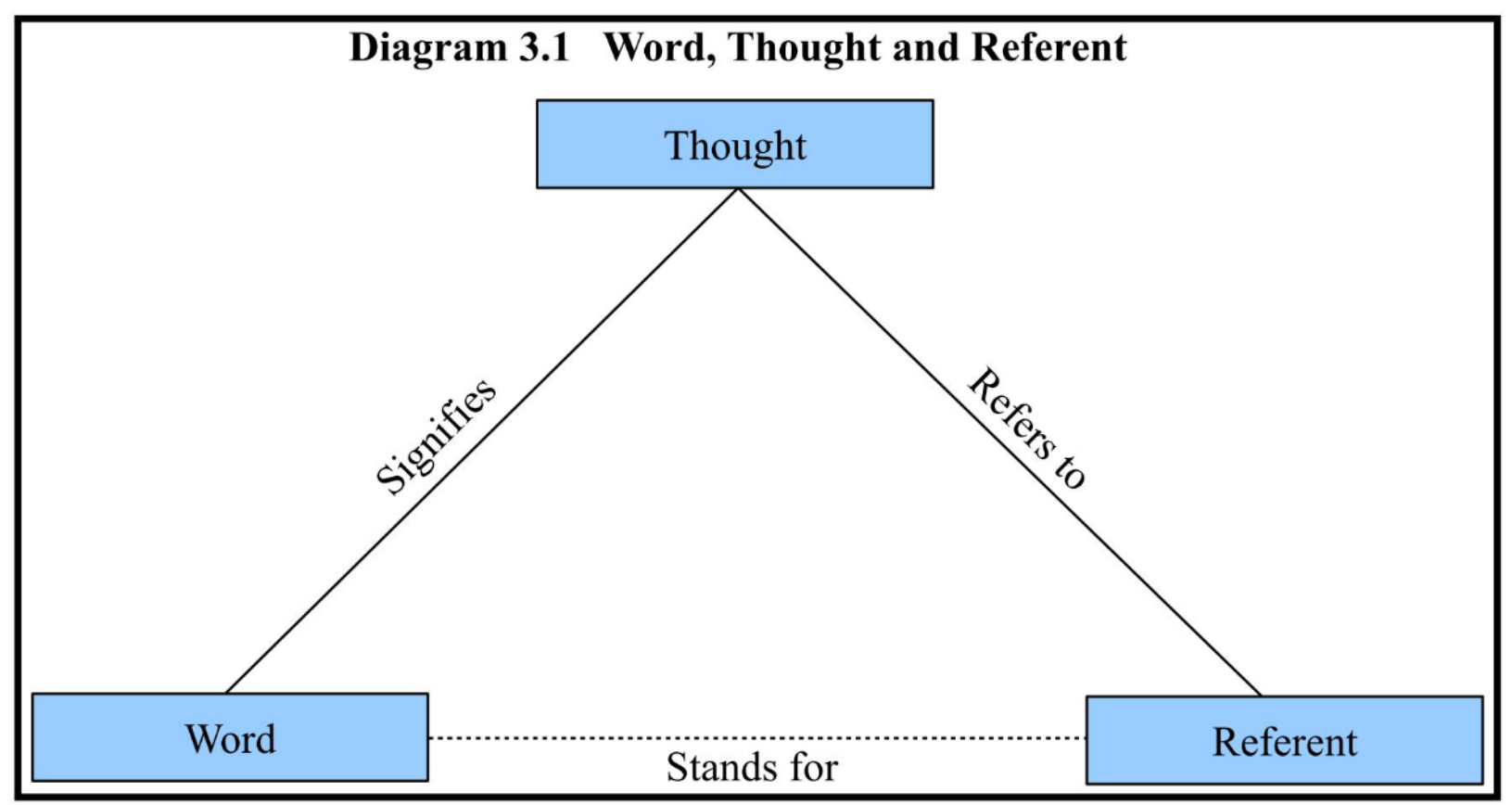

Diagram $3.1^{78}$ depicts the relationship between a word, the thought it signifies, and that to which

76 The word 'referent' was popularised by Ogden and Richards who introduced this word by stating: "The word 'thing' is unsuitable ... because in popular usage it is restricted to material substances ... It has seemed desirable, therefore, to introduce a technical term to stand for whatever we may be thinking of or referring to.” Ogden and Richards, above $\mathrm{n} 18$, at 9 footnote 1 . This is a very broad definition of the word 'referent'. For the purposes of this thesis, it is not necessary to posit referents for every word. Rather, referents will only be posited when they can be readily identified.

77 Ibid, at 11. Ogden and Richards were not the first to use this type of diagram, but they made it famous. See Rita Temmerman Towards New Ways of Terminological Description (John Benjamins Publishing Co, Amsterdam, 2000) at 58 for a discussion of earlier uses of this diagram. This diagram has subsequently been used in a number of books on semantics, for instance: Chase, above n 18, at 66; Ullmann, above n 70, at 32; and FR Palmer Semantics (2ed, Cambridge University Press, Cambridge, 1981) at 24. Variations on this diagram are used in Simon Blackburn Spreading the Word (Oxford University Press, Oxford, 1984) at 3, and in John Lyons Language, Meaning \& Context (Fontana Paperbacks, Bungay, 1981) at 19. It has also been used in a number of legal articles, for instance: Reed Dickerson "Referential Meaning: The Static Aspects" (1969) 10 Jurimetrics J 58 at 58, and Barbara Bintliff “Context and Legal Research” (2007) 99 Law Libr J 249 at 252.

78 For convenience, all the diagrams in this chapter and Chapter Four are collected in Appendix Two, Diagrams. 
the thought refers, its referent. A word signifies a thought. ${ }^{79}$ This thought refers to a referent. The dotted line connecting the word to the referent indicates that the connection between them is indirect. Therefore, words stand for ${ }^{80}$ referents because of connecting thoughts.

For simplicity, Diagram 3.1 uses the term 'word', rather than the term 'words'. This diagram, however, can also apply to the use of more than one word to stand for a referent. The other diagrams in this chapter will also use the singular term 'word', but these diagrams should also be understood to apply to the use of more than one word.

It is helpful to give a simple example to illustrate the elements in Diagram 3.1. If someone says, 'I saw a dog', the word 'dog' in this statement can be viewed in relation to this diagram. The word 'dog' is the word on the left-hand side of the triangle. The idea of the animal that was seen is the thought at the apex of the triangle. The animal itself is the referent on the right-hand side of the triangle. The word signifies a thought which refers to a referent. In this way, the word stands for the referent. This diagram thus illustrates clearly the indirect connection between words and referents and the importance of the connecting thought. It is commonly said that words refer to things. This view of language, however, omits this connecting thought. When analysing meaning, it is important to be aware that the relationship between words and their referents is indirect. Words are associated with referents, but this association is indirect and is through thoughts.

The left-hand side of the triangle in Diagram 3.1 depicts the relationship between words and thoughts. As mentioned, words are signs of thoughts. Signs can be divided into two categories: natural signs and conventional signs. Natural signs have meaning because of a natural connection between the signs and what they signify. ${ }^{81}$ For example, smoke naturally signifies fire. ${ }^{82}$ With conventional signs, however, there is no natural link but the signs are conventionally connected to what they signify. ${ }^{83}$ Words are conventional signs. This means that the connection between words and the thoughts that they signify is established by an agreement to use words to signify these thoughts. For example, the word 'smoke’ conventionally signifies the idea of smoke.

79 For the purpose of this thesis, it is unnecessary to discuss the nature of thoughts in detail, or to address whether they involve words or images or some other form of representation, or even whether they involve representation at all. The thought in this diagram can be loosely defined as the idea associated with a word.

80 Even though on this diagram words stand for referents and thoughts refer to referents, it will not be necessary to maintain this distinction sharply, and this thesis will sometimes speak of words 'referring to' referents. This should not create any difficulty as long as it is borne in mind that the relationship between words and referents is indirect.

81 Ullmann, above n 70, at 13.

82 Lyons, above n 77, at 13.

83 Ibid. 
The right-hand side of the triangle in Diagram 3.1 depicts the relationship between thoughts and referents, that is, it depicts the relationship between thoughts and the things that the thoughts are about. For instance, the idea of smoke refers to smoke itself. It is not necessary to discuss the nature of this relationship in detail. It is useful, however, to distinguish between a thought and the thing to which the thought refers, so it is important to be aware of this relationship.

The base of the triangle in Diagram 3.1 depicts the relationship between words and referents. This relationship is indirect, and is through thoughts. Therefore, this relationship is established by speakers. ${ }^{84}$ Speakers can choose any word to stand for a referent. Ogden and Richards stated: "Between the [word] and the referent there is no relevant relation other than the indirect one, which consists in its being used by someone to stand for a referent.” ${ }^{\text {} 5}$ For this reason, the meaning of a word is determined by what it is used to mean, and meaning is sometimes equated with use. ${ }^{86}$

There is no natural connection between words and thoughts. Therefore, this connection is arbitrary. ${ }^{87}$ This means that the connection between words and referents is also arbitrary. The fact that there is only an arbitrary connection between words and referents can be easily proven by the fact that different languages use different words to stand for the same things.

If the connection between words and thoughts were merely arbitrary, however, communication would be impossible. Although this connection is arbitrary, it is nevertheless conventional. This conventionality is what makes communication possible. Richard Mitchell put this point well: ${ }^{88}$

Language is arbitrary, but it's not anarchic. Although there's no reason why this or that in a language should be 'right' and something else 'wrong,' it does not follow that you can do whatever you please in it. At some point, of course, when you wander too far from what is 'right' you'll cease to be intelligible.

84 In this chapter, the two parties in communication are referred to as the speaker and the interpreter and the actions they perform as speaking and interpretation. The speaker should be understood to include any producer of language being interpreted, including a writer. The interpreter is not limited to the direct audience of spoken language or the intended audience of written language, but can include any person interpreting language. This chapter will also sometimes use the word 'utterance' to refer to a portion of language, and this should be understood to include both spoken and written language.

85 Ogden and Richards, above n 18, at 11.

86 This view of meaning was stressed by Ludwig Wittgenstein: "For a large class of cases ... in which we employ the word 'meaning' it can be defined thus: the meaning of a word is its use in the language." Wittgenstein Investigations, above n 63, at [43].

87 To say that the connection is 'arbitrary' means that it is not a natural or necessary connection. It should not be taken to mean that the connection is random, unpredictable or unreasonable.

88 Richard Mitchell quoted in Engel, above n 9, at 18. 
Language has been defined as "a shared system of rules and conventions mutually intelligible to all members of a particular community”. ${ }^{89}$ Intelligible communication, therefore, depends on the existence of shared conventions. $^{90}$

Words are therefore arbitrary signs conventionally associated with certain thoughts of certain referents. In a book first published in 1763, Isaac Watts stated: ${ }^{91}$

Though names are in their original merely arbitrary, yet we should always keep to the established meaning of them, unless great necessity require the alteration; for when any word has been used to signify an idea, that old idea will recur in the mind, when the word is heard or read, rather than any new idea which we may fasten to it.

This statement highlights the fact that the words a speaker chooses are important because words have thoughts conventionally associated with them. For speakers to use words to signify different thoughts from the thoughts with which they are conventionally associated can mislead interpreters.

It is helpful to define language conventions in more detail. Words are conventional signs. The use of a word to signify a certain thought (and thus to stand for a certain referent) establishes a language convention. This language convention involves an association of the word with a thought. Since this thought is of a referent, this convention is also the association of this word with a referent. For instance, if a speaker uses the word 'dog' to refer to a dog, the speaker is employing the language convention that associates the word 'dog' with dogs.

The primary source of language conventions are agreed usages within speech communities. Dictionaries may record ${ }^{92}$ such conventions. ${ }^{93}$ Conventions, however, can also be created by

89 Farb, above n 17, at 20.

90 This sharing can either be between a few individuals or within a whole community. When these conventions are shared by a particular community, this is sometimes called a 'speech community'. For an influential investigation of the role of speech communities in the interpretation of literature, see Stanley Fish Is There a Text in This Class? (Harvard University Press, Cambridge (Mass), 1980).

91 Isaac Watts Logic (Thomas Tegg, London, 1811) at 77.

92 By recording such conventions, dictionaries give them an authoritative status, and often these conventions are treated as binding rules. Thus, dictionaries which intend to be descriptive become prescriptive because of the way they are treated. The term 'convention' can mean an accepted usage (the way things are done) or a strict rule (the way things should be done). For the purpose of this thesis, conventions should be understood as agreed associations between words and thoughts, which may become general usages. Conventions should not be understood as binding rules.

93 The conventions of specialised speech communities are recorded in technical dictionaries, for example, in dictionaries of medical terms. 
speakers. Such ad hoc conventions can be made known to interpreters by explicit definitions or may be clear from the context of an utterance. Therefore, language conventions include established usages of words within a society generally, technical meanings of words within specialised groups, and new meanings of words specified by explicit definitions or made clear from the context of speaking. Put simply, a convention can be defined as an agreed association of a word with a thought. $^{94}$

Having discussed the relationship between words, thoughts and referents, it is now useful to define the word 'meaning'. In one sense, this word needs no definition. A competent user of language knows what it is for a word to have meaning. Moreover, it has been very difficult for theorists to agree on a definition of 'meaning', 95 and one way to get around these difficulties is to avoid discussing meaning altogether. ${ }^{96}$ Indeed, certain linguists have come close to claiming that words do not have meanings. ${ }^{97}$ If, however, the word 'meaning' is left undefined or vague, the task of interpretation becomes vague, and it becomes difficult to determine whether an instance of interpretation is correct.

The meaning of a word cannot simply be equated with the referent of the word. Two or more words can refer to the same referent, but have different meanings. For instance, the words 'my father' and the words 'my mother's husband' may refer to the same person, but are not equivalent in meaning

94 Although the word 'convention' should be understood to mean the association of a word with a thought, in some contexts it will be convenient to use it to also mean the thoughts that are associated with words. For instance, in the sentence, 'Interpreters need to learn the conventions associated with words', the term 'conventions' could be understood to mean the thoughts conventionally associated with words, and not merely the association itself.

95 This is especially so in the philosophy of language, where there have been a number of influential approaches to meaning. A P Martinich discusses a number of these approaches in "Philosophy of Language” in John V Vanfield (ed) Philosophy of Meaning, Knowledge and Value in the Twentieth Century (Routledge, London, 1997) 11, including, the naming theory of meaning (at 12), the verification theory of meaning (at 18), utterer's meaning (at 21 ), speech acts and conversation (at 22), and the causal theory of naming (at 26).

96 Some linguists, and even some approaches to linguistics, avoid discussing meaning altogether. Commenting on this, Mario Pei noted: "It is ... strange to encounter a school of linguistics that eschews meaning in its analysis of language” Voices of Man (Harper \& Row, Publishers, New York, 1962) at 110.

97 For instance, the linguist Georgia Green stated: "I don't want to talk about the meaning of words. The notion doesn't make sense to me. ... I don't think the meaning is something that is a property of the word.” Judith N Levi and others "Northwestern University/Washington University Law and Linguistics Conference_Proceedings" (1995) 73 Wash U L Q 800 at 828. Such a statement, if taken at face value, is quite misleading. Green later clarifies her statement by stating that meaning (or rather, the way people expect a word to be understood) is "an indirect property of the word. It's a property of the word by virtue of properties of people.” (at 829). Therefore, even on Green’s analysis it is still possible to speak of words having meaning. She is highlighting, however, that words have meanings indirectly. 
in that they do not describe that person in the same way. ${ }^{98}$

In this thesis, the meaning of a word will be defined as the thought ${ }^{99}$ associated with this word. ${ }^{100}$ It may be claimed that since it is impossible to directly discover the thoughts of another person, to define meaning in terms of a thought is to commit a fallacy. ${ }^{101}$ This argument is unconvincing. It is true that it is impossible to directly discover the thoughts of another person. It is also true that this means that it is impossible to directly discover the meaning another person is giving a word. This discovery, therefore, must be indirect. This discovery is possible through the correct use of language conventions.

The definition of the meaning of a word as the thought with which it is associated is a common understanding of word meaning and a useful first step in understanding meaning. This understanding by itself, however, does not give much insight into the nature of meaning, but may just shift the difficulties with the term 'meaning' to the term 'thought'. ${ }^{102}$ An adequate description of meaning needs to explain how meaning is associated with words, when words are meaningless, and how meaning is communicated.

Once meanings are identified with thoughts, however, an important basic conclusion can be drawn. Because words are arbitrarily connected to thoughts, words are arbitrarily connected to meanings.

98 This point was clearly made by the German philosopher Gottlob Frege who drew an important distinction between sense and reference ("Sense and Reference" (1948) 57 Philosophical Review 209). Frege gave the example of the phrases 'morning star' and 'evening star' as words with the same referent but different senses (210). Although there has been considerable debate about what Frege meant by 'sense', for the purpose of this discussion the word 'sense' can be viewed as equivalent to 'meaning'. This distinction thus makes it clear that it is misleading to directly equate the meaning of a word with its referent.

99 Meaning is sometimes discussed in terms of 'intention' rather than 'thought' (see, for instance, HP Grice "Utterer's Meaning and Intention” (1969) 78 Philosophical Review 147 at 153). Because of the associations related to the word 'intention', in this thesis the more general term 'thought' will be used.

100 A definition of meaning as the thought associated with a word was often taken for granted by earlier writers. For example, Karl Britton states: "Words are used to communicate thoughts; words mean thoughts or successions of thoughts” Communication (Kegan Paul, Trench, Trubner \& Co Limited, London, 1939) at 18. Since the latter part of the twentieth century, there have been various objections to identifying the meaning of a word as the thought with which it is associated, especially in the philosophy of language, the most famous of which is Hilary Putnam's twin earth argument (Hilary Putnam "Meaning and Reference" (1973) 70 Journal of Philosophy 699 at 700-703). The details of these objections are beyond the scope of this thesis, and do not arise in relation to interpretation at the level at which it is investigated in this thesis. For the purposes of this thesis, it is convenient to give a definition of the meaning of a word as the thought associated with this word.

101 Compare William K Wimsatt and Monroe C Beardsley's influential article on literary criticism "The Intentional Fallacy" (1946) 54 Sewanee Review 468. In this article the authors claim that "the design or intention of the author is neither available nor desirable as a standard for judging the success of a work of literary art” (at 468).

102 Ruth Kempson states that viewing meanings as concepts "does no more than substitute for the problem term meaning the equally opaque term concept.” Semantic Theory (Cambridge University Press, Cambridge, 1977 ) at 17. 
This insight is so obvious that it is easy to regard it as trivial. ${ }^{103}$ If, however, the arbitrariness of the connection between words and meanings is not seen clearly, certain mistakes regarding meaning can be made. First, interpreters may assume that each word has a single, correct meaning. Second, they may assume that the oldest meaning of a word is the correct meaning or that the etymology of a word gives a clue to its true meaning. ${ }^{104}$ Third, they may uncritically use dictionaries to ascertain the meaning of words regardless of their context. Fourth, they may focus on the supposed ordinary meaning of a word, rather than the specific meaning a speaker has given to a word.

Furthermore, once the meaning of a word has been defined as the thought associated with the word, the basic difficulty with communication becomes apparent: speakers and interpreters ${ }^{105}$ may associate different thoughts with a word, and thus attribute different meanings to this word. In order for an interpreter to discover the thought of a speaker, that is, the meaning of the speaker, it is necessary that this thought be indicated in some way. This is done by the use of language conventions. These conventions, because they are objective in that they are a public or communicated agreement to use a word, make communication possible.

Successful communication, therefore, depends on speakers employing language conventions correctly, which includes either adhering to established conventions or notifying potential interpreters of changes to these conventions if these changes are not clear from the context of the utterance. Speakers make changes to conventions explicit by providing definitions. It is important to distinguish between two kinds of definition: stipulative definitions and reportive definitions. A stipulative definition stipulates the specific meaning that is being given to a word. A reportive definition reports what people commonly use a word to mean. ${ }^{106}$ Stipulative definitions assign new meanings, whereas reportive definitions describe existing meanings. For instance, dictionary definitions are reportive, and statutory interpretation sections are stipulative. If stipulative definitions are not explicitly given when meanings are changed, there is a risk that interpreters will assume that words are being used with their existing meanings.

This section has introduced a number of basic ideas about language that will be important in this chapter. It is useful to summarise these ideas. When considering language and meaning, it is firstly

\footnotetext{
${ }^{103}$ Wolfgang B Sperlich Noam Chomsky (Reaktion Books Limited, London, 2006) at 29.

104 This has been referred to as the "etymological fallacy" (David Crystal Linguistics (Penguin Books Limited, Harmondsworth, 1971) at 63).

105 See $n 84$.

106 John Hospers An Introduction to Philosophical Analysis (4th ed, Routledge, London, 1997) at 15-16.
} 
important to distinguish three elements: words, thoughts and referents. Words signify thoughts which refer to referents. Thus, the connection between words and referents is indirect, and attention should be paid to the intervening thought. Words are arbitrary signs of thoughts. Therefore, speakers can choose any word to signify any thought. This choice, however, needs to be communicated to potential interpreters for intelligible communication of this thought. This is done by speakers employing language conventions which are agreed associations of words with thoughts. The thought that is associated with a word can be viewed as the meaning of that word. Interpreters can ascertain speakers’ meanings when speakers employ language conventions correctly.

(a) Approach to language and interpretation

Having discussed some important concepts in relation to language, it is useful to define the approach to language and interpretation in this chapter in more detail. This chapter focuses on the use of language to signify thoughts and to stand for referents. Language, however, has a variety of functions. First, the use of language is not limited to description. There are many other uses of language. For instance, language is used to promise, to issue commands, and to ask questions. ${ }^{107}$ Since all of these uses of language involve the signification of thoughts and the designation of referents, they may be within the scope of this chapter, but the distinction between such functions will not be emphasised. Second, a distinction is sometimes drawn between the descriptive and emotive aspects of language. ${ }^{108}$ Speakers do not use language merely to describe, but also use language emotively to convey an attitude towards that which is being described. This chapter will not focus on the emotive aspect of language. Third, language is important for social cohesion. ${ }^{109}$ This function of language will not be covered in this chapter.

107 These various functions of language are emphasised by the speech act theorists, most notably John L Austin in How to Do Things with Words (2 ed, Harvard University Press, Cambridge (Mass), 1975) and John R Searle in Speech Acts (Syndics of the Cambridge University Press, London, 1969) and numerous other books. This approach to language has influenced some legal theorists. For examples of the use of speech act theory in analysing language in the law, see Peter M Tiersma "The Language of Offer and Acceptance: Speech Acts and the Question of Intent" (1986) 74 Cal L Rev 189, and Pintip Hompluem Dunn "How Judges Overrule: Speech Act Theory and the Doctrine of Stare Decisis” (2003) 113 Yale LJ 493.

108 This is especially important in literary criticism. For instance, I A Richards distinguished four kinds of meaning: sense, feeling, tone and intention. Sense refers to what the speaker is saying, feeling refers to the speaker's "attitude to what he is talking about", tone refers to "his attitude to his listener", and intention to "the speaker's intention, his aim ... the effect he is endeavouring to promote” Practical Criticism (Kegan Paul, Trench, Trubner \& Company Limited, London, 1935) at 182. The first of these meanings is the descriptive meaning. The second and third are emotive meanings. The fourth is similar to the force of an utterance, discussed in the paragraph accompanying $n$ 118.

109 This aspect of language is dealt with in the discipline of sociolinguistics. See Janet Holmes An Introduction to Sociolinguistics (2 ed, Pearson Education Limited, Harlow, 2001). 
In this chapter interpretation will be viewed as the discovery of the meaning that speakers have given to the words being interpreted. Diagram 3.1 depicts the use of a word to signify a specific thought and to stand for a specific referent. That is, it is depicting the unambiguous use of language. ${ }^{110}$ It is common for emphasis to be placed on the fact that words have many meanings. Although this is true of words in the abstract, in use they generally have a single intended meaning, and it is the task of interpreters to correctly ascertain this single meaning. ${ }^{111}$

This chapter will also focus on the identification of referents. Diagram 3.1, however, should not be taken to imply that all words have identifiable referents. Such a view of language can lead to the view that the meaningfulness of a word depends on the existence of an identifiable referent to which it relates, and consequently the use of "the absence of a referent as a criterion of the absence of meaning." 112 It can also lead to an extreme scepticism about abstract words. ${ }^{113}$ It is true that it is easy to get into arguments about the meaning of words which have no identifiable referent. The fact that a referent cannot be identified for a certain word, however, does not mean that this word is necessarily meaningless. It is not necessary or possible to identify referents in every instance of interpretation. For instance, it is often difficult to posit referents for abstract words such as 'love'. Therefore, referents are a useful element to consider in some instances of interpretation, and unhelpful in others.

This chapter, therefore, investigates the use of language to signify thoughts and to stand for referents. In this chapter, interpretation is viewed as the identification of the meanings that speakers have given to words by identifying the thoughts they have associated with these words and, where possible, the referents to which these thoughts refer.

The next section of this chapter will discuss the process of speaking. In light of this, it is necessary

110 There may be more than one word used to signify a single thought, but if a single word signifies more than one thought, it is ambiguous.

111 This has been recognised in relation to legal interpretation: James Farr "Francis Lieber and the Interpretation of American Political Science” (1990) 52 Journal of Politics 1027 at 1039.

112 JC Cooley "Review of Lionel Ruby Logic" (1953) 50 Journal of Philosophy 619 at 620.

113 George Orwell notes: "Stuart Chase and others have come near to claiming that all abstract words are meaningless ... Since you don't know what Fascism is, how can you struggle against Fascism? One need not swallow such absurdities as this"”, "Politics and the English Language” in The Collected Essays, Journalism and Letters of George Orwell (Penguin Books Limited, Harmondsworth, 1970) Vol 4156 at 169. Orwell is probably referring to Chase, above n 18, where Chase makes such claims as: "The point of every discussion is to find the referent." (68), and: "We cannot escape from concrete referents by using abstract language. If we try to dodge the difficulty, our words become meaningless. We frequently use the abstraction 'mankind'. What is the referent?" (at 69). In these statements, Chase seems to imply that abstract words may become meaningless if a referent cannot be identified for them. 
to point out a shortcoming of Diagram 3.1: this diagram does not distinguish between the processes of speaking and interpretation. Many important details concerning communication are obscured when these two processes are conflated, and it is much clearer if they are separated. Diagram 3.1 distinguishes between the relationship between a word and the thought it signifies and the relationship between that thought and the referent to which it refers, but it does so in a confusing way. This diagram states that the word signifies a thought. Although loosely true, this conflates two distinct processes. In speaking, words encapsulate thoughts, whereas in interpretation, words generate thoughts. The word 'signifies' obscures the distinction between these two processes. Furthermore, Diagram 3.1 states that the thought refers to a referent. This also conflates two distinct processes. In interpretation, although this thought does refer to a referent, it is generated by a word, whereas in speaking the thought may be generated by the referent itself. Again, the words 'refers to', although loosely true, obscure these two processes. Finally, the single thought at the apex of the triangle represents two thoughts: the thought in a speaker's mind and the thought in an interpreter's mind. Therefore, to provide an accurate description of language, it is necessary to discuss the processes of speaking and interpretation separately.

\section{$2 \quad$ Speaking}

Diagram 3.2, below, depicts the relationship between a referent, a thought and a word in the process of speaking.

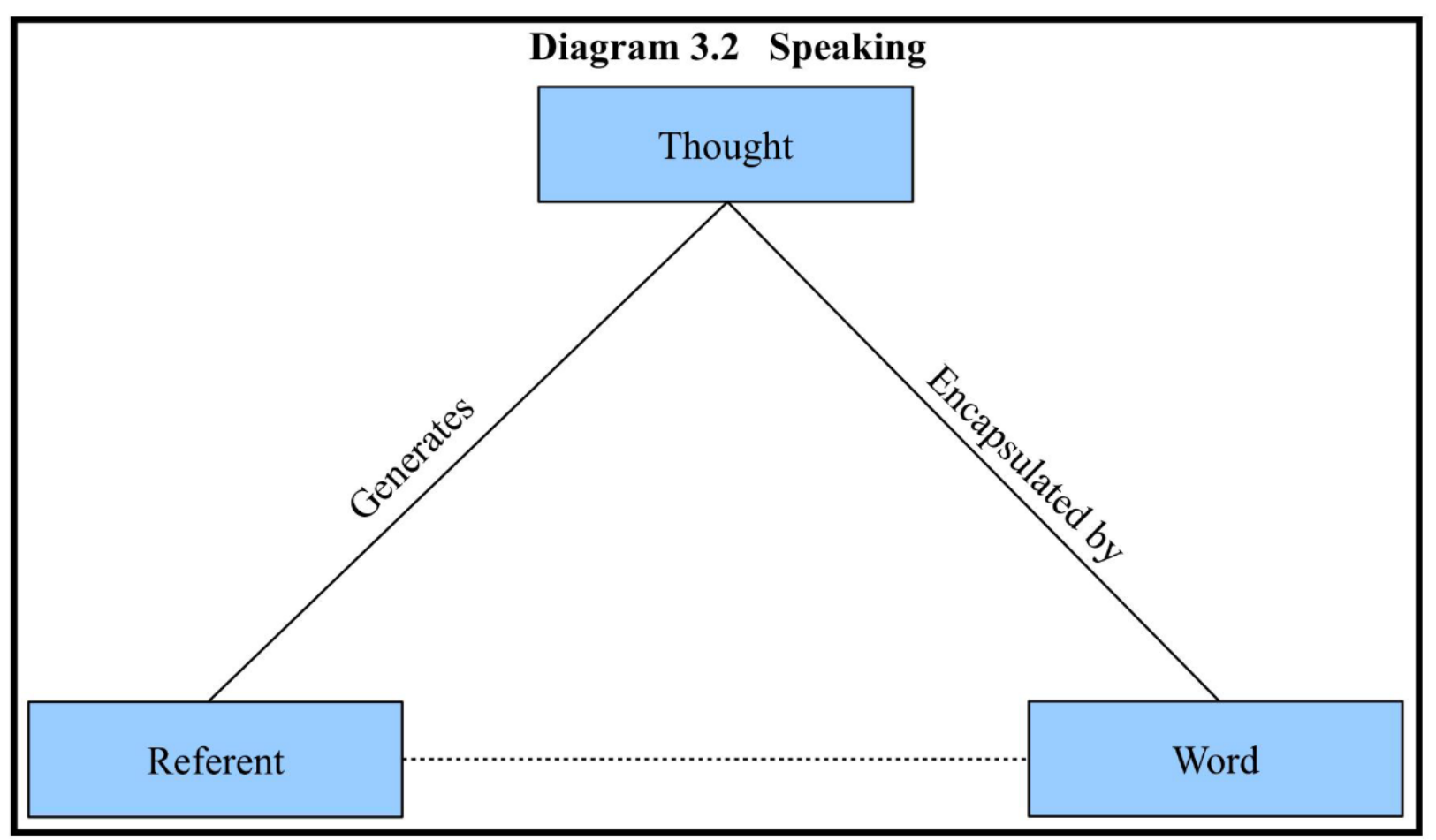


Diagram $3.2^{114}$ depicts the process of speaking, which should be understood to include writing. In this diagram, the semantic triangle is reversed with the word on the right-hand side and the referent on the left-hand side. Going from left to right, a referent generates a thought which is encapsulated by a word. Speaking, therefore, involves a thought in a speaker, which may have been generated by a referent, and which is encapsulated in language.

A referent generates a thought spontaneously. There is considerable debate about the extent to which this generation is dependent on language and influenced by language. ${ }^{115}$ Regardless of whether certain thoughts can exist without language, however, it is clear that for complex or detailed thoughts to be accurately communicated they need to be encapsulated in language. The act of speaking is this encapsulation of a thought in language.

If someone sees a tree and says, 'I can see a tree', the act of speaking, in relation to the word 'tree', can be viewed as beginning at the left-hand side of the triangle with the tree as a referent and proceeding through the connecting thought to the word on the right-hand side. If someone says, 'I saw a tree, yesterday', the act of speaking begins at the apex of the triangle with the thought of the referent, the tree. This thought is still directly based on an experience with this referent. Speakers do not, however, always have direct experience with the referents they speak about. If someone says, 'My sister saw a tree', in relation to the word 'tree', the thought is not directly based on experience. The referent of the word 'tree' is still the actual tree seen, but the speaker has not had direct experience with this referent.

It is therefore useful to view the act of speaking as beginning at the apex of the triangle with a thought. This thought is often of a certain referent, and may have been generated by experience with

\footnotetext{
114 Although the word still stands for the referent, the words 'stands for' have been omitted from the base of the triangle as they could be taken to suggest the referent stands for the word when the diagram is read from left to right.

115 The details of this debate are beyond the scope of this thesis, but the two basic views regarding the relationship between language and reality can be briefly described. In the book The Linguistic Construction of Reality (Croom Helm Publishers Limited, Beckenham, 1987) George W Grace discusses two "conceptions of the way language represents reality" (at 5): the 'mapping view' according to which "there is a common world out there and our languages are analogous to maps of this world" (at 6) and the 'reality-construction view', according to which "it is impossible to draw a clear line between thinking, i.e. bringing a thought into being, and encoding the thought, i.e. putting it into words” (at 10). Lera Boroditsky presents a balanced view on this issue, by stating: "Whether people's native language is covertly involved in all manner of seemingly nonlinguistic tasks ... or whether aspects of grammar are able to influence nonlinguistic representations directly, it appears that thinking involves a collaboration between many different linguistic and nonlinguistic representations and processes." Lera Boroditsky, Lauren A Schmidt, and Webb Phillips "Sex, Syntax, and Semantics” in Dedre Gentner and Susan Goldin-Meadow (eds) Language in Mind (The MIT Press, Cambridge (Mass), 2003) 61 at 76-77. The relationship between language and thought is briefly discussed at Chapter Three D.
} 
this referent. This thought is then encapsulated in words. The key point is that for speakers the thought is first and the choice of language follows.

This thesis has defined the meaning of a word as the thought associated with the word. In Diagram 3.2, the speaker's thought may be viewed as the meaning the speaker is giving to the word. When this is a thought of a definite referent, the meaning of the word can also be loosely equated with this referent. This can be called the speaker's meaning. The speaker's task is to make this thought, this meaning, clear to interpreters.

This chapter has emphasised the role of conventions in associating words with thoughts. A speaker encapsulates thoughts in language by using language conventions. The words speakers choose are often constrained by existing language conventions, for instance, the convention associating the word 'tree' with trees. If a speaker is using a word with a new meaning, that is, to signify a different thought from the thoughts conventionally associated with this word, this new convention should be made clear. Unless this new convention is clear from the context of the utterance, the word should be defined.

The following conversation from the short story Jeeves in the Springtime usefully illustrates the choice of language available to speakers. Bertie Wooster is asking his butler, Jeeves, about $\mathrm{Mr}$ Little, the uncle of Bertie’s friend Bingo Little: ${ }^{116}$

\footnotetext{
“Tell me about old Mr. Little. What sort of chap is he?”

“A somewhat curious character, sir. Since retiring from business he has become a great recluse, and now devotes himself almost entirely to the pleasures of the table.”

“Greedy hog, you mean?”

"I would not, perhaps, take the liberty of describing him in precisely those terms, sir. He is what is usually called a gourmet.”
}

In this extract, three choices of language are used by the speakers to describe Mr Little. Jeeves' initial polite description, that Mr Little "devotes himself almost entirely to the pleasures of the table” is his idiosyncratic way of describing Mr Little. Bertie’s response, "Greedy hog”, is his way of describing the same sort of person. Jeeves then gives a more general term, "gourmet”. This extract clarifies the speaker's main task. In choosing a word, a speaker needs to make his or her

${ }^{116}$ PG Wodehouse “Jeeves in the Springtime” in The World of Jeeves (Herbert Jenkins Limited, 1967, London) 19 at 24. 
thoughts clear to an interpreter. To do this, the speaker needs employ language conventions. Jeeves' initial description was somewhat unclear to Bertie. When his meaning was questioned, he resorted to a more common language convention: "what is usually called a gourmet".

In some situations, speakers need to explicitly clarify the conventions they are employing. This can been illustrated by Evelyn Waugh's description of a cosmetician at a funeral home asking a client about the usual appearance of a recently deceased man: ${ }^{117}$

Did the Loved One wear his own hair? And the normal complexion? We usually classify them as rural, athletic, and scholarly - that is to say red, brown, or white.

The phrase "we usually classify them as" is an indication of the particular conventions employed in this industry. Because the cosmetician is talking to an outsider, these conventions are clarified by explicit definition.

A further aspect of a speaker's meaning is the speaker's intention in saying something, which has been called the 'force' of an utterance. ${ }^{118}$ The speaker's meaning is the speaker's thought, and this thought includes the intention of the speaker. For instance, if someone is loitering in a shop, the shopkeeper may ask, 'Can I help you?' The literal meaning of this utterance is an offer of help, but to interpret the utterance correctly it is necessary for interpreters to pay attention to the shopkeeper's intention in asking this question. ${ }^{119}$ The shopkeeper may intend to make the loiterer leave the shop. Thus, such a statement needs to be interpreted on two levels: the level of the literal meaning and the level of the intention behind the utterance. ${ }^{120}$ The force of an utterance is often indicated by the factual context of the utterance. ${ }^{121}$

This section has briefly discussed speaking. ${ }^{122}$ The speaker's task is to make his or her thoughts clear to an interpreter. Speaking involves the encapsulation of a speaker's thoughts in language.

117 Evelyn Waugh The Loved One (Penguin Books Limited, Harmondsworth, 1948) at 47.

118 Jenny Thomas Meaning in Interaction (Longman, London, 1995) at 18.

119 It is possible to discuss the 'force' of a single word if that word is being interpreted, but is it often clearer to view entire sentences as having a certain force.

120 This is another reason why the meaning of a word cannot merely be equated with a referent. It is not merely that the speaker may be viewing the referent in a certain way, but also that the speaker may have a certain intention in referring to the referent. This intention is part of the meaning of the word.

121 Another important indication is the fact that, interpreted literally, the utterance seems to lack relevance (see HP Grice "Logic and Conversation" in Peter Cole and Jerry L Morgan (eds) Syntax and Semantics (Academic Press, New York, 1975) 41).

122 This discussion is not intended to be a comprehensive analysis of speaking, but is just bringing out some salient points about the process of ordinary speaking so that this process can be compared to speaking in a legal context. 
This is the encapsulation of a speaker's meaning. This encapsulation involves the use of language conventions. For successful communication, speakers need to employ language conventions correctly by either adhering to existing conventions or making new conventions clear to interpreters.

(a) Ineffability

For intelligible communication, a speaker needs to be aware of language conventions and employ them correctly. A person's experience with things, ${ }^{123}$ however, generates thoughts even when the person does not have words to describe these things. In this situation, Diagram 3.3, below, would apply.

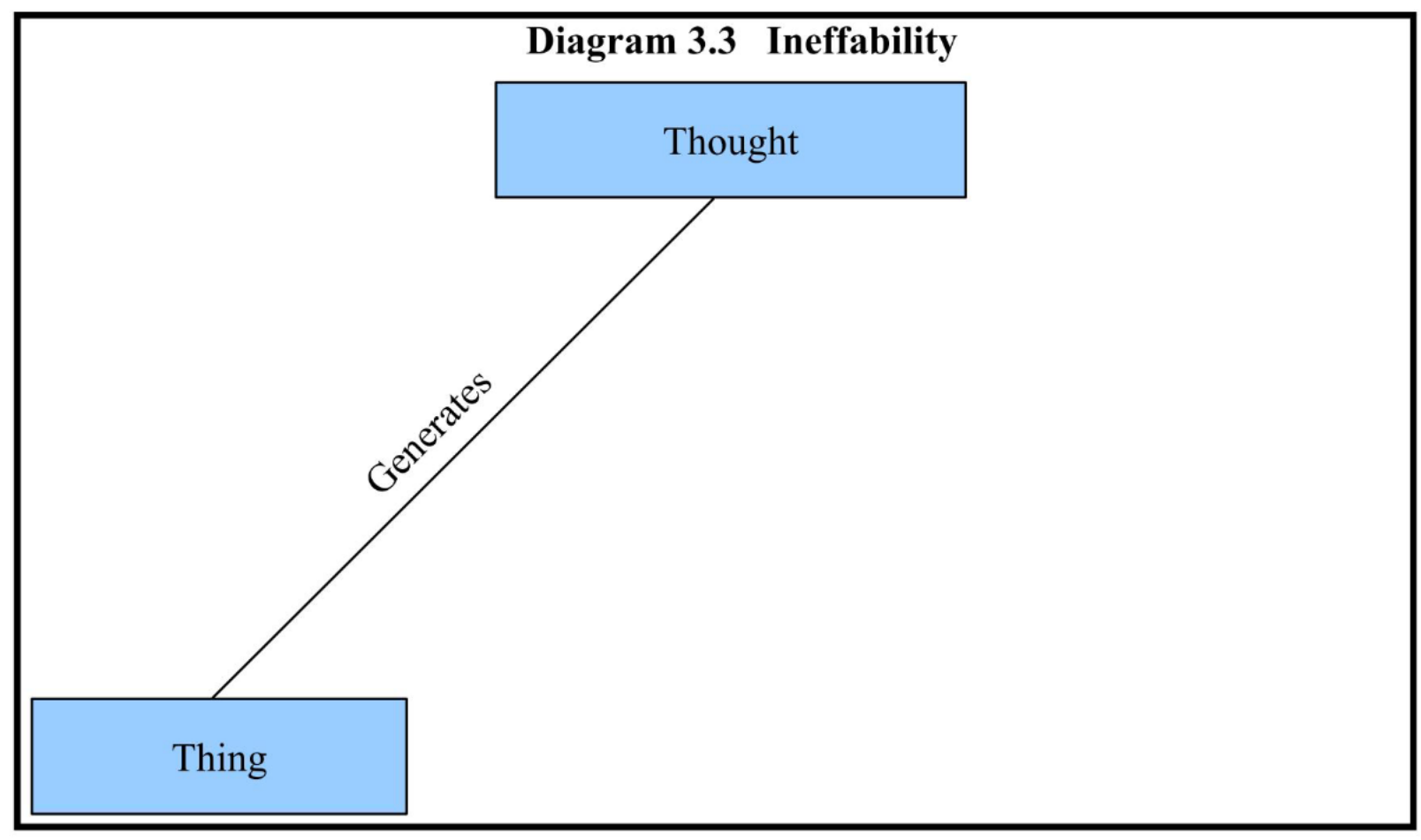

Diagram 3.3 depicts ineffability. In this diagram a thing has generated a thought, but the thought has not been encapsulated in language. Therefore, this thought is ineffable for a speaker. Because this thought is of a certain thing, this thing is also ineffable for the speaker. Words are associated directly with thoughts and indirectly with things. Therefore, ineffability can either be described as a situation in which a speaker does not know which word to use to encapsulate a certain thought or as

${ }^{123}$ The word 'thing' rather than the word 'referent' is used in this section because it is discussing things that have not been referred to by words. 
a situation in which a speaker does not know which word to use to describe a certain thing.

Although a word may have been conventionally associated with a certain thing, a particular speaker's use of this word depends not only on having a thought regarding this thing, but also on knowledge of this word, that is, knowledge of the conventional association of the word with this thing. Therefore, a thing may be ineffable for a speaker because the speaker does not know the language conventions associated with that thing. ${ }^{124}$

'Ineffable' is not used here to refer to things that are intrinsically incapable of being described by language. Rather, it is being used in a new sense to describe a situation in which someone does not know which word to use to encapsulate a certain thought, and thus to stand for a certain thing. ${ }^{125}$

Often ineffability can be caused by a speaker temporarily forgetting a word. Another example of a conversation between Jeeves and Bertie can illustrate this. Bertie asked Jeeves: ${ }^{126}$

\footnotetext{
“I'm on the horns of ... what are those things you get on the horns of?”

"Dilemmas, sir."

“That's right. I'm on the horns of a dilemma.”
}

In such a situation, ineffability often creates no problem because the speaker is well aware of the need to find the correct word.

If the word that is usually used to name something is not known, it may still be possible for this thing to be described and this description may be intelligible to others. This description would then comprise the 'word' in Diagram 3.2 and the triangle would be complete. Diagram 3.3, therefore, is depicting the point in time at which a word has not yet been used by a speaker. Since any object can be given any name, and names are not intrinsically correct, the absence of the knowledge of an existing name may not always be a barrier to communication, but it often creates certain problems. $^{127}$

\footnotetext{
${ }^{124}$ Language conventions are associations of words with thoughts. This means that they are also associations of words with the things to which these thoughts refer.

125 Therefore, this is a stipulative definition giving a new meaning to this word. 'Ineffable' will be used with this meaning throughout this thesis.

${ }^{126}$ PG Wodehouse Stiff Upper Lip, Jeeves (Penguin Books Limited, Harmondsworth, 1966) at 31 (ellipsis in original).

127 This should not be taken to suggest that the term 'word' in Diagrams 3.1 and 3.2 refers to the correct word, that is, the word associated via correct language conventions. Rather, the term 'word' in these diagrams is being used to refer to any word that is used to encapsulate a thought.
} 
Difficulties with interpretation do not occur when something is merely ineffable because ineffability means that no word has been used by a speaker. Difficulties occur when a speaker does not know which word to use to describe a certain thing, but still attempts to describe the thing. In his autobiography Far Away and Long Ago, W H Hudson gives a short description of a tree for which he does not know the name. ${ }^{128}$ Unless readers can recognise the tree from this description, they have to rely on this description for information about the tree. If the name had been given, readers who knew this name would know what tree was being referred to. Even if they did not know this name, they could find out about the tree because the name had been given. Although the semantic triangle may be complete because of Hudson's description of the tree, this description is not as useful as the name of the tree.

Problems also occur when speakers use the wrong word because they do not know the correct language conventions. In this situation, the thought is no longer ineffable because it has been expressed, but there may be difficulties with communication. There is a clear example of this in the novel Pnin. ${ }^{129}$ Pnin is a Russian man in America who struggles with English. He wants to catch a bus, and is talking to a man at an information booth. Pnin asks the man: ${ }^{130}$

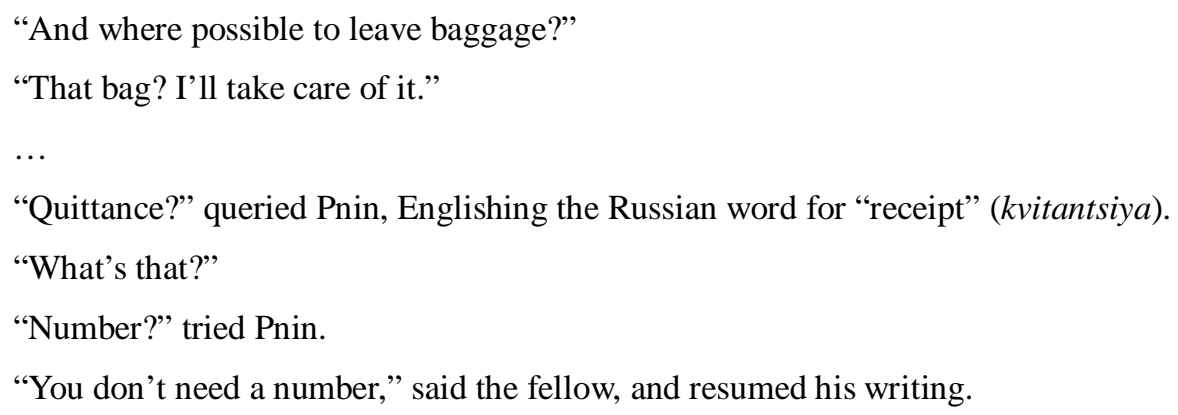

Pnin wanted to ask for a receipt. He knew the thing he wanted to refer to, but not the word conventionally associated with it in English. Thus, it can be said that this thing was ineffable for Pnin in English. Nevertheless, he attempted to refer to this thing by using the word 'quittance', which is not the common word for a receipt. When the man did not understand him, he was able to make himself clear by using the word 'number'. This shows how the wrong word may be used when speakers do not know the correct language conventions. This can be considered as a result of ineffability.

\footnotetext{
${ }^{128}$ WH Hudson Far Away and Long Ago (JM Dent \& Sons Limited, London, 1951) at 6.

129 Vladimir Nabokov Pnin (William Heinemann Limited, London, 1957).

${ }^{130}$ Ibid, at 18.
} 
If speakers are aware that they do not know the word that is conventionally associated with something, they are usually careful in what they say and can indicate to interpreters that they do not know the right word. It is more dangerous, however, when speakers are not aware that they do not know the word that is conventionally associated with a certain thing and mistakenly believe a different word is associated with that thing. This is not ineffability as defined in this thesis because the speaker has associated a word with a thing, but the speaker has used the wrong word.

Because words are arbitrary labels, it may be thought that it is impossible for speakers to use the wrong word. Speakers, however, can use the wrong word in the sense that they do not employ existing conventions or clarify the new conventions they are employing. Such a use of language is wrong because it is misleading to interpreters. Similarly, it is wrong for a speaker to deliberately use new conventions without notification. ${ }^{131}$ In such a situation, interpreters will probably assume that the word is being used to describe the thing with which it is conventionally associated, not the new thing with which the speaker has associated it.

\section{Interpretation}

Diagram 3.4, below, depicts the relationship between a word, a thought and a referent in the process of interpretation.

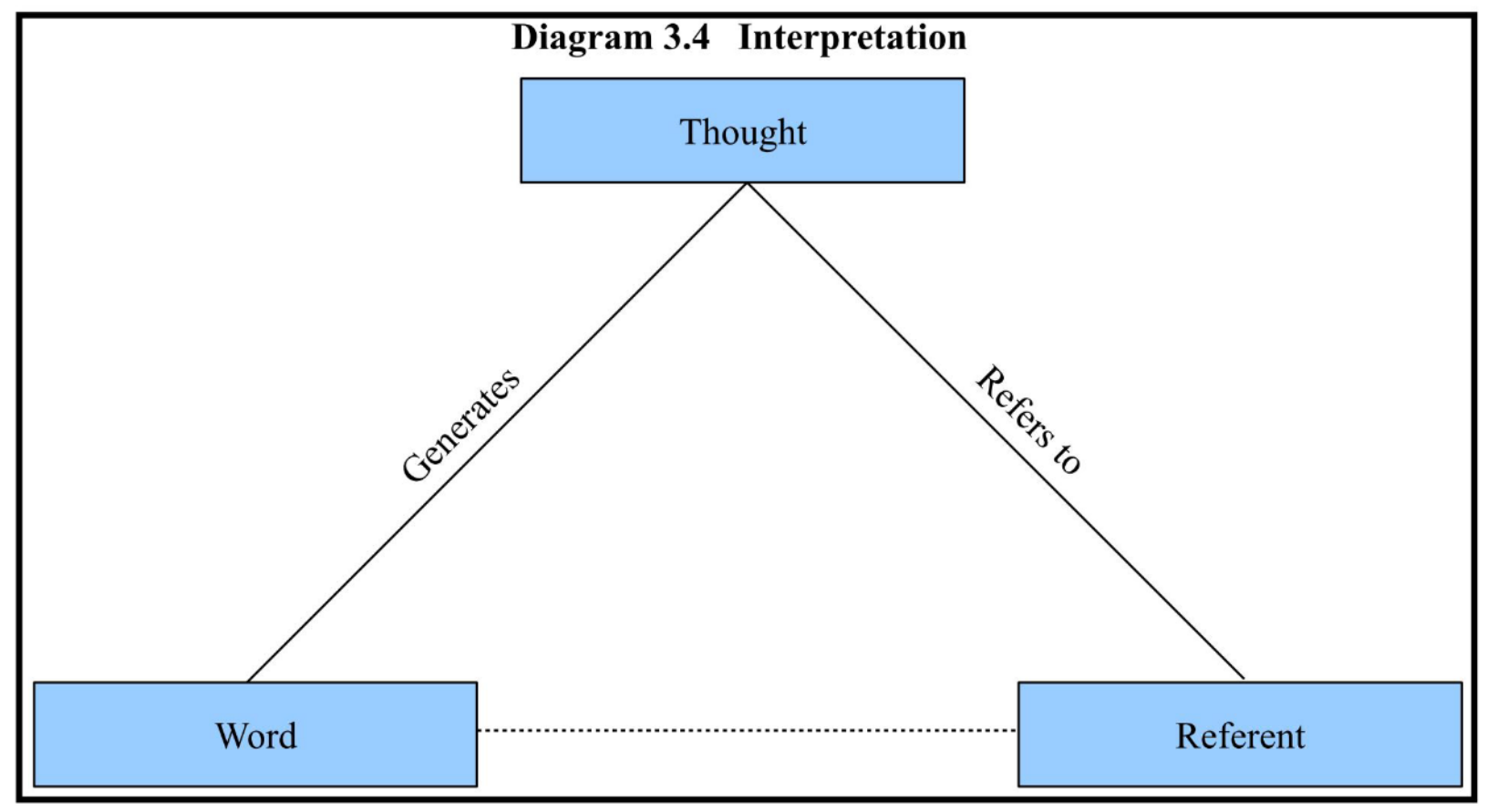

${ }^{131}$ See Chapter Three C.1. 
Diagram 3.4 depicts the process of interpretation. ${ }^{132}$ It should be read from left to right. The first thing is the word heard or read. This word generates a thought. This thought may refer to a certain referent. The thought is usually generated by language conventions, rather than by experience of a referent directly. ${ }^{133}$ In such a situation, the referent is not directly perceived by the interpreter but is imagined. ${ }^{134}$ A thought refers to a referent spontaneously. Difficulties occur, however, with the generation of this thought from a word. The act of interpretation is this generation of a thought by language.

This diagram appears similar to Diagram 3.1 (Word, Thought and Referent), but is useful because it specifically depicts the process of interpretation. Diagram 3.1 appears to show speaking when read from right to left and interpretation when read from left to right. Diagram 3.4, however, illustrates interpretation unambiguously.

Diagram 3.4 shows that the relationship between a word and its corresponding thought are different for a speaker and an interpreter. Whereas a speaker deliberately chooses a certain word to encapsulate a thought, for an interpreter the word generates the thought. For speakers, the thought is first and the word follows; for interpreters, the word is first and the thought follows. To say that the word ‘signifies’ a thought, as in Diagram 3.1, obscures these two distinct processes.

In Diagram 3.4, the meaning of the word is the interpreter's thought. This can be called the interpreter's meaning. Earlier in this thesis, the meaning of a word was defined as the thought with which it is associated. Based on this definition, there are three basic ways to view meaning: as the thought of a speaker, as the thought of an interpreter, or as the thought generally associated with a

\footnotetext{
132 'Interpretation' here, and throughout this thesis, means comprehending the meaning of language, and not the translation of foreign languages.

133 This would not be the case in an instance of shared experience of the same referent, for examples, if a speaker points to a table and says, 'See that table', in relation to the word 'table', the thought is generated by the object, not merely by language. Although the language is calling attention to the object, the thought regarding the object is not based merely on language. This chapter, however, will not consider such situations, because they are not present in the interpretation of written language.

${ }^{134}$ In older philosophy books this was called a conception as opposed to a perception. In Alexander Jamieson's Grammar of Logic 'perception' is defined as "the faculty by which we are informed of the properties of external objects, in consequence of the impressions which they make on the organs of sense” ((AH Maltby and Co, NewHaven, 1822) at 50) and 'conception' is defined as "that faculty of the mind which enables us to form a notion of an absent object of perception” (at 61).
} 
word. ${ }^{135}$ For communication to be effective, ideally speakers and interpreters need to assign the same meaning to a word, that is, ideally the thought of the speaker and the thought of the interpreter need to be the same.

Interpretation has been defined as "that faculty, which enables us to attach to another's language, the same meaning as the author himself attached to it.”136 Thus, the task of interpretation is one of discovering the speaker's meaning, that is, ascertaining the speaker's thought, and, if possible, ascertaining the referent to which this thought refers. The subjective thoughts of speakers, however, are inaccessible to interpreters. Furthermore, speakers are often unavailable to clarify their meanings, ${ }^{137}$ and even if they could do this, this clarification is still open to interpretation and may be no more authoritative than any other opinion on their meaning. For these reasons, this view of interpretation has come under considerable challenge, especially from post-modern literary critics. ${ }^{138}$ Still, this does not negate the fact that interpreters usually have the goal of ascertaining speakers' meanings, and that communication based on this view of interpretation works well for many purposes. ${ }^{139}$ Moreover, even if the discovery of a speaker's exact thoughts is unattainable, it

${ }^{135}$ In relation to communication theory, three similar aspects of meaning have been distinguished. These are: "sender's meaning: sender's intended message ... receiver's meaning: receiver's inferred message ... sign meaning: the sum of the properties of the signal which make it ... apt ... for conveying sender's intended message” Alan Cruse Meaning in Language (2ed, Oxford University Press, Oxford, 2004) at 6. Interestingly, this means that there are three tasks in which an interpreter can engage. For instance, in relation to ascertaining the meaning of a poem, an interpreter can ask three questions: "what did the author intend? ... what is the poem saying? ... [and] what do I make of it?” Kerry S Robichaux “A Prolegomenon to a Hermeneutic of the Bible According to the Intrinsic Being of God” (1999) 4(3) Affirmation \& Critique 3 at 4. This chapter will focus on interpreters answering the first of these questions.

136 JA Ernesti Elements of Interpretation (trans Moses Stuart) (Flagg and Gould, Printers, Andover (Mass) 1822) at 2. In a similar vein, E D Hirsch notes: "The reader should try to reconstruct authorial meaning" The Aims of Interpretation (The University of Chicago Press, Chicago, 1976) at 8.

137 This applies especially to the interpretation of written texts.

${ }^{138}$ For a detailed discussion of the postmodernists' approach to interpretation and meaning, see Kevin J Vanhoozer Is There a Meaning in This Text? (Zondervan, Grand Rapids, 1998). Both Friedrich Nietzsche and Jacques Derrida emphasised the indeterminateness of meanings: "For Nietzsche ... all philosophies, whatever their claim to logic or reason, rested on a shifting texture of figurative language ... The bottomless relativity of meaning, and the ways in which philosophers have disguised or occluded their ruling metaphors, are the point of departure for Derrida's writing like Nietzsche’s before him.” Christopher Norris Deconstruction (Methuen, London, 1982) at 58.

139 In contrast to Derrida's emphasis on the indeterminateness of meaning (see n 138), M H Abrams notes that "the philosophy of language offers an alternative to the supposition that language requires an absolute foundation in order to be determinately meaningful. This alternative sets out from the observation that in practice language often works, that is gets its job done. ... This alternative stance takes as its task not to explain away these workings of language, but to explain how it is that they happen, and in instances of failure, to inquire what it is that has gone wrong." "How to do things with texts" (1979) 46 Partisan Review 566 at 570. 
is still useful for interpreters to have this as an aim. ${ }^{140}$

A speaker's subjective meaning is communicated by the use of language conventions. Therefore, speakers need to ensure that they make the language conventions they are using clear and interpreters need to ensure that they correctly discover such conventions. This means that the governing factor for intelligible communication is the correct use of language conventions. ${ }^{141}$ The interpreter's task is to ascertain the thoughts that the speaker is encapsulating in language by paying attention to the language conventions that the speaker is employing. This is to ascertain a speaker's meaning objectively. Put simply, interpretation involves the interpreter objectively ascertaining the speaker's meaning. ${ }^{142}$

It is useful to consider a few examples of interpretation. In the conversation between Jeeves and Bertie quoted earlier, Bertie correctly interpreted Jeeves’ somewhat cryptic statement that Mr Little “devotes himself almost entirely to the pleasures of the table”. ${ }^{143}$ Bertie’s response ("Greedy hog, you mean?’) shows that he interpreted Jeeves’ statement correctly.

Bill Bryson recounts calling the United States Social Security Administration when his wife had lost her social security card and asking a government official what his wife's social security number was: ${ }^{144}$

"We are only permitted to divulge that information to the designated individual," he replied.

"The person named on the card you mean?"

"Correct."

The phrase 'the designated individual' may seem obscure, but, again, in the context it was

${ }^{140}$ E D Hirsch made this point clearly: "I can never know another person’s intended meaning with certainty because I cannot get inside his head to compare the meaning he intends with the meaning I understand ... But this obvious fact should not be allowed to sanction the overly hasty conclusion that the author's intended meaning is inaccessible and is therefore a useless object of interpretation. It is a logical mistake to confuse the impossibility of certainty in understanding with the impossibility of understanding." Validity in Interpretation (Yale University Press, New Haven, 1967) at 17.

141 This is true by definition. Any situation where communication is not governed by established conventions is an instance of the creation of new conventions, since what makes communication by language possible at all is the use of language to signify thoughts, and this use involves the establishing of conventions, even if only for one specific instance of communication.

142 There are certain words with which it may seem difficult to associate any meaning. For instance, the word 'well' in the sentence, 'Well, I'm going now.' This thesis will not focus on the interpretation of such words, but they should not be considered meaningless.

143 See text accompanying n 116.

144 Bill Bryson Notes from a Big Country (Black Swan Books, London, 1999) at 202. 
interpreted correctly.

Another illustration of interpretation can be seen in a fictional conversation between Stephen Potter and a doctor: ${ }^{145}$

Doctor: Men who come within the ambience of a woman, are more likely to be attracted by, to feel the attraction of, that woman, if she is beautiful.

Potter: You mean they are more likely to fall in love with them if they are pretty?

Doctor: Yes

Although the word "ambience" in this context is unusual and the phrase "to feel the attraction of" makes this statement a somewhat obscure, the meaning was clear from the context. ${ }^{146}$

In each of these examples of interpretation, the interpreters simplified the speakers' statements by translating them into their own words. The correctness of their understanding was then confirmed by the speakers. This shows the basic goal of interpretation. It is not that an interpreter needs to have exactly the same thoughts as a speaker, but that the interpreter arrives at a meaning that is sufficiently similar to that of the speaker. ${ }^{147}$ These examples involve the interpretation of spoken language, but, in principle, the goal of the interpretation of written language is the same. When interpreting written texts, there is no opportunity for interpreters to confirm their understanding with writers. Interpreters, however, still need to arrive at a meaning that is sufficiently similar to the writer's meaning.

These examples also show how language conventions are clarified by the context of an utterance. Words are often conventionally associated with a number of thoughts. The context in which a word is spoken or written can show which conventions apply. For example, the word 'table' in the phrase "pleasures of the table" does not refer to the table itself, but to the food placed on the table. In the

145 Stephen Potter Anti-Woo (William Heinemann Limited, London, 1965) at 15 (italics in original).

146 This example of interpretation shows the danger of limiting interpretation to the identification of referents. In the context of the doctor's utterance the meaning of the word "attraction" is clear, but it would be very difficult to try to posit a referent for this use of the word, especially because it is referring to attraction in the abstract, and not to a specific instance of attraction.

147 These examples also all illustrate an important principle about the interpretation of spoken language: the speaker and the hearer interact to arrive at meaning. This aspect of meaning is emphasised in Thomas, above $n$ 118, which "accords a central place to the roles of both speaker and hearer in the construction of meaning" (preface). This aspect of meaning will not be emphasised in this chapter because this chapter is highlighting aspects of communication relevant to the interpretation of written language. 
abstract the word 'table' can refer to an item of furniture or to the food which is placed on it. Which convention applies in a specific situation is made clear by the context.

It is important also to distinguish two types of context: verbal and factual. The verbal context is the language surrounding the words being interpreted. In relation to written language, this can include a sentence, a chapter, an entire text, and other related texts. It would also include any definitions given. The factual context is the factual background of the language being interpreted. This can include the situation in which the utterance was made, the time the utterance was made, ${ }^{148}$ and the person to whom the utterance was directed. This factual context can also show which conventions apply. For instance, Bill Bryson needed to take into account the fact that he was talking to a government official who might use official language like “divulge” and “designated individual”.

In Diagram 3.4, a word generates a thought and this thought refers to a referent. As mentioned, difficulties mainly occur with the first step: generating a thought from a word. In order to arrive at the correct thoughts, interpreters need to take into account a number of considerations. These can either be viewed as considerations that show the speaker's meaning or considerations that indicate the conventions that the speaker is employing.

It is useful to list some of the considerations which interpreters need to take into account. First, there is the general conventional meaning of the words being interpreted. ${ }^{149}$ Second, there are the specific conventions that apply in certain areas. Third, there is the verbal context of the utterance, including any definitions given. Fourth, there is the factual context of the utterance, including who the speaker is, who the intended interpreter is, and the situation in which the utterance is made. ${ }^{150}$ These four considerations show which specific conventions apply and whether a new convention has been established. These considerations need to be taken into account by interpreters because they are indicators of the speaker's meaning.

148 This time element is especially relevant in relation to the interpretation of written texts. For instance, Martin Gardner explained the usefulness of an annotated edition of Alice's Adventures in Wonderland by stating: "In the case of Alice we are dealing with a very curious, complicated kind of nonsense, written for British readers of another century, and we need to know a great many things that are not part of the text if we wish to capture its full wit and flavour.” Lewis Carroll (Martin Gardner (ed)) The Annotated Alice (Penguin Books Limited, London, 2001) at xiii (italics in original).

149 There may, of course, be more than one general conventional meaning of these words.

150 Meanings can also be made known by other means, for instance, body language and facial expressions. Such matters could also be viewed as part of the factual context of an utterance. Because this thesis is focusing on the interpretation of written language, such considerations will not be discussed. 
The considerations relevant to interpretation are given in Chart 3.1, below.

\begin{tabular}{|l|}
\hline \multicolumn{1}{|c|}{ Chart 3.1 Relevant Considerations for Interpreters } \\
\hline 1.1 General conventional meaning of words. \\
\hline 1.2 Specific conventions applying in certain areas. \\
\hline 1.3 Verbal context of utterance. \\
\hline 1.4 Factual context of utterance. \\
\hline
\end{tabular}

The considerations in Chart 3.1 are all relevant to interpretation because they all are indicators of the speaker's meaning. This is not an exhaustive list of the kinds of considerations that interpreters need to take into account. Any further considerations, however, would only be relevant if they were also indicators of the specific meaning that a speaker is using a word to express.

This section has briefly discussed interpretation. The interpreter's task is to objectively ascertain the speaker's thoughts. Interpretation involves a word generating a thought in the mind of an interpreter. This thought is the interpreter's meaning. Although it is impossible for the interpreter's meaning to be exactly the same as the speaker's meaning, language conventions make it possible for the interpreter's meaning to be sufficiently similar to the speaker's meaning for there to be successful communication. Therefore, interpreters need to take into account various considerations which indicate the conventions that speakers are employing. 
(a) Meaninglessness

Interpretation always begins with a word. This word then generates a thought. If the interpreter has never encountered the word before, the word may not generate any thought. In this case, Diagram 3.5, below, would apply.

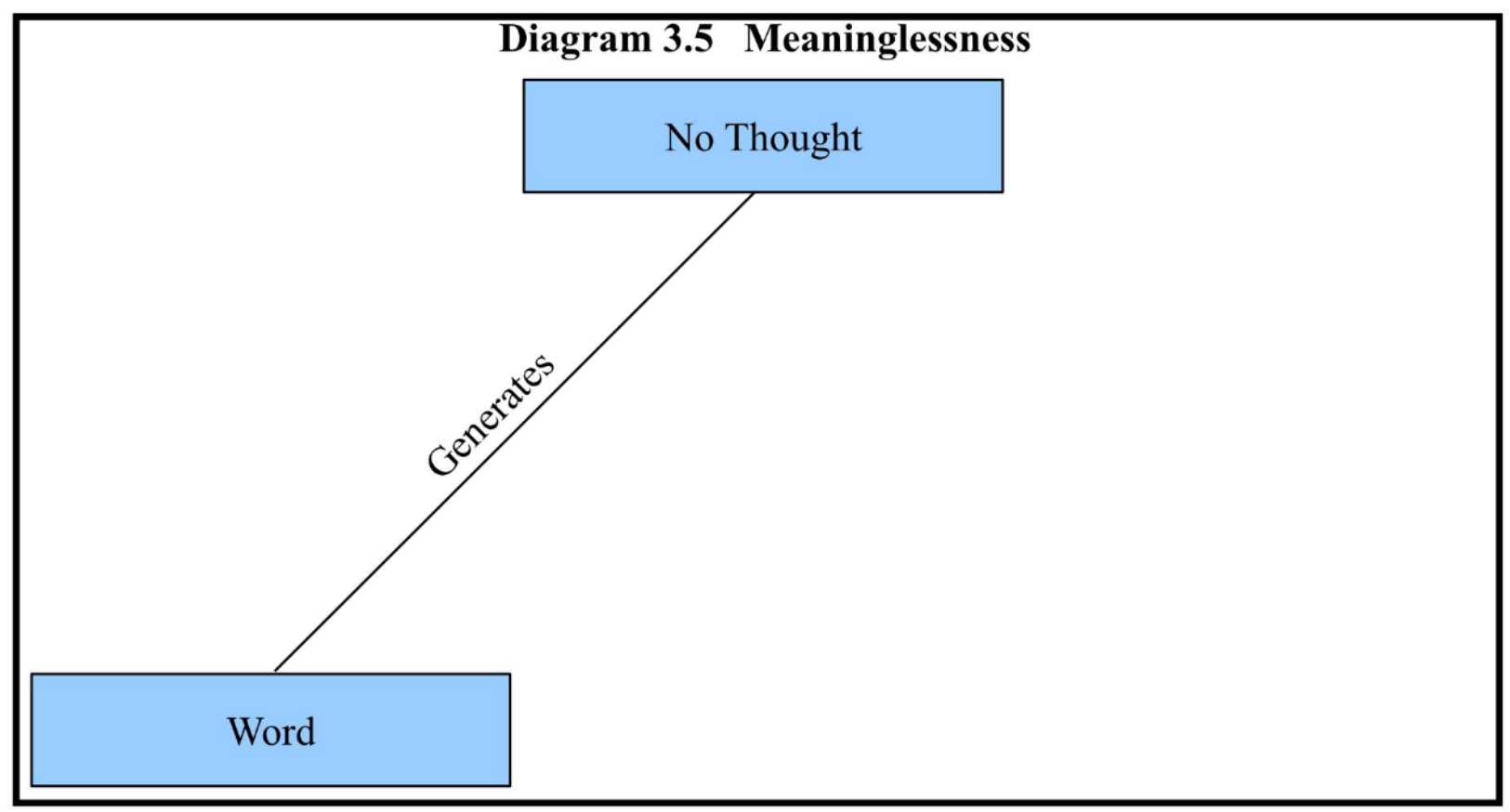

Diagram $3.5^{151}$ depicts a situation in which an interpreter does not know the meaning of a word. 'Meaningless' here means a lack of the knowledge of the language conventions connecting a word to a thought. Unlike the use of the word 'ineffable' in this thesis, this is a common meaning of the word 'meaningless'. When a word is meaningless to an interpreter, it does not generate any thought in the interpreter's mind, and, therefore, it does not refer to any referent.

Whereas a thing may be ineffable for a speaker if the language conventions connecting it to a word are not known by the speaker, a word is meaningless to an interpreter if the conventions connecting it to a thought are not known by the interpreter. Language conventions connect words to thoughts regarding things. Without such conventions, things may be ineffable for speakers and words are meaningless to interpreters. With ineffability, the speaker's thought was based on the speaker's experience with a thing. With meaninglessness, the interpreter has no thought since the interpreter's

151 The word 'generates' in this diagram may be a little misleading since no thought is generated. The point of this diagram is that the word does not generate a thought. In order to depict this diagrammatically, it is necessary to view the word as generating no thought. 
thought is dependent on language conventions and the interpreter has no knowledge of the relevant conventions.

If a speaker refers to an 'ombú', a tree described by W H Hudson in Far Away and Long Ago, ${ }^{152}$ and an interpreter has never heard this word before, this word will be meaningless to the interpreter. The context may help clarify the meaning to a certain extent, for instance, the context may make it clear that the word refers to a tree, but an interpreter will still not know the specific kind of tree. The word itself does not generate any thought. It is not that the word is inherently meaningless, but that it is meaningless to this particular interpreter. A good example of this kind of meaninglessness is a language that is unknown to an interpreter. The words of this language are not meaningless in the abstract, but are meaningless to this particular interpreter.

Sometimes, however, the factual or verbal context may make the meaning of a word somewhat clear even if the word is heard for the first time. Jerome K Jerome asks the question, "[W]hat materials for a wife do you think you will get out of the empty-headed coquettes you are raving and tearing your hair about?" 153 He answers:

You will get the jaded face, and the dull, lustreless eyes, and the untidy hair with the dye showing on it. You will get dirty, shabby frocks and slommicking dressing-gowns, such as your cook would be ashamed to wear.

A reader who had never encountered the word 'slommicking', would probably still realise that it had a negative connotation and referred to unsightly clothing. Still, this understanding is somewhat vague and would need to be confirmed. ${ }^{154}$

In other situations, the context is less helpful. In Mark Twain's novel The Adventures of Huckleberry Finn Tom Sawyer decides to start a band of robbers and discusses this with his friend Ben Rogers: ${ }^{155}$

“Now,” says Ben Rogers, "what's the line of business of this Gang?”

\footnotetext{
152 Hudson, above n 128, at 4.

153 Jerome K Jerome The Diary of a Pilgrimage (JW Arrowsmith, Bristol, 1891) at 183.

154 The Oxford English Dictionary gives 'slommicking' as variant of 'slammakin' and defines the adjectival form of 'slammakin' as “untidy, slovenly” JA Simpson and ESC Weiner (eds) The Oxford English Dictionary (2ed, Clarendon Press, Oxford, 1989) vol 15 at 649.

155 Mark Twain The Adventures of Huckleberry Finn (Penguin Books Limited, London, 1985) at 57-58 (italics in original).
} 
“Nothing only robbery and murder,” Tom said.

"Must we always kill the people?”

“Oh, certainly. It's best. Some authorities think different, but mostly it's considered best to kill them.

Except some that you bring to the cave here and keep them till they're ransomed.”

"Ransomed? What's that?"

“I don't know. But that's what they do. I've seen it in books; and so of course that's what we've got to do."

"But how can we do it if we don’t know what it is?"

"Why blame it all, we've got to do it."

$\cdots$

"how in the nation are these fellows going to be ransomed if we don't know how to do it to them? ... Now what do you reckon it is?”

“Well I don’t know. But per'aps if we keep them till they're ransomed, it means that we keep them till they're dead."

$\cdots$

“So somebody's got to set up all night and never get any sleep, just so as to watch them. ... Why can't a body take a club and ransom them as soon as they get here?”

Tom had seen the word 'ransom' in books. Apart from knowing that it was what kidnappers did to hostages, the word was meaningless to him. Therefore, he guessed its meaning. By the end of the extract, the boys started to use 'ransom' as a synonym for 'kill'. This shows that the context does not always clarify meaning. It also shows that a danger with meaninglessness is that interpreters may guess the meaning of a word they do not know and arrive at the wrong meaning.

Meaninglessness can occur when a speaker attempts to describe something that is ineffable for him or her. Earlier this chapter gave an example of a Russian speaker, Pnin, using the word 'quittance' to describe a receipt. ${ }^{156}$ Pnin used this word because the item he was trying to describe (a receipt) was ineffable for him in English. The man at the information booth replied, "What's that?" showing that this word was meaningless to him.

The danger is more significant, however, when interpreters think they know the meaning of a word, but are wrong. That is, when interpreters are not aware that they do not know the relevant conventions. If a word is not associated with any thought in the mind of an interpreter, it is unlikely that there will be an attempt at interpretation. If, however, a word is unknowingly associated with

156 See text accompanying n 130. 
the wrong thought, the result will be a misinterpretation.

\section{Communication}

To illustrate the nature of communication in a complete way, it is useful to put Diagram 3.2 (Speaking) and Diagram 3.4 (Interpretation) together to form Diagram 3.6, below. 


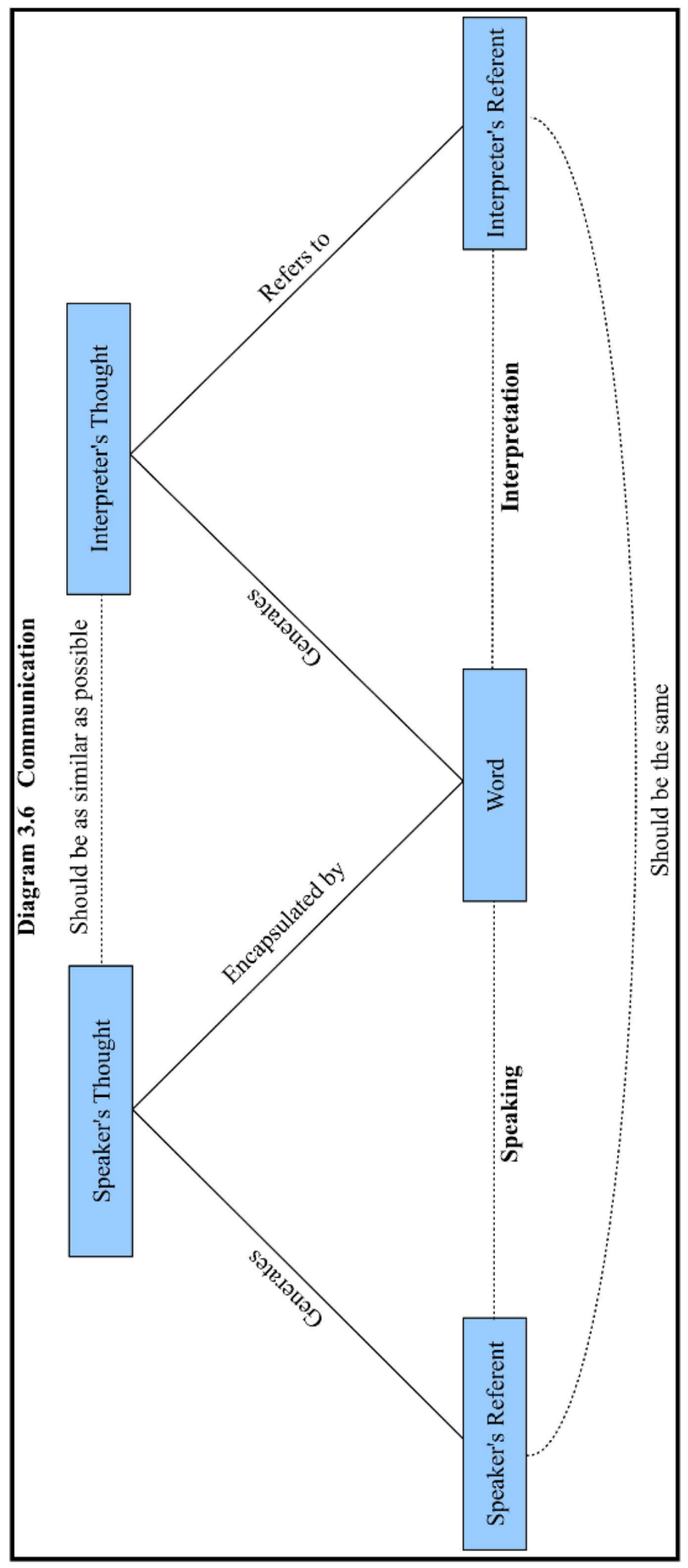


Diagram 3.6 depicts the process of communication. This diagram should be read from left to right. A referent generates a thought in the mind of a speaker. The speaker then encapsulates this thought in a word. This word generates a thought in the mind of an interpreter, which refers to a referent. For intelligible communication, the two thoughts should be as similar as possible and the two referents should be the same.

One problem with Diagram 3.1 (Word, Thought and Referent) is that the acts of speaking and interpretation are conflated, and, although this diagram is useful in pointing out the indirect nature of the connection between words and referents, it does not clearly show the two sides of communication. Diagram 3.6 shows that communication involves two thoughts, which each refer to a referent. It also shows that the speaker and the interpreter share the word. Communication can thus be viewed as the process of a speaker translating thoughts about referents into words and an interpreter translating those words into thoughts about referents. Communication theorists refer to these processes as encoding (by speakers) and decoding (by interpreters). ${ }^{157}$

For successful communication, the two referents should be the same. If a speaker points to a referent to indicate the meaning of a word, ${ }^{158}$ the referents would be the same, and the thoughts would be very similar. Moreover, if a speaker refers to a physical object with which the interpreter is familiar, it is likely that the referents will be identical. A speaker may see an object and later refer to it with language. The interpreter, however, may have never seen this object. In this situation, the speaker's thought is based on direct experience with the referent and the interpreter's thought is an imagination of this referent. Therefore, these thoughts may be quite different. These thoughts, however, still refer to the same referent. Although it may be possible to imagine situations in which successful communication occurs even though an interpreter arrives at a different referent from the speaker, in most situations where successful communication occurs the interpreter's referent will be the same as the speaker's referent.

It is impossible for the two thoughts in Diagram 3.6 to be absolutely identical. The fact that they are in two different people means that they cannot be identical. Successful communication, however, is dependent on the two thoughts being as similar as possible.

\footnotetext{
157 Potter, above n 14, at 47.

158 This is referred to as giving an ostensive definition: F Waismann (R Harre (ed)) The Principles of Linguistic Philosophy (Macmillan and Co Limited, London, 1965) at 94.
} 
In Diagram 3.6 the word 'speaking' is used for the connection between a referent and a word, and the word 'interpretation' is used for the connection between that word and a referent. Thus, when the word at issue stands for an identifiable referent, both speaking and interpretation involve an indirect connection. As seen in the speaking and interpretation sections of this chapter, speaking could also be depicted by the connection between the speaker's thought and the word and interpretation could be depicted by the connection between the word and the interpreter's thought.

The use of language conventions makes the process of communication possible. Speakers encapsulate thoughts in language by using conventions and thoughts are generated in interpreters' minds based on these conventions. If the relevant conventions are not known, things are ineffable for speakers and words are meaningless to interpreters. Therefore, speakers need to indicate the language conventions that they are employing and interpreters need to pay attention to such indications. The four groups of considerations given in Chart 3.1 are indicators of language conventions to which interpreters need to pay attention.

(a) Thought transmission

The difficulties involved in communication can be made clearer by a discussion of the two thoughts in Diagram 3.6. The centre of Diagram 3.6 (Communication) can be extracted to form Diagram 3.7, below, which shows the relationship between the thought in the mind of the speaker and the thought in the mind of the interpreter.

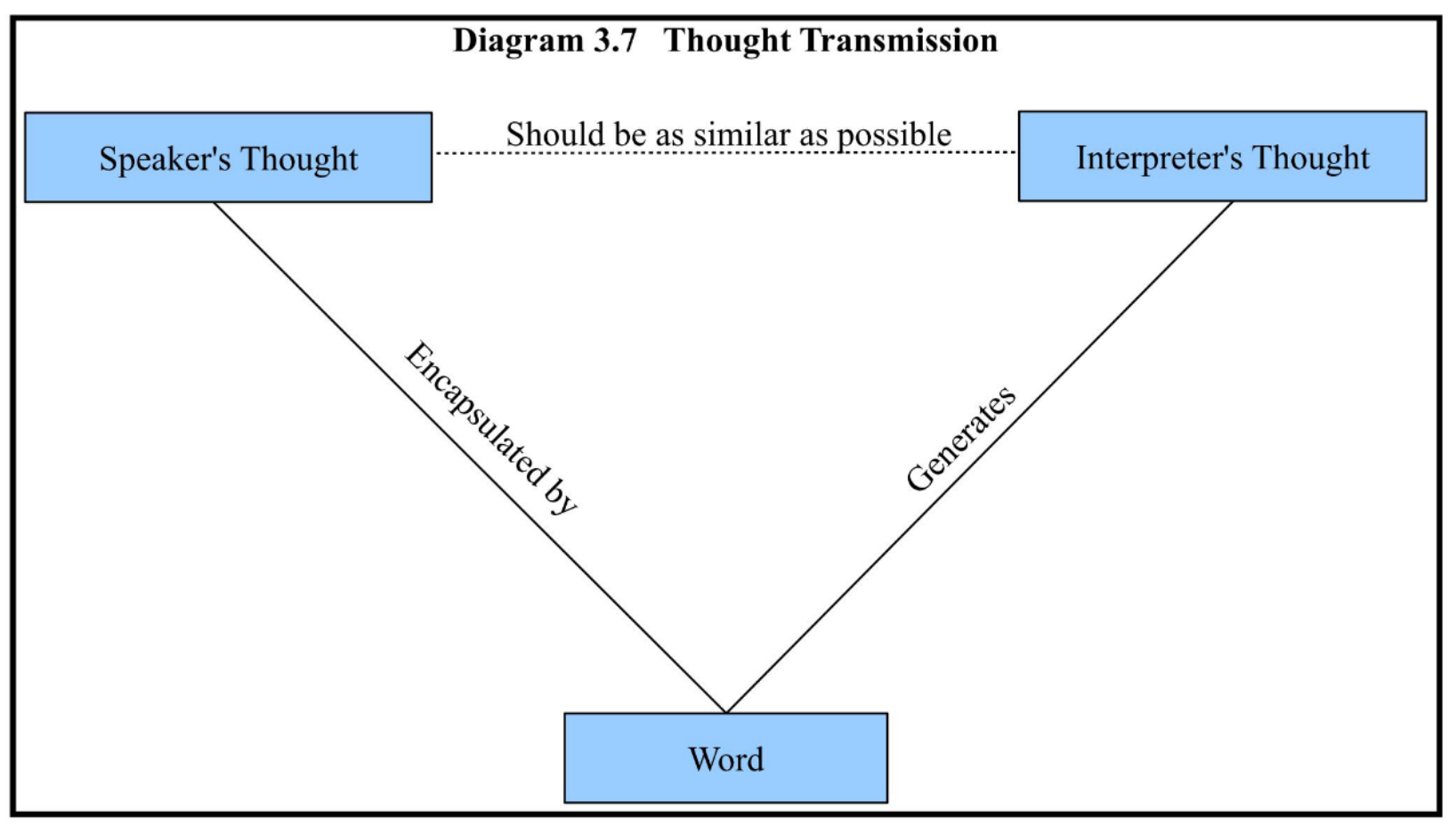


In Diagram $3.7^{159}$ the similarity between the two thoughts determines the effectiveness of the communication. This similarity is determined by the language conventions associating the word with the thoughts. Communication can therefore be defined as the transmission of a thought from one person to another, ${ }^{160}$ and this transmission is made possible by the use of language conventions.

Two possible mistakes are that the speaker chooses the wrong word or the interpreter understands the word wrongly. For instance, if a speaker is thinking of a wolf, but says 'dog', a different thought will be generated in the mind of the interpreter from that in the mind of the speaker. Alternatively, if a speaker says the word 'wolf', but the interpreter understands the word 'wolf' to refer to a dog, the interpreter will again have a different thought from the speaker. Both mistakes, unless caused by a slip of the tongue by the speaker or a mishearing by the interpreter, are based on a wrong understanding of language conventions, that is, either the speaker understanding the word 'dog' to refer to a wolf or the interpreter understanding the word 'wolf' to refer to a dog.

On the speaker's side, such a mistake could be caused because the thing was ineffable for the speaker. For instance, the speaker may not have known the language conventions associated with wolves, and therefore may have guessed that wolves could be described by the word 'dog'. On the interpreter's side, this mistake could be caused because the word was meaningless to the interpreter. For instance, the interpreter may not have known the language conventions associated with the word 'wolf', and therefore may have guessed that this word referred to dogs.

159 As mentioned in relation to Diagram 3.6, the words 'encapsulated by' and 'generates' can represent speaking and interpretation, and thus Diagram 2.7 could be a diagram of communication. Diagram 2.7, however, would be an incomplete depiction of communication because it does not take into account the fact that thoughts refer to things.

160 The linguist Roy Harris disagrees with this view and has pejoratively labelled it 'telementation': see Roy Harris The Language Myth (Gerald Duckworth \& Company Limited, London, 1981). The basic objection to this 'telementation' view of communication was expressed by Michael Toolan: “Crucial to telementation, or 'ideas-transfer' is the assumption, which is either false, unprovable or irrelevant ... that when A speaks to B the same idea that A used and encoded into speech is picked out, highlighted, or recreated in B's head.” “A Few Words on Telementation” (1997) 19 Language Sciences 79 (italics in original). As the discussion related communication has made clear, it is impossible for thoughts to be exactly the same. This, however, does not mean that the goal of communication should not be for them to be as similar as possible. Therefore, communication can be viewed as the transmission of thoughts from one person to another as long as it is borne in mind that this does not mean that the speaker's actual subjective thought is transferred to the interpreter. Rather, this means that the interpreter's thought needs to be as similar to the speaker's thought as is possible. 
(b) Simplified view of communication

Diagram 3.8, below, is formed by extracting the bottom line of Diagram 3.6 (Communication).

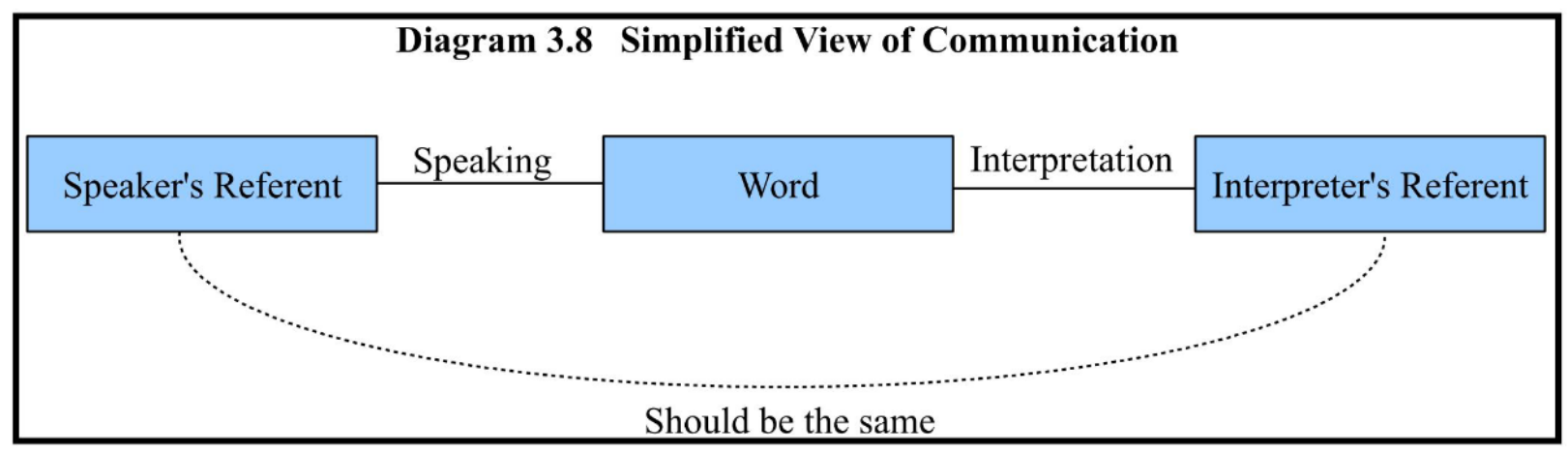

In Diagram 3.8, a speaker refers to a referent with a word by speaking and an interpreter understands this word to refer to a referent by interpretation. Successful communication occurs when the two referents are the same. This diagram illustrates a naïve view of communication in which everything is objective and the connection between words and referents is direct without intervening thoughts.

Because interpreters do not have access to speakers' subjective thoughts, interpretation is necessarily objective. It should not, however, be considered objective in a naïve way. Rather, interpreters need to take into account the indications of speakers' thoughts. To do this, interpreters need to pay attention to the considerations in Chart 3.1. Interpreters can commit fallacies when they neglect such considerations.

Furthermore, based on Diagram 3.8, it would appear that the interpreter's main task is the discovery of a referent. As has been seen, in some cases there may be no identifiable referent, and, even when there is, an interpreter needs to pay attention to the way the referent is being viewed by the speaker, which means that the focus of the interpreter should be on the speaker's thought, and not merely on the referent identified by the speaker.

In some situations, however, it may seem convenient to take Diagram 3.8 as a model of communication. For instance, if a speaker refers to 'Mount Rushmore', it may seem intuitive to say the words refer to the mountain given that name, and Diagram 3.8 may seem to be an adequate 
illustration of communication in this situation. This is because the referent is concrete and easily identifiable and the language conventions are well known. This does not mean that the connecting thoughts are not needed, but just that they can be taken for granted. Having said this, Diagram 3.6 (Communication) would still be a more accurate illustration of communication even in this kind of situation.

\section{Interpretation Fallacies}

This chapter has so far provided a general analysis of language, focusing on the processes of speaking and interpretation. This analysis of language has shown the role of language conventions in connecting words to thoughts and how mistakes can be made due to ignorance of such conventions. This analysis has also shown that the goal of an interpreter should be to objectively ascertain a speaker's meaning. The remainder of this chapter will identify and analyse two interpretative fallacies that can be committed in the ordinary interpretation of language. These fallacies correspond to two fallacies that can be committed in judicial interpretation.

The interpretation fallacies identified in this section are caused by a misunderstanding concerning the nature of meaning. There is no natural or necessary connection between words and their meanings. Therefore, words do not necessarily have specific meanings associated with them. ${ }^{161}$ The interpretation fallacies identified in this chapter are caused by the unconscious assumption that there is a fixed relationship between words and their meanings.

\section{Definition of an interpretation fallacy}

Interpretation has been defined as an interpreter objectively ascertaining a speaker's meaning. It may therefore seem that any time an interpreter reaches a different meaning from a speaker the interpreter has committed an interpretation fallacy. This, however, is too simple a view of interpretation.

161 This also means that there is no direct correspondence between words and their referents. There is a direct one-toone correspondence between a word and its referent only in the case of proper nouns, for instance, people's names (see Kempson, above n 102, at 13). For this reason, it is a little inaccurate to speak of proper nouns having meaning (at 14). 
It has been pointed out that if a speaker does not clarify the language conventions he or she is using, an interpreter cannot be expected to ascertain the speaker's meaning. ${ }^{162}$ This can be illustrated by a conversation between Alice and Humpty Dumpty in Lewis Carroll's novel Through the Looking Glass. Humpty Dumpty tells Alice: ${ }^{163}$

"there are three hundred and sixty-four days when you might get un-birthday presents -”

“Certainly,” said Alice.

“And only one for birthday presents, you know. There’s glory for you!”

"I don't know what you mean by 'glory,”” Alice said.

... "Of course you don't - till I tell you. I meant 'there's a nice knock-down argument for you!'”

"But 'glory’ doesn’t mean ‘a nice knock-down argument,”’ Alice objected.

"'When I use a word," Humpty Dumpty said ... "it means just what I choose it to mean - neither more nor less.”

"The question is,” said Alice, "whether you can make words mean so many different things."

"The question is,” said Humpty Dumpty, "which is to be master - that’s all."

If Humpty Dumpty had not clarified what he meant by the word 'glory', that is, if he had not clarified the language convention he was employing, Alice could not have been expected to interpret his statement correctly. She would be justified in assuming the word was being used with its existing meaning. In this situation, the interpreter and the speaker are assigning different meanings to this word. The interpreter, however, has not made any errors in objectively ascertaining the speaker's meaning. Rather, the speaker has not clarified the meaning he has associated with the word. Therefore, if Alice assumed that 'glory' was being used with its existing meaning, this interpretation would not be fallacious.

Whether or not such an instance of interpretation is wrong is a matter of definition, but it is not fallacious because the interpreter has not made any errors in objectively ascertaining the speaker's meaning. The difference between the speaker's meaning and the interpreter's meaning was due to the fact that the speaker did not clarify the convention that was being employed. A speaker can always claim that he or she subjectively meant something different from the meaning that an

\footnotetext{
162 See Chapter Three B.2.

163 Carroll, above n 148, at 224 (italics in original). Lawyers have often referred to Lewis Carroll's Alice novels and to this conversation in particular. Peter F Sloss wrote a book entitled Alice's Adventures in Jurisprudentia in which Alice visited an imaginary kingdom Jurisprudentia. He stated: "Some years ago, while reading a decision of the California Supreme Court which discussed how a court should determine the meaning of a contract, I was struck with the thought that the question before the Court was the same question that Alice posed to Humpty Dumpty. This story flowed naturally from this simply observation.” Alice's Adventures in Jurisprudentia (Borogrove Press, Belvedere (Cal), 1982) at 3.
} 
interpreter reached. ${ }^{164}$ Such a claim by a speaker should not automatically make interpretations fallacious. Whether an instance of interpretation is fallacious should depend on the whether the interpreter has taken into account the objective indications of the speaker's meaning.

In some situations, an interpreter may not be aware of sufficient contextual information to interpret a word correctly. A good example of this can be seen with the misinterpretation of the word 'cat' in the following conversation: ${ }^{165}$

\begin{abstract}
"What we want is the army to take over this country. See a bit of discipline then, we would ... Flog 'em, is what I say. Give 'em something to remember across their backsides.” He paused and swigged tea. "What's wrong with the cat?" he said, so that anyone coming in at that moment, Alan thought, would have supposed him to be enquiring after the health of the family pet.
\end{abstract}

If someone coming in at that moment understood the word 'cat' to be a reference to the family pet, this would be a misinterpretation. In this situation, however, it would be reasonable for such a person to expect that the word 'cat' referred to the animal, not the cat-o'nine-tails. On the one hand, this is not the speaker's fault, because the speaker has provided sufficient contextual clues to clarify what he means. Therefore, the interpretation is wrong. Still, it is not an unreasonable interpretation. An interpreter could not be expected to know that he or she needed to be aware of more contextual information to interpret the word correctly. The interpreter has associated the word with a different meaning from the speaker, but the interpreter cannot be blamed for this. It is thus an excusable misinterpretation.

In other situations, a word may be ambiguous even if the interpreter is aware of all the relevant contextual information. In Richmal Crompton's novel Just William's Luck, two boys, William and Douglas, are talking about King Arthur and the Knights of the Round Table: ${ }^{166}$

"Well, about this Arthur man,” said William ... “They made him King and he started knights.”

“What d’you mean, started nights?” said Douglas. “There’ve been nights an’ days ever since the world began.”

The words 'knight' and 'night' are homophones, that is, they are words “which are pronounced the

\footnotetext{
164 This is dealt with in the law by evidentiary restrictions in relation to interpretation (see n 344).

165 Ruth Rendell Make Death Love Me (Arrow Books, London, 1980) at 29. This example was given in Thomas, above $\mathrm{n} 118$, at 3.

166 Richmal Crompton Just William's Luck (George Newnes Limited, London, 1949) at 25.
} 
same, but have different spellings and meanings". ${ }^{167}$ Douglas’ interpretation was wrong, but it was an excusable misinterpretation in this context. William's use of the word 'knight', however, was not deliberately misleading. Therefore, although the interpretation was wrong, it should not be considered fallacious, because it was a reasonable interpretation given the information available to the interpreter. There were no significant relevant considerations that Douglas ignored.

It is important to define for the purposes of this thesis what makes an instance of interpretation fallacious. If an interpretation is reasonable based on the information that is available to the interpreter, the interpretation is not fallacious, even if the interpreter associates the word with a different meaning from the speaker. If a speaker uses a word in a misleading way, an interpreter cannot be blamed for arriving at a different meaning from the speaker. Moreover, even if a speaker does not use a word in a misleading way, yet an interpreter still arrives at a different meaning from the speaker, the interpretation is not fallacious if it was reasonable. An interpretation fallacy needs to involve an unreasonable interpretation.

An instance of interpretation is justified when an interpreter takes into account all the considerations which indicate a speaker's meaning. Four kinds of relevant considerations that interpreters may need to take into account have been given in Chart 3.1. The context of the speaking may indicate that interpreters need to investigate certain matters before arriving at an interpretation. Therefore, the considerations that interpreters need to take into account may include information that it is reasonable to expect interpreters to discover and not just information apparent from the immediate context of speaking. The considerations that interpreters need to take into account will be referred to as 'relevant considerations'.

The goal of interpretation is for an interpreter to objectively arrive at the same meaning as the speaker. An interpreter can do this by taking into account certain relevant considerations. A consideration is relevant when it is an indicator of the specific meaning the speaker is expressing. A consideration that is not an indicator of this specific meaning is irrelevant, and should not be taken into account by interpreters. Such considerations will be referred to as 'irrelevant considerations'.

Although the goal of an interpreter is to reach the same meaning as the speaker, in some instances an interpreter may not be able to check his or her meaning with the speaker. ${ }^{168}$ In this situation, it

\footnotetext{
167 Howard Jackson Words and Their Meaning (Longman Group UK Limited, Harlow, 1988) at 4.

${ }^{168}$ For instance, in the interpretation of written texts.
} 
cannot be determined whether the interpreter has reached a different meaning from the speaker's subjective meaning. Furthermore, even if the interpreter has reached a different meaning from the speaker, the interpretation may have been reasonable. Therefore, there needs to be a test for when an instance of interpretation is fallacious that does not depend on the speaker's subjective meaning.

An instance of interpretation is not fallacious if the interpreter takes into account all the necessary relevant considerations. This means that the interpretation is reasonable, even if the interpreter arrives at a different meaning from the speaker's subjective meaning. For the purpose of this thesis, an instance of interpretation is fallacious when it takes into account an irrelevant consideration and it is most likely that a different meaning would have been reached if that consideration had been omitted, or when it omits a relevant consideration and it is most likely that a different meaning would have been reached if that consideration had been taken into account. Fallacies may involve the introduction of more than one irrelevant consideration and the omission of more than one relevant consideration. Because it cannot be definitively said that an interpreter would have reached a different meaning if he or she had taken into account a certain relevant consideration or had omitted a certain irrelevant consideration, the test for fallacious interpretation has to depend on whether it is most likely that a different meaning would have been reached.

The mere fact that a certain irrelevant consideration has been taken into account or that a certain relevant consideration has been neglected by an interpreter does not make an instance of interpretation fallacious. An instance of interpretation is fallacious when the inclusion of an irrelevant consideration or the neglect of a relevant consideration affects the meaning that is reached. It is fallacious when it is most likely that the interpreter would have reached a different meaning if he or she had taken into account the relevant considerations and omitted any irrelevant considerations. In most situations, this will mean that the interpreter reaches a different meaning from the speaker, but the key point is not merely that the meaning is different from the speaker, but that it is an unreasonable meaning.

After providing a general definition of fallacious interpretation, it is necessary to identify specific fallacies that can be committed during interpretation. Because words are arbitrary labels, one word may be used with more than one meaning and two different words may be used with the same 
meaning. ${ }^{169}$ This means that different meanings can be associated with the same word and the same meaning can be associated with different words. ${ }^{170}$

If the same word has been given different meanings by a speaker and an interpreter, the interpreter may assume that the use of the same word implies the same meaning is being expressed by the speaker. If different words have been given the same meaning by a speaker and an interpreter, the interpreter may assume that the use of a different word implies a different meaning is being expressed by the speaker. These assumptions can cause interpreters to introduce an irrelevant consideration and neglect relevant considerations. Therefore, these assumptions can result in fallacious interpretations.

This chapter will look at two interpretation fallacies. The first fallacy involves the assumption 'same word, therefore, same meaning' and can be called the 'same word' fallacy. ${ }^{171}$ The second fallacy involves the assumption 'different word, therefore, different meaning' and can be called the 'different word' fallacy. ${ }^{172}$ These fallacies occur when an interpreter introduces the consideration of the meaning a word can be given, and this consideration is irrelevant for this specific instance of interpretation. This irrelevant consideration then causes the interpreter to reach a meaning that most likely would not have been reached if this irrelevant consideration had been omitted and the relevant considerations had been taken into account. These fallacies are instances of the general fallacy defined in the previous section and involve the introduction of an irrelevant consideration and usually also involve the omission of relevant considerations. As will be seen, some instances of misinterpretation can be viewed as either the 'same word' fallacy or the 'different word' fallacy.

This section discusses an interpretation fallacy that involves the assumption: 'same word, therefore, same meaning'. The goal of interpretation is for interpreters to objectively discover the meaning

\footnotetext{
169 This has been noted by various writers, for instance, Ullmann, above n 70, at 46-48; Robert H Thouless Straight and Crooked Thinking (2ed, Pan Books Limited, London, 1953) at 77; and Ogden and Richards, above n 18, at viii.

${ }^{170}$ It is difficult to say two words have been given exactly the same meaning, but they can be sufficiently similar in meaning to view them as having the same meaning for practical purposes.

${ }^{171}$ When these fallacies are named, single quotation marks are used around the words 'same word' and 'different word' because this is clearer when this name appears in a sentence.

172 These are not the only kind of interpretation fallacies that can be committed in ordinary interpretation. Fallacies can be committed any time irrelevant considerations are introduced and relevant considerations are omitted.
} 
that speakers have given to the word ${ }^{173}$ being interpreted. A speaker may use a word with a certain meaning. The interpreter may associate this word with a different meaning. Thus, the same word has been associated with different meanings by the speaker and the interpreter. The 'same word' fallacy involves the interpreter making an assumption that because the speaker has used a word that the interpreter has associated with a certain meaning, the speaker has given this word this meaning.

There are three steps involved in this fallacy: first, the speaker uses a word with a certain meaning; second, the interpreter associates this word with a different meaning; and, third, the interpreter concludes that because the same word that the interpreter has associated with a certain meaning has been used, the same meaning has been expressed. The missing premise is the assumption that words only have one meaning. ${ }^{174}$

Put another way, this fallacy involves the interpreter making an assumption that because the word being interpreted can have a certain meaning, it has been given that meaning by the speaker. The fact that a certain word can be given a certain meaning, however, does not mean that it is always given that meaning.

What makes an instance of interpretation fallacious, however, is not this assumption by itself. There are situations where such an assumption can lead to the correct interpretation. Fallacies occur when this assumption is incorrect and the meaning that the speaker is expressing is not the meaning that the interpreter has associated with the word. Thus, the interpreter introduces an irrelevant consideration of the meaning a word can have when it is being used to express a different meaning. If this irrelevant consideration causes the interpreter to reach a meaning which it is most likely would not have been reached if this irrelevant consideration had been omitted and any relevant considerations had been introduced, the interpretation is fallacious. This section will give some examples of situations in which interpreters fallaciously draw the conclusion: 'same word, therefore, same meaning'.

In a book first published in 1925, the Roman Catholic apologist G K Chesterton stated: ${ }^{175}$

\footnotetext{
${ }^{173}$ In this discussion of fallacies, the term 'word' should be understood to mean the language being interpreted, and it not limited to single words.

174 This does not necessarily mean that the interpreter believes that words only have one meaning, but this may be a subconscious assumption. At least it can be said that the interpreter has overlooked the fact that the same word can be given different meanings, and the implication of this fact for interpretation: that there needs to be a discovery of the specific meaning the speaker has given to the word.

175 GK Chesterton The Everlasting Man (Ignatius Press, San Francisco, 1993) at 11 (capitalisation in original).
} 
It would be better to see ... the prayer-book as fantastic as the prayer-wheel and the Cross as crooked as the Swastika. Then at least we should not lose our temper as some of the sceptical critics seem to lose their temper, not to mention their wits.

Chesterton's point was that the prayer-book and the cross should be viewed as strange and unfamiliar items. When this book was published, the swastika would have been primarily known as an Indian religious symbol. A modern reader, however, may view the swastika as a symbol of Nazism. If the word was given this meaning, this would be a fallacious interpretation. The use of the same word does not necessarily imply that the same meaning is being expressed.

In this situation, the use and significance of the symbol (the swastika) changed over time, but the word describing it remained the same. Therefore, the meaning of the word describing this symbol changed. The modern meaning of this word is irrelevant when interpreting early references to it. ${ }^{176}$ The relevant consideration in relation to the word 'swastika' is the meaning of the word at the time of the book was published. When interpreting written language, time is an important part of the factual background. ${ }^{177}$ An interpretation which introduced the irrelevant consideration of the modern meaning of this word and omitted the relevant consideration of the meaning of the word at the time it was used would be fallacious.

The 'same word' fallacy can also be committed when interpreting technical terms. For instance, the term 'vapors' in the following passage from Milton's Paradise Lost may cause confusion: ${ }^{178}$

When Adam wak't, so custom'd, for his sleep

Was Aery light, from pure digestion bred,

And temperate vapors bland, which th' only sound

Of leaves and fuming rills, Aurora's fan,

Lightly dispers'd ...

This confusion is clarified when it is seen that "vapors is a definite medical term meaning the

\footnotetext{
${ }^{176}$ A thing may change over time, but the word describing it may remain the same. The fact that the word has not changed may cause an interpreter to overlook changes that have occurred with the thing. To combat this it is sometimes necessary for speakers to use a different word. For example, the term 'neo-Nazi' is useful to refer specifically to modern Nazis as opposed to historical Nazis.

177 This corresponds to consideration 1.4 in Chart 3.1.

178 John Milton (Merritt Y Hughes (ed)) Paradise Lost (The Odyssey Press, Indianapolis, 1962) at 113 (italics in original).
} 
exhalations of digestion." ${ }^{179}$ In this passage, it is not merely that an old meaning has been given to the word 'vapors', but a technical meaning has been given to this word. ${ }^{180}$ An interpreter may assume 'vapors' referred to fog or mist. This would be a wrong interpretation.

Whether or not this interpretation would be considered fallacious for the purposes of this thesis depends on how reasonable such an interpretation was. Since this is not a flagrant misinterpretation, but an understandable one, such an interpretation, although wrong, would probably not be considered to be fallacious. It would only be fallacious if the interpretation was unreasonable given the relevant considerations that the interpreter should have taken into account. If the interpreter was an expert who would be expected to conduct detailed research regarding the meaning of the word being interpreted, the technical meaning of the word would be a relevant consideration. If the interpreter was a layman, it is arguable that an interpretation that missed this technical meaning would not be fallacious, although it would be wrong. This is because the technical meaning of this word would not be a relevant consideration that a layman would be expected to take into account.

This type of fallacy does not always involve the misinterpretation of a specific word, but can involve the misinterpretation of a phrase or an entire sentence. Furthermore, even if the literal meaning of the language being interpreted is correctly understood, the force of the utterance may be misunderstood. A good example of this can be seen in Charles Dickens’ novel Pickwick Papers. ${ }^{181}$ In a very funny scene in the book, Mr Pickwick tries to tell his landlady, Mrs Bardell, that he wants to employ a handyman. Mrs Bardell misunderstands Mr Pickwick’s statement, and thinks that he is asking her to marry him: ${ }^{182}$

\footnotetext{
"Mrs. Bardell,” said Mr. Pickwick, at the expiration of a few minutes.

“Sir,” said Mrs. Bardell again.

“Do you think it’s a much greater expense to keep two people, than to keep one?”

“La, Mr. Pickwick,” said Mrs. Bardell, colouring up to the very border of her cap, as she fancied she observed a species of matrimonial twinkle in the eyes of her lodger; “La, Mr. Pickwick, what a question!” “Well, but do you?” inquired Mr. Pickwick.
}

In this case, the misunderstanding was not primarily concerning the literal meaning of the words

\footnotetext{
179 Ibid, at 113, footnote 5 (italics in original).

180 This corresponds to consideration 1.2 in Chart 3.1.

${ }^{181}$ Charles Dickens The Posthumous Papers of the Pickwick Club (Chapman and Hall, London, 1858) [Pickwick Papers].

182 Ibid, vol 1 at 159 (italics in original).
} 
spoken. Rather, the misunderstanding related to Mr Pickwick's intention in uttering these words. Whereas Mr Pickwick was referring to employing a handyman, Mrs Bardell thought he was referring to marrying her. Both of these meanings can conceivably come within the meaning of the phrase 'keep two people’.

What makes this interpretation fallacious is that such an interpretation was not justified by the factual context of the utterance. ${ }^{183}$ The misinterpretation in this case was due to Mrs Bardell's feelings for Mr Pickwick as seen later in the passage when it says: ${ }^{184}$

She had long worshipped Mr. Pickwick at a distance, but here she was, all at once, raised to a pinnacle to which her wildest and most extravagant hopes had never dared to aspire.

These feelings caused Mrs Bardell to introduce an irrelevant consideration. The relevant consideration in this case is the meaning of the phrase 'keep two people' in the context in which it was uttered: a lodger talking to his landlady. In this context, it is likely that this phrase refers to employing someone. The irrelevant consideration is its possible meaning in a different context. If Mr Pickwick intended to propose to Mrs Bardell, it is likely that he would make a much more definite statement, especially considering the legal consequence of a marriage proposal at the time the book was published. ${ }^{185}$

This fallacy can also be committed due to differences of terminology between disciplines or within a single discipline. In The Meaning of Meaning Ogden and Richards discuss the various meanings given to the word 'meaning' by philosophers and the disputes that this difference in terminology caused. ${ }^{186}$ They note that a group of American professors who had published a collection of essays had "revised and redrafted their language until it met the approval of all other essayists."187 Ogden and Richards quote the essayists saying: “[O]ur familiarity with one another's MEANING has enabled us to understand methods of expression from which at first we were inclined to dissent." ${ }^{188}$ They claim that these professors had "been continuously improving their mutual terminology in the full view of the public for over a decade.” ${ }^{189}$ If a word has been used with a specific meaning within

\footnotetext{
183 This corresponds to consideration 1.4 in Chart 3.1.

184 Pickwick Papers, above n 181, at 160.

${ }^{185}$ Later in the book, Mrs Bardell sues Mr Pickwick for a breach of a promise of marriage (ibid, at 254).

${ }^{186}$ Ogden and Richards, above n 18, at ch 8.

187 Ibid, at 164.

188 Ibid (capitalisation in original).

189 Ibid.
} 
an interpreter's discipline, ${ }^{190}$ it is easy for such an interpreter to expect that speakers will use this word in the same way. If a speaker in a different discipline uses this word with a different meaning, the interpreter can easily commit the 'same word' fallacy.

The 'same word' fallacy occurs because an interpreter assumes that because a certain meaning can be given to the word a speaker is using, the speaker is using the word with that meaning. When this assumption is incorrect, it can cause the interpreter to introduce an irrelevant consideration (the meaning the word can be given) and neglect the relevant considerations which indicated the meaning that the speaker is giving the word. An instance of interpretation is fallacious if the introduction of this irrelevant consideration causes the interpreter to reach a meaning that it is most likely he or she would not have reached if this irrelevant consideration had been omitted and the relevant considerations had been taken into account. Furthermore, it is probable that the meaning the interpreter reaches in this situation will be different from the meaning the speaker has given to the word. To avoid this fallacy an interpreter should identify the specific meaning given to a word when it is used. To do this, the interpreter needs to pay attention to the relevant considerations which indicate this meaning and ignore any irrelevant considerations.

\section{$4 \quad$ Different word, therefore, different meaning}

This section discusses an interpretation fallacy that involves the assumption: 'different word, therefore, different meaning'. A speaker may use a word with a certain meaning. The interpreter may associate this meaning with a different word. Thus, different words have been associated with the same meaning by the speaker and the interpreter. The 'different word' fallacy involves the interpreter making an assumption that because a different word from the word the interpreter has associated with a certain meaning has been used by a speaker, the speaker has given this word a different meaning.

There are three steps involved in this fallacy: first, the speaker uses a certain word with a certain meaning; second, the interpreter associates this meaning with a different word; and third, the interpreter concludes that because a different word from the word the interpreter has associated with a certain meaning has been used, a different meaning has been expressed. The missing premise is

190 This corresponds to consideration 1.2 in Chart 3.1. 
the assumption that words can only be associated with one meaning. ${ }^{191}$

Put another way, this fallacy involves the interpreter making an assumption that because a meaning can be given to certain word, speakers must use that word to express that meaning. The fact that a certain meaning can be associated with certain word, however, does not mean that this meaning is only associated with that word. This section will give some examples of situations in which interpreters fallaciously draw the conclusion: 'different word, therefore, different meaning'. This fallacy is difficult to explain clearly in the abstract, but will be made clear by the examples given in this section.

The popular book Men Are from Mars, Women Are from Venus makes the claim that men and women speak different languages. ${ }^{192}$ Some of the examples given in this book can be viewed as examples of the 'different word' fallacy. The book makes the claim that men interpret women's language literally, whereas "[t]o fully express their feelings, women assume poetic license and use various superlatives”. ${ }^{193}$ For instance, it is claimed that men respond to women's statement such as, "We never go out” with claims such as, "That's not true. We went out last week." ${ }^{194}$ If this occurred, the man would be making the assumption that because the woman is using different words from the words he would use to express the same feelings, she is not expressing those feelings. ${ }^{195}$ Whether or not such an interpretation is fallacious depends on how reasonable this assumption is. If the factual context of the speaking makes the woman's meaning clear, ${ }^{196}$ this assumption would be unjustified and the resulting interpretation would be fallacious.

The previous section identified fallacies caused by the same word being used with different meanings in different disciplines. Fallacies are also created when different words are used with the same meaning in different disciplines. In a book on communication theory, Em Griffin notes that communication professor Robert Craig has identified "seven established traditions of

\footnotetext{
${ }^{191}$ An interpreter may not actually believe this, but at least it can be said that the interpreter has overlooked the fact that the same meaning can be expressed by different words. Compare, n 174.

192 Gray, above n 56, at 59. The linguist Deborah Cameron sought to refute the ideas in this book with her book The Myth of Mars and Venus (Oxford University Press, Oxford, 2007). Whether or not the claims regarding language in this book are correct, the examples given still illustrate this fallacy.

193 Ibid.

194 Ibid, at 60.

195 Zechariah Chafee gives a humorous example of this kind of misunderstanding. He recounts a young wife complaining, "When I ask Charles if he loves me, he acts as if I were asking for information." Chafee, above n 22, at 382. Here the phrase 'Do you love me?' is interpreted as a request for information, rather than a request for a display of affection. A popular book dealing with this topic is Barbara Annis Same Words, Different Language (Judy Piatkus (Publishers) Limited, London, 2003).

196 This corresponds to consideration 1.4 in Chart 3.1.
} 
communication theory". ${ }^{197}$ These traditions have "distinct, alternative vocabularies". ${ }^{198}$ Griffin notes that "scholars within a given tradition talk comfortably with each other, but often take potshots at those who work in other camps." ${ }^{199}$ It is likely that some of these disputes are caused by different words being used with the same meaning. ${ }^{200}$ An interpreter may assume that because a speaker uses a different word from the word the interpreter would use to express a certain meaning in the interpreter's discipline, a different meaning is being expressed by the speaker. This may cause the interpreter to overlook the relevant consideration of the meaning that is given to this word in speaker's discipline. In such a situation, the interpretation would usually be fallacious because the meaning of the word in the speaker's discipline is a relevant consideration. ${ }^{201}$

This fallacy can also be committed because different words are used with the same meanings in two countries which have variations of the same language. For example, an American reader of the Lewis Carroll novel Through the Looking-Glass and What Alice Found There ${ }^{202}$ might assume that the term 'looking-glass' referred to some unknown kind of furniture and not a mirror, because the word 'mirror' was not used. Such an interpretation would be fallacious, because the interpreter is not justified in making the assumption that a different meaning is being expressed. Rather, the interpreter should be aware of the possibility of geographical variations in language, and therefore should investigate and find the meaning of the word rather than simply assuming it does not refer to a mirror.

The 'different word' fallacy occurs because an interpreter assumes that because a certain meaning can be expressed by a certain word, a speaker is not expressing that meaning when the speaker uses a different word. When this assumption is incorrect, it can cause the interpreter to introduce an irrelevant consideration (the fact that a different word can be used to express a certain meaning) and neglect the relevant considerations which indicated the meaning that the speaker is giving the word. An instance of interpretation is fallacious if the introduction of this irrelevant consideration causes the interpreter to reach a meaning that it is most likely he or she would not have reached if this

197 Em Griffin A First Look at Communication Theory (McGraw-Hill, New York, 2003) at 21.

198 Ibid, quoting from Robert T Craig “Communication Theory as a Field” (1999) 9 Communication Theory 119 at 130.

199 Griffin, above n 197, at 22.

${ }^{200}$ In relation to art criticism, Martin Gardner noted “controversies between Marxian critics and their opponents concerning the nature and value of propaganda in art suffer ... from a melange of linguistic confusion. The same words are used by the opposing sides (sometimes by the same side) with widely different meanings, and different words are used with the same meanings.” Martin Gardner “Art, Propaganda, and Propaganda Art” in Order and Surprise (Oxford University Press, Oxford, 1984) 29 at 29.

201 This corresponds to consideration 1.2 in Chart 3.1.

202 Carroll, above n 148, 133. 
irrelevant consideration had been omitted and the relevant considerations had been taken into account. Also, it is probable that the meaning the interpreter reaches when committing this fallacy is different from the meaning the speaker has given to the word. To avoid this fallacy, an interpreter should pay attention to the relevant considerations which indicate the speaker's meaning and ignore any irrelevant considerations.

An interpreter's goal is to objectively discover a speaker's meaning. The two fallacies that have been discussed in this chapter are caused by the interpreter relying on an irrelevant association of a word with a certain meaning and ignoring the relevant considerations which indicate the speaker's meaning. These fallacies both involve the implicit assumption that each word has a single meaning corresponding to it. Thus the assumption - 'one word, therefore, one meaning' - gives rise to two specific fallacies: 'same word, therefore, same meaning' and 'different word, therefore, different meaning'.

The problem with both fallacies is that the interpreter has made an irrelevant association of a word and a meaning and this association governs the interpretation. The interpreter may have made this association prior to the act of interpretation or may have made this association during the process of interpretation. For the 'same word' fallacy, the interpreter has not discovered the meaning of the speaker because the word being interpreted can be given a different meaning. For the 'different word' fallacy, the interpreter has not discovered the meaning of the speaker because the interpreter would not use the word being interpreted to express the speaker's meaning. With both fallacies, the interpreter has found that it is possible to associate a word with a certain meaning. This association, however, was not relevant for this specific instance of interpretation.

Therefore, with both fallacies the interpreter is distracted by possible meanings that words can have, rather than focusing on what the speaker has used words to mean. This is due to a misunderstanding about the nature of meaning. These fallacies are committed because interpreters overlook two aspects of the association between words and meanings: arbitrariness and conventionality. Because the association between words and meanings is arbitrary, there is no fixed association. This means that interpreters cannot merely discover any association between a word and a meaning, but need to ascertain the specific meaning the speaker has expressed. Because this association is conventional, 
interpreters can discover this association by paying attention to relevant considerations which indicate the conventions that the speaker has employed.

Both fallacies involve the introduction of a basic irrelevant consideration - the meaning a word can have. This leads to the omission of the relevant considerations which indicate the meaning the word is being given by the speaker. It is helpful to list the specific irrelevant considerations that interpreters took into account and the relevant considerations that interpreters neglected in the examples that have been given.

In relation to the 'same word' fallacy, the irrelevant considerations introduced by interpreters included: the current meaning of a word when interpreting a text written at a time when the word had a different meaning, the general meaning of a word when it is being used with a technical meaning, a possible intention that can be attributed to a speaker when using certain words that does not fit the factual context of the utterance being interpreted, and the meaning of a word in a certain discipline when that word is being used in the context of another discipline. These are all examples of meanings the words being interpreted can be given which are irrelevant to the act of interpretation at issue. Therefore, in these examples, the interpreters were distracted by the irrelevant consideration of the meaning that can be associated with a certain word. The relevant considerations that were omitted included: the meaning of the word at the time of writing, the technical meanings that can be given to a word, the intention of the speaker as indicated by the factual context of the utterance, and the meaning of a word in the discipline in which it is being used.

In relation to the 'different word' fallacy, the irrelevant considerations introduced included: the fact that the interpreter would use a different word to express the same feeling, the fact that the interpreter would use a different word in his or her discipline, and the fact that a different word is used in a different country that uses a variation of the same language. These are examples of the meaning certain words (the different words which the speaker did not use) can have. Therefore, in these examples, the interpreters were distracted by the irrelevant consideration of the word that can be associated with a certain meaning. The relevant considerations omitted included: the gender of the speaker, the way words are used in the speaker's academic discipline, and the meaning of the word in the speaker's country.

Some of these interpretation fallacies can be viewed as instances of either fallacy. For example, a 
man may misinterpret a woman's statement, "We never go out” because she is using different words from the ones he would use to express the same meaning. This is the 'different word' fallacy. Alternatively, he may misinterpret this statement because he would use the same word to express a different meaning. This is the 'same word' fallacy. Therefore, this misinterpretation can be caused by the introduction of the irrelevant consideration of the words the interpreter would use to express the same meaning ('different word' fallacy), or the introduction of the irrelevant consideration of the meaning the interpreter would express by those words ('same word' fallacy). In both situations, the introduction of the irrelevant consideration results in the neglect of the relevant considerations indicating the speaker's meaning.

An interpretation that does not arrive at the speaker's subjective meaning is not necessarily fallacious for the purposes of this thesis. An instance of interpretation is fallacious when it takes into account irrelevant considerations and omits relevant considerations and it is most likely that the interpreter would have reached a different meaning if he or she had taken into account the relevant considerations and omitted any irrelevant considerations. Relevant considerations that interpreters need to take into account include both information the interpreter can deduce from the context of speaking and information that the interpreter may not know directly from the context but should know that they need to discover. For instance, when interpreting an ancient text, an interpreter should know that they need to investigate the meanings that words had at the time the text was written.

Moreover, it is difficult to say definitively that an interpreter has arrived at a different meaning from the speaker, because there is no way of definitively ascertaining the speaker's subjective meaning. It can be said, however, that the interpretation is fallacious given the relevant considerations that were omitted and the irrelevant considerations that were introduced and given the fact that a different meaning would most likely have been reached if any irrelevant considerations had been omitted and any relevant considerations had been introduced.

\section{$6 \quad$ Interpretation fallacies and categorisation}

It is useful to view these fallacies in relation to categorisation. This will show the underlying reasons for these fallacies and the relationship between them in a clearer way. It will also show the sorts of situations in which they are usually committed. Furthermore, in Chapter Four judicial 
interpretation will be viewed explicitly in relation to categorisation, and this analysis will show how ordinary interpretation can also be viewed in relation to categorisation.

Language is a way of labelling the various items in the world. It would be too much strain on people's memory and too inconvenient if everything had to be designated by a proper noun. For this reason, items are grouped in categories and these categories are given names. When learning a language, people learn a system of categories. Therefore, except in the case of proper nouns, ${ }^{203}$ words can be viewed as the names of categories of items. When words are used, they can refer to an entire category (for example, 'cars') or to a specific item in a category (for example, 'my car'). To view a reference to a specific item in terms of categorisation may seem strange. For instance, if a speaker refers to 'my father', it may seem strange to claim that he or she is using a category name in such a description. Still, the word 'father' is the name of a category designating a certain relationship, and to refer to 'my father' is to designate a member of this category.

When a speaker uses a word to express a meaning, he or she is employing the name of a category to refer to an item. To ascertain the meaning of this word is to determine the item that has been referred to by this word. Interpretation can therefore be viewed as the discovery of the items speakers have assigned to categories. The word being interpreted can be viewed as a category, and the meaning of this word can be viewed as an item that has been assigned to this category.

The item being categorised corresponds to the meaning rather than the referent for two reasons. First, words always have meanings, but do not always correspond to identifiable referents. Second, even if there is an identifiable referent, the way this referent is being viewed is an important component of the meaning of the word, and viewing the item as the referent would not take this component of meaning into account. If, however, a word has an identifiable referent and the way this referent is being viewed by the speaker does not make a significant difference to interpretation, it can be convenient to view the item being categorised as this referent. ${ }^{204}$

${ }^{203}$ Although two people may have the same name, they are not named in this way because of a certain common characteristic. Therefore, proper nouns do not designate categories: Hospers, above n 106, at 9. Fallacies, however, can be committed due to confusion over the referent of a proper noun, and such fallacies can still be viewed as mistakes of categorisation (see $n$ 452).

${ }^{204}$ When legal interpretation involves categorisation, it is always with reference to a specific situation or matter. Therefore, in Chapter Four, the item will be this situation. When legal interpreters include this item in the category designated by the word being interpreted, it will be viewed as the referent of this word, rather than the meaning. This is because it is an identifiable situation, and differences in the way this item is viewed by the legal speaker and legal interpreter are not legally significant unless they mean that the item should be assigned to a different legal category. Therefore, such differences are still taken into account by viewing the item designated by a word as the referent of that word. This difference in the way legal interpretation is viewed in relation to categorisation is discussed at 
The interpretation fallacies that have been discussed in this chapter can be viewed in relation to categorisation. The 'same word' fallacy occurs when the speaker and the interpreter associate different meanings with the same word. In relation to categorisation this is when the speaker and the interpreter assign different items to the same category. For example, Mrs Bardell thought that the phrase 'keep two people' was being used to refer to marriage. Thus, there was an ambiguity in relation to the phrase 'keep two people' because Mr Pickwick was using it with one meaning whereas Mrs Bardell interpreted it with a different meaning. ${ }^{205}$ This interpretation was fallacious because Mrs Bardell made an unjustifiable association of these words with marriage and ignored the relevant considerations that indicated that Mr Pickwick was using them with a different meaning.

The 'different word' fallacy occurs when the speaker and the interpreter associate different words with the same meaning. In relation to categorisation, this is when the speaker and interpreter have assigned the same item to different categories. For example, a speaker and an interpreter may associate the same meaning with two different words: 'mirror' and 'looking-glass' ${ }^{206}$ The words 'mirror' and 'looking-glass' are synonymous - they have the same meaning. The speaker may express this meaning with the word 'looking-glass' and the interpreter may associate this meaning with the word 'mirror'. A fallacy would be committed if the interpreter had a fixed association of this meaning with the word 'mirror' and could not see that the speaker was expressing the same meaning with a different word.

Thus, the 'same word' fallacy and the 'different word' fallacy each involve errors of categorisation. The 'same word' fallacy involves different items being assigned to the same category and the 'different word' fallacy involves the same item being assigned to different categories. These two possibilities with categorisation are depicted in Diagram 3.9, below.

Chapter Four B.1(a).

205 As has been seen, Mrs Bardell's belief was unjustified. Therefore, there was not a genuine ambiguity with this phrase in the context in which it was used. Rather, Mrs Bardell's belief created an unjustifiable ambiguity with the phrase which led to her wrong interpretation.

206 In relation to this example, it may be clearer to say that the same referent was associated with different words by the speaker and the interpreter, but for consistency this example will be viewed as the association of the same meaning with different words. 


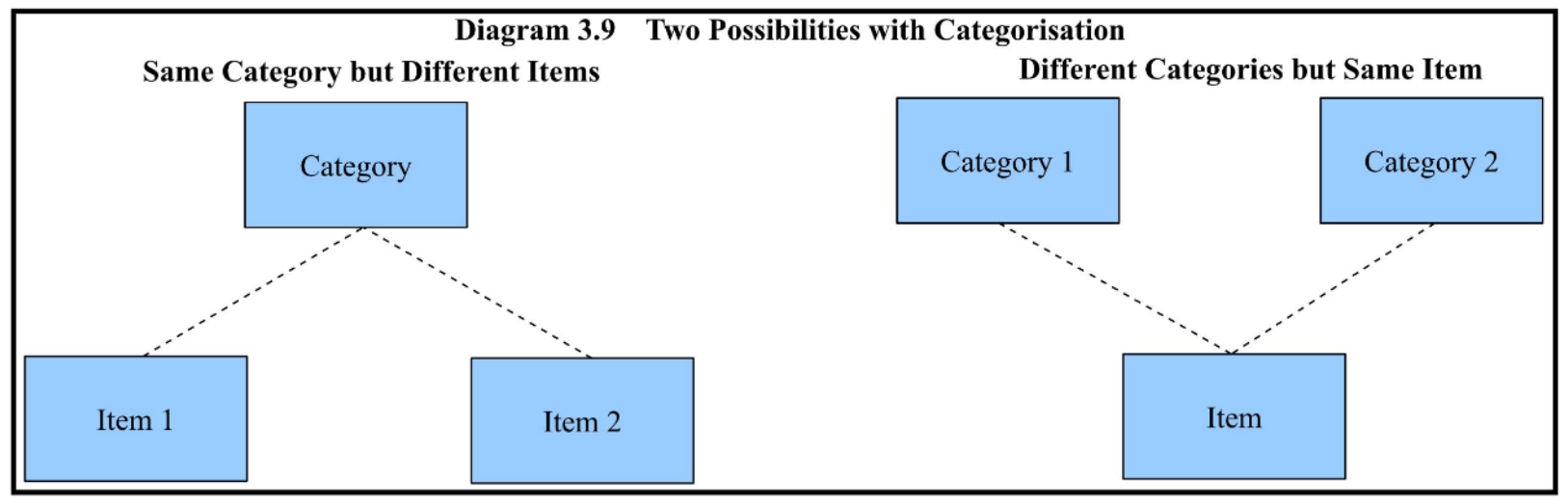

Diagram 3.9 illustrates two possibilities with categorisation. In this diagram, the items correspond to the meanings of words and the categories correspond to the words themselves. The dotted lines indicate that the connection between a category and an item is not fixed, but is arbitrary.

The left-hand side of this diagram illustrates different items being put in the same category. This occurs when the same word (category) can be associated with two or more meanings (items). For example, the phrase 'keep two people' can be associated with two meanings: marriage and employment. The right-hand side of this diagram illustrates one item being put in two different categories. This occurs when two different words (categories) can be associated with the same meaning (item). For example, the words 'mirror' and 'looking-glass' can both be associated with the same meaning.

It is important to note that these two possibilities with categorisation are not necessarily problematic. Indeed, they are an expected result of the arbitrary nature of the relationship between words and meanings. Difficulties can arise when these possibilities occur in concrete instances of interpretation, specifically, when speakers and interpreters give different meanings to the same word or the same meaning to different words. When a speaker and an interpreter give different meanings to the same word, the 'same word' fallacy can result. When a speaker and an interpreter give the same meaning to different words, the ‘different word' fallacy can result.

The difficulty with the 'same word' fallacy is not with the word but the meaning: there are two possible meanings. The difficulty with the 'different word' fallacy is not with the meaning, but the word: there are two possible words. These are opposite difficulties. With the 'same word' fallacy the interpreter is distracted by the wrong meaning; with the 'different word' fallacy the interpreter is distracted by the wrong word. In both cases, however, the interpreter has made an unjustified 
association of a word and a meaning.

Diagram 3.10, below, illustrates the possible associations of categories with items in the abstract.

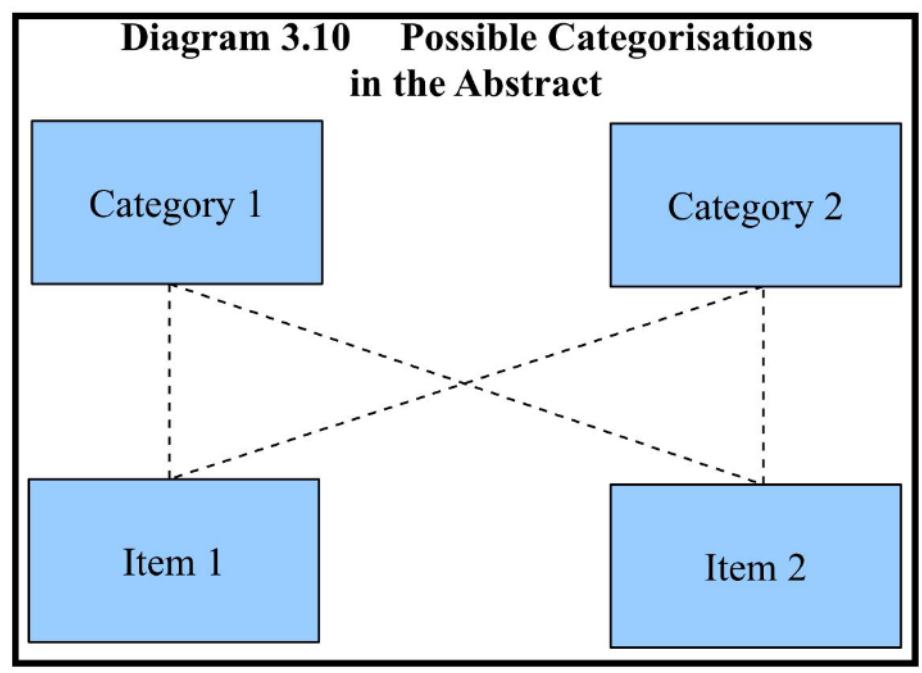

This diagram shows that the inclusion of an item in a category is arbitrary. Any item can be put in any category. That is, any meaning can be expressed by any word. On the one hand, an interpreter may have an expectation that Category 1 would be used to designate Item 2, but the speaker may use Category 1 to refer to Item 1 . That is, an interpreter may expect that a certain word will be used to express a certain meaning but the speaker may use that word to express a different meaning. This can result in the 'same word' fallacy. On the other hand, an interpreter may have an expectation that Item 1 would be assigned to Category 2, but the speaker may assign Item 1 to Category 1 . That is, an interpreter may expect that a certain meaning would be expressed with a certain word, but the speaker may express that meaning with a different word. This can result in the 'different word' fallacy.

This shows that both fallacies are caused by the interpreter's belief that a certain word is associated with a specific meaning, but one is a belief focused more on a word, and the other is a belief focused more on a meaning. When these beliefs are irrelevant to the act of interpretation at issue, they can result in fallacies. These two irrelevant beliefs are the basic irrelevant considerations related to the two specific fallacies identified in this chapter. 
Two possible categorisation fallacies are illustrated in Diagram 3.11, below.

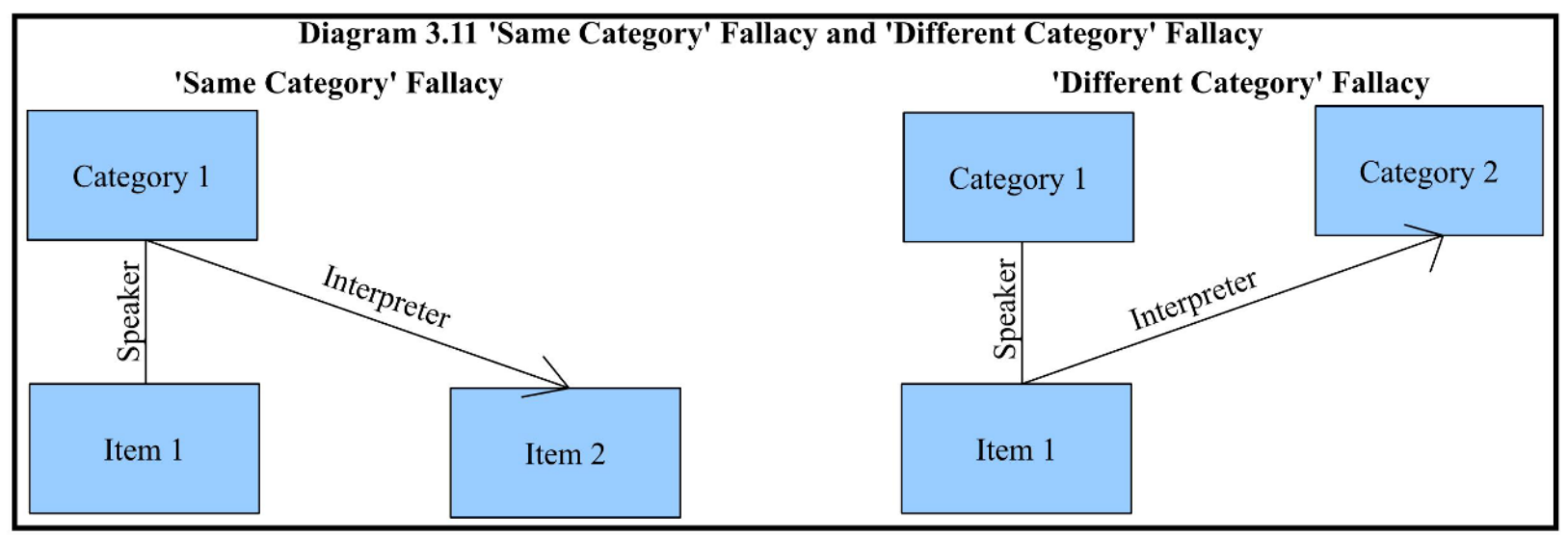

Diagram 3.11 shows the basic conceptual problems with the two fallacies discussed in this chapter from the point of view of categorisation.

The left-hand side of the diagram depicts the 'same category' fallacy, which corresponds to the 'same word' fallacy. This fallacy involves the assumption: 'same category, therefore, same item'. With the 'same category' fallacy, the interpreter has associated a category with an item. The speaker, however, has assigned a different item to this category. That is, the interpreter has associated a certain word with a meaning, but the speaker has used the same word to express a different meaning. Fallacies can occur when the interpreter assumes that because the same word has been used, the same meaning has been expressed. The result of this fallacy is that the interpreter assigns the wrong item to the category, that is, the interpreter associates the wrong meaning with the word being interpreted. For example, marriage is associated with the words 'keep two people' when these words are being used to refer to employment.

The right-hand side of the diagram depicts the 'different category' fallacy, which corresponds to the 'different word' fallacy. This fallacy involves the assumption: 'different category, therefore, different item'. With the 'different category' fallacy, the interpreter has assigned an item to a category. The speaker, however, has assigned this item to a different category. That is, the interpreter has associated a certain meaning with a certain word, but the speaker has expressed this meaning with a different word. Fallacies can occur when the interpreter assumes that because a 
different word has been used, ${ }^{207}$ a different meaning has been expressed. The result is that the interpreter assigns the item to the wrong category. That is, the right meaning is not associated with the word being interpreted. For example, the correct meaning is not associated with the word 'looking-glass'.

Two things should be noted about this diagram. First, the arrows in the diagram are important. With the 'same category' fallacy, the interpreter has associated a category with an item: a word with a meaning. With the 'different category' fallacy the interpreter has associated an item with a category: a meaning with a word. In both situations the interpreter has associated a certain word with a certain meaning. This association of the interpreter can cause these two fallacies when it is irrelevant to the act of categorisation at issue. This association, therefore, is the basic irrelevant consideration that causes interpreters to commit these fallacies.

Second, it is useful to compare the results of the two fallacies. The 'same category' fallacy results in the interpreter assigning an item to a category which the speaker did not assign to this category. That is, it results in the interpreter giving a meaning to a word which the speaker did not give to this word. The 'different category' fallacy results in the interpreter not assigning an item to a category which the speaker has assigned to this category. That is, it results in the interpreter not giving a meaning to a word which the speaker has given to this word. In both cases, the word being interpreted is not given the meaning that the speaker has given it.

It is worth noting that it is not the mere difference of meaning between the speaker and the interpreter that makes an interpretation fallacious. What makes an interpretation fallacious is that the interpreter is not justified in reaching a different meaning from the speaker. Thus, Diagram 3.11 depicts the result of these two fallacies, but this same result could also occur in a situation where an interpreter reaches a different meaning from a speaker in a non-fallacious way. If the meaning an interpreter reaches is based on the relevant considerations and does not introduce any irrelevant considerations, it is not fallacious, even if it results in the speaker and the interpreter giving different meanings to a word.

\footnotetext{
207 The interpreter does not always have to have a specific different word in mind. For this fallacy to be committed it is sufficient if the interpreter believes that the word that needs to be used to express a certain meaning should be different from the one the speaker has used.
} 
The basic ideas in this section are summarised in relation to categorisation in Chart 3.2, below.

\begin{tabular}{|l|l|}
\hline \multicolumn{3}{|l|}{ Chart 3.2 'Same Category' Fallacy and 'Different Category' Fallacy } \\
\hline Same Category, therefore, Same Item & Different Category, therefore, Different Item \\
\hline $\begin{array}{l}\text { Interpreter expects a certain category will } \\
\text { include a certain item. }\end{array}$ & $\begin{array}{l}\text { Interpreter expects a certain item will be } \\
\text { included in a certain category. }\end{array}$ \\
\hline $\begin{array}{l}\text { Speaker assigns a different item to this } \\
\text { category. }\end{array}$ & $\begin{array}{l}\text { Speaker assigns this item to a different } \\
\text { category. }\end{array}$ \\
\hline $\begin{array}{l}\text { Two items are assigned to the same category by } \\
\text { the speaker and the interpreter. }\end{array}$ & $\begin{array}{l}\text { One item is assigned to two different categories } \\
\text { by the speaker and the interpreter. }\end{array}$ \\
\hline $\begin{array}{l}\text { Interpreter concludes same category, therefore, } \\
\text { same item. }\end{array}$ & $\begin{array}{l}\text { Interpreter concludes different category, } \\
\text { therefore, different item. }\end{array}$ \\
\hline $\begin{array}{l}\text { Interpreter assigns a different item to the } \\
\text { category from the speaker. }\end{array}$ & $\begin{array}{l}\text { Interpreter does not assign the same item to the } \\
\text { category as the speaker. }\end{array}$ \\
\hline
\end{tabular}

These same ideas are summarised in relation to words and meaning in Chart 3.3, below.

\begin{tabular}{|l|l|}
\hline \multicolumn{2}{|c|}{ Chart 3.3 'Same Word' Fallacy and 'Different Word' Fallacy } \\
\hline Same Word, therefore, Same Meaning & $\begin{array}{l}\text { Different Word, therefore, Different } \\
\text { Meaning }\end{array}$ \\
\hline $\begin{array}{l}\text { Interpreter expects a certain word will be } \\
\text { associated with a certain meaning. }\end{array}$ & $\begin{array}{l}\text { Interpreter expects a certain meaning will be } \\
\text { expressed by a certain word. }\end{array}$ \\
\hline $\begin{array}{l}\text { Speaker uses this word to express a different } \\
\text { meaning. }\end{array}$ & $\begin{array}{l}\text { Speaker expresses this meaning with a different } \\
\text { word. }\end{array}$ \\
\hline $\begin{array}{l}\text { Interpreter concludes same word, therefore, } \\
\text { same meaning. }\end{array}$ & $\begin{array}{l}\text { Interpreter concludes different word, therefore, } \\
\text { different meaning. }\end{array}$ \\
\hline $\begin{array}{l}\text { Interpreter gives a different meaning to the } \\
\text { word from the speaker. }\end{array}$ & $\begin{array}{l}\text { Interpreter does not give the same meaning to } \\
\text { the word as the speaker. }\end{array}$ \\
\hline
\end{tabular}


The goal of this part of this chapter has been to identify certain specific interpretation fallacies that correspond to fallacies that can be committed in legal interpretation. Therefore, it has not been necessary to discuss many different kinds of fallacies that can be committed in the ordinary interpretation of language. Furthermore, it has not been necessary to discuss in detail the possible variations that can occur with the fallacies that have been identified. It is sufficient if a few clear prototypical examples of fallacies are identified which can be compared with fallacies in legal interpretation. This means that the analysis in this chapter is quite limited. It is useful as a foundation for the discussion of legal interpretation in the following chapter, but is incomplete as a general description of fallacies in the ordinary interpretation of language.

\section{Language and Thought}

This chapter has discussed language and interpretation fallacies. A fundamental issue that has not been addressed in detail is the relationship between language and thought. When language is viewed in relation to categorisation, however, it is possible to address this issue. This section will briefly discuss the relationship between language and thought from the point of view of categorisation. This discussion will provide a way to address some of the general questions about the law raised in Chapter Two.

At the beginning of this chapter it was noted that language can be viewed as a sign system. ${ }^{208}$ Since words are the names of categories, language can also be viewed as a classificatory system or a classificatory scheme. ${ }^{209}$ Therefore, language provides a system of categories which is used to label thoughts and experiences. Because language provides such a classificatory scheme, it is probable that language should exert some influence on thought.

This view that language provides a way to classify the objects in the world is uncontroversial. ${ }^{210}$

\footnotetext{
208 See text accompanying n 68.

209 "[I]ndividual lexical items function as elements in a generalizing of classifying system, whereby we assign portions and aspects of our experience to categories which are recognised by people who have learnt our language.” RA Waldron Sense and Sense Development (Andre Deutsch, London, 1967) at 77.

210 "The lexicon of a language, as well as the grammar, embodies a system of meanings: a certain interpretation and classification of the universe.” Anna Wierzbicka “'Apples' Are Not a 'Kind of Fruit': The Semantics of Human Categorization” (1984) 11 American Ethnologist 313 at 314.
} 
Moreover, language provides a way to classify and retain information and ideas and to pass them on to subsequent generations. ${ }^{211}$ This view of language was eloquently expressed by Richard Trench in a striking metaphor: ${ }^{212}$

\begin{abstract}
It was something for the children of Israel, when they came into Canaan, to enter upon wells which they digged not, and vineyards which they had not planted, and houses which they had not built; but how much vaster a boon, how much more glorious a prerogative, for any one generation to enter upon the inheritance of a language which other generations by their truth and toil have made already a receptacle of choicest treasures, a storehouse of so much unconscious wisdom, a fit organ for expressing the subtlest distinctions, the tenderest sentiments, the largest thoughts, and the loftiest imaginations, which at any time the heart of man can conceive.
\end{abstract}

This quotation highlights the positive and constructive influence that language can have on thought. There have been various views about the extent to which language influences thought, ${ }^{213}$ and many writers have noted that there is some influence. ${ }^{214}$ It is easy to view this influence sceptically and focus on the restriction that language imposes on thought. ${ }^{215}$ This view may be strengthened by a consideration of the fallacies identified in this chapter.

The much more important point, however, is that often it is language that enables thought. ${ }^{216}$ This enabling is due to the fact that language provides a classificatory scheme within which thoughts can be expressed, and the richness of this classificatory scheme is a great benefit to thought. The categorisation that language provides plays an important role in relation to memory, ${ }^{217}$

211 See $n 13$.

212 Trench, above n 66, at 24.

213 An early influential theorist who emphasised the effect that language has on thought was Benjamin Lee Whorf. See Benjamin Lee Whorf (John B Carroll (ed)) Language, Thought and Reality (The MIT Press, Cambridge (Mass), 1956). Although his views fell out of fashion, there has been a revival of a similar view recently. For a recent popular article discussing research related to how different languages shape thought, see Lera Boroditsky "How language shapes thought” (February, 2011) Scientific American 63.

${ }^{214}$ For instance, Stephen Ullmann states: "We have come to regard the vocabulary as a kind of framework, a readymade system of classification, which we inherit from our ancestors and which shapes and fashions our own vision of the universe.” Ullmann, above n 70, at 91. Simeon Potter noted that the "so-called Whorfian hypothesis 'that a man's world-outlook is determined by his linguistic upbringing' has probably been exaggerated by its more exuberant proponents, and yet few experienced philologists would gainsay its intrinsic truth.” Potter, above n 14, at 173.

${ }^{215}$ For instance, Alexander Bryan Johnson states: “The names are at present so identified and confounded with the external existences, that we cannot discover the subordination which language bears to the realities of nature but are continually ... imputing to nature limitations, classifications, ambiguities, imperfections, and properties, of various kinds, which truly belong to language alone.” A Treatise on Language (Harper \& Brothers, New York, 1836) at 50.

${ }^{216}$ Randolph Quirk notes that "language does not only have [a] restrictive influence on thought: language also conditions our thinking in a positive and constructive way.” Quirk, above n 10, at 54.

${ }^{217}$ WVO Quine notes "Actual memories mostly are traces not of past sensations but of past conceptualization or verbalization.” Word and Object (MIT Press, Cambridge (Mass), 1960) at 3. 
imagination $^{218}$ and thinking generally. ${ }^{219}$

\section{E Conclusion}

This section answers the questions raised at the beginning of this chapter. These answers provide a summary of the main ideas in this chapter.

1. What is the goal of interpretation?

The goal of interpretation is for an interpreter to objectively arrive at the same meaning as the speaker. Although a speaker's meaning is subjective, speakers employ language conventions to make their meanings clear. These language conventions are agreed associations of words with thoughts. Therefore, they are objective indicators of a speaker's meaning. An interpreter can ascertain a speaker's meaning by paying attention to various considerations which indicate these conventions, and thus indicate the speaker's meaning. These considerations include: the general conventional meanings of words, the specific conventions that apply in certain areas, the verbal context of an utterance, and the factual context of an utterance. In this chapter, these considerations have been called 'relevant considerations'. Therefore, the goal of interpretation is for an interpreter to arrive at the same meaning as a speaker by taking into account relevant considerations which indicate the speaker's meaning.

2. Is it always unjustifiable for an interpreter to arrive at a different meaning from a speaker?

Although the goal of interpretation is for an interpreter to arrive at the same meaning as a speaker, there are situations in which an interpreter can justifiably arrive at a different meaning from a speaker.

${ }^{218}$ Ludwig Wittgenstein remarks: “A dog believes his master is at the door. But can he also believe his master will come the day after tomorrow? ... Can only those hope who can talk? Only those who have mastered the use of a language.” Wittgenstein Investigations, above n 63, at 174. This quotation illustrates that language makes it possible to think about future events in a concrete way.

219 Monroe Beardsley notes: "Each of use carries around an elaborate and constantly growing classification-scheme for sorting out experience - if we did not, we would find life even more confusing than it is.” Thinking Straight (4th ed, Prentice-Hall, Inc, New Jersey, 1975) at 111. Marina Yaguello states that "[t]o name ... is at the same time to categorize, to organize the world. Words have the power to form concepts: the word actually creates the concept just as much as the concept necessitates the word.” Language through the Looking Glass (Oxford University Press, Oxford, 1998) at 70-71. 
A speaker may use language in a misleading way and may not provide sufficient indications of his or her meaning. In such a situation, an interpreter may reach the meaning that seems to be indicated by the language in the context of the utterance by taking into account various relevant considerations. The fact that the interpreter reaches a different meaning from the speaker's subjective meaning does not make the interpretation unjustifiable because the interpreter has taken into account all the considerations which indicate the speaker's meaning. Furthermore, although the interpreter has reached a different meaning from the speaker, this does not necessarily mean that such an interpretation is wrong because the speaker has used language in a misleading way. Whether or not such an interpretation is wrong is really a matter of definition.

In other situations a speaker may not mislead an interpreter, but an utterance may be ambiguous or unclear and for this reason an interpreter may reach a different meaning from the speaker. If the interpreter takes into account all the relevant considerations which indicate the speaker's meaning, such an interpretation is not unjustified. It can be said that such an interpretation is reasonable, even though the interpreter has reached the wrong meaning.

An interpreter should have the goal of reaching the same meaning as a speaker, but whether or not the same meaning is reached does not depend on the interpreter only but also on the speaker and on the nature of the utterance.

3. What makes an instance of interpretation fallacious?

Interpretation should be based on relevant considerations. A consideration is irrelevant when it is not an indicator of the specific meaning that the speaker is expressing. An instance of interpretation is fallacious when it takes into account an irrelevant consideration and it is most likely that a different meaning would have been reached if that irrelevant consideration had been omitted. An instance of interpretation is also fallacious when it omits a relevant consideration and it is most likely that a different meaning would have been reached if that relevant consideration had been taken into account. Put simply, an instance of interpretation is fallacious when it reaches a meaning that is unreasonable given the relevant considerations that the interpreter should have taken into account. In most situations, this will mean that the interpreter reaches a different meaning from the speaker. 
4. What kinds of fallacies are possible with interpretation?

Two specific fallacies have been identified in this chapter. First, the 'same word' fallacy. This fallacy occurs when an interpreter assumes that because the word being interpreted can have a certain meaning it has been given this meaning by the speaker. Second, the 'different word' fallacy. This fallacy occurs when an interpreter assumes that because a certain meaning can be associated with a certain word, the speaker must be expressing a different meaning when the speaker uses a different word.

When these assumptions are incorrect, they introduce an irrelevant consideration. With the 'same word' fallacy, this irrelevant consideration is the meaning a word can have when it has not been given that meaning. With the 'different word' fallacy, the irrelevant consideration is the word that can be used to express a certain meaning when that meaning has been expressed by a different word.

When an interpreter introduces these irrelevant considerations and it is most likely that a different meaning would have been reached if these irrelevant considerations had not been introduced and the relevant considerations had been taken into account, the interpretation is fallacious.

5. Why are these fallacies committed?

The 'same word' fallacy is committed when an interpreter has a fixed association of a certain word with a certain meaning and does not look beyond this association to the specific meaning that the speaker is expressing. The 'different word' fallacy is committed when an interpreter has a fixed association of a certain meaning with a certain word and does not look beyond this association to the specific meaning that the speaker is expressing.

6. What is the consequence of these fallacies?

The consequence of these fallacies is that the meaning that the interpreter arrives at is unjustified. Furthermore, in most situations it will be a different meaning from the speaker. 
7. How should an instance of interpretation be analysed to see whether it is fallacious?

There are three steps involved in analysing an instance of interpretation to determine whether it is fallacious. First, it is necessary to elicit the relevant considerations related to this act of interpretation. Second, it needs to be determined whether the considerations that the interpreter introduced were relevant. Third, it needs to be determined whether it is most likely that the interpreter would have reached a different meaning if any irrelevant consideration had been omitted and the relevant considerations had been introduced. If it is most likely that a different meaning would have been reached, the interpretation is fallacious.

\section{How can interpreters avoid fallacies?}

Although every interpreter associates words with meanings, these associations should not be fixed, but should be open to change. The connection between words and meanings is arbitrary. Therefore, interpreters should not have fixed associations of words with meanings. Furthermore, this connection is conventional. Therefore, interpreters need to pay attention to the relevant considerations which indicate the conventions that speakers are employing.

9. What is the way to arrive at alternative, non-fallacious interpretations when fallacies have been committed?

An interpretation is fallacious when interpreters omit relevant considerations and introduce irrelevant considerations and this causes the interpreters to arrive at a meaning that they most likely would not have arrived at if they had taken into account all the relevant considerations and had omitted any irrelevant considerations. An alternative non-fallacious interpretation, therefore, is an interpretation that takes into account relevant considerations and does not introduce any irrelevant considerations. This will mean that a different meaning is reached.

This chapter has discussed the ordinary use of language and has identified two interpretation fallacies that can be committed in ordinary interpretation. In Chapter Four, the analysis in this chapter will be used as a basis from which to analyse legal interpretation and the fallacies that judges can commit. 


\section{CHAPTER FOUR}

\section{LANGUAGE IN THE LAW AND JUDICIAL FALLACIES}

\section{A Introduction}

Chapter Two of this thesis discussed the close relationship between law and language and highlighted the importance of judicial interpretation. Chapter Three focused on the ordinary interpretation of language and fallacies that can be committed in such interpretation. This chapter (Chapter Four) continues the analysis of language in the law and judicial interpretation ${ }^{220}$ begun in Chapter Two in the light of the discussion of the ordinary interpretation of language in Chapter Three. It will also identify some fallacies in legal interpretation, corresponding to the fallacies in ordinary interpretation identified in Chapter Three.

Legal interpretation has become a significant focus of academic writing in recent years, ${ }^{221}$ with many approaches to interpretation being discussed. ${ }^{222}$ Furthermore, the topic of law and language has been investigated in a number of recent books. ${ }^{223}$ In this chapter, legal interpretation ${ }^{224}$ will be approached in a fresh way by comparing it with ordinary interpretation, that is, by using the analysis

${ }^{220}$ This chapter will sometimes use the word 'interpretation' to refer to judicial interpretation if this meaning is clear from the context.

${ }^{221}$ For discussions of this academic focus on interpretation, see Brian Bix "H.L.A. Hart and the Hermeneutic Turn in Legal Theory" (1999) 52 SMU L Rev 167; Michael S Moore "The Interpretive Turn in Modern Theory: A Turn for the Worse?” (1989) 41 Stan L Rev 871; and Philip P Frickey “From the Big Sleep to the Big Heat: The Revival of Theory in Statutory Interpretation” (1992) 77 Minn L Rev 241.

${ }^{222}$ For a discussion of various approaches in relation to statutory interpretation, see William N Eskridge, Philip P Frickey and Elizabeth Garrett Legislation and Statutory Interpretation (Foundation Press, New York, 2006). The authors distinguish three kinds of theories of statutory interpretation: intentionalist theories, textualist theories, and dynamic theories (at ch 6).

${ }^{223}$ These include Hutton, above n 20; Peter M Tiersma Legal Language (University of Chicago Press, Chicago, 1999); Dennis Patterson Meaning, Mind and Law (Dartmouth Publishing Company Limited, Aldershot, 2008); Charles W Collier Meaning in Law (Oxford University Press, Oxford, 2009); and Sanford Schane Language and the Law (Continuum, London, 2006).

${ }^{224}$ As mentioned in n 52, the phrases 'legal interpretation' and 'judicial interpretation' are both being used to refer to interpretation by the judiciary, but the phrase 'legal interpretation' will be used when this interpretation is being contrasted with ordinary interpretation. 
of ordinary interpretation in Chapter Three as a point of departure. ${ }^{225}$ Existing approaches to legal interpretation form the background to the analysis in this chapter, but this analysis is constructed on the basis of the discussion of ordinary interpretation in Chapter Three. ${ }^{226}$ Thus, this chapter does not merely summarise or develop existing views on judicial interpretation, but provides a new way to analyse judicial interpretation and detect certain fallacies.

The language investigated in this chapter is language interpreted in the course of judicial decisions, specifically, the language of statutes, regulations and other legal documents such as contracts and wills. As will be seen, however, it is possible to apply some of the analysis in this chapter to judicial decision-making that does not involve the explicit interpretation of language. ${ }^{227}$ Furthermore, this chapter focuses on the judicial interpretation of language that involves the categorisation of specific matters within the legal categories designated by the language being interpreted. ${ }^{228}$

This chapter has two main parts. The first part of this chapter (Chapter Four B, Language in the Law) analyses the processes of legal speaking and legal interpretation. The second part (Chapter Four C, Judicial Fallacies) identifies fallacies in judicial interpretation.

\section{B Language in the Law}

In ordinary language, the relationship between words and thoughts is arbitrary, yet conventional. These two factors are also present in legal language. ${ }^{229}$ The words interpreted by the judiciary are arbitrary labels and are usually chosen based on existing language conventions.

\footnotetext{
225 There have been various attempts to construct theories of legal interpretation, see, for instance, Michael S Moore “A Natural Law Theory of Interpretation” (1985) 58 S Cal L Rev 277; Larry A DiMatteo “A Theory of Interpretation in the Realm of Idealism” (2006) 5 DePaul Bus \& Comm LJ 17; and Jim Evans "Sketch of a Theory of Statutory Interpretation” [2005] NZ L Rev 449. The project embarked on in this thesis is far less ambitious than a full-blown theory of legal interpretation, which may be impossible in principle. For an article arguing against constructing a theory of meaning in the law, see Dennis Patterson “Against a Theory of Meaning” (1995) 73 Wash U L Q 1153. This thesis, however, does provide an original approach to critiquing instances of legal interpretation and detecting fallacies.

${ }^{226}$ In this chapter certain important words and phrases are defined and need to be distinguished from similar expressions that have been used by other writers. These words and phrases include: 'legal word', 'legal category', 'item', 'legal speaking', 'legal ineffability’, 'legal/judicial interpretation', 'legal meaninglessness', 'relevant legal consideration', ‘verbal category', and ‘judicial fallacy’. These definitions are collected in Appendix One, Glossary.

227 See the paragraph accompanying n 311.

228 This is discussed at Chapter Four B.1.(a).

229 The phrase 'legal language' is used in this chapter to refer to the language of legal documents that are subject to judicial interpretation.
} 
In Chapter Three, it was pointed out that language conventions are shown by the context in which words are used. In some instances when a word is used in a legal context it is given a specific legal meaning. For example, the word 'instrument' when used in a legal setting may refer to a legal document, not to a tool, and the word 'consideration' may refer to some payment or action that makes a contract legally binding, not to careful thought. ${ }^{230}$ In these situations, the specific language conventions that apply can be viewed as legal language conventions. This kind of changing of conventions is common in many academic disciplines and other groups in society and is not unique to the law. The creating of new conventions by the use of words in a special way in a certain area gives words technical meanings in addition to their ordinary meaning. ${ }^{231}$ Therefore, in some instances, the meaning given to words in a legal context may be considered as a kind of technical meaning, similar to technical meanings in other areas.

It was also pointed out in Chapter Three that conventions can be explicitly changed by providing definitions. Striking instances of this can be seen in the law; for example, the Freshwater Fish Farming Regulations 1983 (NZ) give a definition of 'fish' that includes seaweed. ${ }^{232}$ Since this meaning is explicitly given in these regulations, it is comparable to a stipulative definition in ordinary language. ${ }^{233}$ Definitions given in legal documents, therefore, may be stipulative in the same way that definitions in academic disciplines, such as philosophy, can be stipulative. ${ }^{234}$

To view legal interpretation as merely ascertaining meanings based on language conventions existing in the community generally, or even conventions existing in the law or specifically created for certain legal documents, is to view it as essentially the same as ordinary interpretation. There are, however, some important differences between legal interpretation and ordinary interpretation. At this stage, three differences can be noted.

First, as mentioned in Chapter Two, legal interpretation often results in, and may even be viewed as,

${ }^{230}$ For a detailed discussion of the characteristics of the language that is used in the law, see David Mellinkoff The Language of the Law (Little, Brown and Company, Boston, 1963).

${ }^{231}$ Judges sometimes take account of such technical meanings when interpreting documents drafted in the context in which such meanings are employed. For a discussion of this in relation to contract interpretation, see Kim Lewison The Interpretation of Contracts (3rd ed, Sweet \& Maxwell, London, 2004) at 116-117.

${ }^{232}$ The Freshwater Fish Farming Regulations 1983, reg 2(1).

233 “'“S]trict', 'narrow', 'technical' and 'legal' meanings are examples of the special assignment of a particular meaning to particular words. These are simply the rarefied conventional usages of a caste of human speakers of language, namely lawyers." McMeel, above n 23, at 258.

${ }^{234}$ There is an important difference, however, between legal dictionaries and dictionaries of technical terms in other disciplines, for instance, medical dictionaries. Legal dictionaries do not merely provide the legal meaning of words, but also state the law. Therefore, an entry in a legal dictionary can become out of date due to a judicial decision or the enactment of a statute. See also Chapter Five C. 
the application of the law to factual situations. The result of ordinary interpretation, however, is that the interpreter objectively ascertains the speaker's meaning. Legal interpretation, therefore, can be distinguished from ordinary interpretation on the basis of its result: it can result in the law being applied to specific situations.

Second, the goal of legal interpretation can be distinguished from the goal of ordinary interpretation. The goal of ordinary interpretation is to discover meaning. It can be said, however, that the goal of legal interpretation is often to implement the law. It has been said that "the principal function of a legislative drafter is to enshrine policy in an accurate and precise manner ... the communication of the law is an entirely different task."235 Although this statement may be contested, it is clear that the goal of legislative drafting is not merely the successful communication of meaning but is also the accurate embodiment of the law. ${ }^{236}$ Similarly, the goal of legal interpretation - including both statutory interpretation and the interpretation of other legal documents - is not merely the discovery of meaning, but may also be the accurate implementation of the law.

Third, in Chapter Three it was pointed out that the governing factor for successful communication in ordinary language is the correct use of language conventions on the part of speakers and the correct discovery of such conventions on the part of interpreters. The governing factor for the implementation of the law in legal interpretation, however, is that the interpretive decision is based on relevant legal considerations. ${ }^{237}$ Language conventions are employed in the drafting of legal documents. One reason these conventions are employed is that they involve a convenient conceptual groupings of items. The writers of legal documents use conventions, however, not merely for the purpose of communicating information about items, but also for the purpose of giving these items a legal status. For this reason, legal interpretation needs to take into account not merely the conventional meaning of the words being interpreted, but also certain legal considerations which determine the legal status that should be given to the items under consideration. Therefore, it may be said that legal interpretation should not merely be governed by language conventions, but also by legal considerations.

\footnotetext{
235 Brian Hunt “Plain Language in Legislative Drafting: An Achievable Objective or a Laudable Ideal?” (2003) 24 Statute L Rev 112 at 122.

${ }^{236}$ A similar view has also been held by linguists who have studied legal language: "To speak of legal language as communicating meaning is in itself rather misleading ... it is designed not so much to enlighten language-users at large as to allow one expert to register information for scrutiny by another.” David Crystal and Derek Davy Investigating English Style (Longman Group Limited, London, 1969) at 193-194.

${ }^{237}$ This notion of relevant legal considerations is discussed again at Chapter Four B.3.
} 
This thesis investigates legal interpretation generally, and is not limited to the interpretation of statutes. In this section, the claims have been made that legal interpretation involves the application of the law to factual situations, the implementation of the law, and involves giving items a legal status. It may be thought that such claims are only true of statutory interpretation. In any instance of judicial interpretation, however, including the interpretation of a contract or a will, the decision that is reached is a legally-binding, authoritative decision. It is a decision regarding the law in relation to the dispute at hand. ${ }^{238}$ In this sense, it is the application of the law to the subject matter in dispute and thus the implementation of the law in relation to the dispute. Furthermore, when judicial interpretation relates to a specific item, it results in this item being given a legal status.

Therefore, legal interpretation can be distinguished from ordinary interpretation on three grounds. These two types of interpretation can have different consequences, goals, and governing factors. Put simply, in ordinary interpretation the primary task is to discover the meaning of a speaker and in legal interpretation the primary task is often to make a legal decision regarding the application of the law. ${ }^{239}$ These three distinctions are important, but they do not conclusively prove that the process of legal interpretation is fundamentally different from the process ordinary interpretation. The question of whether the process of legal interpretation is fundamentally different from ordinary interpretation will be addressed later in this chapter after legal interpretation has been analysed in more detail. $^{240}$

A number of commentators, including judges, have viewed legal interpretation, including both the interpretation of statutes and other legal documents, as essentially similar to ordinary interpretation. Michael Zander stated: "Statutory interpretation is a particular form of a general problem - the understanding of meaning or, more broadly still, communication.”241 Writing extra-judicially, Justice Kirby noted: ${ }^{242}$

\footnotetext{
${ }^{238}$ As was mentioned in $\mathrm{n} 44$, this does not mean that it can be said that all legal documents that judges interpret embody the law.

${ }^{239}$ Of course, this legal decision can be viewed as, and is often viewed as, the discovery of the meaning of the words being interpreted. The point being made here is that this discovery of meaning is not an end in itself, but is determined by the legal decision the court needs to make regarding the specific matter before the court. Furthermore, as will be seen in this chapter, the view that judges are merely involved in discovering meaning can be misleading.

240 At Chapter Four B.4.

${ }^{241}$ Michael Zander The Law-Making Process (6th ed, Cambridge University Press, Cambridge, 2004) at 127.

242 Michael Kirby “Towards a Grand Theory of Interpretation: The Case of Statutes and Contracts” (2003) 24 Stat L Rev 95 at 99 [“Grand Theory”].
} 
Whether in a written contract or an Act of Parliament, the proper approach to the task of interpretation is to attempt to read the words as they would be understood in everyday life ....

Lord Hoffmann remarked that the result of a fundamental change in contract law has been: ${ }^{243}$

to assimilate the way in which [contractual] documents are interpreted by judges to the common sense principles by which any serious utterance would be interpreted in ordinary life. Almost all the old intellectual baggage of 'legal' interpretation has been discarded.

If such claims are correct, it is all the more important that the process of ordinary interpretation is understood clearly, and that legal interpretation be explicitly viewed in terms of it and not mistakenly distinguished from it.

Writing regarding the interpretation of tax treaties, Brian Arnold noted that "interpretation is a fundamental, universal, and intuitive human activity that applies to all forms of human communication”. ${ }^{244}$ He further noted: ${ }^{245}$

Interpretation of language is an intuitive skill that we acquire without the benefit of formal instruction ... we do not have to be taught that language is purposive; that aspect of language is inherent in its nature as the primary means of human communication. Nor do we have to be taught that all language is context dependent; we learn this informally at a young age.

As has been seen in Chapter Three, however, even with ordinary interpretation it is dangerous for interpreters to merely rely on their intuition when engaging in interpretation. ${ }^{246}$ It is likely that this will also be true of legal interpretation, whether it is viewed as essentially the same as ordinary interpretation or as a different activity altogether.

Although some differences between legal interpretation and ordinary interpretation can be pointed

${ }^{243}$ Investors Compensation Scheme Ltd v West Bromwich Building Society [1998] 1 WLR 896 (HL) at 912. For discussions of Lord Hoffman's decision in this case, see Adam Kramer "Common Sense Principles of Contract Interpretation (and how we've been using them all along)" (2003) 23 Oxford J Legal Stud 173 and Ewan McKendrick “The Interpretation of Contracts: Lord Hoffmann's Re-Statement” in Sarah Worthington (ed) Commercial Law and Commercial Practice (Hart Publishing, Oxford, 2003) 139.

244 Brian J Arnold "The Interpretation of Tax Treaties: Myth and Reality” (2010) 64 Bulletin for International Taxation 2 at 2.

245 Ibid, at 4.

${ }^{246}$ For instance, the fallacies identified in Chapter Three were committed because of a misunderstanding regarding the nature of meaning. 
out in the abstract, the actual process of legal interpretation needs to be discussed in some detail to discover whether it differs fundamentally from ordinary interpretation. The remainder of this chapter, therefore, will analyse language in the law and legal interpretation on the basis of the analysis of ordinary language and interpretation in Chapter Three. This analysis will clarify the nature of legal interpretation, will show whether legal interpretation is fundamentally different from ordinary interpretation, and, most importantly, will provide a way to identify fallacies in legal interpretation.

\section{$1 \quad$ Legal words, legal thoughts and legal referents}

Just as the connection between words and referents is indirect in ordinary interpretation, in legal interpretation the connection between legal words and legal referents is also indirect. This is illustrated in Diagram 4.1, below, which is based on Diagram 3.1 (Word, Thought and Referent).

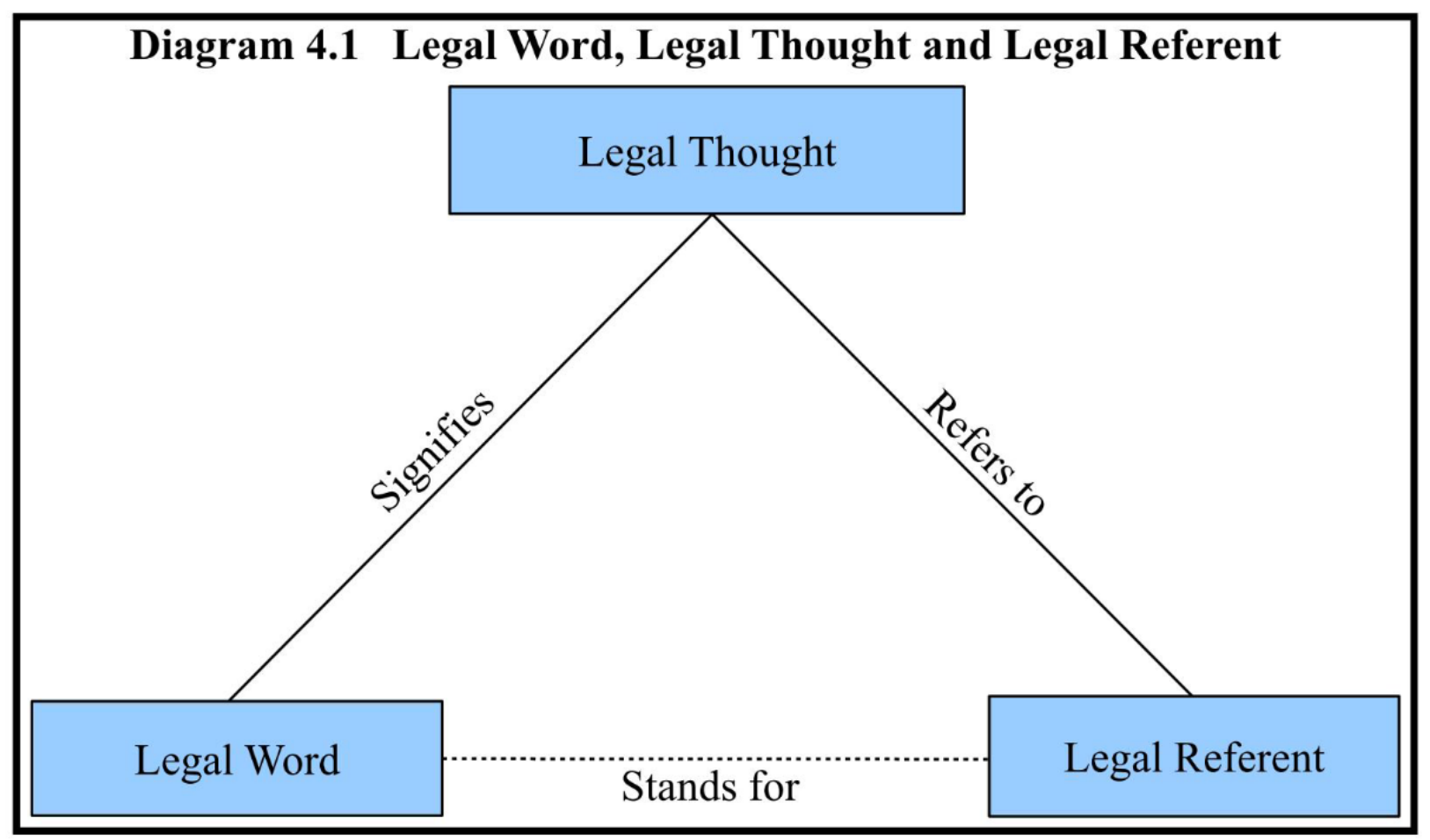

Diagram 4.1 illustrates the relationship between words in the law, the thoughts they signify, and the things to which these thoughts refer. This diagram shows that the three elements that are present in ordinary language can also be identified in relation to legal language. 
The singular term 'legal word' has been used in this diagram for simplicity. This does not mean, however, that this diagram merely applies to the use of single words. This diagram can also apply to the use of more than one word to stand for a legal referent. Furthermore, the other diagrams in this chapter which use the term 'legal word' can also apply to the use of more than one word.

On the left-hand side is the legal word. This should be understood as a word that is subject to judicial interpretation. ${ }^{247}$ Diagram 4.1, therefore, applies to quite a specific range of words. It does not apply to all language used in a legal setting or to all language used by legal professionals, ${ }^{248}$ but it applies to the language of legal documents that are subject to interpretation by the judiciary. On the right-hand side is the legal referent, which is that to which the legal word refers. The connection between the legal word and the legal referent is not direct, but is through the legal thought.

The legal thought is harder to define and shows a shortcoming of this diagram. It is not merely the thought of the interpreting judge. ${ }^{249}$ If it were, this diagram would merely illustrate judicial interpretation. The thought of the 'legal speaker' ${ }^{250}$ is also relevant. This diagram, therefore, although useful in showing the indirect relationship between legal words and legal referents, has the same shortcoming as Diagram 3.1: it conflates the processes of speaking and interpretation. Having said this, it is important to note that there is more involved in the legal thought in Diagram 4.1 than the thought in Diagram 3.1. Legal language conventions may be relevant to this legal thought, and not merely ordinary language conventions. More importantly, this legal thought may be influenced by considerations related to the law itself.

The nature of the legal referent in Diagram 4.1 may also be different from an ordinary referent. Since judges authoritatively determine what legal words refer to, it can be said that the authoritative recognition of a legal referent requires judicial interpretation. In ordinary interpretation, if it is difficult for interpreters to identify the referent of a word, this referent can sometimes be identified by the speaker. In legal interpretation, however, there is the need of judicial interpretation for a referent to be authoritatively identified. Speakers cannot change an instance of judicial interpretation by clarifying the referents they were seeking to identify. For an instance of judicial

\footnotetext{
247 This thesis will focus on the interpretation of statutes, regulations and other legal documents, such as contracts and wills. It will not cover the interpretation of judicial decisions. Therefore, this 'legal word' should be understood to refer to a word in these legal documents that is subject to judicial interpretation.

${ }^{248}$ For instance, lawyers, judges, and legal academics.

${ }^{249}$ It is necessary to use the singular word 'judge' here because even in situations where a number of judges concur, judgments are still delivered by individual judges.

250 The 'legal speaker' and the act of 'legal speaking' are discussed in Chapter Four B.2.
} 
interpretation to be changed there is the need for the decision to be either reversed on appeal or changed by legislative action. Thus, the authoritative recognition of the referent requires judicial interpretation. $^{251}$

Moreover, legal interpretation often occurs with reference to a definite situation. If a judge decides that this situation comes within the meaning of the word being interpreted, this situation can be considered to be the referent of that word. This means that once a word has been judicially interpreted and a judge has decided that a certain situation comes within the meaning of this word, the word has an identifiable referent. In ordinary language, the fact that a word has been interpreted does not necessarily mean that it has been given an identifiable referent. ${ }^{252}$

Furthermore, the two relationships depicted in this diagram can be distinguished from those in ordinary language. The relationship between the legal word and the legal thought is not merely governed by conventions. As will be seen, certain legal considerations may override these conventions. $^{253}$ The relationship between the legal thought and its legal referent is still automatic because the thought is just a conceptual representation of the referent. It is useful, however, to view this thought as being actively applied to a referent in judicial interpretation, rather than passively referring to a referent. This is because there is the need of a judicial decision to connect a legal thought to a legal referent. It is not enough for judges to merely think of a certain referent when interpreting a word or to identify a referent outside the context of a judicial decision. For a referent to be officially identified it needs to be explicitly stated in a judicial decision. ${ }^{254}$

Therefore, a consideration of the elements in Diagram 4.1 and the connections between them shows that certain important distinctions can be made between legal language and ordinary language. Both the nature of each element in this diagram and the connections between them can be distinguished

251 This does not mean that there needs to be a judicial decision to recognise every referent referred to in a legal document. The vast majority of legal documents function effectively without any judicial decisions on their meaning. What this does mean is that if there is a dispute regarding a referent, there is the need of a judicial decision to authoritatively resolve this dispute.

${ }^{252}$ For instance, in an example given in Chapter Three, Stephen Potter correctly interpreted what the doctor meant by the word 'attraction', but he did not identify a specific referent for this word (see text accompanying $n$ 145).

253 Although these considerations may be viewed as part of the factual background which shows what the conventions are, they are different from the kind of considerations present in ordinary language. This is discussed at Chapter Four B.4.

${ }^{254}$ It could be said that this distinction between a thought referring to a referent and a thought being applied to a referent is merely two ways of viewing the same action. It is important to bear in mind, however, that the application of the legal thought to a referent involves the application of the law to that referent. To say the law 'refers to' a certain situation is different in meaning from saying that the law has been 'applied to' that situation. In relation to legal speaking, however, it may be accurate to say that the thought of the legal speaker refers to a certain referent. 
from the nature of the elements and their connections in Diagram 3.1.

(a) Approach to language in the law and judicial interpretation: categorisation

This section will discuss the approach to language in the law and judicial interpretation in this chapter. This chapter focuses on instances of judicial interpretation which involve categorisation. This does limit the scope of this chapter, but, as will be seen, a crucial group of instances of judicial interpretation that are legally significant involve categorisation. Judicial interpretation is often viewed as involving the discovery of the meaning of the words being interpreted. In this chapter, judicial interpretation will be viewed as involving the categorisation of the item at issue within the legal category designated by the words being interpreted. This section will introduce this way of viewing legal interpretation and will show how it is different from the way ordinary interpretation was viewed in relation to categorisation in Chapter Three.

There are some important differences between the processes of speaking and interpretation in ordinary language and these processes in the law. Whereas in ordinary interpretation, there is often a single speaker whose language is being interpreted, in legal interpretation, there may not be a single speaker. For instance, in relation to statutes, there are the legislators and in relation to contracts, there are two parties. Furthermore, even if a single speaker is identifiable, interpreters often do not have access to such a speaker to clarify what he or she meant. For instance, in relation to wills, the speaker is dead. Even in cases where the speakers are living, interpreters are often prohibited from asking them to give evidence regarding what they intended their language to mean. Furthermore, even if there is a speaker and his or her intentions are clear, these intentions may not be relevant to the situation at issue. When drafting a legal document, a speaker sometimes does not anticipate a certain situation occurring. If such a situation occurs, an interpreter will still have to make a decision regarding the meaning of the speaker's words with reference to this situation. ${ }^{255}$ For these reasons, it may be difficult to directly compare speaking in a legal context with speaking ordinarily.

Furthermore, legal interpretation is different in various ways from ordinary interpretation. In ordinary interpretation, the task is often to ascertain the speaker's intention. In legal interpretation,

\footnotetext{
255 This can occur, for instance, in the interpretation of a contract where the dispute concerns a matter the parties did not contemplate at the time the contract was drafted: see DW McLauchlan "Contract Interpretation: What Is It About" (2009) 31 Sydney L Rev 5 at 9.
} 
the task may be to impute a presumed intention when no actual intention existed. Moreover, because legal interpretation involves the application of the law, the interpreter needs to be aware of various legal considerations, and not just the linguistic meaning of the words being interpreted. Furthermore, legal interpretation takes place in a very specific framework with a hierarchy of courts, the possibility of appeal, binding precedent, evidentiary rules, and various canons of interpretation. For these reasons, it may be difficult to directly compare legal interpretation with ordinary interpretation.

Chapter Three discussed how ordinary interpretation can be viewed as categorisation. To compare legal interpretation with ordinary interpretation and to analyse legal interpretation based on ordinary interpretation it is necessary to find a level at which they are similar. Despite the differences between these kinds of interpretation, there is an essential similarity which can be seen clearly when they both are viewed in relation to categorisation. ${ }^{256}$ Thus, viewing legal interpretation as categorisation makes it easier to compare legal interpretation with ordinary interpretation. More importantly, viewing legal interpretation as categorisation provides a useful way to critique instances of legal interpretation and detect interpretation fallacies. Therefore, in this chapter, legal interpretation will be viewed as categorisation.

To clarify what it means to view legal interpretation as categorisation, it is necessary to define some important concepts. When legal interpretation is viewed in terms of categorisation, the word or words being interpreted can be viewed as the name of a legal category. Legal speaking ${ }^{257}$ can be viewed as the creation of such legal categories. Legal interpretation can be viewed as the assignment of items to legal categories, that is, legal categorisation. The matter before the court that prompted the instance of legal interpretation and that needs to be either included within the category designated by the word being interpreted or excluded from this category can be viewed as an item that needs to be categorised. There are various legal considerations relevant to the assignment of items to legal categories. These are considerations judges need to bear in mind when engaging in legal categorisation, and correspond to the considerations relevant to ordinary interpretation.

To make this clear it is helpful to view Diagram 4.1 in relation to categorisation. The legal word on the left-hand side, which is a word subject to judicial interpretation, can be viewed as the name of a legal category. The thought at the apex of the triangle, which corresponds to the meaning of the

\footnotetext{
256 This is shown at Chapter Four C.6.

257 'Legal speaking' will be defined and discussed in detail at Chapter Four B.2.
} 
word being interpreted, is a thought concerning the item or items in the legal category. This thought is therefore governed by any considerations relevant to the inclusion of items in the category. The referent on the right-hand side is an item that has been included within the legal category.

It is important to point out a difference between the legal categorisation that this chapter focuses on and the categorisation in ordinary interpretation discussed in Chapter Three. In Chapter Three, when ordinary language was viewed in relation to categorisation, the meaning of the word was viewed as the item being categorised within the category designated by the word. Therefore, because words always have meanings, on this analysis ordinary interpretation always involves categorisation. If the meaning given to the word in legal interpretation is viewed as the item being assigned to the legal category, legal interpretation also always involves categorisation. When viewing legal interpretation in relation to categorisation, however, it is helpful to view the act of categorisation in a slightly different way. This way of viewing the act of categorisation will, on the one hand, mean that legal interpretation does not always involve categorisation. On the other hand, however, it will mean that the discussion of legal interpretation in terms of categorisation will provide a very helpful way to analyse judicial decisions and to identify fallacies in such decisions.

In ordinary interpretation, it is the act of speaking that prompts interpretation. Legal interpretation, however, is often prompted by a certain situation occurring or is in relation to a certain matter. For instance, a statute may need to be judicially interpreted when someone does a certain act that may come within the scope of one of the provisions of the statute. Similarly, a contract may need to be judicially interpreted when a certain situation arises and there is a dispute regarding the meaning of the language in the contract in relation to that situation. Furthermore, a will may need to be interpreted when there is a dispute about the person who is a beneficiary under the will. The meaning of the word being interpreted, therefore, has to be determined in relation to this situation or matter, and not in the abstract.

When legal interpretation is viewed in relation to categorisation, it is useful to view the matter before the court which has prompted the interpretation as the item that needs to be categorised. This matter can include a variety of things. It can be an event that has occurred (for example, a person committing a crime), an object or objects that are in dispute (for example, certain plots of land when the issue is the plot of land to which a contract refers), or a person (for example, a beneficiary under a will). The key point is that there is often a definite matter or situation to which the interpretation relates. This matter or situation can be viewed as the item which needs to be categorised. This 
chapter will focus on instances of judicial interpretation which involve such categorisation. Therefore, this chapter will not focus on situations where courts merely determine the meaning of a word in the abstract and this determination of meaning does not relate to the situation before the court. Although such a determination of meaning can be viewed as categorisation based on the description given in Chapter Three, it will not be viewed as legal categorisation in this chapter. Therefore, an instance of judicial interpretation involves categorisation whenever it relates to a specific matter and has the effect of deciding the legal status of that matter.

In Chapter Three, the item being categorised was equated with the meaning of the word rather than the referent. There were two reasons for this. First, some words do not have identifiable referents. Second, even if they do, the way the referent is viewed by the speaker is an important consideration and is part of the meaning of the word, and to equate the item with the referent could mean that the way this referent is being viewed is neglected. In this chapter (Chapter Four) the item being categorised is equated with the situation or matter before the court. When this item is included within the legal category designated by the word being interpreted, it will correspond to the referent of the word. There are two reasons why it can correspond to the referent, rather than the meaning. First, there is a definite identifiable situation that can be posited as the referent. Second, the way this situation is viewed by speakers is only legally significant if it affects the way this situation will be treated in the law, that is, the way it will be categorised. ${ }^{258}$ Therefore, if the way the item is being viewed by a speaker is legally significant, this will affect the legal category to which it should be assigned, and this would mean that it becomes the referent of a different word. For this reason, to equate the item included within a legal category with the referent of the word designating that legal category will not mean that legally significant differences in the way this item is being viewed by speakers are neglected.

The way that legal interpretation is viewed in relation to categorisation, therefore, differs from the way ordinary interpretation was viewed in relation to categorisation in Chapter Three. This difference, however, reflects an essential difference between these two kinds of interpretation. In ordinary interpretation, interpreters are focused on discovering the meaning that has been given to a word by a speaker. Viewed in relation to categorisation, this involves the discovery of the item that is within a category. Therefore, the item to be categorised can be viewed as the meaning that needs to be discovered. In legal interpretation, judges are often focused on whether the matter or situation

\footnotetext{
${ }^{258}$ Similarly, the force of the speaker's utterance, that is, the speaker's intention regarding the matter to which he or she is referring, is only significant if it affects the way this item should be categorised.
} 
before the court fits within the language being interpreted. Viewed in relation to categorisation, this involves the decision whether to categorise an item within the legal category designated by the word being interpreted. Therefore, the item to be categorised can be viewed as the matter or situation before the court. Thus, because the focus of legal interpretation is different from the focus of ordinary interpretation, when these two kinds of interpretation are viewed in relation to categorisation they need to be viewed in a different way.

The court may decide that the item at issue in an interpretive decision fits within the legal category designated by the word being interpreted. Alternatively, the court may exclude this item from this category. Therefore, the focus in legal interpretation is not merely on a certain category and the item that should be assigned to it, but on a specific item and whether it should be assigned to a certain category. This does not mean that the act of categorisation in legal interpretation is essentially different from categorisation in ordinary interpretation. The basic act of categorisation is the same it involves the assignment of an item to a category - but the focus of the interpreter is different. In ordinary interpretation the focus is on the category. In legal interpretation the focus is on the item.

Therefore, this thesis is limited to instances of judicial interpretation where the judge needs to decide whether a certain situation should be assigned to or excluded from the legal category designated by the word being interpreted. This is an important point about the scope of this thesis. This thesis is not concerned with judicial interpretation that is not in relation to any specific situation or judicial interpretation that is concerned with a specific situation, but does not concern whether or not that situation should be included within the legal category designated by the word being interpreted.

An objection to limiting the scope of this thesis in this way is that it does not cover all instances of judicial interpretation. It is true that there are situations in which judges merely determine the meaning of words, and this determination does not involve the assignment of items to legal categories. For example, obiter dicta statements made by judges concerning the meaning of a certain word in the course of a decision or instances of judicial interpretation which merely involve a clarification of the law may not relate to any specific item. Such interpretation is not within the scope of this thesis. Since judicial interpretation often occurs in the context of a specific dispute, however, it often involves categorisation. This is because the dispute is related to a specific matter that either needs to be assigned to the legal category designated by the word being interpreted or excluded from this category. Such instances of judicial interpretation are important because they 
involve the application of the law to specific factual situations. Therefore, they are a crucial group of instances of judicial interpretation that are legally significant in a particular way. Focusing on instances of judicial interpretation that involve the legal categorisation of the specific item before the court, therefore, provides a convenient way to limit this thesis to these particular legally significant instances of interpretation.

There are, however, some interpretive decisions that involve the application of the law to factual situations that may not seem to involve such categorisation. For instance, a court may have to decide whether a contract or a trust has been created by a legal document, and this may depend on the interpretation of certain language. ${ }^{259}$ It may seem that this act of interpretation does not involve categorisation, but merely involves determining the legal significance of the words being interpreted. The words being interpreted, however, refer to certain items. These items are within the legal category created by these words. Determining the legal significance of these words involves determining the nature of the legal category to which the items designated by these words have been assigned. Even though it may not seem intuitive to view such a decision as categorisation, it has the effect of determining the legal significance of the category to which certain items have been assigned, and, in this sense, can be viewed as categorising these items within a category with this significance. ${ }^{260}$

Therefore, in many situations when judges interpret language, they determine meaning in relation to specific items and this interpretation results in items being given a legal status. Thus, these items are either included within a legal category or excluded from a legal category. Both the acts of including an item within a legal category and excluding an item from a legal category can be considered as acts of categorisation. Therefore, it can be said that this chapter only focuses on certain instances of judicial interpretation, but these instances of judicial interpretation are legally significant in an important way.

An objection to viewing legal interpretation in terms of categorisation is that it creates unnecessary complications. There needs to be a discussion of legal categories in addition to legal words and of the considerations relevant to legal categorisation in addition to legal thoughts. Viewing legal

\footnotetext{
${ }^{259}$ In some situations, determining whether, for instance, a trust has been created by a document is a separate activity from interpreting the language in this document. In other situations, the meaning of the language, and especially the intention expressed in the language, may be crucial in determining whether a trust has been created. See Chapter Four C.7

${ }^{260}$ For a discussion of an example of this kind of interpretation showing how it involves categorisation, see the paragraph accompanying n 509 .
} 
interpretation in terms of categorisation, however, provides a useful way to avoid certain fallacies. Moreover, as will be seen, in various respects an approach focused on categorisation is clearer than an approach based either on the meaning of words or on the intention of speakers. ${ }^{261}$

The points made in this section can be briefly summarised. In this chapter judicial interpretation will be viewed as categorisation. Although both ordinary interpretation and legal interpretation are similar in that they involve categorisation, there is an essential difference in focus between them. Ordinary interpretation is focused on the discovery of meaning, that is, the discovery of an item in a category. Legal interpretation that involves categorisation is focused on correctly applying the law to the situation before the court, that is, deciding whether to assign an item to a category. For this reason, in this chapter the situation before the court will be viewed as the item that needs to be categorised within the legal category designated by the word being interpreted. This will provide a very helpful way both to analyse legal interpretation and to identify fallacies in such interpretation.

Diagram 4.1 has the same limitations as Diagram 3.1. A problem with Diagram 3.1 (Word, Thought and Referent) was that it did not distinguish between the processes of speaking and interpretation. Similarly, Diagram 4.1 does not distinguish between speaking and interpretation in the law. The word 'signifies' conflates the distinction between a legal speaker encapsulating a thought in a word and this word generating a thought in the mind of a legal interpreter. Furthermore, the words 'refers to' conflate the distinction between a referent generating a thought in the mind of a legal speaker and a legal interpreter applying a thought to a referent.

The shortcomings of Diagram 4.1 can also be seen when legal language is viewed in terms of categorisation. Legal interpretation can be understood as assigning a matter to a category and legal speaking can be understood as establishing a category to which items need to be assigned by interpretation. Diagram 4.1 does not distinguish between these two acts. Moreover, Diagram 4.1 does not distinguish between the legal speaker's referent and the legal interpreter's referent. That is, it does not distinguish between the item or items that prompted the creation of a legal category, and the item which is assigned to this category by interpretation. ${ }^{262}$ This diagram is therefore only of limited usefulness. To see the way language functions in the law in more depth it is necessary to separate the processes of legal speaking and legal interpretation, that is, the processes of the creation of legal categories and the assignment of matters to such categories.

\footnotetext{
${ }^{261}$ See the paragraph accompanying $\mathrm{n} 499$ and the following two paragraphs.

262 In some cases these items may be the same, but, especially in statutory interpretation, they may be different.
} 
Chapter Three discussed speaking, which was defined to include writing. This chapter (Chapter Four) will use the phrase 'legal speaking' to designate a corresponding process in the law. The phrase 'legal speaking, ${ }^{263}$ is used to refer to the entire process by which the language being judicially interpreted comes into being and is given meaning by legal speakers. The word 'drafting' is too narrow to describe this process because 'drafting' only applies to one stage in this process. ${ }^{264}$

Legal speaking is depicted in Diagram 4.2, below, which is based on Diagram 3.2 (Speaking).

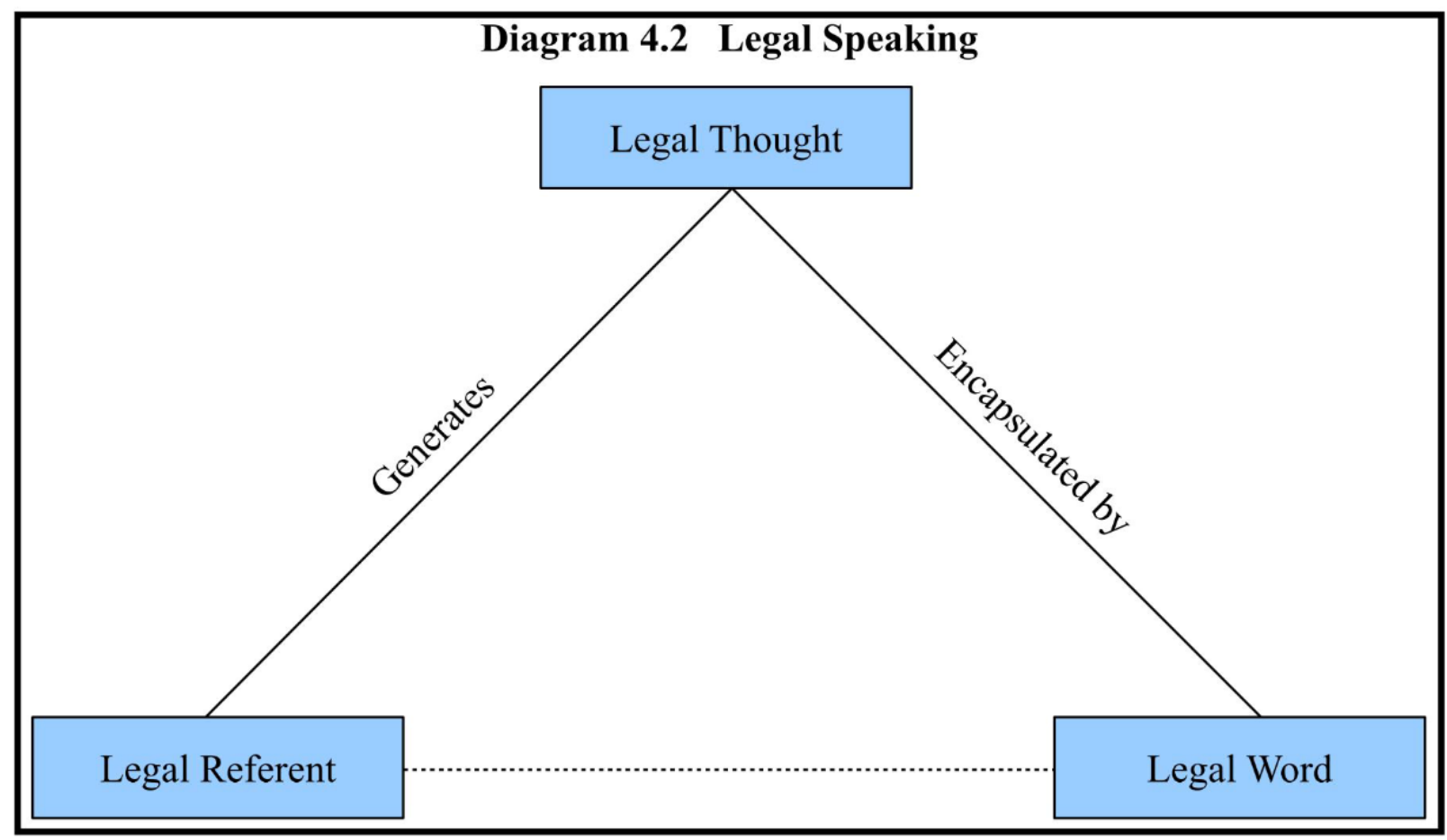

Diagram 4.2 depicts the process of legal speaking. This process involves the creation of the words of a document that is subject to judicial interpretation and the assignment of a meaning to these words by legal speakers. On the left-hand side is the legal referent. The referent generates the thought in the mind of the legal speaker, which thought is then encapsulated by the legal word. As will be seen, however, there are difficulties with merely viewing legal speaking as the encapsulation

${ }^{263}$ For simplicity, the term 'speaking' will sometimes be used in this chapter to refer to legal speaking when the context makes it clear that this does not refer to ordinary speaking. Similarly, the term 'speaker' will sometimes be used to refer to the legal speaker.

${ }^{264}$ For instance, a previous judicial decision regarding the meaning of a certain provision in a statute may be relevant when that provision is being interpreted. As will be seen, in relation to this act of interpretation, this previous decision can be considered as part of the act of 'legal speaking', but it would be misleading to refer to it as 'drafting'. 
of a thought regarding a referent in language. Difficulties occur with the notions of the 'legal speaker', the 'legal referent' and the 'legal thought'. These difficulties have been briefly mentioned previously in this chapter, but it is useful to consider them here in more detail.

This section will begin by discussing the elements in this diagram. It will discuss the legal speaker and the act of legal speaking, the legal speaker's referent, the legal speaker's thought, and the legal speaker's word. It will show how these elements differ from corresponding elements related to speaking in ordinary language and how it is useful to view legal speaking in relation to categorisation. It will then use an example of legal speaking to illustrate these points. It will conclude by eliciting some considerations that legal interpreters need to bear in mind in relation to the act of legal speaking.

First, the legal speaker is not the same as a speaker ordinarily. There are some situations in which it is easy to identify a legal speaker. For instance, when interpreting a will, it is useful to view the testator as the legal speaker. ${ }^{265}$ In other situations, however, there may not be a specific person who can be considered to be the legal speaker. For instance, in relation to statutes, it is difficult to posit a single speaker to whom the speaking can be attributed. Furthermore, when interpreting a specific provision, judges have to bear in mind previous interpretive decisions related to that provision. These previous interpretations affect the meaning of the provision and therefore can be considered as part of the act of legal speaking in relation to subsequent interpretations. Thus, the legal speaker is not limited to the legislators or the drafters of the statute, but may include judges. Therefore, factors relevant to legal speaking can include both considerations relating to the initial creation of a document and relating to subsequent interpretations of that document. For this reason, it is helpful to view legal speaking as the process by which legal categories are created. When viewed in this light, it can be seen that 'legal speaking' is not limited to a single act of speaking, but includes all that is relevant to the creation of legal categories designated by certain words.

When analysing specific instances of interpretation, it may be misleading to use the term 'legal speaker' if such a speaker cannot be easily identified. It is still useful, however, to refer to a 'legal speaker' and to the act of 'legal speaking' when analysing this process in the abstract. Therefore, this chapter will use the term 'legal speaking' to designate the process of the creation of legal categories and will use the term 'legal speaker' to refer to the person or persons responsible for this

${ }^{265}$ The fact that wills are usually drafted by lawyers does not change this because wills express a testator's intentions and it is the testator who signs the will. 
creation.

In some situations, legal speaking does involve a specific person encapsulating a thought in language. When such language is being interpreted, it is still helpful to view this act of interpretation as categorisation, because viewing it merely as the discovery of meaning can cause certain important legal considerations to be either overlooked or misapplied when they are introduced. $^{266}$

Second, the legal speaker's referent is not the same as a speaker's referent ordinarily. In Chapter Three, a speaker's referent was the thing to which the speaker's thought referred. In that chapter, it was not necessary to posit referents for certain words. The legal speaker's referent can be defined as the items which legal speakers have included in the legal category by the process of legal speaking. This referent can include objects, categories of objects, actions, and factual situations. Therefore, in every situation where a legal speaker uses a certain word to designate a certain item, it is useful to posit a legal speaker's referent for that word.

A legal speaker, however, may create a legal category without having any specific items in view. In such a situation, it is not useful to posit a legal speaker's referent. For instance, a statutory provision may be drafted without a specific situation in view, or there may be a general clause in a contract or a will that has been included without the drafters considering any specific item or situation that should fall within it.

In many situations, however, the act of legal speaking does result in items being included within the legal category by legal speakers. The most obvious items would be the items that prompted the creation of the legal category. For instance, if a contract relates to the sale of a specific building, the language describing this building in the contract can be viewed as the name of a legal category and the building itself can be viewed as the item the legal speaker ${ }^{267}$ has assigned to this category. Moreover, when a word in a statutory provision is judicially interpreted, the judge may include a specific item in the legal category designated by this word. This means that subsequent interpreters may need to bear such an item in mind, and, in relation to these subsequent interpreters, this item can be considered to be part of the legal speaker's referent in relation to this word. For this reason,

\footnotetext{
${ }^{266}$ See the paragraph accompanying n 499.

267 Although there are two parties in relation to a contract, for simplicity it is still useful to use the singular term 'speaker'.
} 
an act of judicial interpretation in relation to a certain word may be viewed as part of the act of 'legal speaking' for a subsequent interpreter of that word.

Thus, the legal speaker's referent comprises any items that have been included within the legal category at the time the word describing the category is interpreted, some of which have been officially included in the category by judges and others which were included within the category when it was created but have not been judicially recognised. It is useful to group all these items together under the term 'legal speaker's referent', because they are all items that an interpreter may need to take into account in deciding whether to assign a new item to this category. The point being made here is not that all these items have the same legal status, but that they are all relevant when considering the act of legal speaking generally. This shows that there is a significant difference between the legal speaker's referent and the referent in ordinary speaking.

Third, the legal speaker's thought is not the same as a speaker's thought ordinarily. It has been pointed out that there may be no single person to whom this thought can be attributed. This is even clearer once it is seen that the act of legal speaking includes not merely the original speaker or speakers, but may also include subsequent interpreters.

The legal speaker's thought is of the referent, that is, it is of the item or items which have been put within the legal category designated by the word. In this sense, these items generate the thought. Speakers, however, assign items to categories for specific reasons. The speaker's thought is of certain items which have been included in a legal category, but this thought relates to the reason the items have been included in the category. Put another way, the thought relates to the reason certain items have been given a legal status with an attendant legal consequence. The legal speaker's thought, therefore, is different from a thought regarding a referent in ordinary speaking because it includes various legal considerations. This legal thought can be considered the legal speaker's meaning.

Importantly, even if it is not possible to ascribe any thoughts to any specific legal speaker, it is still usually possible to discern reasons for the creation of a legal category. Such reasons do not necessarily need to be viewed in relation to thoughts, but can be viewed simply as the reasons items are included in a legal category. Even in situations where there is no actual thought that can be attributed to a speaker regarding a certain matter that is before the court, these legal reasons are still relevant to an interpretive decision. 
Fourth, the legal word on the right-hand side of Diagram 4.2 is a word in a legal document that is subject to judicial interpretation. It can be viewed as the word (or words) that has been chosen to designate a certain legal category. This word is usually chosen based on existing language conventions. Alternatively, the word may have been explicitly defined in the legal document, and new conventions may have been established. The speaker's use of the legal word results in the creation of a legal category and the meaning this word has been used to express indicates the speaker's intention regarding the items that should be included within this category.

Therefore, it is useful to view Diagram 4.2 explicitly in relation to categorisation. On this view, the legal word is the name of the legal category. The legal referent includes any items that have been assigned to this category by the process of legal speaking. The legal thought is a thought that comprises all the considerations relevant to the inclusion of these items in this category. Thus, legal speaking can be viewed as the creation of legal categories. When a legal category is created by legal speaking, this often also involves as the assignment of certain items this legal category. This assignment, however, should be distinguished from the assignment of items to legal categories by judicial interpretation, because if the legal speaker's assignment of a certain item is in dispute, there needs to be an act of judicial interpretation to authoritatively decide whether this item should be assigned to this legal category.

Diagram 4.2, therefore, could have been drawn explicitly in relation to legal categorisation with an item generating a thought which is encapsulated in the legal category to which the item is assigned. This, however, would make it difficult to compare legal speaking with ordinary speaking. Moreover, in this chapter it will still be useful in some instances to refer to the 'legal referent' in addition to items, and it will usually be necessary to refer to 'legal words' in addition to legal categories. Therefore, the diagrams in the remainder of this chapter will depict legal words, legal thoughts, and legal referents, but the discussion in this chapter will be in relation to categorisation.

An example of statutory drafting should make the nature of legal speaking clearer. Section 3(1) of the Road Traffic Act 1930 (UK) made it an offence to use trailers, defined in the Act as 'vehicles', ${ }^{268}$ on a road without pneumatic tyres. If this provision was being interpreted, and the judge focused on the word 'vehicle', this word can be considered the legal word designating a legal

${ }^{268}$ Road Traffic Act 1930 (UK), s 1. 
category. Initially, the items in this category would seem to include the items commonly described by the word 'vehicle'. These items would comprise the speaker's referent and the legal speaker's thought would be a thought regarding these items.

This legal speaker's thought, however, is not merely a thought regarding certain items, but is also a thought regarding the legal status that these items should be given. Therefore, in relation to the word 'vehicle' in this Act, this thought includes the reason for the law, which in this instance is probably the protection of the surface of roads. ${ }^{269}$ There may be items which could damage the surface of roads, but which would not normally be considered to be vehicles. Therefore, there may be items which should be within this legal category, even though they are not necessarily the items that are conjured up by the conventional meaning of the word 'vehicle'. The interpretation section of this chapter will discuss a judicial decision interpreting this provision to show what sorts of considerations should be taken into account in the interpretation of this word 'vehicle'. 270

This example shows that various considerations are relevant to the legal speaker's thought. These can be viewed as considerations relevant to the act of legal speaking, that is, to the establishment of a legal category. There is the reason for the category, for instance, the protection of roads. There are the items that are to be included in the category, for instance, items that damages roads. Then there is the word that has been used to encapsulate the category, for instance, the word 'vehicle'.

To aid interpretation, speakers need not only to use language to describe the items in the legal category based on linguistic conventions, but also need to make the reason for the existence of the legal category clear. This can be done in a variety of ways: by providing definition sections in a legal document, by giving examples of items that certain provisions in the document are designed to capture, or by explicitly stating the reason for a provision in a document. ${ }^{271}$

Chapter Three, of this thesis, discussed ordinary speaking and concluded that it involved the use of language conventions to encapsulate thoughts in language. This section has discussed a corresponding process in the law, which can be called 'legal speaking'. It is helpful to view 'legal

269 This was noted by Lord Goddard CJ in Garner v Burr [1951] 1 KB 31 at 33. This case will be discussed in Chapter Four B.3.

270 See the paragraph accompanying n 299.

271 The techniques that can be used to make legal documents clear are emphasised by the plain legal language proponents. See for instance, Richard Wydick Plain English for Lawyers (Carolina Academic Press, Durham, 1998), Michele Asprey Plain Language for Lawyers (The Federation Press, Sydney, 2003), Mark Adler Clarity for Lawyers (2nd ed, The Law Society, London, 2006), and Peter Butt and Richard Castle Modern Legal Drafting: A Guide to Using Clearer Language (Cambridge University Press, Cambridge, 2001). 
speaking' as everything that is involved in the creation of a legal category, rather than merely an act in which a person encapsulates a thought in language. It is possible to elicit four general groups of considerations relevant to this act of legal speaking. These considerations comprise the legal speaker's thought.

First, the word that has been used to describe the legal category is important. This word may have been chosen based its conventional meaning or may have been explicitly defined. This meaning can help clarify which items should be in the category. Second, there is the reason that the legal category has been created. This is the reason the legal consequence should apply to items in this category. Third, one or more items may have been assigned to the legal category by the act of speaking. These can include items assigned to the category by the initial creation of the category and also items assigned to the category by judges in subsequent interpretations of the word designating the category. These items show what the category is designed to capture. Fourth, there may be general legal considerations related to the category that has been set up. ${ }^{272}$

Thus, there are four groups of considerations that are relevant to the act of legal speaking: linguistic considerations, considerations related to the category itself, considerations related to items in the category, and general legal considerations. As will be seen later in this chapter, interpreters need to bear these considerations in mind when engaged in interpretation. ${ }^{273}$ Furthermore, in specific instances of interpretation, even though it may be difficult to identify a legal speaker to whom a thought can be attributed, these four groups of considerations are still relevant.

\section{(a) Legal ineffability}

Before a legal category has been created there is a thing that needs to be categorised (the item) and a legal thought regarding it, but no legal word. This is depicted by Diagram 4.3, below, which is based on Diagram 3.3 (Ineffability).

\footnotetext{
${ }^{272}$ For example, policy considerations that do not relate to the specific purpose of this legal category, but to legal, economic or social principles that are relevant to this category.

273 Therefore, even though this section has focused on legal speaking, the goal of this section is mainly to highlight matters that interpreters need to bear in mind in relation to the act of legal speaking.
} 


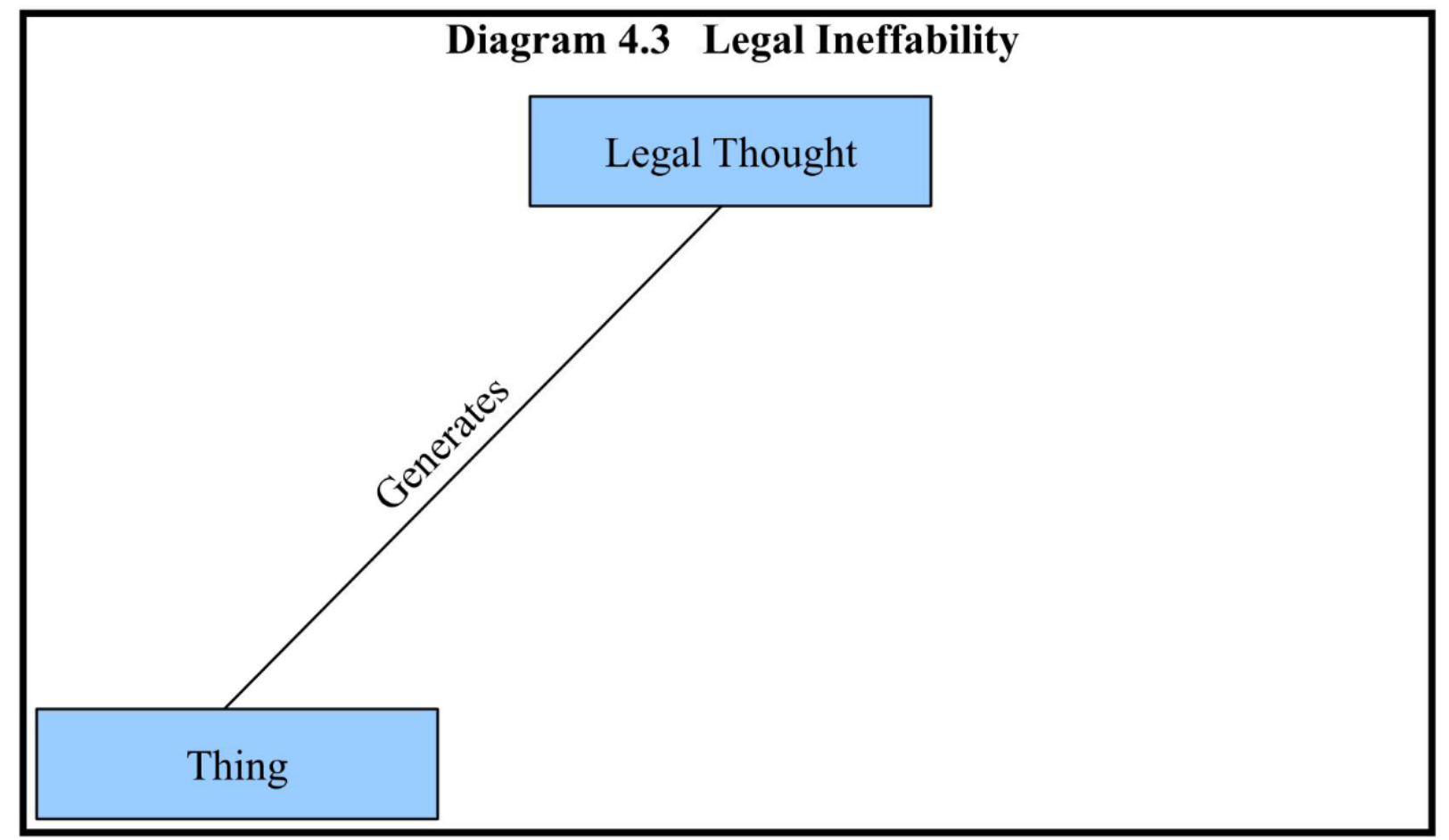

Just as Diagram 3.3 (Ineffability) did not refer to things intrinsically incapable of being expressed in language, Diagram 4.3 does not refer to things intrinsically incapable of being legally categorised. Legal ineffability refers to a situation in which a legal speaker does not know which words to use to correctly encapsulate a legal thought. Put another way, the legal speaker does not know the specific language necessary to create a legal category with a certain consequence. Therefore, the thought regarding this category can be considered legally ineffable for this speaker.

Legal ineffability may occur because a speaker is not aware of certain conventions that apply in the law. In most situations, legal speakers are free to use any words they want to express their intentions. To make these intentions clear, however, it is better if they follow existing legal conventions.

As with ineffability ordinarily, if legal speakers are aware that they do not know the correct legal conventions, they will probably not attempt to create legal categories. Difficulties can occur when speakers are not aware of the existing legal conventions, but still attempt to draft legal documents. Such a situation can be considered to be the result of legal ineffability, rather than an instance of legal ineffability, because the speaker's thought has been expressed. In such a situation, however, the courts may not give effect to the legal speaker's intentions. 
In the past, in certain jurisdictions the common law has sometimes required specific words be used to achieve a certain legal result. ${ }^{274}$ Legal speakers who were not aware of these requirements may have been unable to create the legal categories necessary to achieve this kind of result. These kinds of requirements, however, are less common today.

In some instances, however, there may be rules of interpretation which mean that a speaker should not use certain language. For instance, a legal speaker may intend to create a trust. If this speaker uses precatory language - that is, language expressing a wish or desire rather than a definite command - the court may conclude that no trust was created. Alyssa A DiRusso noted: ${ }^{275}$

A person's language is often judged to show lack of intent - meaning that no trust is created - when he or she uses 'precatory' language: words of preference or guidance rather than explicit direction.

If speakers are not aware of this approach to interpretation, they may express their intention in polite language, rather than as an explicit direction. In such a situation, it could be that a court does not recognise that these words create a trust.

When precatory language is used, the courts sometimes recognise a 'precatory trust', which is a "trust created by certain words, which are more like words of entreaty and permission than of command or certainty." ${ }^{276}$ In the American Court of Appeals case Sanger v Sanger ${ }^{277}$ the issue was whether a will created a precatory trust. ${ }^{278}$ The testator, Barbara Sanger, included the following provision in her will: ${ }^{279}$

In the event I own a home as of the date of my death, it is my wish that if any child of mine wishes to reside in such home he or she shall be allowed to by my other children ....

The testator's son claimed that this provision created a precatory trust. The Court held that their

\footnotetext{
${ }^{274}$ For instance, David M Becker noted: “To ' $B$ and her heirs' is an acknowledged language format. At one time it was the only phrase that would accomplish the creation of a fee simple absolute. Today, although it is not the only way to create such estate, 'and heirs' remains a popular and reliable format for achieving this result." "Debunking the Sanctity of Precedent” (1998) Wash U L Q 853 at 859 (italics in original).

275 Alyssa A DiRusso "He Says, She Asks: Gender, Language, and the Law of Precatory Words in Wills” (2007) 22 Wis Women's LJ 1 at 2.

${ }^{276}$ Henry Campbell Black (Joseph R Nolan and Jacqueline M Nolan-Haley eds) Black's Law Dictionary (6th ed, West Publishing Co, St Paul (Minn), 1990) at 1176 quoted in Frank L Schiavo “Does the Use of 'Request,' 'Wish,' or 'Desire' Create a Precatory Trust or Not?” (2006) 40 Real Prop Probate \& Trust J 647 at 650.

277 Sanger v Sanger (2003) 268 Wis2d 846 (CA). This case is briefly mentioned in Schiavo, above n 276, at 663-664.

278 Sanger $v$ Sanger, ibid, at [1].

279 Ibid, at [2].
} 
primary goal was “to discern and give effect to the testator's intent.”280 The court then stated: ${ }^{281}$

The general rule is that 'precatory' words in a will, such as 'it is my wish,' are construed as recommendations to the devisee, but are not binding commands, as they would be if made to the personal representative ....

Therefore, because the words being interpreted were directed to the devisees, and not to the executor, no trust was created. The testator may have intended to create a trust, but because of the language used, the Court did not recognise a trust. Thus, the testator's intention may have been frustrated. $^{282}$

Legal ineffability occurs when legal speakers do not know the correct language to use create a legal category with a certain consequence. It describes a situation where a certain legal thought - that is, an intention that a legal consequence should apply to certain items - is ineffable for a particular speaker. A speaker, however, may still attempt to create a legal category with a certain legal consequence. If he or she does not use the right legal conventions, however, the court may not give effect to their intentions. This is similar to communication failing in ordinary language because speakers are not aware of the correct conventions. ${ }^{283}$ This is most likely to occur in situations where laymen draft legal documents, for instance, it can occur with home-made wills.

\section{Legal interpretation}

Legal interpretation is depicted in Diagram 4.4, below, which is based on Diagram 3.4 (Interpretation).

\footnotetext{
${ }^{280}$ Ibid, at [5]

281 Ibid.

282 This thesis will return to this decision and discuss whether it was fallacious in this chapter at C.5.

${ }^{283}$ For instance, the use of the word 'quittance' discussed at Chapter Three B.2.(a).
} 


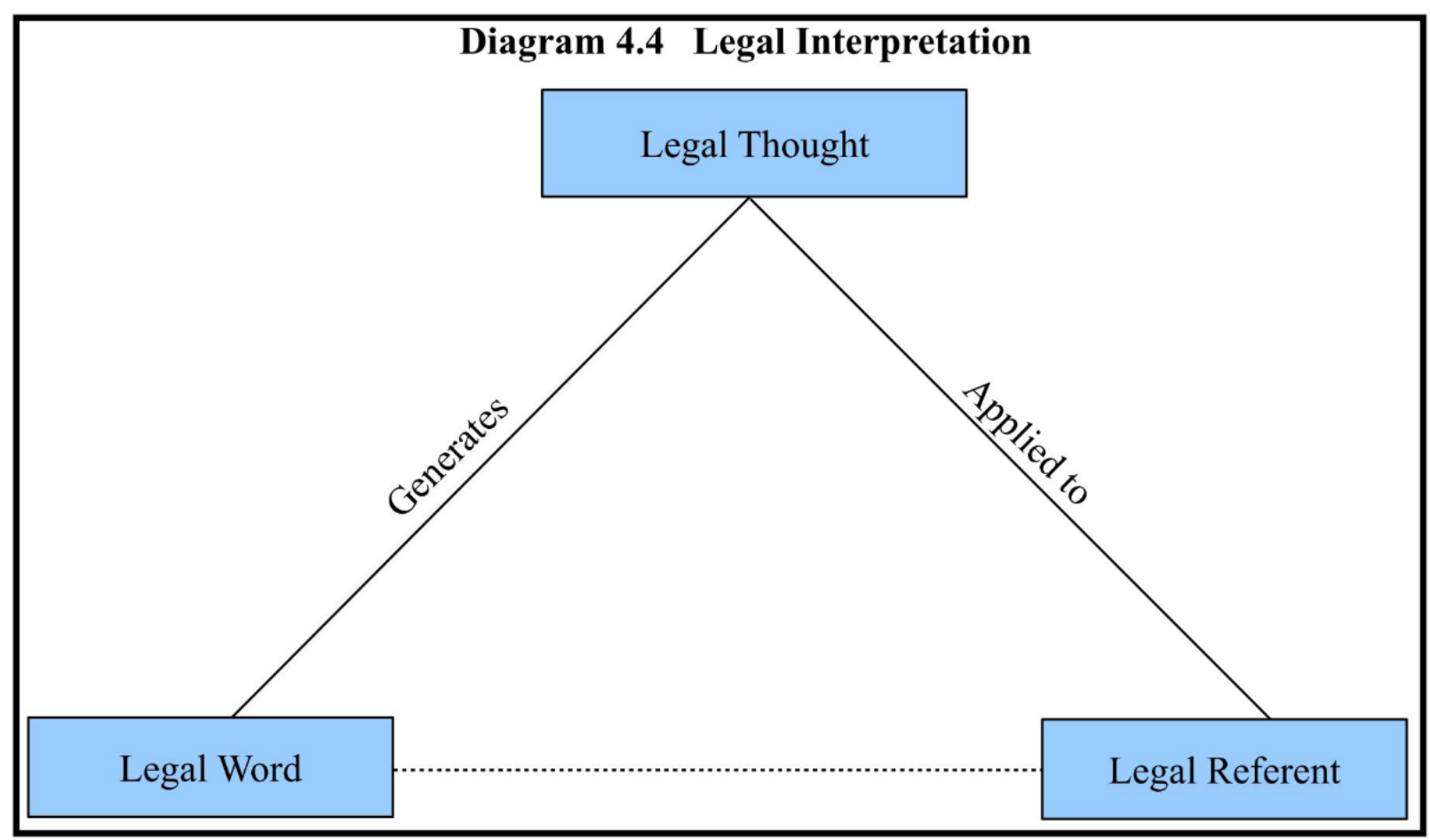

Diagram 4.4 depicts the process of legal interpretation, that is, the process of the judicial interpretation of language. Legal interpretation can be defined as the process by which judges assign a meaning to certain words. ${ }^{284}$ In relation to legal interpretation, the view has been expressed that: ${ }^{285}$

[T] he meaning of a statute must, in the first instance, be sought in the language in which the act is framed, and if that is plain ... the sole function of the courts is to enforce it according to its terms.

$\cdots$

Where the language is plain and admits of not more than one meaning, the duty of interpretation does not arise ....

On this view, there is no need of interpretation if statutory language is unambiguous. ${ }^{286}$ It is much clearer, however, to view any assignment of a meaning to a word as interpretation. In many cases this assignment of meaning is simple and almost automatic. In other cases, more is involved. It is

${ }^{284}$ Arthur Corbin defined interpretation as "the process whereby one person gives a meaning to the symbols of expression used by another person” Arthur L Corbin Corbin on Contracts (West Publishing Co, St Paul, 1960) vol 3 at 2. Corbin stated that in relation to contract interpretation, both words and conduct may require interpretation (at 3). This chapter will focus on the interpretation of words, not conduct. Earlier in this thesis a distinction was drawn between the interpretation of words and the interpretation of the law. This chapter will focus on the interpretation of words and not merely the interpretation of the law. As has been noted, this chapter is limited to interpretation that involves categorisation.

${ }^{285}$ Caminetti v United States (1917) 242 US 470 (SC) at 485.

286 Compare the quotation by Lord Steyn in $n 490$. 
not helpful, however, to distinguish between these two acts and view only one as 'interpretation', since they both involve the same basic activity.

Diagram 4.4 is similar to Diagram 4.1 (Legal Word, Legal Thought and Legal Referent), but it specifically depicts the process of legal interpretation and not just the relationship between words, thoughts and referents in the law. In Diagram 4.4, the act of interpretation begins on the left-hand side with the word being interpreted. ${ }^{287}$ This word generates a certain thought in the mind of the interpreting judge. This thought is then applied to a referent. Thus, the connection between the legal word being interpreted and the legal referent for which the word stands is indirect, and is through the legal thought.

This section will begin by discussing each of the elements depicted in this diagram and the relationship between them. It will then discuss some cases involving the judicial interpretation of language. Following this, it will elicit some considerations that judges need to bear in mind when engaged in interpretation. It will conclude by briefly comparing legal interpretation to ordinary interpretation and comparing an approach to legal interpretation focused on categorisation to an approach to legal interpretation focused on the discovery of an intention.

The 'legal word' in Diagram 4.4 is the specific language being interpreted by a judge. This thesis is limited to the interpretation of legal documents such as statutes, contracts and wills. It does not cover the interpretation of other judicial decisions. ${ }^{288}$ Therefore, the legal word is the word or words in such documents that require interpretation.

This legal word is the same as the legal word identified in the legal speaking section. Thus, the legal speaker and the legal interpreter share the word. This word may have been defined in the document being interpreted, or may have been selected on the basis of a meaning it is usually used to express. An interpreter, however, cannot merely rely on ordinary language conventions to interpret this word since other considerations may be relevant to an interpretive decision. For this reason, it is helpful if this word is viewed as the name of a legal category to which items can be assigned by judicial interpretation and not merely a word for which a linguistic meaning needs to be discovered.

\footnotetext{
${ }^{287}$ For convenience, the term 'word' is used rather than 'words'. Judicial interpretation, however, may be of a phrase or an entire sentence, and not merely a single word. The analysis and the fallacies identified in this chapter apply both to the interpretation of single words and of more than one word.

${ }^{288}$ However, previous judicial decisions regarding the meaning of a word in a legal document that is being interpreted are relevant.
} 
The legal thought at the apex of the triangle is the thought in mind of a specific person: the interpreting judge. ${ }^{289}$ Therefore, in one sense, the thought of the legal speaker is more complicated than the thought of the legal interpreter. There may, however, be more considerations relevant to the thought of the legal interpreter than the thought of the legal speaker. Viewed in relation to categorisation, the thought of the legal speaker involves such matters as the reason for the existence of the legal category and the reason certain items should be assigned to the category. The legal interpreter, however, may have to bear in mind not only the factual context at the time of the initial creation of the category, but also the factual context at the time of interpretation. ${ }^{290}$ Viewed in relation to categorisation, the interpreter may need to take into account two periods of time: the time when the category was first created and the time at which this act of categorisation is taking place. ${ }^{291}$ Put simply, the interpreter's thought includes whatever considerations are relevant to the assignment of an item to the category designated by the word being interpreted. These considerations will be given in more detail later in this section. This thought can be viewed as the legal interpreter's meaning.

Legal interpretation that involves categorisation is always in relation to a specific situation. This situation is the item that needs to be categorised. This item can be a physical object, a category of objects, an action or a situation. The item is whatever is being given a legal status by the act of interpretation. When this item is assigned to the category designated by the word being interpreted, this item is the legal interpreter's referent in relation to this word.

Diagram 4.4 states that the legal thought is applied to the legal referent. The words 'applied to' rather than 'refer to' are used in this diagram because the thought does not merely spontaneously refer to the referent, but is deliberately applied to the referent by the authoritative decision of a

289 As mentioned in $\mathrm{n} 249$, it is useful to view judicial decisions as the interpretation of an individual person even when other judges concur.

290 This is true both of statutory interpretation, where interpreters may need to posit a legislative intention concerning a matter that never occurred to the legislators and the interpretation of other legal documents such as contracts where interpreters may need to attribute a presumed intention to the parties.

291 Some theories of statutory interpretation focus on the original legislative intention and others focus more on the purpose behind the statute and applying this purpose in light of the situation at issue. That is, some focus more on the time of the creation of the category and others focus more on the time an interpretive decision is being made. The point being made here is that both periods of time are potentially relevant for interpreters. Maimon Schwarzschild notes: "Several broad theoretical approaches to interpretation are on offer. They include textualism (or 'plain meaning' ...); original intent; history and precedent; adapting to (what are believed to be) present-day popular expectations and needs; and 'philosophy', in the sense of doing what is right in accordance with the best ethical thought." "Mad Dogmas and Englishmen: How Other People Interpret and Why" in J Goldsworthy and T Campbell (eds) Legal Interpretation in Democratic States (Ashgate Publishing Company, Aldershot, 2002$) 93$ at 93. 
judge. The application of this thought to the referent is the application of the law to this referent and is the inclusion of this referent within the legal category designated by the word being interpreted.

Judicial interpretation either results in the inclusion of the item at issue within the legal category designated by the word being interpreted or the exclusion of this item from this category. If interpretation results in the inclusion of the item in the category, that item is the referent in Diagram 4.4. If, however, judicial interpretation does not result in the inclusion of an item in the category, the judge may still identify the kind of item that should be included in the category. In this situation, the item identified by the judge is the legal interpreter's referent. Thus, the interpreter's referent is whatever item the judge identifies as fitting within the category.

A judge may have to make an interpretive decision regarding whether a specific item fits within the legal category designated by a certain word. The judge may exclude this item from the category, and may not indicate what kind of item should be included within the category. In such a case, there is no interpreter's referent. However, there is still an item and there still has been a legal decision regarding the status of that item. This shows that the primary focus of instances of legal interpretation which involve categorisation should not be on giving a meaning to the word being interpreted, but should be on categorising the item under consideration. This difference in focus will be discussed again at the end of this section.

Diagram 4.4 can be viewed in relation to the assignment of items to legal categories. The legal word on the left-hand side is the name of a legal category, the legal thought at the apex of the triangle is a judge's thought which comprises all the considerations relevant to the assignment of items to this category, and the legal referent on the right-hand side is an item that has been assigned to the category by an act of interpretation.

It will be helpful to give some examples to illustrate the process of judicial interpretation. As mentioned in the previous section, under the Road Traffic Act 1930 (UK) it was an offence to use trailers on a road without pneumatic tyres. ${ }^{292}$ In March 1950, Lawrence Burr was charged with this offence while towing an empty poultry shed fitted with iron wheels along a road behind a tractor. At first instance, he was found not guilty. The word 'trailer' was defined as a 'vehicle' in the Act, so the Court focused on the word 'vehicle'. ${ }^{293}$ The Court decided that the poultry shed was not a

\footnotetext{
${ }^{292}$ Road Traffic Act 1930 (UK), s 3(1).

293 Ibid, s 1.
} 
'vehicle' within the Act, "because it was not an instrument or thing by which persons or goods were conveyed". 294

On appeal, Burr was convicted of the offence. Lord Goddard CJ stated that: ${ }^{295}$

[A]ccording to the dictionary definition, a 'vehicle' is primarily to be regarded as a means of conveyance provided with wheels ... and used for the carriage of persons or goods ... but I think that the Act is clearly aimed at anything which will run on wheels which is being drawn by a tractor ....

His Lordship noted that one of the reasons for the regulations ${ }^{296}$ was "the protection of road surfaces; and, as this vehicle had ordinary iron tyres, not pneumatic tyres, it was liable to damage the roads. ${ }^{297}$ In a concurring judgment, Hilbery J stated: ${ }^{298}$

\begin{abstract}
Having regard to the purpose of the Act ... I am satisfied that we ought to give a generous construction to the material words ... I am satisfied that, for the purpose of the Act, this poultry house on wheels being drawn along the highway was a vehicle.
\end{abstract}

This case illustrates that judicial interpretation does not merely involve ascertaining the linguistic meaning of words, but is also governed by legal considerations, in this instance, the purpose of the Act which was the protection of roads.

In Garner v Burr, the word 'vehicle' needed to be interpreted so as to include certain items that should come within the legal category designated by this word and to exclude items that should not. The decision of the lower Court appears to have been made based on the common meanings of the words 'vehicle' and 'trailer'. On appeal, this decision was reversed because of a legal reason: the purpose of the Act. The judges had to decide whether the item (the poultry shed) fitted within the legal category designated by the word 'vehicle'. The considerations relevant to this decision were not merely linguistic considerations concerning the conventional meaning of this word, but also included the legal consideration of the purpose of the Act.

This analysis of Garner $v$ Burr may lead to the conclusion that legal interpretation is fundamentally

${ }^{294}$ Garner v Burr, above n 269, at 32.

295 Ibid, at 33.

296 There is a reference to 'regulations' here because under the Act it was an offence to use a vehicle which did not comply with the applicable regulations.

297 Garner v Burr, above n 269, at 33.

298 Ibid, at 34. 
different from ordinary interpretation. This conclusion would be based on the assumption that the word would have been interpreted differently in ordinary language. It was the context of the Act, however, specifically the purpose of the Act, which determined the meaning of the word 'vehicle' in this decision. This is similar to the way in which context determines meaning ordinarily. Ordinarily, interpreters also take into account the purpose of speaking. As will be seen, however, it can sometimes be easy to make commit fallacies legal interpretation if legal interpretation is viewed as merely ascertaining the meaning of words based on context. It can be much clearer if it is viewed as categorisation based on certain relevant considerations.

The purpose behind the language being interpreted is an important legal consideration since it is the reason the legal category designated by that language was established. This thesis, however, does not merely advocate a purposive approach to legal interpretation. There are relevant legal considerations that do not relate to the purpose of the Act. For instance, if the poultry shed was being used to convey a critically injured person to a hospital to receive urgent medical care, it may be that the courts would decide that it was not a vehicle. ${ }^{299}$ In this case, an overriding consideration would be the need to provide urgent medical care and this general consideration may be held to be more important than the specific purpose behind the statute. ${ }^{300}$ Because judges are limited to interpreting statutory provisions and cannot draft exceptions to these provisions, the term 'vehicle' would need to be interpreted so as to include items which should be put within this legal category and to exclude items which should not be put within this category.

Garner v Burr also highlights the fact that interpreters need to bear in mind not only the original context of the legal speaking, but the factual situation before the court. In ordinary interpretation, the meaning of a word is governed by the thought of the speaker. In the law, meaning is not merely governed by the speaker's thought, but is also determined by the decision that needs to be made in relation to the situation before the court. The task of legal interpreters is to implement the law in changing contexts and not merely to discover a speaker's meaning.

Moreover, legal interpretation does not merely involve identifying specific items to which speakers have referred, but may involve determining whether a new item should fit within an existing

\footnotetext{
${ }^{299}$ In such a situation, it may be that either the police would not press charges or that the court would acknowledge that it was a vehicle but would not enter a conviction. To establish this exception as precedent, however, the court may decide that the poultry shed was not a vehicle for the purposes of this Act.

${ }^{300}$ It could be said that in this situation the judge is not interpreting, but simply making a decision. The judge, however, would usually frame this decision in terms of the interpretation of the word 'vehicle'.
} 
category of items. In Garner v Burr, the word ‘vehicle’ designated a legal category, but the task of the interpreter was not merely to determine which items had prompted the creation of this category, but to decide whether the item at issue (the poultry shed) should be assigned to this category. To do this, judges needed to determine whether the item at issue was analogous to the existing items in the legal category. As will be seen, however, even if a judge needs to ascertain the specific item referred to by a legal speaker, it is still useful to view this act of interpretation as categorisation. ${ }^{301}$

Although judicial interpretation does not merely involve ascertaining linguistic meaning, the law needs to be intelligible to the public. Therefore, judges should not merely assign items to legal categories based on legal considerations while ignoring the linguistic meaning of the word being interpreted. This was pointed out clearly in the American case McBoyle v United States ${ }^{302}$ where the issue was whether an aeroplane was a motor vehicle for the purpose of an Act dealing with the theft of motor vehicles. In his decision Justice Holmes stated: ${ }^{303}$

\begin{abstract}
Although it is not likely that a criminal will carefully consider the text of the law before he murders or steals, it is reasonable that a fair warning should be given to the world in language that the common world will understand, of what the law intends to do if a certain line is passed. ... When a rule of conduct is laid down in words that evoke in the common mind only the picture of vehicles moving on land, the statute should not be extended to aircraft, simply because it may seem to us that a similar policy applies, or upon the speculation that, if the legislature had thought of it, very likely broader words would have been used.
\end{abstract}

Thus, on Justice Holmes' view, the judiciary should not overly extend the meaning of words, and thus the scope of legal categories, merely on the basis of legal policy or a supposition as to the legislature's intentions. To do so would be unfair to the public who are regulated by the words of statutes. The test Justice Holmes proposes to ascertain whether an extension of meaning is unwarranted is the sort of pictures a word evokes in the mind of the ordinary reader.

Justice Holmes' approach introduces another important consideration. The fact that public are regulated by statutes is a relevant consideration and a reason why words should be given a meaning with which the public are familiar. Therefore, Justice Holmes claimed that this meaning should not be extended to cover a new situation merely because a similar policy seems to apply.

\footnotetext{
301 See the paragraph accompanying n 499.

${ }^{302}$ McBoyle v United States [1931] 283 US 25 (SC).

${ }^{303}$ Ibid, at 27.
} 
It is useful to view Justices Holmes' statement in the light of another case decided by Lord Goddard CJ, Corkery v Carpenter. ${ }^{304}$ In this case, the defendant was riding a bicycle while drunk. The Court found the defendant guilty of being drunk while in charge of a carriage under section 12 of the Licensing Act 1872 (UK) by deciding that this bicycle was a carriage within the words of this section. Lord Goddard CJ stated: ${ }^{305}$

In this case the object of the Act is clear: it is the protection of the public and the preservation of public order; and for this purpose, I think, a carriage can include any sort of vehicle, certainly a vehicle which is capable of carrying a person ....

His Lordship concluded: "I am clearly of the opinion that the words of the Licensing Act are wide enough to embrace a bicycle under the expression 'carriage'.”306

It is unlikely that the word 'carriage' could evoke a bicycle in anyone's mind ${ }^{307}$ or that the word 'vehicle' could evoke a wheeled poultry shed in anyone's mind. Therefore, the test set out by Justice Holmes cannot be applied too strictly. Although it is true that legislation should ideally be intelligible to the public whom it regulates, this has not stopped the judiciary interpreting language counter-intuitively. If Justice Holmes' test of intelligibility were strictly followed on every occasion, it would place a great restriction on the application of the law. Therefore, the common meaning of a word, or the thought a word would evoke in someone's mind, is only one consideration relevant to an interpretive decision, and needs to be weighed up against other relevant considerations.

The cases discussed in this section illustrate the basic procedure involved in judicial interpretation. When engaged in interpretation which involves categorisation, judges need to determine whether a certain item should be assigned to the legal category designated by the words being interpreted. These words have often been chosen based on their ordinary meaning and, in the case of statutes, this document regulates the public. Therefore, there are important reasons why judges should give these words a meaning that they would ordinarily have. In some situations, however, judges need to include an item within this legal category which would not normally be described by these words. The practical result of including this new item within this category is that the legal meaning of the

${ }^{304}$ Corkery v Carpenter [1951] 1 KB 102.

305 Ibid, at 105.

306 Ibid, at 107.

${ }^{307}$ Indeed, as the lawyer for the defendant pointed out, a bicycle is explicitly contrasted with a carriage in the popular song Daisy Bell: ‘It won’t be a stylish marriage, I can’t afford a carriage, But you'll look sweet upon the seat Of a bicycle made for two.” Ibid, at 103 (capitalisation in original). 
words being interpreted is altered. ${ }^{308}$

This section has only given examples of statutory interpretation. This analysis can also apply to the interpretation of other documents. This will be shown by the fallacy analysis later in this chapter. ${ }^{309}$ Moreover, the analysis in this section can even apply to judicial decisions which do not involve the interpretation of language at all. This can be seen by a consideration of a very famous case, the House of Lord's decision of Donoghue v Stevenson. ${ }^{310}$

The specific details of this decision are not relevant for the purposes of this discussion, but it can be viewed as deciding the scope of the tort of negligence. Viewed in this way, the issue was whether the factual situation of a snail being found in a bottle of ginger-beer fitted within the legal category of situations where a manufacturer is liable for damages for negligence. Thus, the Court had to determine the legal status of this item (the action of allowing the snail into the bottle) by deciding whether it fitted within this legal category. Such a decision has significant ramifications because a decision to include this item within this legal category means that analogous items should also be within this category. To decide whether the item should fit within this category, various relevant legal considerations needed to be taken into account. These were considerations related to the tort of negligence. Such a decision, therefore, also involves categorisation, even though it does not involve the interpretation of language. ${ }^{311}$

This section has shown that legal interpretation can be viewed as categorisation based on a variety of relevant considerations. In the legal speaking section, four groups of considerations relevant to an act of legal speaking were identified: linguistic considerations, considerations related to the legal category, considerations related to items, and general legal considerations. When the word created by this act of legal speaking is being interpreted, interpreters may need to take into account these four groups of considerations.

Legal interpretation, however, is not merely governed by these considerations related to legal

308 Thus, the word obtains a specific 'legal meaning' in addition to its ordinary meaning. This is an important argument against simplistic attempts to clarify legal language. No matter how clear the language appears when originally drafted, once it has been legally interpreted, it may get a legal meaning and this apparent clarity may become misleading.

309 At Chapter Four C.4.

310 Donoghue v Stevenson [1932] AC 562 (HL).

311 This sort of categorisation will not be discussed in this chapter. The point being made here is that the analysis in this section does not only apply to situations when the judiciary explicitly interprets language, but can apply more broadly to judicial decision-making generally. 
speaking. It is useful here to elicit the kinds of considerations that can be relevant to legal interpretation which involves categorisation. These considerations can also be put in four groups: considerations related to the word being interpreted, considerations related to the legal category that is designated by this word, considerations related to items relevant to this act of categorisation, and general legal considerations. These are considerations that can be included within the legal interpreter's thought at the apex of the triangle in Diagram 4.4.

First, there are considerations related to the word being interpreted. The interpreter needs to pay attention to the correct linguistic conventions associated with the word. These include both ordinary language conventions and legal conventions. The legal conventions are seen both in specific definitions and in conventions existing in the law generally. There is also the verbal context. This is inseparable from the consideration of the linguistic conventions because it is the verbal context which shows which conventions apply. The verbal context in relation to a certain word or phrase includes the sentence it is in, the paragraph it is in, the entire text it is in and other related texts. Furthermore, there is the factual background. This also shows the relevant linguistic conventions. All these points can be summarised by saying that legal interpreters need to pay attention to the correct linguistic meaning of the word or words being interpreted. This linguistic meaning is a relevant consideration because it shows the speaker's intention in relation to the legal category designated by that word. Also, in relation to statutory interpretation, if possible words should be given the meanings that the public would expect them to have since the public are regulated by statutes. Viewed in relation to categorisation, the considerations related to the word being interpreted show the reason for the legal category and the items which the public would expect to be included within the category.

Second, there are considerations related to the legal category that the word designates. These include the reason ${ }^{312}$ for or the purpose of legal category. ${ }^{313}$ In many cases, the same reasons that prompted the creation of a category should govern the assignment of matters to that category. These

${ }^{312}$ In relation to statutory interpretation, there are arguments against the courts consulting Hansard. These arguments, however, are based on the fact that Hansard is not a relevant consideration. These were discussed by Lord Steyn extra-judicially in Johan Steyn "Interpretation: Legal Texts and their Landscape” in Basil S Markesinis (ed) The Coming Together of the Common Law and the Civil Law (Hart Publishing, Oxford, 2000) 79 at 87-88. Steyn quotes Lord Renton who noted that in piloting a Bill “one often [has] to change one's mind on particular clauses, or even on a principle, in order to get the Bill passed. So Hansard inevitably contains contradictions or ambiguous statements by those responsible." (at 87). Steyn also quotes Lord Hoffmann who stated that "trying to find guidance in a minister's attempt to made sense of his or her departmental brief at short notice while standing at the despatch box is usually a hopeless quest.” (at 87).

313 Such considerations include the purpose behind the relevant area of law. For instance, when interpreting a contract, the purpose in relation to the legal category at issue may include purposes relevant to contract law generally. 
reasons need to be viewed in relation to the specific act of categorisation at issue. Another important consideration is the consequence of assigning an item to the category or excluding an item from the category. Also, there may need to be a consideration of other legal categories, and how they relate to this legal category. ${ }^{314}$

Third, there are considerations related to items relevant to this act of categorisation. These include items that prompted the creation of the category, items already in the category, ${ }^{315}$ and items that have been excluded from the category. These items help to show what the category is designed to capture. Subsequent items are often included in this category by analogy with the items already in the category or items that prompted the creation of the category. If the item at issue is significantly different from the item that prompted the creation of the category, there needs to be a determination whether this difference is legally significant. ${ }^{316}$ If the legal speaker did not contemplate whether the item at issue should be included within the legal category, the court needs to make this decision on the basis of the general purpose of the category and whether the inclusion of the item within the category would be consistent with this purpose. It is also important for judges to bear in mind how items that are analogous to the item at issue have been dealt with in the law.

Fourth, there are more general legal considerations. These include any relevant rules of interpretation, for instance, rules relating to how to resolve ambiguities. Furthermore, general policy considerations are relevant. ${ }^{317}$ Lastly, there are considerations related to the law generally. ${ }^{318}$ These rules, policy considerations, and general legal considerations need to be applied with reference to the act of categorisation at issue.

There also are various limits on interpretation, including limits on judicial discretion and

${ }^{314}$ For instance, when considering whether to assign a certain item to a legal category, the fact that this item is already captured by a different legal category may be a relevant consideration.

315 These items may have different legal statuses. They include items that speakers have assigned to the category that have not been judicially recognised, items that judges have officially assigned to the category, and even items that judges have said would hypothetically be in the category in obiter dicta statements.

${ }^{316}$ It may also be possible in ordinary interpretation for the item the interpreter assigns to a category to be different from the item that prompted the speaker's creation of the category. This was not mentioned in Chapter Three, however, because it is not common in ordinary interpretation. If a speaker said, 'Please get me some vegetables from the shop', the way the word 'vegetables' should be interpreted would depend on what was available at the shop (compare the discussion concerning the faithful servant in Levi, above $\mathrm{n}$ 97, at 940-953).

317 For instance, there may be considerations related to economic efficiency. Policy considerations would also include such matters as the need to provided urgent medical care mentioned in the hypothetical variation on Garner $v$ Burr earlier in this chapter (see the paragraph accompanying $n$ 299).

${ }^{318}$ For instance, that the law should be intelligible and should be applied consistently. General legal considerations would also include pragmatic considerations, for instance, the argument that if certain evidence was admissible, there would be greater uncertainty and cost (See Chartbrook Ltd v Persimmon Homes Ltd [2009] UKHL 38 at [35]). 
evidentiary limits that courts need to bear in mind. ${ }^{319}$ The application of such limits needs to be viewed in relation to this act of categorisation, though they are not really considerations that judges should bear in mind while engaged in interpretation, but are practical restrictions on interpretation.

These considerations relevant to legal interpretation are given in the Chart 4.1, below.

\begin{tabular}{|c|c|}
\hline \multicolumn{2}{|c|}{ Chart 4.1 Relevant Legal Considerations for Judges } \\
\hline $\begin{array}{l}1 \text { Consideration related to the word being } \\
\text { interpreted. }\end{array}$ & $\begin{array}{l}1.1 \text { The correct linguistic meaning of the word } \\
\text { shown by the verbal context and the factual } \\
\text { background. }\end{array}$ \\
\hline 2 Considerations related to the legal category. & $\begin{array}{l}\text { 2.1 Reasons for the legal category. } \\
2.2 \text { The consequence of the assignment of an } \\
\text { item to the category or the exclusion of an item } \\
\text { from the category. } \\
\text { 2.3 Other legal categories. }\end{array}$ \\
\hline $\begin{array}{l}3 \text { Considerations related to items relevant to this } \\
\text { act of categorisation. }\end{array}$ & $\begin{array}{l}\text { 3.1 The item/s that prompted the creation of the } \\
\text { category. } \\
\text { 3.2 The item/s already in the category. } \\
\text { 3.3 Items in other categories. } \\
\text { 3.4 Analogous items to the item at issue. }\end{array}$ \\
\hline 4 General legal considerations. & $\begin{array}{l}\text { 4.1 Rules of interpretation. } \\
\text { 4.2 Policy considerations. } \\
\text { 4.3 Considerations related to the law generally. }\end{array}$ \\
\hline
\end{tabular}

The considerations in Chart $4.1^{320}$ are all relevant legal considerations because they are all related to the act of categorisation before the court. They are either related to the specific category at issue or to the specific item at issue. Even general legal considerations (consideration 4.3) are only relevant if they can be related to the act of categorisation before the court. To say that certain considerations are relevant to this act of categorisation means that they are either reasons that support the inclusion of the item at issue within the legal category or the exclusion of the item from this category. The considerations given in Chart 4.1 are not exhaustive, and it may be possible to discover more considerations within each group or other groups of considerations. Any further considerations,

\footnotetext{
319 See Chapter Four C.7.

${ }^{320}$ Consideration 1.1 corresponds to all the considerations in Chart 3.1.
} 
however, would have to be related to the specific act of categorisation that is before the court.

Consideration 1.1 is the correct linguistic meaning of the word being interpreted. The reason this consideration is relevant is that it shows the reason for the legal category and, in the case of statutory interpretation, if possible words should be given their correct linguistic meaning because the law needs to be intelligible to the public. This means that the reasons for consideration 1.1 can be given as consideration 2.1 and consideration 4.3. For this reason, it may be thought that consideration 1.1 is unnecessary. It is useful, however, to include this as a separate consideration because it is often the most important consideration in relation to judicial interpretation.

Therefore, legal interpretation can be viewed as categorisation, and this categorisation is governed by various relevant considerations. Viewing legal interpretation in terms of categorisation is helpful in that it elicits these four groups of considerations that are potentially relevant to judicial interpretation. $^{321}$ Some specific considerations can be put within a number of these groups, for instance, a relevant precedent could be viewed as a meaning that has been judicially assigned to the word or as an item already assigned to the category. These considerations can be viewed as considerations relevant to determining the meaning of the word being interpreted, but are clearer when viewed as considerations relevant to an act of legal categorisation.

Chapter Three referred to 'relevant considerations'. The considerations identified in this chapter are called 'relevant legal considerations' to distinguish them from the considerations discussed in Chapter Three. For simplicity, the term 'relevant considerations' will sometimes be used to refer to these relevant legal considerations. ${ }^{322}$ The analysis of judicial fallacies later in this chapter will provide more specific examples of these relevant legal considerations. ${ }^{323}$

The fact that these four groups of considerations can be elicited does not mean that judicial interpretation is a simple or straight-forward exercise. In relation to a specific act of interpretation,

${ }^{321}$ Many of these considerations are given in books on legal interpretation. For instance, Ruth Sullivan's book Statutory Interpretation (2nd ed, Irwin Law Inc, Toronto, 2007) is structured according to various approaches to statutory interpretation and includes chapters on 'ordinary meaning' (Chapter 3), 'technical meaning and meanings fixed by law’ (Chapter 4), 'original meaning' (Chapter 6), ‘the entire context’ (Chapter 8), 'textual analysis’ (Chapter 9), 'purposive analysis' (Chapter 10), ‘consequential analysis' (Chapter 11), and 'policy analysis' (Chapter 12). In this thesis, however, these various considerations are all linked to the essential act that judges are engaged in: assigning items to legal categories.

${ }^{322}$ For instance, the phrase 'relevant considerations' is used in the abstract to this thesis because there is no need in that context to distinguish relevant legal considerations from the considerations relevant in ordinary interpretation.

${ }^{323}$ At Chapter Four C.3 and C.4. 
judges need to weigh up the various relevant considerations to make a decision. ${ }^{324}$ Moreover, there may be relevant considerations that support different interpretations. The point being made in this section is that all these considerations are potentially relevant to judicial interpretation.

The aim of this thesis is to provide a way to detect fallacies in judicial interpretation. The goal of this section has been to view judicial interpretation from the point of view of categorisation and to elicit some considerations which would be relevant to such an act of categorisation. An instance of legal interpretation which takes such considerations into account is legally justified.

It is helpful to briefly compare this analysis with the analysis of ordinary interpretation in Chapter Three. $^{325}$ In relation to ordinary interpretation, the focus is on an interpreter objectively discovering the speaker's meaning. To do this, there is the need for the interpreter to take into account a number of considerations. In relation to legal interpretation which involves categorisation, the focus is on a legal interpreter assigning an item to the correct legal category. To do this, there is also the need for the legal interpreter to take into account a number of considerations.

Since both ordinary interpretation and legal interpretation can be viewed as categorisation based on relevant considerations there is an essential similarity between these two kinds of interpretation. There is, however, an important difference between them. The considerations that are relevant to legal interpretation are not identical to the considerations are relevant to ordinary interpretation. In ordinary interpretation, interpreters needed to pay attention to considerations which determine the conventions speakers are using. The considerations that are relevant to legal interpretation, however, are not limited to factors relevant to the act of legal speaking. ${ }^{326}$

Legal interpretation can be viewed, and is often viewed, as the discovery of meaning. In some

324 This thesis will not discuss in detail how judges should determine how much weight to accord to various considerations. There are, however, a few basic principles that are useful in determining this. First, concrete considerations should usually outweigh abstract ones: see Eskridge, above n 222, at 250. Secondly, in many situations a consideration in relation to original meaning may be less important than the way the law should apply to the situation before the court. Thirdly, specific considerations should be accorded more weight than general ones.

325 At Chapter Three B.3.

326 This shows a shortcoming of Diagram 4.4. Although the thought of the legal speaker is generated by the word, it is not merely governed by linguistic considerations but also by broader legal considerations. Therefore, although this diagram is useful when comparing legal interpretation to ordinary interpretation, it should not be taken as a comprehensive illustration of legal interpretation. 
situations, it may be more accurate to view it as the declaration of meaning. ${ }^{327}$ Still, the goal is for the judiciary to arrive at the meaning of the word being interpreted. This is true by definition, but obscures an important distinction between ordinary interpretation and legal interpretation. In ordinary interpretation, the interpreter is focused on the word being interpreted and the task is to give a meaning to this word. Viewed in relation to categorisation, in ordinary interpretation the interpreter is focused on the category and the task is to assign an item to this category. In legal interpretation which involves categorisation, the interpreter is focused on the situation before the court and the task is to determine whether this situation is captured by the word being interpreted. ${ }^{328}$ Viewed in relation to categorisation, in legal interpretation, the interpreter is focused on the item at issue and the task is to decide whether to assign this item to the legal category designated by the word being interpreted.

Therefore, legal interpretation which involves categorisation is not merely a matter of discovering a meaning, but of categorising the situation before the court. Viewing this kind of legal interpretation as the discovering of the meaning of a word is approaching the task from the wrong direction. The meaning given to the word is the result of legal interpretation, but is not the primary goal. Judges should not begin with the category and look for the item, but should begin with the item and determine whether it should be assigned to the category. The legal interpreter's meaning can be considered as the thought at the apex of Diagram 4.4. The task of interpretation, however, is not merely to arrive at this thought, but to decide whether to assign the item at issue to the legal category under consideration. Therefore, viewing legal interpretation in terms of categorisation can be clearer than viewing it in terms of the discovery of meaning.

In some situations, viewing legal interpretation in terms of categorisation is also clearer than an approach to legal interpretation based on the discovery of an intention. Writing extra-judicially, Justice Michael Kirby stated that a statute "is prepared by many hands and submitted to a decisionmaker of many different opinions, so ... to talk of a single 'intention' is self-deception.” ${ }^{329}$ Also writing extra-judicially, Chief Justice Spigelman stated: ${ }^{330}$

327 See Tiersma “Ambiguity”, above n 24, at 1097. The distinction that Tiersma draws between interpretation and construction in this article is different from the distinction drawn by Arthur Corbin discussed in the paragraph accompanying n 516.

${ }^{328}$ In relation to statutory interpretation, Rupert Cross stated: "[I]nterpretation is the process by which the courts determine the meaning of a statutory provision for the purpose of applying it to the situation before them.” Rupert Cross (John Bell and George Engle (eds)) Statutory Interpretation (3rd ed, Butterworths, London, 1995) at 34.

329 Kirby "Grand Theory”, above n 242, at 98-99.

330 JJ Spigelman “The poet’s rich resource: Issues in statutory interpretation” (2001) 21 Aust Bar Rev 224 at 225-226 [“Statutory Interpretation”]. 
The concept of attributing an intention to a legislature poses a number of problems. Indeed, there may not have been any actual intention at all. The words of a statute may represent a compromise between contending positions, where the actual working out of the application of the statute is, in practice, left to courts precisely because those responsible for the legislation are not able to agree on what the position should be.

Therefore, two basic problems with focusing on legislative intention in statutory interpretation are that there may be no single intention or there may be no actual intention at all. Similar problems also apply to other legal documents. There may be no identifiable intention, no actual intention related to the matter at issue, or more than one intention. ${ }^{331}$

These problems can be avoided when interpretation is viewed in relation to categorisation. Rather than merely viewing interpretation as ascertaining an intention which may not exist, it can be viewed as categorisation based on relevant considerations. It still may be convenient to view some of these considerations in relation to intention, but this is just a way of saying that they relate to the purpose of the category, and does not need to be taken to imply that there is an actual intention. Furthermore, as will be seen in the fallacy analysis, a focus on categorisation often provides a better way to elicit relevant considerations and avoid irrelevant considerations than a focus on intention. Lastly, as will be seen, viewing legal interpretation as categorisation provides a better way to detect and avoid fallacies than viewing it either as the discovery of meaning or intention. ${ }^{332}$

Diagram 4.4 is helpful because it shows that in the law words are connected to referents by judicial interpretation. This interpretation involves the assignment of items to legal categories. For such an assignment to be legally justified, it needs to be based on various relevant legal considerations.

\footnotetext{
${ }^{331}$ Legal documents are sometimes drafted in a deliberately ambiguous way, with the ambiguity left to be resolved by judicial interpretation. In relation to statutory interpretation Philip A Joseph has noted that the courts need to "resolve linguistic ambiguities in legislation, adapt existing legislation to cover new circumstances, build legislative meaning around undefined terms and concepts, and exercise judicial discretions in legislation." "Parliament, the Courts and the Collaborative Enterprise” (2004) 15 KCLJ 321 at 338. Thus, the introduction of ambiguities in statutory drafting may be a method of delegating the decision-making power to the judiciary. For discussions of the deliberate use of ambiguity in drafting other legal documents, see Philip Thomas "Legal Skills and the Use of Ambiguity" (1991) 42 N Ir Legal Q 14 and William T Allen and Galya Levy "The Uses of Ambiguity in Commercial Contracts: On Facilitating Re-Bargaining” in Sarah Worthington (ed) Commercial Law and Commercial Practice (Hart Publishing, Oxford, 2003) 163.

332 See Chapter Four C.3 and C.4.
} 
(a) Legal meaninglessness

A legal category may exist, but the reason for this category may be unclear to an interpreter. This is illustrated by Diagram 4.5, below, which is based on Diagram 3.5 (Meaninglessness).

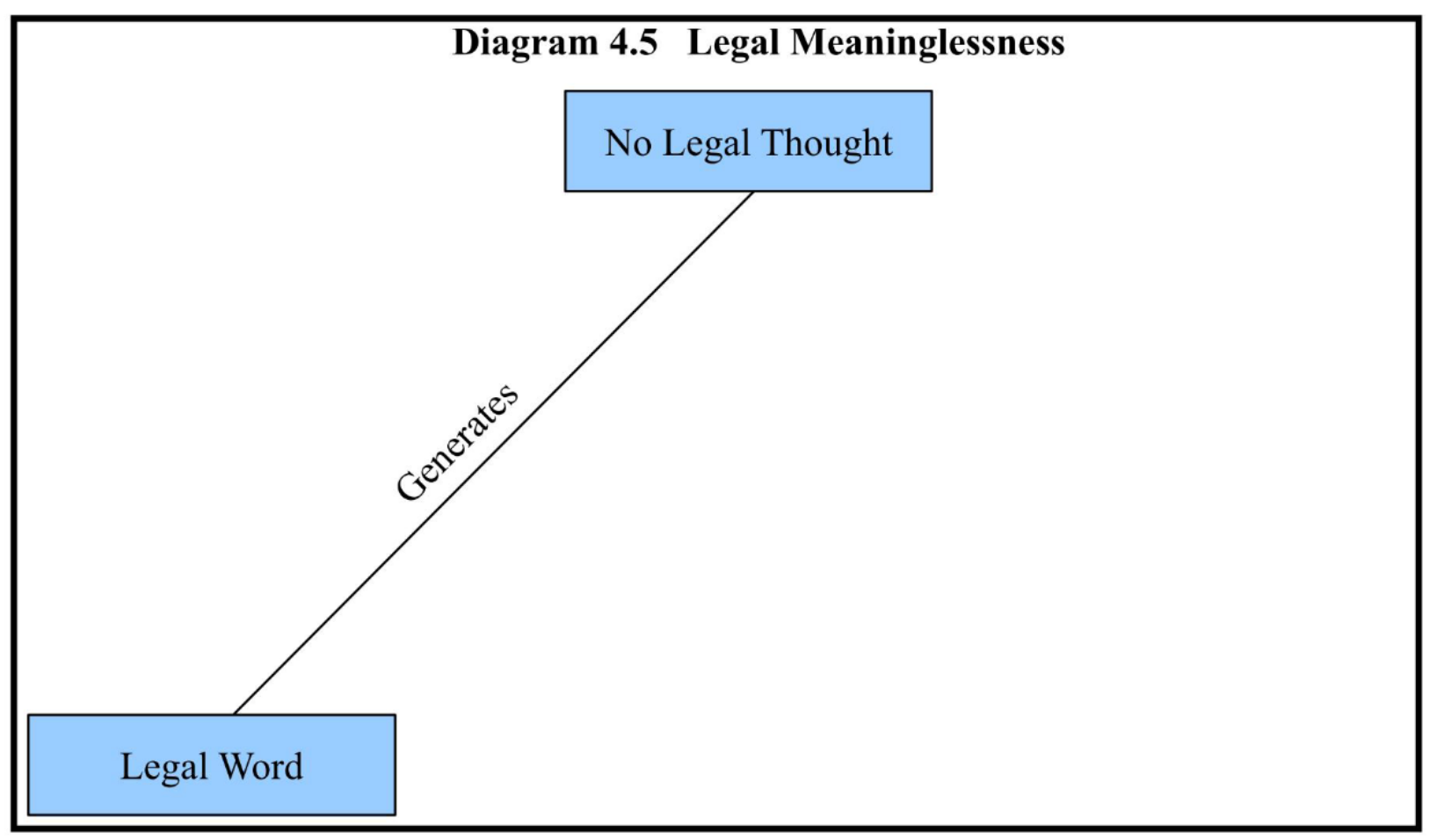

Diagram 4.5 depicts legal meaninglessness. In some cases, it may be unclear to an interpreter which situations prompted the creation of the legal category designated by the word being interpreted or the reason for the existence of the category. In such cases, there is a legal word but no clear legal thought or legal referent to which the word can be seen to apply. Thus, this word can be viewed as legally meaningless to the interpreter.

In Diagram 3.5, which depicted meaninglessness in ordinary interpretation, there was no thought at all. In Diagram 4.5 there is no 'legal' thought. There may be a thought generated by the conventional meaning of the word, but this word is legally meaningless in the sense that the legal reason for the existence of the legal category designated by this word and the kind of items which should be included within this category are unclear. 
Legal meaningless can occur when there has been a mistake in drafting. ${ }^{333}$ It can also occur in a number of other situations in relation to statutory interpretation. For instance, there may have been a political compromise in which the legislators decided to delegate decision-making power to the judiciary and therefore left a provision deliberately vague or ambiguous. This could cause legal meaninglessness if the interpreter was not aware of this compromise and was therefore unclear regarding the reason for the provision. Legal meaninglessness can also be caused when the factual situation that gave rise to a certain provision does not exist any longer but the provision is still in force and requires interpretation. ${ }^{334}$ Furthermore, when an Act is imported from one jurisdiction to another, a difference in the physical or political circumstances in the new jurisdiction may mean that certain provisions are not relevant to that jurisdiction. In this situation, the original intention behind the provision may not have any relevance for the situation before the court.

Just as meaninglessness in ordinary interpretation can occur when speakers attempt to describe something that is ineffable for them, meaninglessness in legal interpretation can occur when legal speakers attempt to create a legal category with a certain legal consequence that is legally ineffable for them. If a speaker does not know the correct way to create a certain legal category with a specific legal consequence, but still drafts a document with the intention of creating such a category, a judge may be unclear regarding what the category is intended to capture. If a legally meaningless word is being interpreted by a judge, the judge still needs to make a decision regarding the meaning of the word. In such a situation, the judge may be justified in interpreting the word literally.

\section{$4 \quad$ Legal communication}

To have a complete view of the nature of legal communication, it is useful to combine Diagram 4.2 (Legal Speaking) and Diagram 4.4 (Legal Interpretation) to form Diagram 4.6, below, which is comparable to Diagram 3.6 (Communication):

\footnotetext{
${ }^{333}$ In some situations, rectification may be possible if the courts are clear that a mistake has been committed and are clear about the intention of the legal speaker. Meaninglessness occurs when this intention is not clear.

334 J F Burrows notes: "In theory statute law knows no doctrine of frustration or desuetude, and the mere fact that the very subject-matter of a statutory provision no longer exists does not mean that the provision itself ceases to exist as law.” JF Burrows and RI Carter Statute Law in New Zealand (4th ed, LexisNexis, Wellington, 2009) at 386.
} 


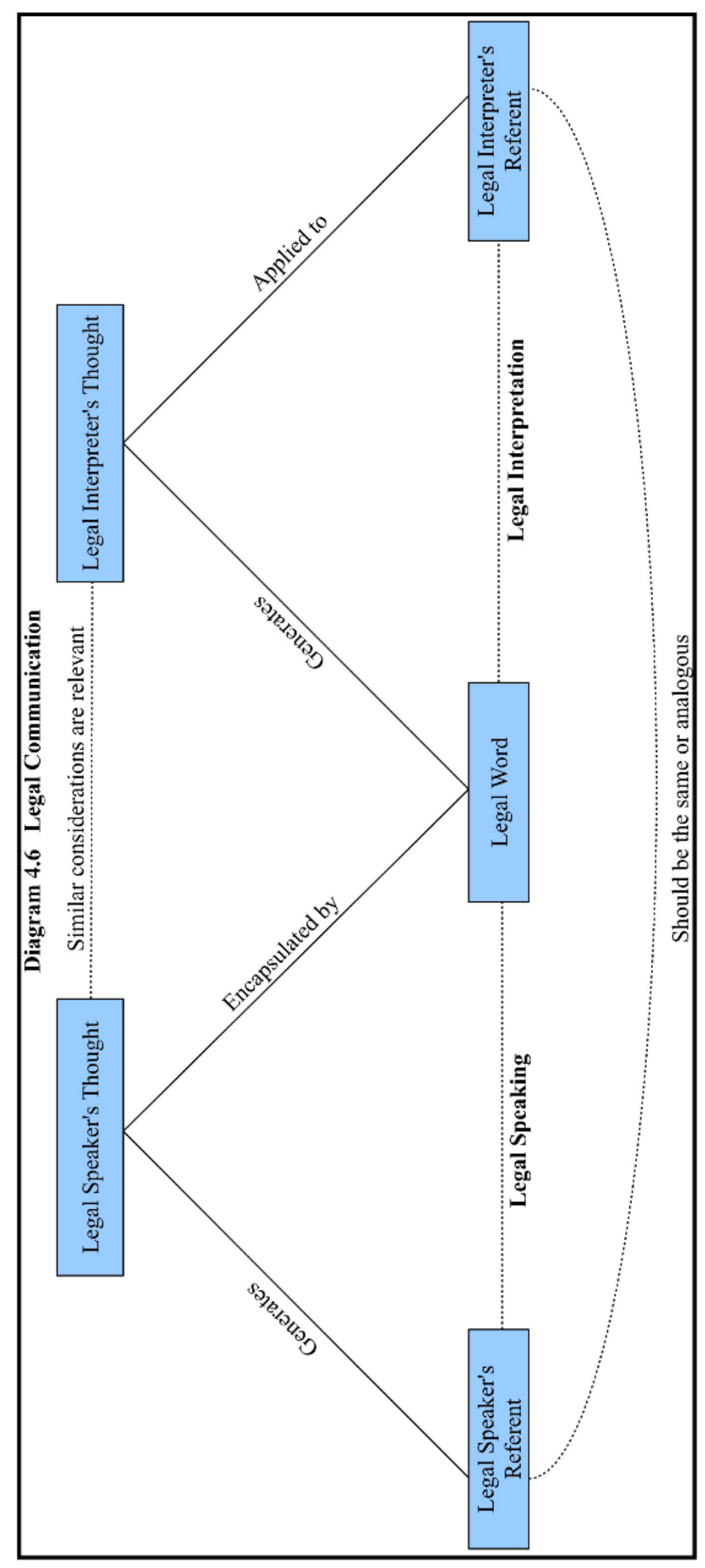


Diagram $4.6^{335}$ depicts the relationship between legal speaking and legal interpretation, which can be called 'legal communication'. The legal speaker's referent on the left-hand side includes any item or items that legal speakers have assigned to the legal category. These items generate the legal speaker's thought. This thought is a thought regarding these items and the reason they have been assigned to this category. Therefore, this thought includes the reason for the creation of the category. This thought is encapsulated by the legal word, which is the word chosen to designate the legal category. The legal interpreter's thought is generated by this word. It is also governed by similar considerations to the ones relevant to the speaker's thought. The interpreter's thought is then applied to the interpreter's referent on the right-hand side. This referent is the item that the interpreter assigns to the legal category.

There are some important differences between Diagram 4.6 and Diagram 3.6 (Communication). First, whereas in ordinary communication the interpreter's referent should be the same as the speaker's referent, Diagram 4.6 states that the legal interpreter's referent should be the same as or analogous to the legal speaker's referent. The legal interpreter is not limited to assigning the same item to the legal category as the item that the speaker has assigned to this category. There may be a number of specific items included in the legal speaker's referent, and an interpreter may need to assign an item to the category that is analogous to these items. ${ }^{336}$

Second, the goal of legal interpretation is not merely that the legal interpreter's thought be as similar as possible to the legal speaker's thought. There may be considerations relevant to the interpreter's thought that were not relevant to the speaker's thought. The legal interpreter's thought and the legal speaker's thought, however, are governed by similar kinds of considerations. That is, considerations related to the legal category and the items that should be in that category. For this reason, Diagram 4.6 states that the considerations relevant to the legal interpreter's thought are similar to the considerations relevant to the legal speaker's thought.

Therefore, in legal communication, a legal interpreter's thought is not restricted to the specific considerations relevant to the legal speaker and the legal interpreter's referent is not restricted to the specific referent identified by the legal speaker.

\footnotetext{
335 This diagram can be seen as a more sophisticated depiction of the two processes depicted in Diagram 2.1.

${ }^{336}$ In ordinary interpretation there may also be situations where an interpreter needs to identify a referent that is not exactly the same as the referent identified by the speaker. For an example of this, see n 316.
} 
In ordinary interpretation, problems occur when the interpreter does not take into account all the considerations which indicate the speaker's meaning or when the interpreter takes into account considerations which are not relevant to the speaker's meaning. In legal interpretation which involves categorisation, problems occur when the legal interpreter does not take into account all the considerations which are relevant to the decision regarding whether to include the item at issue in the legal category or when the interpreter takes into account considerations that are not relevant to this decision. For this reason, it is useful to view these instances of legal interpretation as legal categorisation, rather than merely as the discovery of meaning.

The result of legal interpretation is that an item is either included within the legal category or excluded from this category. If it is included within this category, it becomes the legal interpreter's referent, and when these same words are interpreted at a later date, this item will become one of the items that comprise the legal speaker's referent. Thus, on the definition given in this thesis, an act of legal interpretation can become part of the act of legal speaking in relation to a subsequent interpretation of the same word.

It is useful now to return to the three differences between legal interpretation and ordinary interpretation mentioned at the beginning of this chapter. The three differences were: first, whereas the result of ordinary interpretation is the interpreter objectively ascertaining the speaker's meaning, the result of legal interpretation is often the application of the law to situations; second, whereas the goal of ordinary interpretation is the discovery of meaning, the goal of legal interpretation is often the implementation of the law; and third, whereas ordinary interpretation is governed by language conventions, legal interpretation needs to be governed by legal considerations. ${ }^{337}$

These three differences can be seen clearly when legal interpretation is viewed in relation to categorisation. Legal interpretation often involves the assignment of items to legal categories. This assignment gives these items a legal status with attendant legal consequences. Thus, the law is implemented by being applied to these items and such implementation needs to be based on legal considerations.

At the beginning of this chapter the question was raised was whether these three differences meant that the process of legal interpretation is fundamentally different from ordinary interpretation. The

337 At Chapter Four B. 
analysis in this chapter has shown that the process of legal interpretation is fundamentally similar to ordinary interpretation. There may be differences in the considerations that legal interpreters need to bear in mind, but the act of legal interpretation involves the same basic process as ordinary interpretation. This can be seen when both kinds of interpretation are viewed in relation to categorisation. Both kinds of interpretation can involve the assignment of an item to a category based on relevant considerations.

In addition to these three differences, it is possible to note various other differences between legal interpretation and ordinary interpretation. These include: that judges are the authoritative interpreters and that interpretation takes place in the context of a legal decision, that intention may need to be presumed where it is not discoverable or did not exist, that there may be a delay in interpretation and the act of interpretation may occur in the context of a different factual situation from the act of speaking, and that speakers do not usually give direct evidence of their intentions. Again, these differences do not mean that the actual process of legal interpretation is fundamentally different from ordinary interpretation, but may mean different considerations need to be taken into account in legal interpretation. The way to ensure that all the relevant considerations are taken into account is to view legal interpretation as categorisation based on relevant considerations.

It is important to address here a distinction that is sometimes drawn between ordinary interpretation and legal interpretation. It is sometimes claimed that legal interpretation is objective whereas ordinary interpretation is concerned with subjective intentions. This view was outlined by Lord Hoffmann writing extra-judicially: 338

It is said that in ordinary life we are concerned to discover, as best we can, what is going on in the mind of the person whose words have to be interpreted. What matters is his or her subjective intent, what he or she really meant. In the law, on the other hand ... subjective intention is irrelevant.

Thus, whereas in ordinary interpretation the goal is to ascertain the subjective intentions of the speakers, in legal interpretation this is not the case and the goal is to ascertain the meaning of speakers objectively. ${ }^{339}$

\footnotetext{
338 Leonard Hoffmann “The Intolerable Wrestle with Words and Meanings” (1997) 56 S African LJ 656 at 660.

339 This view was expressed by Lord Nicholls writing extra-judicially in this way: "In everyday life we seek to identify what a speaker or writer actually intended by the words he has used. As we all know, the law proceeds on a different footing: words are taken as intended to convey the meaning, that is, the idea, they would reasonably convey to the hearer or reader.” Donald Nicholls “My Kingdom for a Horse: The Meaning of Words” (2005) 121 LQR 577 at 579 (italics in original).
} 
This, however, can be a confusing distinction. Lord Hoffmann stated that he believed that this view of interpretation was fallacious, ${ }^{340}$ and noted: ${ }^{341}$

[F]or the purposes of interpreting what other people say, we have no direct access to their subjective mental states ... our interpretation is bound to be objective in the sense that it will be our best effort to construe what such a person, using those words against that background, would have meant.

Interpreters cannot directly ascertain the subjective intentions of speakers in either legal interpretation or ordinary interpretation. Both kinds of interpretation are necessarily objective. The fact that speakers may attribute a certain uncommunicated meaning to their words does not change the meaning that should be legitimately ascribed to those words in either kind of interpretation. Both in ordinary interpretation and in judicial interpretation, interpreters have to ascertain meaning based on objective information. Therefore, it is inaccurate to claim that ordinary interpretation is concerned with subjective intentions.

Furthermore, to claim that legal interpretation does not aim at discovering subjective intentions, although correct, can be misleading. It can lead to the view that actual intentions, even when discoverable, are irrelevant. ${ }^{342}$ Such a view can defeat the whole purpose of interpretation, which may be to give effect to speakers' actual intentions. ${ }^{343}$ Therefore, the claim that legal interpretation is objective and ordinary interpretation is subjective is misleading in two ways: first, ordinary interpretation is also objective, and second, this claim can lead to the wrong view that legal interpretation is never concerned with actual intentions. The objective test in legal interpretation, therefore, should not be taken to imply that actual intention is irrelevant. Rather, it should mean that for an intention to be recognised by the courts, it needs to be communicated.

A valid distinction between legal interpretation and ordinary interpretation is that the evidence admissible in legal interpretation may be more restricted than the evidence available in ordinary

${ }^{340}$ Hoffman, above $n$ 338, at 660 .

${ }^{341}$ Ibid, at 661. See also David Goddard “The Myth of Subjectivity” (1987) 7 Legal Stud 263 and DW McLauchlan “Objectivity in Contract” (2005) 24 U QLJ 479 [“Objectivity”].

${ }^{342}$ For instance, in relation to contract interpretation David McLauchlan notes: "Courts routinely say that the search is always for the parties' presumed intention and that they are unconcerned with their actual intention." DW McLauchlan "Common Intention and Contract Interpretation” [2011] LMCLQ 30 at 31 (italics in original).

343 Again, in relation to contract interpretation, David McLauchlan notes “an objective approach, at least as properly understood, requires implementation of a proven actual mutual intention. That intention is the objective intention, although surely it would be better to say that the objective principle has not application where actual mutual intention is established.” McLauchlan “Objectivity”, above n 341, at 480 (italics in original). 
interpretation. ${ }^{344}$ If this is what is meant by saying that legal interpretation is objective, then such a claim is correct. ${ }^{345}$ It is misleading, however, to use the word 'objective' in this way.

This thesis, however, is not making the claim that uncommunicated subjective intentions are relevant in legal interpretation. If, for instance, people sign standard form contracts and do not turn their mind to a certain provision, and thus does not have any intention regarding this provision, in most situations they should be taken to have intended this provision. In this sense, it is their objective intention that is relevant, not their uncommunicated subjective intention, even if this is their actual intention. Lord Hoffmann's definition of interpretation makes this clear: ${ }^{346}$

Interpretation is the ascertainment of the meaning which the document would convey to a reasonable person having all the background knowledge which would reasonably have been available to the parties in the situation in which they were at the time of the contract.

(a) Legal thought transmission

The central part of Diagram 4.6 (Legal Communication) can be extracted to form Diagram 4.7, below, which is comparable to Diagram 3.7 (Thought Transmission).

${ }^{344}$ For instance, legal speakers usually cannot give evidence of their subjective intentions. For a discussion of the reasons for this in relation to contract interpretation, see Christopher Staughton "How Do the Courts Interpret Commercial Contracts?” (1999) 58 CLJ 303 at 305-306.

345 Writing extra-judicially, Lord Hoffmann states: "When the law speaks of objective interpretation, what it really means is that it is artificially restricting the amount of background which can be used in aid of construction.” Hoffmann, above n 338, at 661.

${ }^{346}$ Investors Compensation Scheme Ltd v West Bromwich Building Society [1998], above n 243, at 912. 


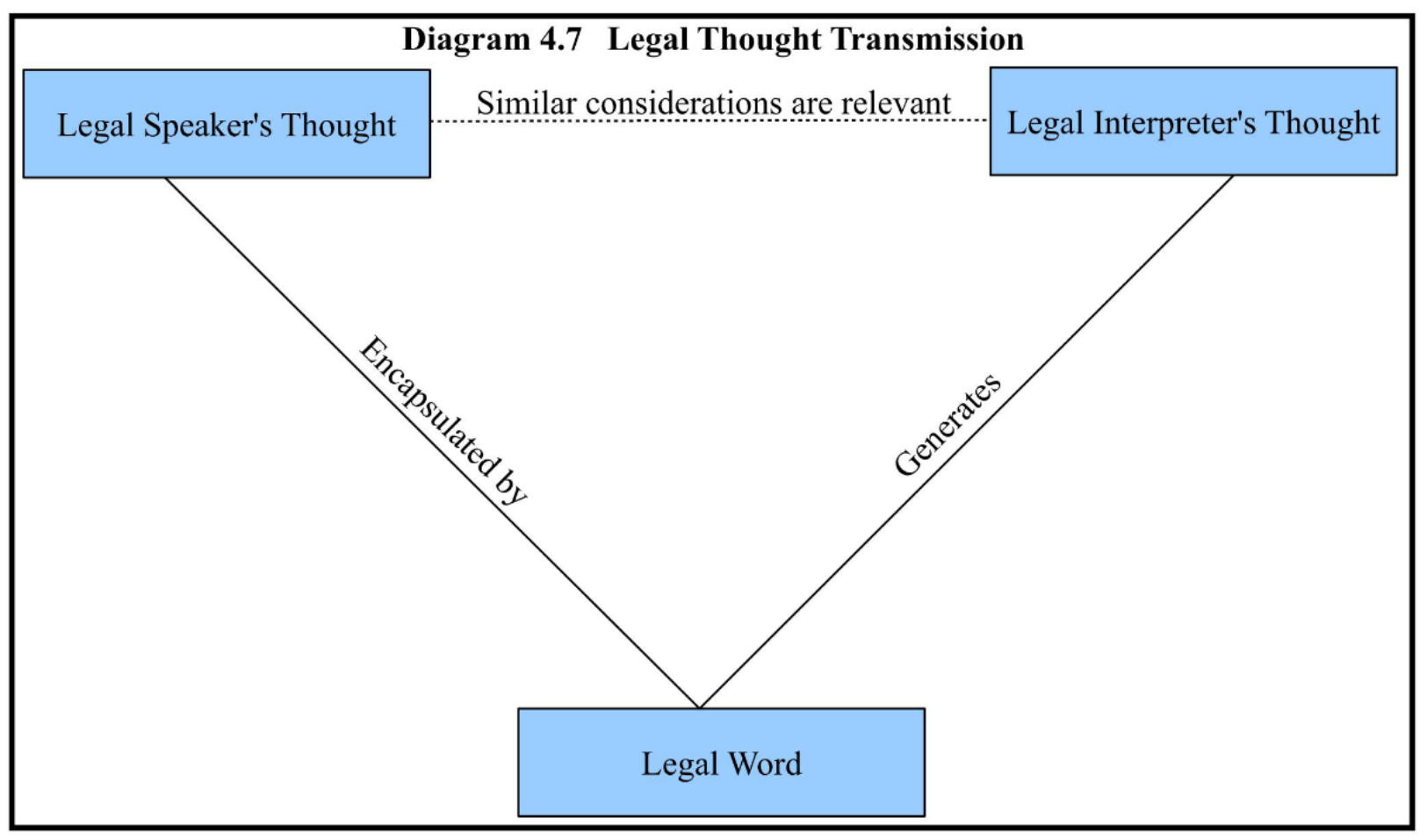

Diagram 4.7 shows the relationship between the legal speaker's thought and the legal interpreter's thought. The legal speaker's thought is encapsulated by the legal word. The legal interpreter's thought is generated by this word. Difficulties can occur when a legal speaker wrongly encapsulates a thought. This may happen because a legal thought is ineffable for the speaker. Difficulties can also occur when the word does not generate the right thought in the mind of a legal interpreter. This may happen because the word is legally meaningless to the interpreter.

In ordinary interpretation, the similarity between the speaker's thought and the interpreter's thought determines the correctness of the interpretation. In the law, an interpretation is correct if takes into account the relevant legal considerations. These can include considerations relevant to the act of legal speaking, but may include other considerations.

A distinction between construction ${ }^{347}$ and application was drawn in a New Zealand Supreme Court case dealing with the interpretation of a provision in the Employment Relations Act 2000. Justice Anderson stated: 348

\footnotetext{
${ }^{347}$ As used here, 'construction' is a synonym for 'interpretation'. Compare the discussion of the distinction between interpretation and construction in the paragraph accompanying $\mathrm{n} 516$.

${ }^{348}$ Air Nelson Ltd $v$ The New Zealand Amalgamated Engineering, Printing and Manufacturing Union Incorporated [2010] NZSC 53, [2010] 3 NZLR 433 at [19]. The distinction drawn in this quotation is discussed in Christopher Walshaw “Judicial process: construction or application?” [2010] NZLJ 357.
} 
The judgements in the Courts below illustrate the difficulty of trying to find a definition for what is really a contextual judgment. The essential question is not concerned with the meaning of 'work' but with recognising the nature and scope of particular work in particular cases. That is, the issue is not one of construction but of application.

This distinction between 'construction' and 'application' is a distinction between giving a meaning to a word and making a decision concerning the application of the provision being interpreted in a particular situation. ${ }^{349}$ In many situations, courts are not merely concerned with the meaning that the speaker gave to a word, but are concerned with the application of the law in a particular situation. Therefore, legal interpreters cannot merely focus on ascertaining the legal speaker's thought, but may need to focus on applying the law to the situation at issue. Having said this, the considerations relevant to the legal interpreter's thought are similar to the considerations relevant to the legal speaker's thought.

(b) Simplified view of legal communication

The bottom line of the Diagram 4.6 (Legal Communication) provides Diagram 4.8, below, which is comparable to Diagram 3.8 (Simplified View of Communication).

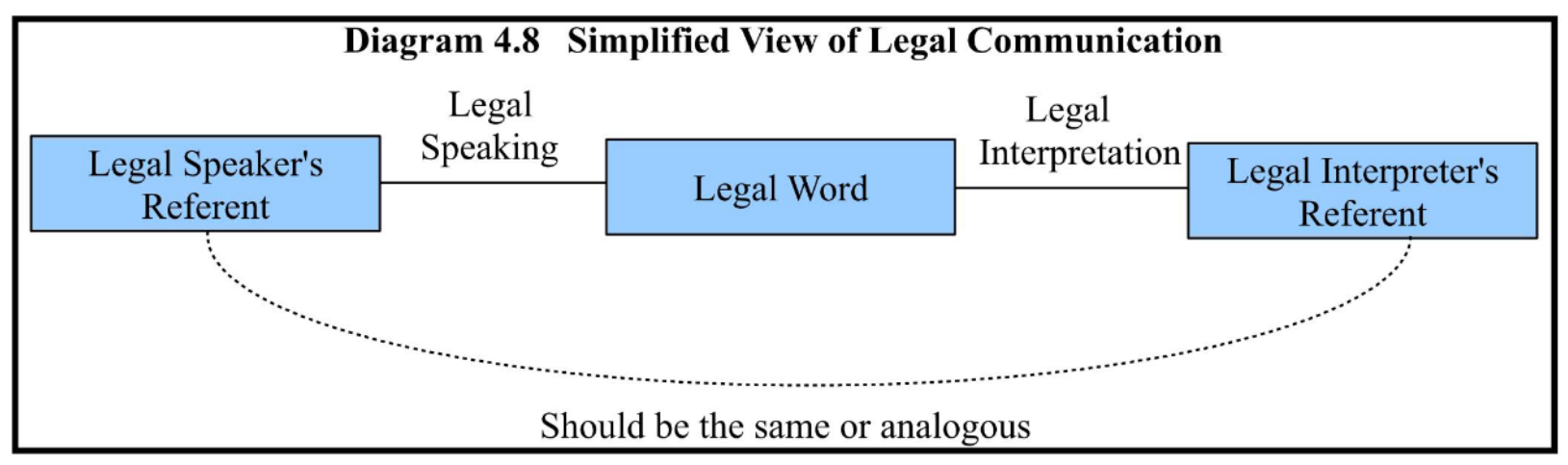

Diagram 4.8 presents a simplified view of legal communication. On this view, it is clear that the legal speaker's referent and the legal interpreter's referent are connected by the word being interpreted. In Diagram 4.8 everything is objective. It is the subjective aspect of legal interpretation, however, that creates problems. This does not mean that legal interpretation can take account of

${ }^{349}$ Compare the famous statement by Oliver Wendell Holmes: "General proposition do not decide concrete cases." Lochner v New York (1905) 198 US 45 (SC) at 76. 
uncommunicated subjective thoughts, but that relevant legal considerations that provide indications of such thoughts need to be borne in mind. Diagram 4.8, therefore, presents a naïve view of legal communication in which there is no need to pay attention to any indications of subjective thoughts.

As has been pointed out, a legal interpreter is not limited to identifying referents specifically indicated by speakers. That is, the items a legal interpreter should assign to a legal category are not limited to items legal speakers have assigned to the category. It is important to see, however, the items legal interpreters assign to a category should be analogous to the items that legal speakers have assigned to the category. This is because the items that legal speakers have assigned to a legal category indicate the reason for this category. Furthermore, all the items officially assigned to a certain legal category by judicial interpretation ${ }^{350}$ have the same legal status and are treated the same way in the law. Because they are treated in the same way, they should be analogous in a certain relevant respect.

Diagram 4.8 shows that legal interpretation connects the legal word to the legal interpreter's referent. Although this is true, in the legal interpretation section it was stressed that the focus of legal interpretation is different from the focus of ordinary interpretation. In legal interpretation which involves categorisation, the legal interpreter's task is not primarily focused on discovering the item that should be assigned to a legal category, but on deciding whether or not to assign the specific item before the court to this category. Whereas ordinary interpretation begins with the category and the task is to discover the item that should be assigned to this category, legal interpretation often begins with an item and the task is to decide whether this item should be assigned to the legal category. It has been said that the process of judicial interpretation is fundamentally similar to the process of ordinary interpretation. It is important to note that this difference of focus in legal interpretation does not make a significant difference to the process of interpretation. The essential process of both types of interpretation is the same - it is the assignment of an item to a category.

So far this chapter has compared legal speaking and interpretation with ordinary speaking and interpretation. There are two reasons why such a comparison is useful. First, since the process of ordinary interpretation is fundamentally similar to legal interpretation, viewing legal interpretation

\footnotetext{
${ }^{350}$ As has been mentioned, the judicial assignment of items to the legal category designated by a word becomes part of the act of legal speaking in relation to subsequent interpretations of that word. Therefore, such items would be part of the legal speaker's referent in Diagram 4.8 .
} 
in terms of ordinary interpretation makes it clear what legal interpretation involves. Second, there are fallacies that can be committed in legal interpretation which are similar to the fallacies that can be committed in ordinary interpretation. The remainder of this chapter will, therefore, focus on identifying fallacies in judicial interpretation on the basis of the fallacies that can be committed in ordinary interpretation identified in Chapter Three.

\section{Judicial Fallacies}

Even though judging involves the interpretation of language, and how judges interpret language has far-reaching consequences, judges are not required to have formal training in any of the language disciplines. ${ }^{351}$ One consequence of this is that judges may be just as susceptible to language fallacies as the general public.

Judicial interpretation often involves the assignment of items to legal categories. In Chapter Three it was noted that there is no natural or necessary connection between words and their meanings. For this reason, words do not necessarily have specific meanings associated with them. Similarly, there is no necessary connection between the word by which an item can be described and the legal category to which it should be assigned. Rather, items should be assigned to legal categories on the basis of relevant legal considerations. Judges can commit fallacies when they assume that the word by which a certain item can be described determines the legal category to which it should be assigned.

The goal of this thesis is to provide a way to detect fallacies in judicial interpretation. The remainder of this chapter will identify some specific fallacies that judges can commit and provide a method by which these fallacies can be detected and by which alternative, non-fallacious interpretations can be reached. These legal interpretation fallacies will be referred to as 'judicial fallacies'.

${ }^{351}$ Steven Wisotsky noted: "Judges are not linguists or grammarians, although they are of necessity arbiters of language" "How to interpret statutes - or not: the phantom of plain meaning" (2009) 83 Florida Bar Journal 43 at 44. As the interpretation section of this thesis has shown, however, judges should not make interpretive decisions merely on the basis of linguistic meaning. Therefore, training in the language disciplines by itself would not be sufficient as a qualification for a judge. 
It is important to define for the purposes of this thesis what makes an instance of judicial interpretation fallacious. This chapter has shown that judicial interpretation often involves the assignment of items to legal categories based on various relevant legal considerations. An instance of judicial interpretation is justified when the judge takes into account these relevant legal considerations. These relevant legal considerations are considerations related to the specific act of legal categorisation at issue. They are reasons for this act of categorisation. If a certain consideration does not relate to the specific act of categorisation at issue, judges should not take it into account. Such considerations will be referred to as 'irrelevant considerations'. 352

Chapter Three discussed how speakers can mislead interpreters. In such a situation, an interpreter may reach a different meaning from a speaker, but this would not be a fallacious interpretation. That chapter also discussed situations in which speakers did not deliberately mislead interpreters, but an interpretation which reached a different meaning from the speaker was not fallacious because it was reasonable given the information available to the interpreter.

Judges are responsible for reaching decisions that take into account the relevant legal considerations that are available to them. Even if a speaker uses language in a misleading way, the judge is required to look beyond the language used to the legal issue. Therefore, the fact that a judicial decision seems reasonable based on the apparent meaning of the language being interpreted may not necessarily mean the decision is not fallacious. In some situations, however, a speaker may deliberately hide certain facts, and a judge may not be aware of this. An instance of judicial interpretation which omitted these facts would not be fallacious because the judge could not be expected to know he or she needed to take them into account. Such concealed facts should not be viewed as 'relevant legal considerations' and judges cannot be expected to take them into account. This sort of situation corresponds to speaker's misleading interpreters in ordinary interpretation.

An instance of judicial interpretation is fallacious in two situations: first, when it takes into account an irrelevant consideration and it is most likely that a different result would have been reached if that consideration had been omitted; second, when it omits a relevant legal consideration and it is

\footnotetext{
352 These irrelevant considerations have not been called 'irrelevant legal considerations', because they may not be related to the legal issue at all, but may merely relate to the meaning a word can have in the abstract. Sometimes, however, these irrelevant considerations are misapplied legal considerations.
} 
most likely that a different result would have been reached if that consideration had been taken into account. Fallacious interpretations may involve the introduction of more than one irrelevant consideration or the omission of more than one relevant consideration. Furthermore, fallacies often involve both the introduction of irrelevant considerations and the omission of relevant legal considerations.

This definition of fallacious interpretation has referred to a 'different result' rather than a 'different meaning' because this chapter is viewing judicial interpretation which involves categorisation as the assignment of items to categories, not as the discovery of meaning. This assignment results in an item either being included within a legal category or excluded from the legal category. Thus, to say a different result would have been reached means that the item before the court would have been categorised in a different way. The fact that a different result would have been reached, however, means that a different meaning would have been given to the word being interpreted.

The consequence of such a fallacious interpretation is that items are either unjustifiably included in or unjustifiably excluded from a legal category. Therefore, a judicial fallacy results in a wrong categorisation. For this reason, it can be said that a judicial fallacy reaches the wrong result. ${ }^{353}$ The result is wrong because if any irrelevant considerations had been omitted and the relevant considerations had been introduced, it is most likely that a different result would have been reached.

The mere fact that a certain irrelevant consideration has been introduced in an interpretive decision does not make that decision fallacious. If this consideration was not determinative, it may not affect the decision regarding whether to assign the item at issue to the legal category. Although an instance of interpretation is unjustified to the extent that it is based on an irrelevant consideration, if this irrelevant consideration does not affect the categorisation of the item at issue, it is not fallacious. Furthermore, the mere fact that judges omit a certain relevant considerations does not make an interpretive decision fallacious. Judges cannot be expected to take into account every possible relevant consideration when interpreting language. A decision is only fallacious when it is most likely that a different result would have been reached if that relevant consideration had been introduced.

\footnotetext{
353 The use of the word 'wrong' here should not be understood to mean that the court did not have the power to make this decision or that the decision does not have any legal standing. See the paragraph accompanying $n 47$ and the two following paragraphs.
} 
It is impossible to say definitively that an interpretive decision would have been made differently if a certain prima facie relevant consideration had been introduced because judges have the discretion to either introduce such a consideration and decide that it is irrelevant for this act of interpretation, or to decide that it is relevant, but is not important enough to change the result of this act of interpretation. It is possible, however, to say that it is most likely that the introduction of a certain relevant consideration would change the result of an act of interpretation. Similarly, it is impossible to say definitively that an interpretive decision would have been made differently if a certain irrelevant consideration had been omitted, because judges have the discretion to reach any result and may have reached the same result without introducing this irrelevant consideration. It can be said, however, that that it is most likely that the omission of a certain irrelevant consideration would change the result of an act of interpretation. Therefore, it can be said that a certain interpretive decision is fallacious given the fact that it is most likely that a different decision would have been reached if any irrelevant considerations had been omitted and any relevant considerations had been introduced.

Viewed in relation to categorisation, the two fallacies identified in Chapter Three were 'same category, therefore, same item', and 'different category, therefore, different item'. In legal interpretation which involves categorisation, judges are focused on whether to assign a specific item to a legal category rather than merely discovering the item that a speaker has assigned to a category. ${ }^{354}$ This difference in focus means that the fallacies in judicial interpretation need to be viewed in a different way from the fallacies in ordinary interpretation, even when both are viewed in relation to categorisation.

Words are usually the names of categories. For instance, the word 'vehicle' is the name of a category of items which includes all vehicles. Describing an item by a word involves assigning it to the category designated by that word. To call a certain item a vehicle is to assign it to the category 'vehicle'. In this chapter, it will be useful to use the term 'verbal category' to refer to the word that has been used to describe an item. Therefore, to describe an item by a word is to assign it to the

\footnotetext{
${ }^{354}$ Legal interpretation may involve the discovery of the item that a legal speaker has assigned to a category, but it does not always involve this, and even if it does, the legal speaker's assignment is not determinative. Furthermore, even in situations where legal interpretation involves the discovery of an item that a legal speaker has assigned to a legal category, it is still useful to view this act of interpretation as a decision regarding whether a certain item should be assigned to a category. See the paragraph accompanying n 500 .
} 
verbal category designated by that word. To call an item a vehicle is to assign it to the verbal category 'vehicle'.

The goal of legal interpretation is to assign items to the correct legal category. This legal category has been designated by a certain word. For instance, the word 'vehicle' was used to designate the legal category in Garner v Burr. ${ }^{355}$ This means that the legal category has been designated by a certain verbal category. ${ }^{356}$ For instance, in Garner v Burr the legal category at issue was designated by the verbal category 'vehicle'.

An item may not normally be within a certain verbal category according to common usage, but may be the kind of item that should be within a legal category which is designated by that verbal category. For instance, an item may not be commonly called a 'vehicle', but may be the kind of item which should be within the legal category designated by the word 'vehicle' in a certain statute. Similarly, an item may be within a certain verbal category according to common usage, but may not be the kind of item that should be within a legal category which has been designated by that verbal category. For instance, an item may be commonly called a 'vehicle', but may not be the kind of item which should be within a legal category designated by the word 'vehicle' in a certain statute. Therefore, an important basic principle is that the legal category to which an item should be assigned is not necessarily determined by the verbal category to which it can be assigned. Rather, the legal category to which an item should be assigned should be determined by relevant legal considerations.

Because this chapter is viewing judicial interpretation as categorisation, the discussion of the fallacies in this chapter will be in terms of verbal categories and legal categories. When interpreting, judges often have to decide whether a certain situation should be within the scope of the word being interpreted. They can be distracted by the fact that this situation can be described by this word in common usage. Viewed in relation to categorisation, when interpreting, judges often have to decide whether a certain item should be assigned to a certain legal category. They can be distracted by the fact that this item can be assigned to the verbal category that has been used to designate this legal category.

\footnotetext{
355 Above n 269.

356 This verbal category may be a single word or may be a phrase. It is the language that has been used to designate the legal category, that is, language that is being interpreted by the court.
} 
The following sections of this chapter will discuss two specific judicial fallacies. The first fallacy is caused by the assumption that because an item can be put within the verbal category which has been used to designate the legal category, it should be put within this legal category. The second fallacy is caused by the assumption that because an item can be put within a different verbal category from the verbal category which has been used to designate the legal category, it should be put outside this legal category.

These assumptions can result in judicial fallacies. The verbal category to which an item can be assigned may be an irrelevant consideration in relation to the specific act of categorisation before the court. If the introduction of this irrelevant consideration results in an interpretive decision being reached that would most likely not have been reached if this consideration had not been introduced, the interpretation is fallacious. Furthermore, the introduction of such an irrelevant consideration often results in the neglect of relevant considerations. Therefore, a fallacy caused by these assumptions always involves the introduction of at least one irrelevant consideration (the verbal category to which an item can be assigned) and usually also involves in the neglect of relevant considerations. Such a fallacy can be viewed as an instance of the general judicial fallacy defined in the previous section of this chapter.

The first fallacy discussed in this chapter involves the assumption 'same verbal category, therefore, within legal category'. This can be called the 'same verbal category' fallacy. The second fallacy discussed in this chapter involves the assumption 'different verbal category, therefore, outside legal category'. This can be called the 'different verbal category’ fallacy. ${ }^{357}$

These two fallacies correspond to the 'same category' fallacy and the 'different category' fallacy identified in Chapter Three. They have been described differently from these ordinary language fallacies, however, because legal interpretation that involves categorisation focuses on assigning an item to a legal category rather than discovering the item which has been assigned to a category. If the goal of an interpreter is to discover an item, a categorisation fallacy is caused by the assumption 'same category, therefore, same item'. If the goal of an interpreter is to assign an item to the correct legal category, a categorisation fallacy is caused by the assumption 'same verbal category, therefore, within legal category'. Therefore, the focus of legal interpretation means that judicial fallacies need to be described differently from the ordinary language fallacies identified in Chapter

\footnotetext{
${ }^{357}$ When these fallacies are named, single quotation marks are used around the words 'same verbal category' and 'different verbal category' because this is clearer when this name appears in a sentence.
} 
Three, although they both involve the same basic categorisation error. ${ }^{358}$

The following two sections of this chapter will discuss these two interpretation fallacies. In order to explain the nature of these fallacies clearly, these sections will each primarily focus on one instance of judicial interpretation and will go into some detail to demonstrate why the interpretations were fallacious. These decisions have been chosen because they provide clear, prototypical examples of fallacies. A detailed discussion of these decisions, therefore, shows clearly what these fallacies involve and how they can be detected.

3 Same verbal category, therefore, within legal category

In ordinary interpretation, the task of interpreters is to correctly ascertain a speaker's meaning. In legal interpretation that involves categorisation, the task of interpreters is to assign the item at issue to the correct legal category. In both situations, interpretation is objective. This means that both kinds of interpretation need to be based on objective relevant considerations.

The first interpretation fallacy in Chapter Three was the 'same word' fallacy. This fallacy involves the interpreter making an assumption that because a speaker uses a word that the interpreter associates with a certain meaning, the speaker is expressing that meaning. The goal of an interpreter, however, should be to ascertain a speaker's meaning based on relevant considerations. This assumption causes interpreters to overlook the relevant considerations that indicate the speaker’s meaning.

A corresponding judicial fallacy involves the assumption: 'same verbal category, therefore, within legal category’. It involves a judge making an assumption that because the item under consideration can be assigned to a certain verbal category, it should be included within a legal category which has been designated by the same verbal category. The goal of judicial interpretation which involves categorisation, however, is to assign items to legal categories based on relevant legal considerations. This assumption causes the judge to overlook these relevant legal considerations.

The fact that an item can be assigned to the verbal category that has been used to designate the legal 358 The fact that these judicial fallacies and the ordinary language fallacies discussed in Chapter Three both involve the
same categorisation error is shown in Chapter Four C.6. 
category does not mean that it should necessarily be included within this legal category. Whether or not an item should be assigned to a legal category depends on relevant legal considerations, not merely the verbal category to which it can be assigned.

The area in which the courts engage in interpretation the most is statutory interpretation. ${ }^{359}$ This section will analyse an American decision interpreting a provision of the United States Code dealing with the involvement of firearms in a drug trafficking offence. This section will do four things. First, it will introduce this decision and discuss the act of interpretation that occurred, that is, the act of categorisation that occurred, and will compare this decision to an analogous decision. Second, it will discuss whether this act of interpretation reached the correct linguistic meaning of the word being interpreted. Third, it will elicit various relevant legal considerations related to this act of categorisation and will also determine whether the considerations that the Court introduced were relevant. Fourth, it will determine whether the instance of judicial interpretation in this decision was fallacious.

The United States Supreme Court decision Smith $v$ United States ${ }^{360}$ concerned the interpretation of 18 USC $\S 924(c)(1)$, which referred to "any person who, during and in relation to any ... drug trafficking crime ... uses or carries a firearm”. The defendant ${ }^{361}$ attempted to trade a MAC-10 firearm for two ounces of cocaine and was charged with two drug trafficking offences. ${ }^{362}$ Importantly, "the indictment alleged that the [defendant] knowingly used the MAC-10 and its silencer in relation to a drug trafficking crime.” ${ }^{363}$ Under $§ 924(c)(1)$, a person who uses a firearm is subject to a mandatory prison sentence of five years, ${ }^{364}$ and, if, as in this situation, the firearm is a "machinegun ... or is equipped with a firearm silencer", ${ }^{365}$ the mandatory prison term is 30 years. ${ }^{366}$

\footnotetext{
359 "[P] robably as many as nine out of ten cases heard on appeal by the Court of Appeal and the House of Lords turn upon or involve the meaning of words contained in statutes or secondary legislation.” Zander, above n 241, at 128; "The vast majority of cases decided in [New Zealand] courts involve the application of statutes." Burrows and Carter, above n 334, at v.

360 Smith $v$ United States (1993) 113 SCt 2050 [Smith].

361 The decision refers to the defendant as 'the petitioner'. For convenience, this discussion will use the term 'defendant'.

${ }^{362}$ Smith, above n 360, at 2053.

363 Ibid.

36418 USC § 924(c)(1)(A)(i).

365 The MAC-10, a machine pistol, came within the definition of 'machinegun' in this Statute (26 USC § 5845(b)), especially since it "had been modified to operate as an automatic" (Smith, above n 360, at 2052).

36618 USC § 924(c)(1)(B)(ii).
} 
The issue for the Court ${ }^{367}$ was whether the defendant's actions constituted use of a firearm within the meaning of this provision. ${ }^{368}$ Therefore, the case involved the interpretation of the word 'use'. Viewing this interpretive decision in relation to categorisation, the issue was whether the item before the Court (the defendant's actions) should be assigned to the legal category designated by the word 'use' in this provision.

Justice O’Connor, delivering the majority opinion, stated: "When a word is not defined by statute, we normally construe it in accord with its ordinary or natural meaning." 369 She consulted definitions of 'use' in Webster's New International Dictionary and Black's Law Dictionary and concluded that the defendant's actions fell "squarely" within those definitions. ${ }^{370}$ She stated that the defendant's actions: ${ }^{371}$

can be described as 'use' within the everyday meaning of that term. [The defendant] 'used' his MAC-10 in an attempt to obtain drugs by offering to trade it for cocaine.

She concluded that "using a firearm in a guns-for-drugs trade may constitute 'us[ing] a firearm' with the meaning of $\S 924(c)(1) . " 372$ Furthermore, she held that there was no need to precisely determine the meaning of the phrase 'in relation to' because the defendant's use of the gun "meets any reasonable construction" of this phrase. ${ }^{373}$ Therefore, the defendant's actions were held to be within the meaning of this provision, that is, the item at issue was held to be within this legal category, ${ }^{374}$ and the defendant was subject to the mandatory minimum 30 -year sentence. ${ }^{375}$

In her decision, Justice O’Connor approvingly quoted a Court of Appeals decision ${ }^{376}$ discussing this provision in relation to the trading of guns: ${ }^{377}$

It may well be that Congress, when it drafted the language of [§] 924(c), had in mind a more obvious use

\footnotetext{
${ }^{367}$ In this thesis, the word 'court' is capitalised when it is referring to a specific court. Therefore, in the discussion of interpretation fallacies, this word is often deliberately capitalised.

368 Smith, above n 360, at 2052.

369 Ibid, at 2054.

370 Ibid.

${ }^{371}$ Ibid.

372 Ibid, at 2058.

373 Ibid, at 2059.

374 The legal category can either be viewed as being designated by the verbal category 'use' or by the verbal category 'uses a firearm'. As long as the verbal context is borne in mind, it is convenient to view the legal category as being designated by the verbal category 'use'.

${ }^{375}$ Smith, above n 360, at 2060.

376 United States v Harris (1992) 294 US AppDC 300 (SC).

377 Smith, above n 360, at 2059 (insertions in original).
} 
of guns in connection with a drug crime, but the language [of the statute] is not so limited [;] nor can we imagine any reason why Congress would not have wished its language to cover this situation.

The basic reason for Justice O'Connor's interpretation was that the defendant's actions could fit within the meaning of the word 'use'. This instance of interpretation, therefore, involved the assumption that because the item before the Court (the defendant's actions) could be assigned to the verbal category which was used to designate the legal category (that is, the verbal category 'use'), this item should be within this legal category. Whether or not the defendant's actions should be within this legal category, however, should be determined by the relevant legal considerations, and not merely the verbal category to which they could be assigned. Justice O'Connor could not imagine any reason why the legislature would not have wished this item to be within this legal category. To determine whether there are any reasons why this item should not be within this category, it is necessary to take into account the legal considerations relevant to this act of categorisation. Once these legal considerations are clear, it will be possible to determine whether Justice O’Connor’s interpretation was fallacious.

In a dissenting opinion, Justice Scalia stated: “To use an instrumentality ordinarily means to use it for its intended purpose" 378 and "to speak of 'using a firearm' is to speak of using it for its distinctive purpose, i.e., as a weapon.” ${ }^{379}$ He stated that the majority “does not appear to grasp the distinction between how a word can be used and how it ordinarily is used." ${ }^{380}$ He concluded that the provision should not apply to the trading of a gun. Therefore, on his decision, the item (the defendant's actions) should have been outside this legal category.

Before critiquing this decision, it is useful to compare it to an analogous decision, Muscarello $v$ United States, ${ }^{381}$ where the same provision was being interpreted (18 USC § 924(c)(1)) but the word at issue was 'carries'. The defendant, Frank Muscarello, ${ }^{382}$ had a firearm locked in the glove compartment of a truck which he used to drive to a location where he was selling drugs. ${ }^{383}$ The issue in this decision was whether he 'carried' the firearm or, more specifically, as stated by the Court, “whether the phrase 'carries a firearm' is limited to the carrying of firearms on the

\footnotetext{
378 Ibid, at 2061.

379 Ibid (italics in original).

380 Ibid (italics in original).

${ }^{381}$ Muscarello v United States (1998) 118 SCt 1911 [Muscarello].

382 There were three defendants, but for simplicity this analysis will just focus on Frank Muscarello. The other defendants had guns in the trunk of their car.

${ }^{383}$ Muscarello, above n 381, at 1914.
} 
person." ${ }^{384}$ Viewing this interpretive decision in relation to categorisation, the issue was whether the item before the Court (the defendant's actions) should be assigned to the legal category designated by the word 'carries' in this provision.

Delivering the majority decision, Justice Breyer consulted the Oxford English Dictionary, Webster's Third New International Dictionary and Random House Dictionary of the English Language to ascertain the primary meaning of the word 'carry'. ${ }^{385}$ He also considered the etymological origin of the word, ${ }^{386}$ and considered examples of how the word had been used in literature and newspapers. ${ }^{387}$ He stated that: "The relevant linguistic facts are that the word 'carry' in its ordinary sense includes carrying in a car”388 and that "neither the statute's basic purpose nor its legislative history support circumscribing the scope of the word 'carry' by applying an 'on the person' limitation.” ${ }^{389}$ Therefore, the defendant's actions were held to be within the scope of the phrase 'carries a firearm', ${ }^{390}$ that is, within the legal category designated by this phrase, ${ }^{391}$ and he was convicted of this offence.

In a perceptive dissenting opinion, Justice Ginsburg concluded that 'carries a firearm' indicates “not merely keeping arms on one's premises or in one's vehicle, but bearing them in such manner as to be ready for use as a weapon.”392 She focused not on the meaning of 'carries' but on the meaning of 'carries a firearm' and conducted a computer search of newspapers using this phrase. ${ }^{393}$ She also looked at the definition of the phrase in Black's Law Dictionary. ${ }^{394}$

More importantly, in coming to her conclusion, Justice Ginsburg took into account what was at stake for the defendant. She took into account the fact that the majority's interpretation would result in a five-year minimum prison term. ${ }^{395}$ She noted that if there had not been any gun present during the criminal activity, the sentencing range for the offence under the United States Sentencing

\footnotetext{
384 Ibid, at 1913.

385 Ibid, at 1914.

${ }^{386}$ Ibid. He consulted the Barnhart Dictionary of Etymology and the Oxford Dictionary of English Etymology.

387 Ibid, at 1914-1915.

388 Ibid, at 1916.

389 Ibid.

390 Ibid, at 1919-1920.

391 This legal category can either be viewed as being designated by the verbal category 'carries' or by the verbal category 'carries a firearm'.

392 Muscarello, above n 381, at 1920.

393 Ibid, at 1921.

394 Ibid.

395 Ibid, at 1920-1921.
} 
Commission Guidelines Manual would have been between six to twelve months. ${ }^{396}$ The fact that a firearm was 'possessed' during the offence would have increased this range to between ten to sixteen months. ${ }^{397}$ Furthermore, she stated that "it is not apparent why possession of a gun in a drug dealer's moving vehicle would be thought more dangerous than gun possession on premises where drugs are sold.” ${ }^{398}$ She concluded that the defendant should not be convicted under this provision. Therefore, on her decision, the item (the defendant's actions) was excluded from this legal category.

For simplicity, this analysis will focus on Smith, ${ }^{399}$ but many of the points discussed will also apply to Muscarello. This analysis will elicit a number of important legal considerations relevant to the act of interpretation in Smith. Some of these considerations relate to the specific provision being interpreted, others to criminal law, and others relate to the law generally. They are all legal considerations relevant to this act of legal categorisation. This discussion will also consider the considerations that were taken into account by the Court ${ }^{400}$ in Smith and determine whether they were relevant.

The relevant legal considerations can be viewed as indicators of legislative intention. Legislative intention is really a fiction, and is a way of referring to the reasons for the law and the goals of the law in statutory interpretation. Viewed in relation to categorisation, it is a way of referring to the reasons for the legal category and the goals of the category. It is convenient to view some of the relevant legal considerations as indicators of legislative intention. ${ }^{401}$ For this reason, this analysis will sometimes view these considerations as indicators of legislative intention, but it will primarily view them in relation to categorisation.

In statutory interpretation, an important consideration is the meaning of the words being

396 Ibid, at 1920

397 Ibid, at 1921.

398 Ibid, at 1922.

399 In Watson $v$ United States (2007) 552 US 74 (SC) the United States Supreme Court in a unanimous decision interpreting the same provision (18 USC $\S 924(c)(1)$ ) held that a transaction going the other way, that is, the trading of drugs for a firearm, did not constitute 'using' a firearm. The Court did not, however, overrule Smith. In a concurring opinion, Justice Ginsburg stated that she would overrule Smith to "render our precedent both coherent and consistent with normal usage.” (at 84).

400 In this analysis, the word 'Court' will be used to refer to the majority decision in Smith.

401 Writing extra-judicially, Lord Hoffmann stated that in relation to the interpretation of legislation or a Constitution "there is obviously no question of ascertaining the meaning of a real person. Instead, the court is concerned with what it calls the intention of Parliament or the framers of the Constitution. These are legal constructs ... but they are none the less useful shorthand to identify the imaginary speaker whose utterances the courts are concerned to interpret.” Hoffmann, above n 338, at 663. 
interpreted. ${ }^{402}$ This meaning is important because the words have been specifically chosen to designate the legal category and, therefore, their correct linguistic meaning often indicates the reason for this category. In Smith, the Court primarily focused on the meaning of the words being interpreted. This determination of meaning, however, was influenced by certain legal considerations. The most notable legal consideration the Court focused on in Smith was that words should be given their "ordinary or natural meaning”. ${ }^{403}$ One reason for this legal consideration is that the legislature uses words with their ordinary meaning, therefore ascertaining the ordinary meaning of the words being interpreted shows the intention of the legislature. Therefore, it shows the reason for the legal category. ${ }^{404}$ Another reason for this consideration is that the public are regulated by statutes, so statutory words should be given a meaning with which the public are familiar. ${ }^{405}$ This is a consideration in relation to a goal of the law generally: to be intelligible to the public. $^{406}$

The provision being interpreted was "any person who, during and in relation to any ... drug trafficking crime ... uses or carries a firearm”. ${ }^{407}$ The Court, however, did not look at the meaning that should be given to 'use' in this context, that is, the meaning the word did have, but the ordinary meaning of 'use', the meaning the word can have. ${ }^{408}$ The meaning a word can have is the thought generally associated with this word. ${ }^{409}$ This general meaning, however, does not conclusively determine the meaning of the word in a specific context. The fact that the defendant's behaviour can fit within an ordinary meaning of the word 'use' does not mean that it necessarily fits within the meaning of the word in this specific instance.

The dissent's approach to meaning seems more correct. Justice Scalia drew a distinction between

\footnotetext{
402 This corresponds to consideration 1.1 in Chart 4.1.

403 Smith, above n 360, at 2054.

404 This corresponds to consideration 2.1 in Chart 4.1. Because the ordinary meaning of the words being interpreted shows the reason for the legal category, a consideration of this meaning can either be viewed as corresponding to consideration 1.1 in Chart 4.1 or as corresponding to consideration 2.1.

405 These two reasons were explained clearly by J F Burrows: "[I]n many cases, decisions are made simply on the basis of 'ordinary meaning', 'primary meaning', 'dictionary meaning' ... It is important that this should be so, for people should be entitled to rely on what they regard as an indisputably obvious meaning. Moreover, any other view would make nonsense of the careful use of words by drafters, and would render difficult any sensible theory of communication.” Burrows, above n 334, at 293.

406 This corresponds to consideration 4.3 in Chart 4.1. Therefore, another reason that consideration 1.1 is relevant in this instance is that it accords with this goal of the law. Compare n 404.

40718 USC § 924(c)(1).

408 Justice O'Connor stated that defendant's "treatment of his MAC-10 can be described as 'use' within the everyday meaning of that term.” (Smith, above n 360, at 2054 (emphasis added)).

409 See the paragraph accompanying n 135.
} 
"how a word can be used and how it ordinarily is used." 410 At issue, however, is not the ordinary meaning of the word 'use', but the meaning in this specific instance. The fact that the word 'use' can mean to use as an item of barter should not be conclusive. Even if it could be proven that this word is ordinarily used with this meaning, this should still not settle the issue. Any considerations related to the meaning of the word which do not help to indicate the meaning the word has in this instance of use are irrelevant considerations.

Justice Scalia noted that to use something ordinarily means "to use it for its intended purpose.»411 Regardless of whether it 'ordinarily' means this, given the context of criminal activity and the requirement that the use be 'in relation to' this activity, it is likely that 'use' in this provision means to use as a weapon. Furthermore, the word 'use' should be considered in relation to the word 'carry'. Because the using and carrying are of a firearm, when these words are used together, 'carry' would seem to indicate to have on one's person ready to use as a weapon, whereas 'use' would seem to indicate to use as a weapon, which would include brandishing, pistol whipping, or discharging. The phrase 'uses or carries', therefore, captures people who merely have a firearm with them, but do not use it, and those who both have it at hand and use it. Justice Scalia concluded that 'use' refers to use as a weapon and 'carry' refers to having ready for use as a weapon. ${ }^{412}$ It is most likely that this is the correct linguistic meaning of these words in this context.

Therefore, it is most likely that the correct linguistic meaning of the word 'use' in this context is use as a weapon, and not merely use as an item of trade. It is most probably incorrect on a purely linguistic basis to conclude that 'use' in this context should include using as an item of commerce. ${ }^{413}$ As has been mentioned, the correct linguistic meaning of the word being interpreted is a relevant legal consideration for two reasons: it shows the reason for the legal category and it accords with the general legal principle that statutes should be intelligible to the public. ${ }^{414}$ Therefore, the Court should have taken into account the relevant legal consideration of the correct linguistic meaning of the word 'use' in this context. The meaning the word 'use' can have is an irrelevant consideration if it does not show the meaning the word does have. The result of the Court's approach to meaning was that a meaning was given to the word 'use' that was most

\footnotetext{
410 Smith, above n 360, at 2061 (italics in original).

411 Ibid, at 2061.

412 Ibid, at 2063.

${ }^{413}$ For an analysis of the approaches to linguistic meaning in both Smith and Muscarello, see Solan, above n 26, at 258259.

414 Therefore, as mentioned in n 404 and n 406, a consideration in relation to ordinary meaning can either be viewed as corresponding to consideration 1.1 in Chart 4.1 or as corresponding to considerations 2.1 and 4.3.
} 
probably neither the meaning the legislature would have intended nor the meaning that the public would have expected. Thus, the way the legal consideration of giving words their ordinary meaning was applied had the opposite of its intended effect.

The Court had to decide whether the defendant's actions fitted within this provision. This is to decide whether this item should be assigned to this legal category. In relation to this act of categorisation, a relevant consideration is the linguistic meaning of the word being interpreted. The meaning the word being interpreted can have is only relevant to this decision if indicates the meaning the word does have. In this instance, the meaning that the Court decided the word 'use' could have was not relevant to the meaning it did have. Thus, the relevant legal consideration that words should be given their ordinary meaning was misapplied and this caused the Court to introduce an irrelevant consideration. This shows clearly how legal considerations that a court introduces should be related to the specific act of categorisation at issue. If they are not related to this act of categorisation, they can be misapplied and this can result in the introduction of irrelevant considerations.

Judicial interpretation, however, involves more than merely ascertaining the correct linguistic meaning of the words being interpreted. Even if the majority could be convinced that they gave an incorrect meaning to the word being interpreted, this fact by itself would not be sufficient to prove that the interpretive decision was wrong. The interpretation section of this chapter has shown that there are situations in which it is legally justifiable for judges to give unnatural meanings to words. To limit judicial discretion to assigning the correct linguistic meaning to words would defeat the whole purpose of having judges interpret language. If linguistic meaning is all that is at issue in legal decision-making, judges could be replaced by linguists or lexicographers. ${ }^{415}$ The issue, therefore, is not merely whether the Court arrived at the correct linguistic meaning of the word being interpreted, but whether the interpretation was justified by relevant legal considerations. This will determine whether the item at issue was assigned to the correct legal category. The correct linguistic meaning of the word is only one relevant legal consideration related to this act of categorisation. It is therefore necessary to elicit other legal considerations relevant to this act of categorisation.

A rule in statutory interpretation is that words should be given a consistent meaning within a ${ }^{415}$ For an article addressing the issue of "why linguistics should have anything to offer those who would interpret legal
texts” (at 1047), see Robert K Rasmussen "Why Linguistics" (1995) 73 Wash U L Q 1047 . 
statute. ${ }^{416}$ The reason for this rule is that the legislature uses words with consistent meanings throughout a statute. The Court in Smith noted that elsewhere in the statute the word 'use' referred to use of a firearm as an item of barter. ${ }^{417}$ Justice Scalia correctly dismissed this argument by noting that the word 'use' is not a technical term or a legal term, but a common word that is "inordinately sensitive to context." ${ }^{418}$ With a word like 'use', it is erroneous to assume that because it includes bartering in one provision, it must have that meaning in all other provisions in the same statute. The aim of this rule of interpretation is to help judges discover the legislature's intention in using words. The way it was applied in this case, however, resulted in a frustration of that intention. This rule should not have been applied rigidly, but should only have been applied if it was relevant to this specific legal category. If this rule had been considered in the light of this specific act of legal categorisation, it would have been very clear that this rule was inapplicable in this instance of interpretation.

A rule of statutory interpretation in relation to criminal law is the rule of lenity. This is the rule that ambiguous criminal statutes should be interpreted in favour of defendants. ${ }^{419}$ The reason for this rule was given in a statement quoted by Justice Ginsburg in Muscarello: ${ }^{420}$

[B]ecause of the seriousness of criminal penalties, and because criminal punishment usually represents the moral condemnation of the community, legislatures and not courts should define criminal activity. This policy embodies the instinctive distaste against men languishing in prison unless the lawmaker has clearly said they should.

Justice O’Connor in Smith stated that the “mere possibility of articulating a narrower construction ... does not by itself make the rule of lenity applicable.” ${ }^{421}$ She held that the provision was not sufficiently ambiguous for the rule to apply.

The rule of lenity is a relevant legal consideration because it is a general legal rule related to this kind of categorisation (categorisation in criminal law). The fact that a dissenting opinion was filed (with which two other judges joined) holding that the word had a different meaning from the

\footnotetext{
${ }^{416}$ A United States Supreme Court authority on this point is Texas Department of Transportation v Needham (2002) 82 SW3d 314 (SC): "Statutory terms should be interpreted consistently in every part of an act." (at 318). This corresponds to consideration 4.1 in Chart 4.1.

${ }^{417}$ Smith, above n 360, at 2057.

418 Ibid, at 2062.

419 Ibid, at 2063. This corresponds to consideration 4.1 in Chart 4.1.

${ }^{420}$ Muscarello, above n 381, at 1925. Justice Ginsburg is quoting from United States v Bass (1971) 404 UC 336 (SC) at 348.

${ }^{421}$ Smith, above n 360, at 2059.
} 
meaning at which the Court arrived should have been an indication that there was sufficient ambiguity for this rule to apply. Furthermore, whether or not a rule is applicable should be determined by the reason for the rule. Since the reason for this rule is distaste against people languishing in prison, the length of the prison sentence (a 30-year mandatory prison term) should be a relevant factor in applying this rule. Therefore, this rule should have been applicable in this decision.

It can be seen in an even clearer way that this rule should have been applicable when this decision is viewed in relation to categorisation. A decision regarding whether the rule of lenity was applicable in this instance of interpretation should have been made in light of this specific act of categorisation. This means that the consequence of this act of categorisation (the length of the prison sentence) is relevant to the decision regarding whether this rule is applicable. Taking this consequence into account, it is clear that this rule should have been applicable and the word 'use' should have been held to be ambiguous and this ambiguity should have been resolved in the defendant's favour. Therefore, the rule of lenity was a relevant legal consideration that was misapplied in this decision because it was not applied in light of the act of categorisation at issue.

An important legal consideration is the purpose of the provision under consideration. ${ }^{422}$ This purpose shows the reason the category was established. In relation to the purpose of this provision, the Court in Smith noted that "drugs and guns are a dangerous combination." 423 The problem with describing the purpose of the provision at this level of generality is that it covers any situation where a weapon is present in a drug crime. The provision, however, refers to when firearms are used in relation to a drug crime. The provision is aimed at situations in which the use of a firearm is a factor in the crime, ${ }^{424}$ not merely at the general combination of drugs and guns. The Court also noted that "an item of commerce ... can be converted instantaneously from currency to cannon.” ${ }^{425}$ Although this is true, again this is not what this provision is aimed at. It is aimed at situations where the gun is actually used, not merely where there is a potential for it to be used. If the legislature merely intended to catch any situation where drugs and guns were combined, where a weapon was

\footnotetext{
${ }^{422}$ This corresponds to consideration 2.1 in Chart 4.1.

${ }^{423}$ Smith, above n 360, at 2060.

${ }^{424}$ This corresponds to consideration 3.1 in Chart 4.1.

${ }^{425}$ Smith, above n 360, at 2060.
} 
present in a drug crime, a better word would have been 'possessed'. ${ }^{426}$ If the meaning of the word 'use' in this provision is to be extended to cover trading, there needs to be a strong legal justification based on the specific purpose of this provision. The purpose of a provision considered at a high level of generality is an irrelevant consideration. It is not the specific purpose behind this category. Therefore, the legal consideration of the purpose of the provision was misapplied because it was not viewed in relation to this specific category. This misapplication resulted in the introduction of an irrelevant consideration. The specific purpose of the provision is shown by the correct linguistic meaning of the word. This specific purpose is to catch situations in which a gun is used as a weapon in a drug crime.

Another relevant legal consideration is the consequence of an interpretive decision. This is the consequence of putting the item at issue in the legal category. ${ }^{427}$ It is useful to estimate the sentence the defendant in Smith would have received for his drug offences ${ }^{428}$ under the United States Sentencing Commission Guidelines Manual if he had not been convicted of using a gun in the course of this offence under § 924(c)(1). ${ }^{429}$ Under the Guidelines, the defendant's base offence level for conspiracy to possess two ounces of cocaine (57 grams) with intent to distribute would be $16 .{ }^{430}$ A two-level enhancement for possessing a firearm brings this level up to $18,{ }^{431}$ which would give him a sentence range of 27-33 months. ${ }^{432}$ This sentence could be increased based on his criminal history $^{433}$ or reduced due to his acceptance of responsibility. ${ }^{434}$ Because the defendant was convicted of using a firearm in the course of his offending, he was subject to a 30-year mandatory minimum sentence, regardless of any previous offending or acceptance of responsibility. This significant discrepancy in prison time between a conviction for using a weapon during a drug crime

426 This provision was amended in 1998 to include a reference to a person who "in furtherance of any such crime, possesses a firearm” (18 USC § 924(c)(1)). Although this is not relevant to the decision in Smith, it is consistent with the argument that the legislature was not concerned with the danger that mere possession of a firearm posed, but with possession in furtherance of a crime. In 2002 it was amended again and now gives a longer sentence when the firearm is 'brandished' and even longer one when it is 'discharged'. Again, this is not relevant to the decision in Smith, but shows the meaning of 'use' in an even clearer way. Since both brandishing and discharging are to use a firearm as a weapon, it is likely that use which is not brandishing nor discharging would still be use as a weapon, perhaps using the firearm to intimidate without brandishing it.

427 This corresponds to consideration 2.2 in Chart 4.1.

${ }^{428}$ He was also convicted of other offences which are not relevant to this analysis (Smith, above n 360, at 2053).

${ }^{429}$ Although the Sentencing Guidelines were not discussed in Smith, Justice Ginsburg discussed the sentencing of the defendant in Muscarello in detail (above n 381, at 1920-1921), and this calculation of the probable sentence in Smith is based on her discussion.

430 United States Sentencing Commission Guidelines Manual § 2D1.1(c).

431 Ibid, $\S 2 \mathrm{D} 1.1(\mathrm{~b})(1)$.

432 Ibid, § 5A Sentencing Table.

433 Ibid.

434 Ibid, § 3E1.1(a). 
and a conviction for merely possessing a weapon during such a crime ${ }^{435}$ needs to be borne in mind, and indicates that 'use' refers to something much more significant than mere possession. The consequence of assigning the item to this category is a relevant legal consideration that the Court did not take into account.

A related legal consideration is that if the defendant had not been convicted under $\S 924(c)(1)$, the fact that the defendant possessed a firearm during transaction would still be taken into account in his sentencing. Therefore, the defendant's action was already captured by a different legal category. ${ }^{436}$ The dangerous combination of drugs and guns and the potential for an item of commerce to be converted into a cannon would thus be taken into account by the longer sentence which would be given for possessing this firearm. Indeed, these factors are most probably the reason for the sentence enhancement for possession of a firearm. The fact that the defendant's actions were already captured by a different provision indicates that § 924(c)(1) was not intended to capture these actions. This fact is a relevant legal consideration that the Court omitted.

A further relevant legal consideration is how the law would treat analogous situations, that is, how the law would treat analogous items to the item at issue. ${ }^{437}$ This legal consideration relates to the law generally. Since the law treats like situations alike, ${ }^{438}$ (shown, for instance, by the doctrine of precedent) how the law would deal with analogous situations is relevant. An analogous situation would be trading jewellery for drugs. Since the firearm was not used as a weapon but an item of barter, the only legally relevant distinction between these actions is that there was a potential for the firearm to be used. This distinction would be taken into account by the increased sentence for possessing a firearm. This distinction, however, does not justify the much harsher penalty given under § 924(c)(1). There needs to be a legal reason for distinguishing between these situations and giving a much harsher penalty when a firearm is traded. This fact that an analogous situation would be in a different legal category is a relevant legal consideration that the Court did not take into account. ${ }^{439}$

An even stronger analogy, however, can be drawn. If the defendant had used the firearm as a weapon, he would definitely have been caught under this provision. Under Court's decision,

\footnotetext{
${ }^{435}$ This corresponds to consideration 3.3 in Chart 4.1.

436 This corresponds to consideration 2.3 in Chart 4.1.

${ }^{437}$ This corresponds to consideration 3.4 in Chart 4.1.

${ }^{438}$ For a brief discussion of this aspect of the law, see John Farrar Introduction to Legal Method (Sweet \& Maxwell, London, 1977) at 63-76.

${ }^{439}$ This corresponds to consideration 3.3 in Chart 4.1.
} 
therefore, the law treats the use of a firearm as a weapon in the same way as its use as an item of barter. This means that these two actions are legally indistinguishable and punishable by the same penalty. The Court's decision resulted in two fundamentally different actions being in the same legal category. ${ }^{440}$ A strong argument can be made that the legislature would have intended there to have been a distinction between these two actions. This is a relevant legal consideration that the Court did not introduce.

It is now necessary to determine whether the Court's decision in Smith was fallacious. The issue in Smith was whether the defendant's actions should be within the meaning of the phrase 'use a firearm', that is, whether they should be assigned to this legal category. In order to make this decision the Court should have taken into account the relevant legal considerations related to this act of categorisation. These include considerations related to the word being interpreted, the legal category, items that are relevant to the category, and general legal considerations.

The specific relevant legal considerations that the Court should have taken into account in Smith include: the correct linguistic meaning of the word 'use' in this context (which relates to the reason for this category and the general legal principle that the law should be intelligible), the specific purpose behind this category, the consequence of putting an item in this category, the fact that possession of the firearm during a drug offence was captured by another category, how the law would treat analogous items, the fact that fundamentally different items would be captured by this category, and the rule of lenity. The Court did not introduce any of these relevant legal considerations. $^{441}$

The Court should not have taken into account any considerations that were irrelevant to this act of categorisation. The Court focused on the fact that the defendant's actions could be described by the word 'use'. Therefore, the basic assumption behind the Court's decision was that because the defendant's action could be put in the verbal category used to designate the legal category, it should be put within this legal category. This consideration was irrelevant because even though it is possible to describe the defendant's actions by the word 'use', this was not the correct linguistic meaning of 'use' in this provision. The primary irrelevant consideration that the court took into

\footnotetext{
440 This corresponds to considerations 3.2 in Chart 4.1.

${ }^{441}$ In Chart 4.1 there are eleven groups of legal considerations that are potentially relevant to judicial interpretation. There were considerations in ten of these groups which were relevant to the decision in Smith (the only consideration not relevant was consideration 4.2 which is policy considerations). The Court either ignored these considerations or misapplied them.
} 
account, therefore, was the fact that the item could be put within the verbal category 'use'. Other irrelevant considerations included an inapplicable general formulation of the purpose behind the category and the application of a rule of interpretation (the intra-statutory consistency of meaning) without regard to whether it was relevant to this act of categorisation.

This interpretive decision was fallacious because it is most likely that a different result would have been reached if the relevant legal considerations had been taken into account and irrelevant considerations had been omitted. This can be shown by the fact that the dissenting opinion, which omitted the main irrelevant consideration and introduced a more relevant consideration (how a word is ordinarily used, rather than how it can be used), reached a different result.

Although the decision in Muscarello has not been analysed in detail, the relevant legal considerations are similar. Furthermore, the interpretive decision was based on a similar irrelevant consideration (how the word 'carry' can be used). This interpretive decision was also fallacious because it is most likely that a different result would have been reached if this irrelevant consideration had been omitted and the relevant legal considerations had been introduced. This can be shown by the fact that the dissention opinion, which omitted the irrelevant consideration and introduced a relevant consideration (the consequence of the decision), reached a different result.

Alternative, non-fallacious interpretations for both Smith and Muscarello can be reached by making these interpretive decisions on the basis of the relevant legal considerations rather than irrelevant considerations. Therefore, a non-fallacious interpretation in Smith would result in the defendant's actions being outside the scope of the word 'use', and in Muscarello it would result in the defendant's actions being outside the scope of the word 'carries'. If the Courts had arrived at these non-fallacious interpretations, the decisions would have achieved the desired goals of the provisions being interpreted and would have done so for the correct reasons. Therefore, the decisions would have correctly implemented the law and would have been legally justifiable decisions.

This analysis has shown that it is possible to detect fallacies when judicial interpretation is viewed as categorisation based on relevant considerations. It has also shown that it is possible to provide alternative, non-fallacious interpretations when such fallacies have been committed.

To conclude it is useful to briefly consider why this fallacy was committed in Smith, and how such a fallacy can be avoided. First, the Court in Smith focused on the meaning of the word 'use'. This 
focus on meaning introduced the possibility of the irrelevant consideration of the meanings this word can have in the abstract. Furthermore, viewing judicial interpretation as the discovery of meaning limited the Court's view. Justice O’Connor could not “imagine any reason why Congress would not have wished its language to cover this situation”. ${ }^{442}$ These reasons are seen clearly when legal interpretation is viewed in relation to categorisation, and not merely in relation to ascertaining the meaning of the word being interpreted. Even an approach to interpretation focused on legislative intention does not elicit all the relevant considerations as clearly as an approach based on categorisation. $^{443}$

Second, the Court's approach was primarily focused on the word 'use' and the meaning it could have and not the defendant's actions and whether they should fit within this legal category. This means the Court focused on the category and the items that should be within it, rather than the item at issue and whether it should be within the category. If the focus had been on how to categorise the defendant's actions, it would have been clear that a possible meaning that the word 'use' can have in the abstract is not relevant to how the defendant's actions should be categorised unless it indicates the meaning the word does have. Furthermore, if the focus had been on the item at issue and how it should be categorised, the Court would have seen that the legal considerations that were introduced needed to be related to this act of categorisation, and these legal considerations would not have been misapplied.

Therefore, viewing interpretation in relation to categorisation is not only a useful way to detect fallacies, but also provides a way for judges to avoid them.

\section{$4 \quad$ Different verbal category, therefore, outside legal category}

The second interpretation fallacy in Chapter Three was the 'different word' fallacy. This fallacy involves the interpreter making an assumption that because a speaker does not use the word that the interpreter associates with a certain meaning, the speaker is not expressing that meaning. This assumption causes interpreters to overlook the relevant considerations which indicate the speaker's meaning.

\footnotetext{
442 See text accompanying $n 337$.

443 Although considerations related to the consequence of the decision, whether the item under consideration is captured by a different provision, and how other items would be treated by the law can be linked to intention, they may be overlooked by a focus on intention. The relevance of such considerations is much clearer when the decision is viewed in relation to categorisation.
} 
A corresponding judicial fallacy involves the assumption: 'different verbal category, therefore, outside legal category'. It involves a judge making an assumption that because the item under consideration can be assigned to a different verbal category from the verbal category by which the legal category has been designated, it should be excluded from the legal category. This assumption causes the judge to overlook the relevant legal considerations.

A judge may realise that the item at issue can be assigned to a different verbal category from the one used to designated the legal category. This, however, may not be sufficient for the 'different verbal category' fallacy to be committed. This fallacy often involves a judge believing that the item under consideration should be assigned to a different verbal category from the verbal category by which the legal category has been designated. This does mean that the judge always identifies a specific different verbal category to which the item should be assigned. The emphasis is usually on the fact that the item should be in a different verbal category from the one used to designate the legal category, and not necessarily on which different verbal category the item should be in.

The fact that an item can be assigned to a different verbal category from the one which has been used to designate the legal category does not mean that it should necessarily be excluded from this legal category. Even the fact that it would normally be assigned to a different verbal category does not mean that it should be excluded from the legal category. Whether or not an item should be excluded from a legal category depends on relevant legal considerations, not merely the verbal category to which it can be assigned.

The previous section discussed an American decision dealing with statutory interpretation. This section will discuss a United Kingdom decision dealing with the interpretation of a will. This section will do four things. First, it will introduce this decision and discuss the act of interpretation that occurred, that is, the act of categorisation that occurred. Second, it will discuss whether this act of interpretation reached the correct linguistic meaning of the words being interpreted. Third, it will compare this decision to an analogous decision to elicit the primary relevant legal consideration related to this act of categorisation and will also determine whether the considerations that the Court introduced were relevant. Fourth, it will determine whether the instance of judicial interpretation in this decision was fallacious. 
The House of Lords' decision National Society $v$ Scottish National Society ${ }^{444}$ concerned the interpretation of a will. The testator, who had lived in Scotland his entire life, ${ }^{445}$ bequeathed $£ 500$ to 'the National Society for the Prevention of Cruelty to Children'. ${ }^{446}$ This was the exact name of a London society, with which he had no known connection. ${ }^{447}$ Near his home, however, was the office of the Scottish National Society for the Prevention of Cruelty to Children, with whose activities he was familiar. ${ }^{448}$ The bequest was included in a series of bequests to Scottish charities. ${ }^{449}$ Furthermore, the testator's brother had become a director of the Scottish society before the will was drafted. ${ }^{450}$ The Scottish Courts gave the money to the Scottish society, as this seemed to be the testator's intention. ${ }^{451}$ The Law Lords, however, unanimously reversed this decision and the bequest went to the London society.

The Court's assignment of the bequest to the London society can be viewed as the assignment of the London society to the legal category created by the words 'the National Society for the Prevention of Cruelty to Children ${ }^{452}$ and the exclusion of the Scottish society from this category. The main reason the Law Lords refused to assign the Scottish society to this legal category was that its official name was slightly different from the words used to describe the legal category and the name of the London society was exactly the same as these words. The Scottish society could be assigned to a different verbal category (that is, 'the Scottish National Society for the Prevention of Cruelty to Children') from the verbal category by which the legal category was designated (that is, 'the National Society for the Prevention of Cruelty to Children'). Therefore, in relation to the Scottish society, this decision can be viewed as involving the assumption 'different verbal category, therefore, outside legal category'. ${ }^{453}$

\footnotetext{
444 National Society v Scottish National Society [1915] AC 207 (HL) [National Society].

445 Ibid, at 209.

446 Ibid, at 211.

447 Ibid, at 209.

448 Ibid.

449 Ibid, at 208.

${ }^{450}$ It could not be proven that he was aware of this, but he was "on intimate terms" with his brother (ibid, at 209).

451 "The Courts in Scotland [examined] the circumstances of the testator, and the evidence in regard to his presumed intention, and they came to the conclusion that the testator did really intend to benefit [the Scottish society].” (National Society, above n 444, at 212).

452 These words can be considered a name, and thus function as a proper noun. Proper nouns are not usually considered to designate categories, but rather to designate specific items (see n 203). These words, however, can still be viewed as a verbal category because the Court had to make a decision whether to assign a certain item to the category designated by these words. Furthermore, even though it is a little inaccurate to refer to proper nouns having 'meaning' (see $\mathrm{n}$ 161), in this decision the Court still referred to the 'meaning' of these words (see text accompanying n 454). For convenience, this analysis will also refer to the 'meaning' of these words.

453 As will be noted later (see Chapter Four C.6), in relation to the London society this decision can be viewed as an instance of the 'same verbal category' fallacy. Thus, these two fallacies are very closely related and whether a specific instance of fallacious interpretation is viewed as involving the 'same verbal category' fallacy or the ‘different verbal category’ fallacy may depend on the way the act of interpretation is viewed.
} 
The Court focused on the meaning of the words being interpreted. Lord Dunedin stated that: ${ }^{454}$

[T] his money is probably going to the society to which, if we could have asked him, the testator would not have sent it. But that is not the question for a Court of law; the question for a Court of law is, taking the will as it stands, who is the beneficiary - what is the meaning of the words used?

In making this decision, a number of the Law Lords stated that there was no ambiguity in the words used. ${ }^{455}$ Therefore, evidence regarding the background facts was held to be inadmissible. ${ }^{456}$ The Law Lords claimed that the terminology was "clear" 457 and the language was "precise and accurate". ${ }^{458}$ They held the words being interpreted "should receive their ordinary meaning". 459 Furthermore, the language "should be given its natural meaning", ${ }^{460}$ On this basis, the words were interpreted literally, and the bequest went to the society to which the testator probably did not intend to send it. ${ }^{461}$

In this decision, the Court focused on the meaning of the testator's words, rather than the intentions of the testator in using those words. Because the Scottish society could be assigned to a different verbal category from the verbal category that was used to designate the legal category, ${ }^{462}$ this society was held to be outside the legal category, regardless of the testator's intention. This interpretation involved the assumption that because the item before the Court could be assigned to a different verbal category from the one used to designate the legal category, this item should be outside this legal category. Alternatively, it may be said that the Court made the assumption that because this item would normally be assigned to this different verbal category, it should be outside this legal category. ${ }^{463}$ Whether or not this item should be assigned to the legal category, however,

${ }^{454}$ National Society, above n 444, at 214. This view was not shared by the other Law Lords who were less convinced about the testator's presumed intentions.

455 Ibid, at 213 per Earl Loreburn, at 215 per Lord Atkinson, and at 215 per Lord Parmoor. See n 489.

${ }^{456}$ Lord Dunedin stated: "The effect of a question of ambiguity arising is this: that it allows of an inquiry not into intention, but into any such facts and circumstances as may help to give you a key to the meaning of the words which the testator used.” Ibid, at 214.

457 Ibid, at 215 per Lord Atkinson.

458 Ibid, at 216 per Lord Parmoor.

459 Ibid, at 215 per Lord Atkinson.

460 Ibid, at 216 per Lord Parmoor.

${ }^{461}$ Furthermore, the Scottish society was ordered to pay the costs of both the action in the Court of Session in Scotland and the costs of the appeal to the House of Lords (National Society, above n 444, at 216). Thus, the bequest had the ultimate effect of depriving this society of money.

462 The different verbal category was the 'Scottish National Society for the Prevention of Cruelty to Children'.

${ }^{463}$ Even if the item would normally be assigned to a different verbal category, this still should not determine the legal category to which it should be assigned. Furthermore, it is important to bear in mind that verbal categories are arbitrary. Within Scotland, this society could very well be referred to by the name the 'National Society for the 
depends on the relevant legal considerations related to this act of categorisation, and not merely the verbal category to which it can be assigned.

Because the act of interpretation was focused on the meaning of the words being interpreted, it is useful to initially analyse this decision purely on the basis of linguistic meaning. ${ }^{464}$ Based on the background information of the testator's life and connections, the other bequests in his will, and his knowledge of the Scottish society, it seems clear that he intended to bequeath the legacy to this Society. The fact that the name used in his will was the exact name of the London society seems coincidental. An argument in favour of the Law Lords' decision that was not mentioned by the Law Lords is that the will referred to "the Scottish Society for the Prevention of Cruelty to Animals", 465 and all the other bequests to charities made it clear that the charities were in Scotland. ${ }^{466}$ Still, if the testator had intended the bequest to go to the London society he would probably have listed this bequest separately from the bequests to Scottish charities and would most probably have indicated that he was referring to a society in London since all his other bequests indicated that the charities were in Scotland. Furthermore, given the fact of the testator's connections with the Scottish society, and especially the fact that his brother was a director of this society (which none of the Law Lords mentioned either), it is most likely that there was mistake in drafting in the words under consideration, rather than a deliberate omission. ${ }^{467}$

Because it is likely that the testator intended these words to designate the Scottish society, on a purely linguistic basis these words should be taken to refer to this society. This correct linguistic meaning is a relevant legal consideration that the Court omitted. Still, it is possible that the decision the Court reached was legally justifiable due to other relevant legal considerations.

In order to elicit the legal considerations relevant to this act of categorisation it is helpful to consider the English Court of Appeal case Re Rowland ${ }^{468}$ which concerned the interpretation of a home-made will. ${ }^{469}$ The testator and his wife drowned when the ship they were on sank. ${ }^{470}$ The will provided that the estate would go to the testator's wife, unless the wife's decease "preced[ed] or

\footnotetext{
Prevention of Cruelty to Children', even if this was not its official name.

464 This corresponds to consideration 1.1 in Chart 4.1.

465 National Society, above n 444, at 208 (emphasis added).

466 Ibid, at 208.

${ }^{467}$ Chafee, above n 22, viewed this decision as illustrating the fallacious "tendency to believe that a word points to this object and only this, and that no other word can point to it.” (at 385).

${ }^{468}$ Re Rowland [1963] Ch 1 (CA).

469 Ibid, at 3.

470 Ibid, at 3-4.
} 
coincid[ed] with” the testator's decease, in which case it would go to the testator's brother and nephew. ${ }^{471}$ The case turned on the interpretation of the word 'coinciding' and the issue, as stated by Russell LJ, was “did the wife's death on the facts of this case precede the testator's death or coincide in point of time with it?"472

His Lordship stated: ${ }^{473}$

\begin{abstract}
I see no room ... for 'coinciding,' in its normal and natural meaning, to involve some broad conception of overlapping or of occurring within a particular period. In my judgment the normal and natural meaning of 'coinciding with' in relation to deaths occurring is the same as 'simultaneous' ....
\end{abstract}

He further noted: ${ }^{474}$

\begin{abstract}
It is an unsound approach to the construction of the will to ask oneself what the testator, if he had thought of an event not covered by the natural and normal meaning of his language, would have wished had he directed his mind to the event. The question is what events does his language cover?
\end{abstract}

His Lordship held that there was "no sufficient evidence that the wife's death either preceded or coincided with that of the testator". ${ }^{475}$ Therefore, the estate went to the wife and under her will to her niece.

Viewed in relation to categorisation, the word 'coincide' named the legal category, and the question for the Court was whether the item at issue (that is, the factual situation of the husband and wife being lost at sea) fitted within this category. The majority held that because this item did not seem to fit within the usual meaning of this word, that is, because it did not seem to fit within the verbal category 'coincide', it should not be put within this legal category. The majority did not focus on the specific different verbal category that the situation could fit within, but focused on the fact that it did not fit within the verbal category 'coincide'. Russell LJ, however, indicated that the situation could fit within the words "on the same occasion and by the same cause." ${ }^{476}$ This can be considered as an example of the kind of different verbal category which would capture this situation. The majority's decision, therefore, can be summarised as 'different verbal category, therefore, outside

\footnotetext{
${ }^{471}$ Ibid, at 3.

472 Ibid, at 16.

473 Ibid, at 15-16.

474 Ibid, at 17.

475 Ibid, at 19.

${ }^{476}$ Ibid, at 17.
} 
legal category’.

In a dissenting speech, Lord Denning noted: ${ }^{477}$

[I]n point of principle the whole object of construing a will is to find out the testator's intentions ... True it is that you must discover his intention from the words he used: but you must put upon his words the meaning they bore to him ... you must put upon them the meaning which he intended them to convey, and not the meaning which a philologist would put upon them.

He noted that is fallacious to proceed "on the assumption that, in construing a will, 'It is not what the testator meant, but what is the meaning of his words. ${ }^{478}$ Lord Denning further stated: ${ }^{479}$

I have myself known a judge to say: 'I believe this to be contrary to the true intention of the testator but nevertheless it is the result of the words he has used.' When a judge goes so far as to say that, the chances are that he has misconstrued the will.

Russell LJ came close to making such a statement by stating: ${ }^{480}$

One may hazard the guess that if [the testator] could now be asked to whom in the event which happened he would wish his property to go, he would say that he would wish it to go to his selected alternates. But that would not mean that he has expressed that wish by his will ....

Lord Denning held that when making the will the testator would have used the words 'coinciding with': ${ }^{481}$

not in the narrow meaning of 'simultaneous,' but in the wider meaning of which they are equally capable, especially in this context, as denoting death on the same occasion by the same cause ....

His Lordship held that the Court "should give his words the meaning which he plainly intended they should bear." 482 Thus, he held that the estate should have gone to the testator's brother and nephew. The dissenting judgment, therefore, looked beyond the apparent meaning of the words to the underlying intention expressed by these words and on this basis held that the item at issue

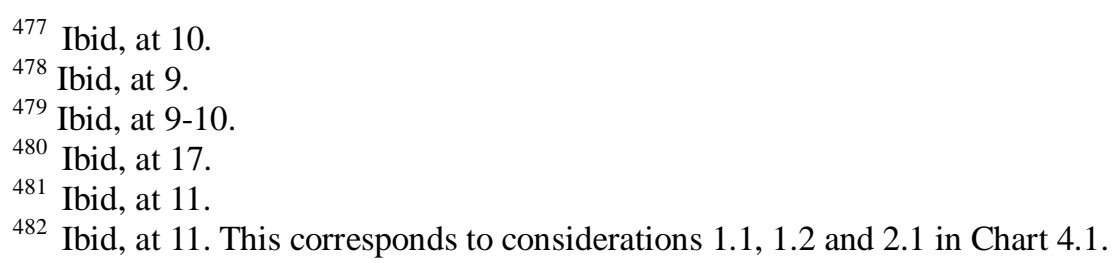


should be within the legal category.

In coming to his decision, Lord Denning took into account the goal of interpreting a will - to discover the testator's intention. ${ }^{483}$ The consideration of word meaning was secondary, and was in service of this goal. ${ }^{484}$ He thus identified the primary goal of the law in relation to the interpretation of wills. With this goal in mind, word meaning is relevant, but primarily because it is an indication of the testator's intention.

The remainder of this section will focus on the decision in National Society. It will discuss the legal considerations relevant to the act of interpretation in National Society and whether the considerations that the Court introduced were relevant.

Lord Denning's dissent in Rowland shows clearly the main goal of the interpretation of wills. The main reason the law enforces legally valid wills is that the law respects the intentions of testators as expressed in the language of their wills. The goal of the interpretation of wills, therefore, is to give effect to these intentions. ${ }^{485}$ Therefore, the primary relevant consideration in National Society is the intention of the testator shown by the correct linguistic meaning of the words being interpreted. To consider the meaning of words without reference to the intention of the testator can introduce irrelevant considerations and result in a wrong interpretation.

In National Society, Lord Parmoor observed, "The leading principle in all cases of this character is that the Court has not to make a will, but to interpret the words which the testator has used.” ${ }^{486}$ The reason for this principle ${ }^{487}$ is that the testator's intention has been expressed in the words of the will and speculation regarding an unexpressed intention may result in the testator's intention being frustrated. This principle thus reinforces the basic purpose behind the interpretation of wills, which is to give effect to testators' intentions. Its application in this case, however, had the opposite of its intended effect. Based on this principle, the Court restricted its investigation to the literal meaning

483 This view was echoed by Canadian Chief Justice Bayda in the decision Haidl $v$ Sacher: "[A]scertaining the testator's true intention is the real and only purpose of the whole exercise” ([1980] 1 WWR 293 (CA) at [24]). For a discussion of this decision commending this approach, see Doug Surtees "Procedure 'B' is for Bayda” (2007) 70 Sack L Rev 259. This corresponds to consideration 2.1 in Chart 4.1.

${ }^{484}$ Still, even from a purely linguistic perspective, the meaning at which the majority arrived was most probably wrong. E R Emmet used the majority's decision in Rowland to illustrate the dubious distinction between what writers intend and what their words mean: Learning to Philosophize (Penguin Books Limited, Harmondsworth, 1968 ) at 65.

485 This corresponds to consideration 2.1 in Chart 4.1.

${ }^{486}$ National Society, above n 444, at 215.

487 This principle corresponds to consideration 4.1 in Chart 4.1. 
of the words under consideration. This principle was applied in such a way that the words being interpreted were given a literal meaning regardless of the testator's intention in using them. In this way, what was originally a relevant consideration was misapplied and this resulted in the introduction of an irrelevant consideration. This would not have happened if this this legal principle had been applied in light of the reason for the act of categorisation at issue: to give effect to the testator's intentions.

Another legal rule applied in National Society was the inadmissibility of evidence regarding the background facts when the words in a will are unambiguous. ${ }^{488}$ The aim of this rule is to prevent the actual intentions of testators being frustrated by dubious claims regarding their presumed intentions. A difficulty with this rule is that it is often necessary to consider the background facts to determine whether the words are ambiguous. ${ }^{489}$ Having regard to the background facts, not only were the words in the will ambiguous, but they most likely referred to the Scottish society. Thus, there is a problem not only with the way this rule was applied, but with the rule itself. ${ }^{490}$ This rule resulted in the judges relying on an apparent lack of ambiguity to reach a decision that neglected the most important legal consideration. This rule also resulted in the introduction of the irrelevant consideration of the literal meaning of the words being interpreted. Furthermore, this rule should have been applied in light of this act of categorisation, and since the main goal of this act of categorisation is to discover the testator's intentions, it is clear that this rule should not be applied so as to frustrate these intentions when they are clear from the background facts. ${ }^{491}$

It is now necessary to determine whether the decision in National Society was fallacious. The primary relevant legal consideration in relation to this act of categorisation is the intention of the testator. Thus, a correct legal categorisation would need to take into account indications of this intention. This intention is indicated by the meaning of the words being interpreted in light of the factual background.

\footnotetext{
488 See text accompanying n 456.This corresponds to consideration 4.1 in Chart 4.1.

489 Therefore, this rule of interpretation relies on a mistaken view about meaning under which the meaning given to words can be determined in isolation from the factual context in which they are used.

490 Judges do not strictly adhere to this rule anymore. Writing extra-judicially, Lord Steyn stated: "The purpose of interpretation is sometimes mistakenly thought to be a search for the meaning of words. This in turn leads to the assumption that one must identify an ambiguity as a pre-condition to taking into account evidence of the setting of a legal text. ... This is the wrong starting point. Language can never be understood divorced from its context. ... The true purpose is to find the contextual meaning of the language of the text, ie, what the words would convey to the reasonable person circumstanced as the parties were.” Johan Steyn “The Intractable Problem of The Interpretation of Legal Texts” (2003) 25 Sydney L Rev 5 at 6.

491 This is especially the case when judges are aware that they are probably sending the money "to the society to which, if we could have asked him, the testator would not have sent it.” (see text accompanying n 454).
} 
There are two specific relevant legal considerations that the Court in National Society should have taken into account: first, the linguistic meaning of the words, and, second, the intention of the testator as indicated by these words and various background facts. These considerations are supported by the legal rule that the court should not 'make' a will which would frustrate testators' intentions. ${ }^{492}$ The relevant background facts include the fact the testator had lived in Scotland his entire life, the fact that he was familiar with the activities of the Scottish society and his brother was a director of this society, the fact that he had no known connection with the London society, and the fact that the bequest was included in a series of bequests to Scottish charities. The two relevant legal considerations are really the same consideration viewed from two perspectives because the linguistic meaning of the words is determined by the background facts. ${ }^{493}$ The Court did not take these relevant considerations into account.

The primary irrelevant consideration that the Court took into account in this decision was the fact that the item at issue (the Scottish society) could be put within a different verbal category from the verbal category used to designate the legal category. This consideration was irrelevant because it meant the words were given a meaning that was most likely not the meaning the testator intended them to have. Other irrelevant considerations included the fact that the London society fitted within the verbal category that designated the legal category, a misapplication of the principle that the Court should not make a will, and the fact that the words seemed unambiguous when taken literally and when the testator's intention was omitted.

This interpretive decision was fallacious because it is most likely that a different result would have been reached if the primary relevant legal consideration (the intention of the testator as expressed by the words being interpreted) had been taken into account and irrelevant considerations had been omitted. This can be shown by the fact that the Scottish Courts, which took the primary relevant consideration into account, ${ }^{494}$ reached a different result.

It is possible, however, that the Court could have reached the same result without committing a fallacy. The decision would not have been fallacious if the Court had omitted the irrelevant considerations and had focused on the intention of the testator. If the Court did this, an argument

\footnotetext{
492 See text accompanying n 486.

493 These two perspectives mean that this consideration can be viewed in relation to two considerations in Chart 4.1: consideration 1.1 and consideration 2.1.

${ }^{494}$ See n 451.
} 
could be made that the testator actually intended the London society to receive the money. Although it is unlikely that the testator intended this, ${ }^{495}$ it is possible that the Court could decide that the contextual factors were not sufficient to indicate an intention for the money to go to the Scottish society. In this situation, the decision would be not fallacious because the primary relevant consideration (the testator's intention) would have been taken into account. The Court's decision was fallacious, however, because this consideration was not taken into account, and it is most unlikely that the same result would have been reached if it had been. Rather, it is most likely that a different result would have been reached if the relevant consideration had been taken into account.

This primary relevant legal consideration also applies to Rowland. The interpretive decision in Rowland was based on an irrelevant consideration (the literal meaning of the word 'coincide'). Another irrelevant consideration in Rowland was the inadvisability of asking what a testator would have done if he had thought of the situation that occurred. ${ }^{496}$ This consideration was irrelevant because it is most likely that the testator did think of the situation that occurred. ${ }^{497}$ The Court in Rowland also omitted the primary relevant consideration: the intention of the testator. Furthermore, it most likely that the Court would have reached a different result if the irrelevant considerations had been omitted and the relevant consideration had been introduced. This can be shown by the fact that the dissent in Rowland, which took into account the primary relevant consideration and omitted the irrelevant considerations, reached a different result. Therefore, the interpretive decision in Rowland was also fallacious.

Alternative, non-fallacious interpretations for both National Society and Rowland would involve the introduction of the primary relevant consideration and the omission of any irrelevant considerations. This would mean that a different result would have been reached in both decisions: the bequest would have gone to the Scottish society in National Society and estate would have gone to the testator's brother and nephew in Rowland. ${ }^{498}$

To conclude it is helpful to consider why the fallacy was committed in National Society and how such a fallacy can be avoided. First, the decision was focused on the meaning of the word being interpreted. This meant the primary legal consideration of the intention of the testator was not

\footnotetext{
495 See the paragraph accompanying n 464.

496 See text accompanying n 474.

${ }^{497}$ Lord Denning thought that the situation that occurred was exactly the sort of situation the testator would have had in mind when he drafted the will: Rowland, above $n$ 468, at 11.

498 See text accompanying n 471.
} 
introduced and the irrelevant consideration of the literal meaning of the words divorced from their factual context was introduced. Earlier in this chapter the notion of 'legal meaninglessness' was discussed. This occurs when a judge is unclear regarding the reason for a legal category. Lord Dunedin thought that it was likely that the testator intended to benefit the Scottish society. ${ }^{499}$ Nevertheless, he gave the bequest to the London society. If the words being interpreted had been legally meaningless, there might have been some justification for interpreting them literally. This, however, was not a case of legal meaninglessness, so there was no justification for interpreting the words literally. This analysis of National Society shows that even when the courts are interpreting language which involves a specific person encapsulating a thought in language it is helpful if this act of interpretation is viewed as an act of categorisation based on relevant legal considerations.

Second, the Court did not focus on the items to be categorised (the Scottish society and the London society) and whether they should be assigned to the legal category, but on the legal category and what should be assigned to it. It did not focus on either the Scottish society or the London society and whether they fitted within this legal category, but on the apparent meaning of the words designating the legal category. A focus on the items would have shown that the essential issue was the intention of the testator, not the literal meaning of the words being interpreted, and also would have meant that the legal considerations that were introduced would have been related to this act of categorisation and would not have been misapplied. ${ }^{500}$

It may be thought that an approach based purely on the intention of the testator would suffice to avoid the fallacy in this decision. There are a number of reasons why an approach based on categorisation would be preferable to an approach based on intention. First, an approach based on categorisation provides a useful way to detect irrelevant considerations and therefore provides a useful way to avoid them. Second, an approach based on intention can still slip into literalism because the court can view the discovery of intention as limited to the discovery of the meaning of the words being interpreted. ${ }^{501}$ Third, if interpretation is viewed in relation to intention, the court may consider that they have two tasks: to determine an intention and also to introduce legal considerations related to this act of interpretation. Following this, it may be easy for the court to apply these legal considerations without reference to the primary goal of this act of interpretation -

\footnotetext{
499 See n 454.

500 This shows that even when a court is focused on discovering the item that a legal speaker has assigned to a legal category, it is still useful for the court to approach the act of interpretation as a decision regarding whether the item at issue should be assigned to this category.

${ }^{501}$ For instance, in Rowland Russell LJ stated: “The question is what events does [the testator's] language cover? To ask more is to desert from the source from which his intention is to be gathered, his will as proved.” (at 17).
} 
giving effect to this intention. Fourth, viewing the decision merely in terms of intention can cause confusion because subjective intentions are never discoverable and this may cause the court to focus on the literal meaning of the words being interpreted. Under an approach based on categorisation it can be seen that although the subjective intention is not discoverable, making a decision based on the literal meaning of the words will not achieve the goal of the law in relation to this category. Lastly, there may be situations in which a court should not fulfil a testator's intentions. ${ }^{502}$ These points do not mean that judges should not focus on intention when making this sort of decision. Indeed, the intention of the testator was the primary relevant consideration that the judges should have taken into account. To avoid fallacies, and especially to detect fallacies, however, it is useful to view this decision in relation to categorisation, rather than merely in relation to intention.

Therefore, viewing interpretation in relation to categorisation is not only a useful way to detect fallacies, but also can provide a better way for judges to avoid them than an approach based either on the discovery of meaning or the discovery of intention.

Smith and National Society have been examined in detail because they provide clear examples of judicial fallacies. It could be said that these decisions are not representative examples of the way judges usually interpret language. These decisions, however, have not been given to provide representative examples of interpretation, but rather have been given to provide clear examples of fallacies. The analysis of these decisions has provided many details concerning the way fallacies can be committed, the sort of relevant considerations that should be taken into account in judicial interpretation, and the sort of irrelevant considerations that can be taken into account.

In Smith the legal category was designated by the word 'use'. The Court held that because the item at issue (the defendant's action) could fit within the verbal category 'use', it should be put within this legal category. In assigning this item to the legal category, the Court both introduced irrelevant considerations and omitted relevant considerations. It is unlikely that such a fallacy would have been committed if the act of interpretation had been viewed as categorisation based on relevant

\footnotetext{
${ }^{502}$ For instance, if the testator does not provide for certain family members a court may not give effect to his or her intention (for instance, in New Zealand if a testator does not provide for certain close relatives, claims against the testator's estate can be made by such relatives under the Family Protection Act 1955 (NZ)). Although this does not relate to the interpretation of a will but is a more general consideration regarding the legal effect of a will, it shows that courts are not solely focused on giving effect to the intentions of testators.
} 
legal considerations.

In National Society the legal category was designated by the words 'the National Society for the Prevention of Cruelty to Children'. These words were the verbal category designating the legal category. The Court held that because an item (the Scottish society) could be put within a different verbal category from this verbal category, it should be outside the legal category. In refusing to assign this item to this legal category, the Court both introduced irrelevant considerations and omitted relevant considerations. Again, it is unlikely that such a fallacy could be committed if the act of interpretation had been viewed in relation to categorisation.

To detect a judicial fallacy there is the need to decide whether a consideration that a court introduces is relevant. This can be seen by determining whether this consideration relates to the specific act of categorisation at issue. The analysis of these decisions has shown what it means for a legal consideration to be related to the act of categorisation at issue. It means that this consideration is either relevant to the particular item at issue or relevant to the specific legal category. Put simply, it is relevant to the assignment of the particular item at issue to the specific legal category. Viewing interpretation as categorisation and determining whether the considerations introduced are relevant to the specific act of categorisation before the court, therefore, provides a clear way to determine whether a consideration is relevant. An approach to judicial interpretation focused either on the discovery of meaning or intention creates the possibility for irrelevant considerations to be introduced and does not provide such a clear test for determining when a consideration is relevant.

The verbal category to which an item can be assigned should not automatically determine the legal category to which it should be assigned. With the 'same verbal category' fallacy, the judge is distracted by the irrelevant consideration of the fact that item at issue can be assigned to the verbal category designating the legal category. With the 'different verbal category' fallacy, the judge is distracted by the irrelevant consideration of the fact that the item at issue can be assigned to a different verbal category from the one used to designate the legal category.

In Smith and National Society, the verbal category to which the item could be assigned was the basic irrelevant consideration that the Courts introduced. These decisions also both introduced other minor irrelevant considerations that supported the result the Courts reached. Some of these other irrelevant considerations may have been introduced due to the basic irrelevant consideration. For instance, it is unlikely that a judge would think that the rule that statutory words should be given a 
consistent meaning throughout a statute would apply to the word 'use' in a statute unless the judge had already decided that this word captured the situation before the court. Furthermore, some of the irrelevant considerations that the Courts introduced in both Smith and National Society resulted from a relevant legal consideration being misapplied by the judge. This would be unlikely to occur if these relevant legal considerations had been applied in the light of the act of categorisation before the Courts.

The introduction of the basic irrelevant consideration (the verbal category to which the item could be assigned) also resulted in the neglect of the relevant legal considerations. It is possible for a court to introduce an irrelevant consideration and still introduce the relevant considerations. In most situations, however, the introduction of an irrelevant consideration causes the relevant legal considerations to be neglected.

The basic reason for these fallacies was the Courts' approaches to interpretation. First, both Courts were focused on discovering the meaning of the word being interpreted. Although it is true by definition that legal interpretation results in the assignment of a meaning to a word, if it is viewed as the discovery of meaning an irrelevant consideration can be introduced: a meaning that the word can be given that is not relevant to the meaning it has been given. Second, the Courts focused on the legal category and which items could fit within it, rather than the item at issue and whether it should be assigned to this category. This meant that the considerations that were introduced were not related to the act of categorisation in which the Courts were engaged.

It is useful now to explicitly return to the central contention of this thesis. This contention is that that judges commit certain fallacies when interpreting language and that it is possible to detect such fallacies and arrive at alternative, non-fallacious interpretation when they occur. To prove this contention there needs to be a definition of fallacious interpretation. This definition is that an instance of judicial interpretation is fallacious when it takes into account an irrelevant consideration and it is most likely that a different result would have been reached if that consideration had been omitted, or when it omits a relevant consideration and it is most likely that a different result would have been reached if that relevant consideration had been taken into account. Alternative, nonfallacious interpretations can be provided by taking into account relevant considerations and omitting irrelevant considerations.

This chapter has identified two specific fallacies which result in the introduction of an irrelevant 
consideration and usually the omission of relevant considerations: the 'same verbal category' fallacy and the 'different verbal category' fallacy. ${ }^{503}$ Both of these fallacies involve judges making the assumption that a decision should be made based on the verbal category to which an item can be assigned. When this assumption results in the introduction of an irrelevant consideration (the verbal category to which an item can be assigned) and the omission of relevant considerations, it can result in fallacies being committed. The analysis of Smith and National Society has shown that judges do commit these fallacies, that is it possible to detect these fallacies, and that it is possible to arrive at alternative, non-fallacious interpretations when they occur.

It is helpful now to briefly return to the case of Sanger $v$ Sanger discussed earlier. ${ }^{504}$ The legal category in this case can be viewed as the category created by the words being interpreted: "it is my wish that if any child of mine wishes to reside in such home he or she shall be allowed to by my other children”. ${ }^{505}$ The Court held that no trust was created by these words. Viewed in relation to categorisation, this means that the words being interpreted did not designate the legal category of a trust. The reason given was the rule of interpretation that precatory words are not binding commands when directed to devisees rather than the executor. ${ }^{506}$

The primary relevant legal consideration in this case was the intention of the testator. ${ }^{507}$ The aim of the rule of interpretation that the Court followed is to help judges give effect to this intention. Although it is possible that the testator did intend to create a trust, it is also arguable that she was merely providing a recommendation to the devisees. Therefore, the application of this rule of interpretation did not necessarily frustrate the testator's intention, but may have helped give effect to this intention. ${ }^{508}$ This means that the decision that was reached was supported by the primary relevant legal consideration. For this reason, it cannot be said that this decision was fallacious.

It may not seem that this act of interpretation involved categorisation. By deciding that no trust was

\footnotetext{
${ }^{503}$ It is possible for irrelevant considerations to be introduced for other reasons - for example, a bias or a mistake - but this thesis only discusses these two kinds of fallacious interpretation.

504 At Chapter Four B.2.(a).

505 See text accompanying n 279.

506 See text accompanying n 281.

507 See text accompanying n 280.

${ }^{508}$ Even if it seemed clear that the testator's intentions would be frustrated by the application of this rule, a lower court may be bound to apply the rule. Such a decision would not be fallacious because the binding rule of interpretation is a relevant legal consideration. Such a decision, however, may not be justified. For a discussion of situations in which courts are forced to make unjustified decisions, see Chapter Four C.7. In other situation, however, courts have discretion to decide whether certain rules apply. For instance, the Court in Smith had the discretion to decide whether the rules of interpretation relating to lenity and to the intra-statutory consistency of meaning were applicable.
} 
created, however, the Court held that the fact that the son was in the category designated by these words did not have the effect of making him a beneficiary of a trust. In other words, the Court accepted that the son was within the category created by these words, but decided that the legal effect of being within this category was not to make him a beneficiary of a trust. The focus of this decision, therefore, was not whether or not an item was within a certain legal category, but the nature of the category the item was within. Still, this act of interpretation involved categorisation in relation to the son. This can be seen by the fact that if the Court had held that a trust had been created, the son would have been a beneficiary under this trust. Therefore, it can be said that the effect of this instance of interpretation in relation to the son was that he was excluded from the legal category of being a beneficiary under a trust and was included in a legal category which did not have this consequence. Therefore, a decision regarding the legal status of a category has the same effect as assigning any items within this category to a category with that status. ${ }^{509}$

The analysis of these judicial fallacies has shown that it is helpful to view some instances of judicial interpretation as involving categorisation. Under this view, the situation before the court is viewed as an item that needs to be assigned to a legal category and the word being interpreted is viewed as the name of a legal category. The cases considered in the fallacy section show the kinds of items that can be assigned to legal categories. These items include actions (trading a gun for drugs), events (two deaths coinciding), and objects (a charitable society).

Chapter Three discussed ordinary interpretation in terms of assigning items to categories. This section will analyse legal categorisation on the basis of that analysis. This will show in a clearer way the sorts of situations in which the fallacies that have been identified in this chapter can be committed and the essential problem with these fallacies.

\footnotetext{
509 Therefore, this decision can still be viewed as involving a decision regarding whether or not to assign an item to a certain legal category. See the earlier discussion of interpretation and categorisation in the paragraph accompanying n 260.
} 
Diagram 4.9, below, which is based on Diagram 3.9 (Two Possibilities with Categorisation), shows two possibilities with legal categorisation.

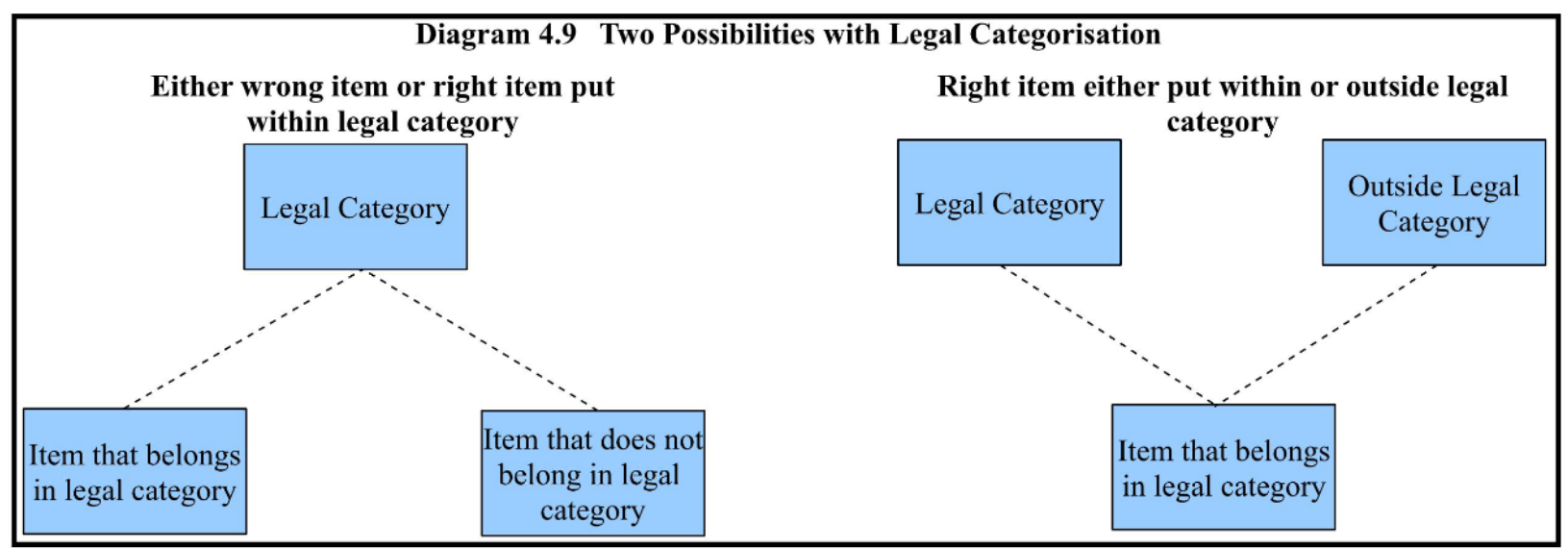

In Diagram 4.9 the items correspond to the matters before the court, and the legal categories correspond to the categories designated by the word being interpreted. The task of legal interpreters is to assign items to the correct legal category. If the items are included within the legal categories, they correspond to the referents of the words, not the meaning. When ordinary interpretation was viewed in relation to categorisation, the items being categorised corresponded to the meanings of words and the categories corresponded to the words being interpreted. The way legal interpretation is viewed in relation to categorisation is different from the way ordinary interpretation was viewed in relation to categorisation because the focus of legal interpretation is different from the focus of ordinary interpretation.

The left-hand side of Diagram 4.9 depicts the possibility of either an item that belongs in a certain legal category or an item that does not belong in the legal category being assigned to this legal category. Whether or not an item belongs in a legal category is determined by the relevant legal considerations. An item that does not belong in a legal category can be assigned to the legal category due to the 'same verbal category' fallacy. This occurs when an item that should not be in the legal category can be assigned to the same verbal category as the verbal category by which the legal category is designated.

The right-hand side of Diagram 4.9 depicts the possibility of an item that belongs in a legal category being either included within this legal category or being excluded from it. An item can be wrongly excluded from a legal category due to the 'different verbal category' fallacy. This occurs when an 
item that should be in the legal category can be put in a different verbal category from the verbal category by which the legal category is designated.

Diagram 4.9 depicts essentially the same two categorisation possibilities as Diagram 3.9. In Diagram 3.9 the left-hand side depicted two items being put in the same category. This could occur when the speaker and the interpreter put different items in the same category. This could be the result of the 'same word' fallacy, and would mean the interpreter had assigned a different item to the category from the speaker. In Diagram 3.9 the right-hand side depicted one item being put in two categories. This could occur when the speaker and the interpreter assigned the same item to different categories. This could be the result of the 'different word' fallacy, and would mean that the interpreter had not assigned the same item to the category as the speaker.

In ordinary interpretation, the assignment of items to categories should be governed by relevant considerations. These considerations relate to the specific meaning that is being expressed by the speaker. In legal interpretation, the assignment of items to categories should be governed by relevant legal considerations. The relevant legal considerations do not all relate to the legal speaker's meaning, but may relate to other matters, for instance, the law generally or the specific situation before the court. Having noted this difference, because both ordinary interpretation and legal interpretation involve categorisation, the same two possibilities with categorisation apply to them.

Diagram 4.10, below, which is based on Diagram 3.10 (Possible Categorisations in the Abstract), can be used to show the possible legal categorisations in the abstract.

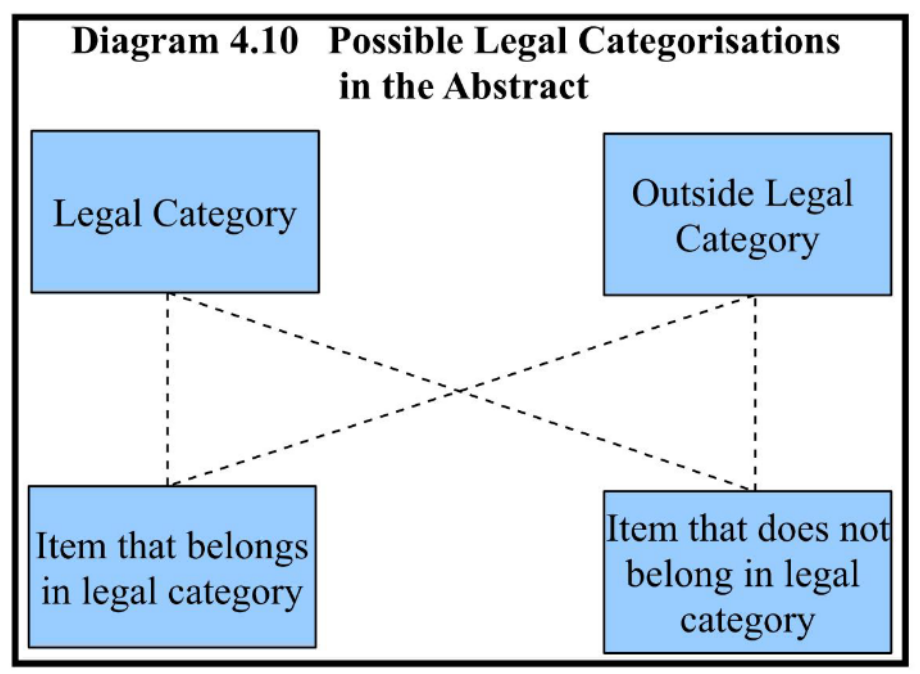


Diagram 4.10 shows the possible associations of items with categories in the abstract. On the one hand, two possible items can be put in the legal category: either an item that belongs in the legal category or an item that does not belong in the legal category. On the other hand, an item can be categorised in two possible ways: either within the legal category or outside of it.

One danger is that an item that does not belong in the legal category may be assigned to it. For example, the defendant's actions were wrongly categorised within the legal category 'use' in Smith. Another danger is that an item that does belong within the legal category may be excluded from it. For example, the Scottish society was wrongly excluded from the legal category 'the National Society for the Prevention of Cruelty to Children' in National Society.

Both fallacies can be caused by the assumption that the legal category to which an item should be assigned can be determined by the verbal category to which it can be assigned. In Smith the item was assigned to the legal category because it could be assigned to the same verbal category. In National Society the item was excluded from the legal category because it could be assigned to a different verbal category. Thus, the primary irrelevant consideration in these two decisions was the verbal category to which the item at issue could be assigned.

The fallacies that can be committed with judicial interpretation are depicted in Diagram 4.11, below, which is based on Diagram 3.11 (Same Category and Different Category Fallacies).

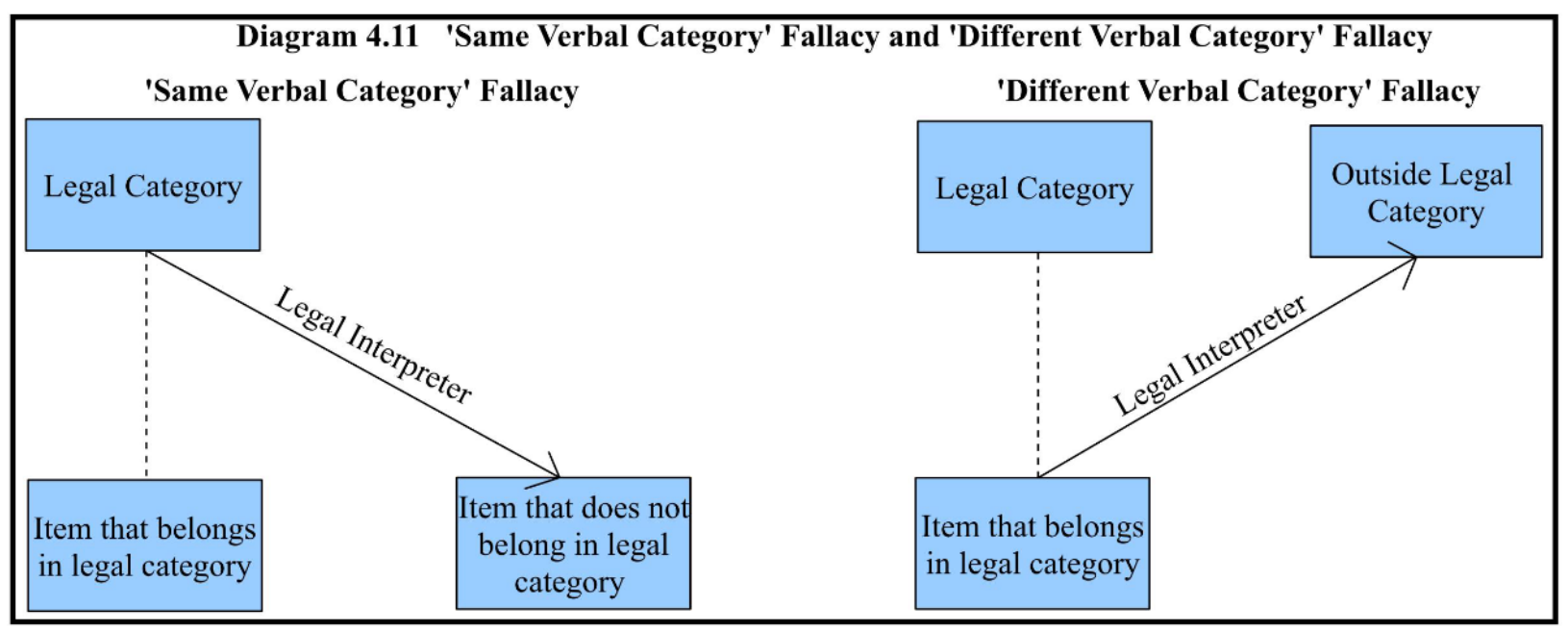

Diagram 4.11 depicts the two fallacies discussed in this chapter. Diagram 3.11 depicted the 
interpreter either assigning an item to a different category from the category to which the speaker had assigned it or not assigning an item to the same category as the category to which the speaker had assigned it. Diagram 4.11 depicts the legal interpreter either assigning an item that does not belong to a legal category to this legal category, or excluding an item that belongs to a legal category from this legal category. It is helpful to discuss this diagram in relation to Smith and National Society.

The left-hand side of this diagram can be used to depict the act of categorisation in Smith. In Smith the issue was whether the item before the Court should be assigned to the legal category 'use'. The Court looked at what they considered to be the ordinary meaning of the word 'use' and saw that it captured the item. In other words, the item could be assigned to the verbal category 'use'. The relevant legal considerations, however, showed clearly that the item did not belong within this legal category. Nevertheless, the defendant's actions were held to be within the legal category because they could be put within the same verbal category as the one used to designate the legal category. The 'same verbal category' fallacy, therefore, results in the wrong inclusion of items within a legal category.

The right-hand side of this diagram can be used to depict the act of categorisation in National Society. In National Society the issue was which of the items before the Court should be assigned to the legal category 'the National Society for the Prevention of Cruelty to Children'. These words labelled the legal category and the issue was which society fell within this category. The Law Lords did not associate the Scottish society with this verbal category. Rather, they associated the Scottish society with a different verbal category: 'the Scottish National Society for the Prevention of Cruelty to Children'. Thus, the Scottish society could be put within a different verbal category from the one used to designate the legal category. The relevant legal considerations showed clearly that the Scottish society belonged to this legal category. Nevertheless, this society was held to be outside the legal category because it could be put within a different verbal category from the one used to designate the legal category. The 'different verbal category' fallacy, therefore, results in the wrong exclusion of items from a category.

National Society can also be analysed as an instance of the 'same verbal category' fallacy. Under this analysis, the legal category is still the category described by the language in the will. The item before the Court can be viewed as the London society. The Law Lords wrongly included the London society in the legal category because it could be put within the verbal category used to 
describe the legal category. This involves the fallacious assumption 'same verbal category, therefore, within legal category'. Therefore, in National Society the item before the Court can either be viewed as the London society or the Scottish society. If the item is viewed as the London society, the interpretive decision is an instance of the 'same verbal category' fallacy; if the item is viewed as the Scottish society, the interpretive decision is an instance of the 'different verbal category' fallacy. This shows that these two fallacies are very closely related. They are both based on the assumption that the verbal category to which an item can be assigned determines the legal category to which it should be assigned.

The corresponding diagram in Chapter Three, Diagram 3.11, depicted the interpreter assigning an item to a different category from the category to which the speaker had assigned it. When ordinary interpretation is viewed in relation to categorisation, the speaker has assigned an item to a category and the goal of the interpreter is to discover this item. Therefore, in ordinary interpretation, the interpreter's goal is to discover the item which a speaker has assigned to a category. The interpreter focuses on the category, and needs to discover an item that fits within it. In legal interpretation that involves categorisation, the goal is to assign the item before the court to the correct legal category. Ordinary interpretation is focused on the category, and what item should be assigned to it. Legal interpretation is focused on the item, and whether it should be assigned to the legal category.

The fallacies that have been identified in this chapter involve the courts focusing on the word being interpreted and the meanings it could be given. This is a focus on the category and items that can be assigned to it. If legal interpretation had been viewed as categorisation, and the focus had been on whether the item before the court should be assigned to the legal category at issue, it is unlikely that these fallacies would have been committed. Thus, the focus of the act of categorisation was not appropriate for legal interpretation, even though such a focus is appropriate for ordinary interpretation.

Having noted this difference in focus between legal interpretation and ordinary interpretation, the diagrams in this section show that an essential similarity between legal interpretation and ordinary interpretation can be seen when both are viewed in relation to categorisation. Moreover, certain fallacies that can be committed in ordinary interpretation and legal interpretation are essentially the same when viewed in relation to categorisation. 
The basic ideas in this section are summarised in Chart 4.2, below.

\begin{tabular}{|l|l|}
\hline \multicolumn{2}{|c|}{ Chart 4.2 'Same Verbal Category' Fallacy and 'Different Verbal Category' Fallacy } \\
\hline $\begin{array}{l}\text { Same Verbal Category, therefore, Within } \\
\text { Legal Category }\end{array}$ & $\begin{array}{l}\text { Different Verbal Category, therefore, } \\
\text { Outside Legal Category }\end{array}$ \\
\hline $\begin{array}{l}\text { Interpreter needs to decide whether to assign a } \\
\text { certain item to a certain legal category. }\end{array}$ & $\begin{array}{l}\text { Interpreter needs to decide whether to assign a } \\
\text { certain item to a certain legal category. }\end{array}$ \\
\hline $\begin{array}{l}\text { Interpreter finds that the item can be assigned } \\
\text { to a certain verbal category. }\end{array}$ & $\begin{array}{l}\text { Interpreter finds that the item can be assigned } \\
\text { to a certain verbal category. }\end{array}$ \\
\hline $\begin{array}{l}\text { This verbal category is used to designate the } \\
\text { legal category at issue. }\end{array}$ & $\begin{array}{l}\text { This verbal category is not used to designate } \\
\text { the legal category at issue. }\end{array}$ \\
\hline $\begin{array}{l}\text { The interpreter takes into account the irrelevant } \\
\text { consideration that the item can be assigned to } \\
\text { the verbal category designated by the words } \\
\text { being interpreted. }\end{array}$ & $\begin{array}{l}\text { The interpreter takes into account the irrelevant } \\
\text { consideration that the item can be assigned to a } \\
\text { different the verbal category from the one } \\
\text { designated by the words being interpreted. }\end{array}$ \\
\hline $\begin{array}{l}\text { This usually causes the interpreter to omit the } \\
\text { relevant legal considerations. }\end{array}$ & $\begin{array}{l}\text { This usually causes the interpreter to omit the } \\
\text { relevant legal considerations. }\end{array}$ \\
\hline $\begin{array}{l}\text { The item is wrongly included in the legal } \\
\text { category. }\end{array}$ & $\begin{array}{l}\text { The item is wrongly excluded from the legal } \\
\text { category. }\end{array}$ \\
\hline
\end{tabular}

\section{$7 \quad$ Application of this analysis}

The goal of this chapter is to provide a way to critique instances of judicial interpretation and detect fallacies. This section will discuss some practical considerations related to determining whether an instance of judicial interpretation is fallacious. This section will mention five practical considerations related to the application of the analysis in this chapter.

First, the analysis in this chapter only applies to instances of interpretation that involve a decision whether to classify the item before the court within the category designated by the language being interpreted. This, however, covers an important group of instances of judicial interpretation that are legally significant.

Second, it is not always legally unjustifiable for a judge to introduce ostensibly irrelevant 
considerations or omit ostensibly relevant considerations when engaged in interpretation. There may be situations where a judge is restricted from introducing certain ostensibly relevant considerations or forced to introduce certain ostensibly irrelevant considerations. A number of examples of this can be given. First, a court may be restricted by binding precedent from introducing a certain consideration or may be forced by binding precedent to introduce a certain consideration. ${ }^{510}$ Second, a court may be procedurally restricted from introducing certain matters. ${ }^{511}$ Third, a court may be limited by its jurisdiction from introducing certain considerations. ${ }^{512}$

In such situations, a decision may be reached which may seem to be fallacious, but is actually nonfallacious because the judge is restricted from introducing certain ostensibly relevant considerations or is forced to introduce certain ostensibly irrelevant considerations. The relevance of a consideration is determined by how the consideration relates to the act of categorisation at issue. Considerations that the court is required to take into account in relation to a specific act of categorisation are therefore relevant by definition. Similarly, if the court is restricted from introducing a certain consideration it is irrelevant by definition. Therefore, an interpretive decision that appears to be fallacious may not be fallacious because the court was forced to introduce certain considerations that seem irrelevant or was prohibited from introducing certain considerations which seem relevant. This thesis is not making the claim that judges should go beyond their existing power to make any decision that takes into account what appear to be relevant considerations or that judges should omit any considerations which they are obliged to introduce because they appear to be irrelevant considerations. Rather, it is claiming that within their power judges should make decisions that take into account relevant considerations and omit irrelevant considerations.

Third, in some situations, the relevant legal considerations may be unclear. For instance, there may be a number of conflicting purposes relating to a certain statutory provision. This means that in some situations it may be difficult, or impossible, to determine that an interpretive decision is fallacious.

${ }^{510}$ For instance, in some jurisdictions, under the parol evidence rule, evidence of the parties' prior negotiations is inadmissible when interpreting a contract. Evidence of such negotiations may be relevant, but a court may be prohibited from introducing it. For a discussion of this rule, see DW McLauchlan "Interpretation and Rectification: Lord Hoffmann's Last Stand” [2009] NZ Law Review 431.

511 For instance, in a civil trial there may be restrictions on the judge introducing considerations that were not raised by counsel: J A Jolowicz On Civil Procedure (Cambridge University Press, Cambridge, 2000) at 254.

${ }^{512}$ For instance, in statutory interpretation there may be a jurisdictional restriction on courts correcting mistakes or filling gaps, even if the purpose of the provision is clear and it is clear that there is a mistake or a gap. For a discussion of this, see Sullivan, above $\mathrm{n} 321$, at ch 7. 
Fourth, in some situations, courts may introduce certain irrelevant considerations, but it may be unclear whether a different decision would have been made if these considerations had not been introduced. In such a situation, these considerations can be identified as irrelevant and it can be said that the decision is unjustified to the extent that it relies on such considerations. It cannot be said, however, that such a decision is fallacious.

For instance, it is clear that Justice O'Connor's decision in Smith introduced an irrelevant consideration related to word meaning (how a word can be used) ${ }^{513}$ It is also arguable, however, that Justice Scalia's consideration regarding word meaning (how a word ordinarily is used), ${ }^{514}$ though not as irrelevant, was still not the most relevant consideration. Nevertheless, Justice Scalia reached the right result. A different result would not have been reached if the relevant consideration regarding word meaning (how the word was used) had been introduced. Thus, Justice Scalia's interpretive decision was not fallacious.

Fifth, there may be important legal considerations related to a decision involving interpretation, which do not relate to this act of interpretation. Although judicial interpretation has been defined as legal categorisation, it is not necessarily all that is involved in such categorisation. Professor Arthur Corbin draws an important distinction between interpretation and construction ${ }^{515}$ in relation to contract interpretation. He remarks that: ${ }^{516}$

\begin{abstract}
By 'interpretation of language' we determine what ideas that language induces in other persons. By 'construction of the contract,' ... we determine its legal operation - its effect upon the action of courts and administrative officials. If we make this distinction, then the construction of a contract starts with the interpretation of its language but does not end with it; while the process of interpretation stops wholly short of a determination of the legal relations of the parties.
\end{abstract}

This is the distinction between the meaning of the language in a legal instrument and the legal effect of this instrument. ${ }^{517}$ This is a useful distinction. Interpretation involves assigning an item to the

\footnotetext{
513 See n 408.

514 See text accompanying n 411.

515 This distinction is useful, but the use of the words 'interpretation' and 'construction' may be misleading because 'construction' is often used as a synonym for 'interpretation'. See n 347.

516 Corbin, above n 284, at 9.

517 A distinction between construction and interpretation has also been drawn by other writers. Francis Lieber drew this distinction in a different way: see Francis Lieber Legal and Political Hermeneutics (Charles C Little and James Brown, Boston, 1839) at 23 and 56. For an article comparing the way this distinction was drawn by Corbin and Lieber, see Lawrence A Cunningham "Hermeneutics and Contract Default Rules: An Essay on Lieber and Corbin” (1995) 16 Cardozo L Rev 2225. Peter Tiersma also drew this distinction in a different way: see n 327.
} 
category designated by the word being interpreted, but this may not be all that is involved in a legal decision that involves interpretation. There may also need to be a determination of the legal effect of the document being interpreted, whether, for instance, there is a binding contract. Such a determination should not be considered as part of the act of interpretation. Still, this kind of determination may affect the interpretation. Corbin notes: ${ }^{518}$

Just as construction must begin with interpretation, we shall find that our interpretation will vary with the construction that must follow. Finding that one interpretation of the words will be followed by the enforcement of certain legal effects, we may back hastily away from that interpretation and substitute another that will lead to a more desirable result.

Thus, there may be situations where considerations related to the legal effect of a decision may be introduced as relevant considerations related to a specific instance of interpretation, but this is not always the case.

In this light, it is useful to consider the case Riggs $v$ Palmer ${ }^{519}$ where the Court decided that a grandson who killed his grandfather in order to inherit under his will was not entitled to inherit under this will. The basic reason for this decision was the common law maxim that, "No one shall be permitted to profit by his own fraud, or to take advantage of his own wrong”. ${ }^{520}$ This maxim can be considered to be a legal consideration, but it would be misleading to view it as a consideration that related to the interpretation of the will. This was not a situation where the Court interpreted the will at all, but a situation where the Court did not give effect to a provision in the will for a general legal reason. Such a legal reason can be considered a relevant legal consideration related to the legal decision that was reached, but it would be misleading to view it as a relevant legal consideration related to the interpretation of the will.

\section{Detecting fallacies and providing alternative, non-fallacious interpretations}

This chapter has identified two fallacies that can be committed in judicial interpretation. It is useful now to explicitly set out a practical way to detect such fallacies in relation to a specific instance of judicial interpretation and to arrive at alternative, non-fallacious interpretations. The process of detecting these fallacies and providing alternative interpretations can be set out in five steps.

\footnotetext{
${ }^{518}$ Corbin, above n 284, at 12.

519 Riggs v Palmer (1889) 115 NY 506 (CA).

520 Ibid, at 511
} 
This thesis has focused on instances of judicial interpretation that involve the categorisation of specific matters within the legal category designated by the word being interpreted. To detect fallacies, such interpretive decisions should be viewed as acts of categorisation. Such acts of categorisation involve judges making the decision whether to assign an item to a legal category. Therefore, the first step is to identify both the legal category and the item. The legal category is the category designated by the word that has been interpreted. This act of interpretation is an act of categorisation and has either resulted in the inclusion of a matter within this legal category or the exclusion of a matter from this category. This matter that has either been included within or excluded from this category by this act of categorisation is the item.

The second step is to identify the relevant considerations that relate to this act of categorisation. These include considerations related to the word being interpreted, the legal category designated by this word, items relevant to this act of categorisation, and general legal considerations. Chart 4.1 lists the kinds of considerations that are potentially relevant to an act of categorisation.

The third step is to identify the reasons that have been given for the act of categorisation that has occurred. It then needs to be determined whether these reasons are relevant, that is, whether they can be related to this act of categorisation. In relation to the specific fallacies identified in this chapter, it needs to be determined whether the act of categorisation has been made on the basis of an irrelevant consideration regarding the verbal category to which the item can be assigned.

The fourth step is to determine whether it is most likely that a different result would have been reached if any irrelevant considerations that were introduced (including the primary irrelevant consideration of the verbal category to which the item can be assigned and any other irrelevant considerations) had been omitted and if the relevant legal considerations had been introduced. Once this is done, it can be seen whether the two specific fallacies identified in this chapter have been committed.

This automatically leads to the fifth step, which is to provide the alternative, non-fallacious interpretation by omitting any irrelevant considerations and introducing the relevant considerations. 
These five steps are set out in Chart 4.3, below.

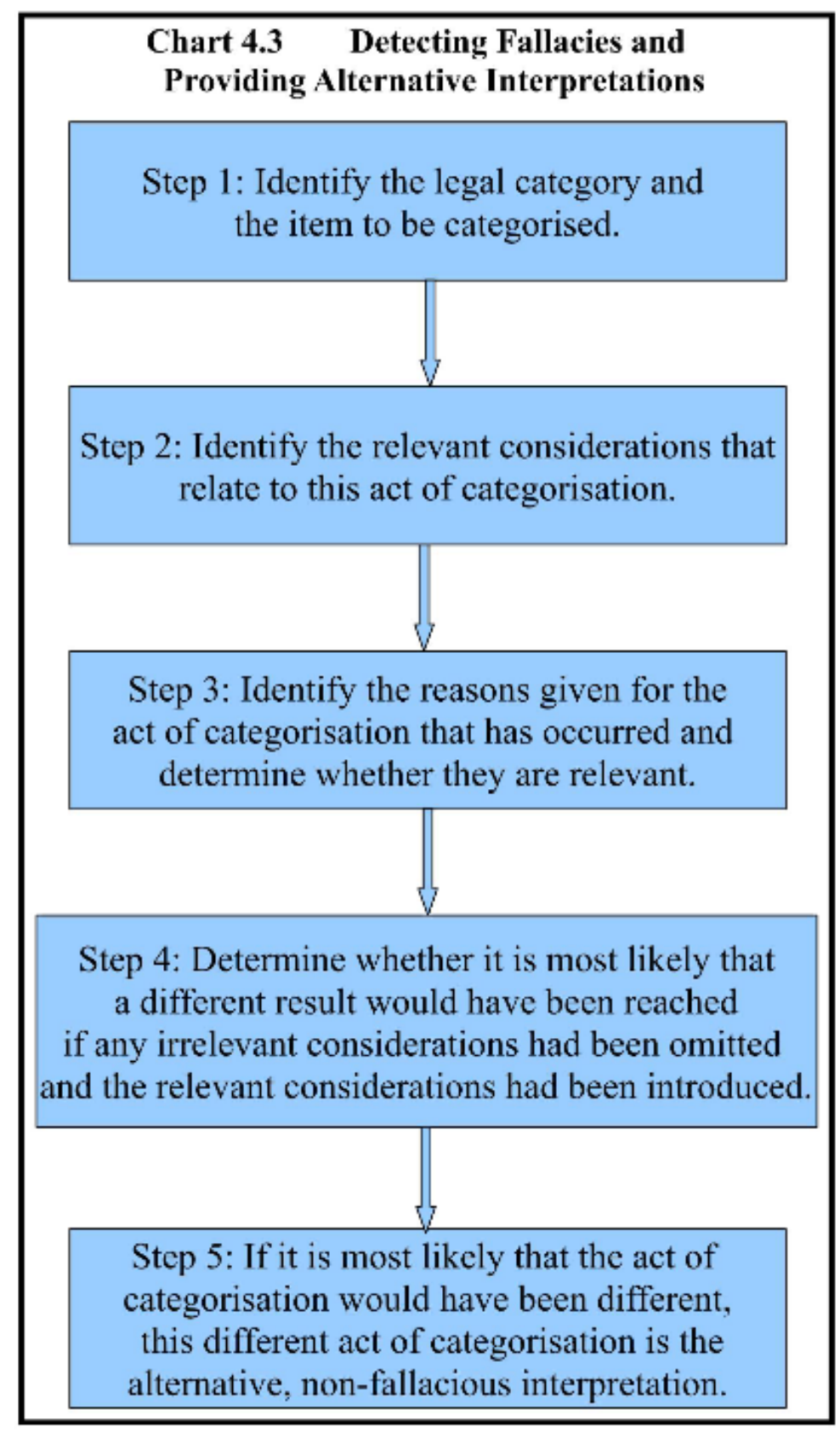

Chart 4.3 sets out the steps that can be used to detect fallacies and provide alternative, nonfallacious interpretations. This chart shows how to detect any fallacy that is caused by the introduction of irrelevant considerations and the omission of relevant considerations. The specific fallacies identified in this paper are identified by these same steps, but the primary irrelevant consideration relates to the verbal category to which the item at issue can be assigned. Judges can avoid fallacies by viewing interpretation as categorisation and following the first two steps in Chart 4.3 and then categorising the item at issue by taking into account the relevant considerations. 
It is now useful to analyse another case to illustrate this process of detecting fallacies. The House of Lords' decision Mannai Investment v Eagle Star Life Assurance ${ }^{521}$ involved the interpretation of a lease. The lease was for a term of 10 years from 13 January $1992 .^{522}$ Clause 7(13) of the lease provided:

The tenant may by serving not less than six months' notice in writing on the landlord or its solicitor such notice to expire on the third anniversary of the term commencement date determine this lease and upon expiry of such notice this lease shall cease and determine and have no further effect.

The tenant attempted to bring the lease to an end by serving a notice ${ }^{523}$ on the landlord. The tenant's notice stated: "Pursuant to clause $7(13)$ of the lease we as tenant hereby give notice to you to determine the lease on 12 January 1995”. ${ }^{524}$

The third anniversary of the "term commencement date", however, was 13 January 1995, not 12 January 1995. Therefore, the tenant made a mistake in the date that was given in the notice. The landlord claimed that the notice was ineffective due to the tenant's mistake, even though the notice was served on the landlord more than six months before 13 January $1995 .^{525}$

The issue was whether the notice was an effective notice under clause 7(13). In a dissenting speech, Lord Goff stated: ${ }^{526}$

At first sight it seems unreasonable that the notice should not have been effective. It was obvious that the tenant was trying to give an effective notice under the clause, and that it had mistakenly assumed that the anniversary of the term commencement date was not 13 January but 12 January 1995. ... It is tempting therefore to assist the tenant who has made a mistake of this kind, when it must have been obvious to the landlord that the tenant intended to give an effective notice under the clause.

Lord Goff, however, stated "a notice under such a clause will only be effective if it conforms to the specification in the clause. ${ }^{\text {527 }}$ His Lordship further noted: ${ }^{528}$

\footnotetext{
${ }^{521}$ Mannai Investment v Eagle Star Life Assurance [1997] AC 749 (HL) [Mannai Investment].

${ }^{522}$ Ibid, at 752.

${ }^{523}$ There were two leases with identical break clauses and two identical notices were served by the tenant (ibid, at 752), but for simplicity this analysis will refer to 'the lease' and 'the notice'.

${ }^{524}$ Ibid.

${ }^{525}$ Ibid, at 766 .

${ }^{526}$ Ibid, at 753 .

${ }^{527}$ Ibid, at 755 .
} 
The question .... is: does the notice which was given, properly construed, comply with the agreed specification? If it does, it is effective for its purpose. If it does not, it is not so effective; and the mere fact that the person serving the notice plainly intended, and was trying, to give an effective notice under the clause, and that the recipient of the notice realised that he was doing so, makes no difference. ... The key does not fit the lock, and so the door will not open.

His Lordship noted that counsel for the tenant had submitted that: ${ }^{229}$

a more relaxed approach be adopted to the construction of notices of this kind, so that, if it is clear that the giver of the notice intended to comply with the provision of the clause, he should be held to have done so, despite an erroneous choice of the date on which the notice is to take effect.

However, he rejected this submission, noting that: ${ }^{530}$

It seems to me that the adoption of such a test in truth requires that a new meaning should be given to clauses of this kind, so that they are read as requiring no more than that the giver of the notice should express a clear intention to exercise his rights under the clause ....

For these reasons, his Lordship decided that the notice was not effective.

Lord Steyn disagreed with Lord Goff's decision and stated: ${ }^{531}$

The question is not whether 12 January can mean 13 January: it self-evidently cannot. The real question is a different one: does the notice construed against its contextual setting unambiguously inform a reasonable recipient how and when the notice is to operate under the right reserved?

Lord Steyn, therefore, stated that "it would have been obvious to a reasonable recipient that the notices contained a minor misdescription and that the notices conveyed that the tenant sought to determine the leases” and held that the notice was effective. ${ }^{532}$

Lord Hoffmann also held that the notice was effective. ${ }^{533}$ His Lordship stated: ${ }^{534}$

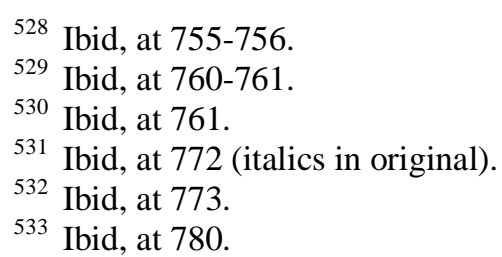


It is of course true that the law is not concerned with the speaker's subjective intentions. But the notion that the law's concern is therefore with the 'meaning of his words' conceals an important ambiguity. The ambiguity lies in a failure to distinguish between the meaning of words and the question of what would be understood as the meaning of a person who uses words.

His Lordship held that "[t]he notice should be construed against the background of the terms of the lease. Interpreted in this way, the notice in the present case was valid”. ${ }^{535}$ Lord Clyde also decided that the notice was effective. ${ }^{536}$ Therefore, the majority of the Law Lords held that the notice was effective.

The process of detecting fallacies can be applied to Lord Goff's decision in this case. First, the legal category and the item under consideration need to be identified. The legal category is the category designated by the words "the third anniversary of the term commencement date" in clause 7(13) of the lease, which are the words being interpreted. The item under considerations is the notice given by the tenant, specifically, the phrase "12 January 1995". The question is whether these words in the tenant's notice fit the description in clause 7(13) of the lease. Viewed in relation to categorisation, the issue is whether this item can fit within this legal category.

Second, the relevant legal considerations related to this legal category need to be identified. As Lord Steyn and Lord Hoffmann pointed out, the primary relevant consideration that relates to this act of categorisation is the intention of the tenant and whether this intention was communicated to the landlord. ${ }^{537}$ The tenant's notice interpreted against the factual background clearly expressed the requisite intention and this was also clearly communicated to the landlord. The legal category designated by clause 7(13) was created so the tenant could indicate its intention to break the lease. ${ }^{538}$ The requirements to break the lease, therefore, should be that the tenant gives notice that indicates an intention in accordance with clause 7(13).

A further relevant consideration is the consequence of refusing to assign the item to the category and of assigning the item to this category. ${ }^{539}$ The consequence of Lord Goff's refusal to assign the

\footnotetext{
534 Ibid, at 775 .

535 Ibid, at 780 .

536 Ibid, at 783 .

537 This corresponds to consideration 2.1 in Chart 4.1.

538 This also corresponds to consideration 2.1 in Chart 4.1.

539 This corresponds to consideration 2.2 in Chart 4.1.
} 
item to this category is that the landlord could take advantage of the tenant's mistake. The consequence of assigning this item to this category, however, is to give effect to the intention of the tenant and to deny the landlord the opportunity of taking advantage of the tenant's mistake.

Third, the reason for the act of categorisation in Lord Goff's decision needs to be identified. Lord Goff decided that this item was not within this category (in his Lordship's words, "the key does not fit the lock" ${ }^{540}$ ). The reason his Lordship gave was that the notice did not "comply with the agreed specification”. ${ }^{541}$ Therefore, because the notice did not say '13 January 1995', it was not effective. The notice was not effective because the date that the tenant used was different from the one required on a literal reading of clause $7(13)$.

It is necessary to determine whether this consideration concerning the literal meaning of clause 7(13) is relevant to this act of categorisation. The reason for this legal category was to provide an opportunity for the tenant to break the lease. This was done by the tenant giving notice indicating this intention. Lord Goff held that because a different date was mistakenly given, the notice was not effective. The fact that the wrong date was given, however, is an irrelevant consideration, when considered in the light of the reason for this legal category. The fact that the tenant expressed its intention using the wrong date should not mean that this notice was not effective if the intention was clearly expressed.

It was not merely that the landlord would have known that the tenant had mistakenly written the wrong date, but the landlord would have known the specific reason for the mistake. Lord Goff noted that Hobhouse LJ in the Court of Appeal pointed out that "the tenant had mistakenly read the clause as if it said 'to expire at the end of the third year of the term"”. ${ }^{542}$ Moreover, the notice that the tenant gave even referred to clause $7(13)$ in the lease. ${ }^{543}$ Lastly, the notice was given more than six months before 13 January 1995. Thus, the fact that the wrong date was given did not have any practical effect on the landlord. The date was just an arbitrary date chosen so that the tenant could indicate an intention to break the lease. Given these considerations, it is even clearer that the fact that the wrong date had mistakenly been given could not mislead the landlord and is therefore not a

\footnotetext{
540 See text accompanying n 528.

541 See text accompanying n 527.

542 Mannai Investment, above n 521, at 753.

${ }^{543}$ Interestingly, Lord Goff stated "the trap which the tenant fell into in the present case is easily avoided by adopting the familiar stratagem of invoking, as an alternative to the specific date, a date identifiable by reference to the terms of the clause itself” (ibid, at 761). Nevertheless, his Lordship did not think that the fact that the tenant had used the words "pursuant to clause 7(13)" in the notice was sufficient to counteract the mistake that had been made.
} 
relevant consideration in relation to this act of categorisation.

Although, strictly speaking, it may be said that this instance of interpretation did not involve the interpretation of words, but of a number, it can still be seen as precisely analogous to the fallacy 'different verbal category, therefore, outside legal category'. The item (the tenant's notice, and specifically, the phrase ' 12 January 1995') could be put in a different verbal category from the verbal category designating the legal category: 'the third anniversary of the term commencement date'. Lord Goff pointed out this different verbal category: "the end of the third year of the term". 544 The fact that the item could be put in this different verbal category, or even that it would normally be put in this different verbal category, however, does not necessarily mean it should be outside the legal category. The fact that the item could be put in this different verbal category was irrelevant to this act of legal categorisation because the reason for this legal category was to give the tenant an opportunity to indicate its intention to break the lease, and this item (the notice) indicated this intention clearly. The difference in date had no practical effect on the landlord, did not mean that the tenant's intention was not communicated, and did not even mean that the intention was any less clear than if the correct date had been given because the notice referred to clause 7(13) in the lease. It was therefore an irrelevant consideration, ${ }^{545}$ because it was not a valid reason to exclude the item from this legal category.

Fourth, there needs to be a determination of whether it is most likely that Lord Goff's act of categorisation would have been decided differently if this irrelevant consideration had been omitted and the relevant legal considerations had been introduced. Lord Goff’s decision was based on an irrelevant consideration in relation to this act of categorisation. Furthermore, it neglected the relevant consideration of the reason for the legal category. Lord Goff's decision would most likely have been made differently if the irrelevant consideration had been omitted and the relevant consideration had been introduced. ${ }^{546}$ This is seen by the result in the decisions which introduced this relevant consideration. For these reasons, Lord Goff's decision was fallacious.

\footnotetext{
544 See text accompanying n 542.

545 In many situations, a mistake in the date in a notice would be a relevant consideration. The point being made here is that it was an irrelevant consideration for this instance of interpretation. An analogous irrelevant consideration would be if the tenant made a minor spelling mistake that did not affect intelligibility.

546 The fact that it may be possible to find relevant considerations that could support the result reached by Lord Goff (for instance, a policy argument based on a conjecture regarding the economic efficiency of literal interpretation) does not mean that such a decision is not fallacious. These sort of relevant considerations need to be weighed up against the relevant consideration of giving effect to the tenant's intention which is the reason for the existence of the legal category, and is therefore a much more relevant consideration.
} 
Fifth, the alternative, non-fallacious interpretation would be the decision reached by the majority of the Law Lords which took the relevant legal consideration into account and omitted the irrelevant consideration of the verbal category to which the item could be assigned.

The reason this fallacy was committed was that Lord Goff focused on the legal category (clause 7(13)) and the item that he expected to be assigned to it, rather than the item before the Court and whether it should be assigned to this legal category given the reason for this act of categorisation.

It is helpful to make a few more points about Mannai Investment. First, to say the consideration that Lord Goff introduced (the mistaken date) was an irrelevant consideration is to say it is not relevant to the exclusion of the item from this legal category. A relevant consideration is a reason for an act of categorisation. The Court needed to consider the fact that the wrong date had been given, but then the decision needed to be made whether this fact was a valid reason for excluding the item from the legal category. Therefore, to say that this is an irrelevant consideration does not mean that it should not be taken into account by the Court at all. It means that it is not a reason that supports the exclusion of this item from this category. ${ }^{547}$

Second, this analysis should not be taken to suggest that tenants can express their intention in any form whatsoever. The notice given needed to comply with clause 7(13). For instance, the notice needed to be in writing. If the tenant merely orally informed the landlord of an intention to break the lease, this would not be sufficient. The crucial point is that the notice that was given did comply with clause $7(13)$. Given the reason for clause $7(13)$, the minor mistake in the date should not be sufficient to mean that the notice did not comply. Therefore, the claim is not being made that every time a party to a contract makes a mistake but succeeds in communicating an intention, this intention should be recognised and given effect to by the courts. Rather, in the context of this specific act of categorisation, it was correct to give effect to the clear, communicated intention of the tenant.

It is therefore not the case that a decision that the tenant's notice was effective would have the result mentioned by Lord Goff that clauses of this kind "are read as requiring no more than that the giver

\footnotetext{
547 Similarly, in Smith the Court may have needed to consult dictionaries, but if it is clear that the meanings given in the dictionaries are not relevant to the meaning that is being expressed in the provision, this meaning is an irrelevant consideration in relation to the act of categorisation before the Court.
} 
of the notice should express a clear intention to exercise his rights under the clause". ${ }^{548}$ The notice does need to comply with the clause. Rather, deciding that the tenant's notice was effective had the result that clauses of this kind are interpreted with reference to the reasons they exist.

Third, if a majority of the Law Lords had concurred with Lord Goff's decision, a decision in a lower court that had reached a similar result would not be fallacious, because that court would be constrained to decide this way due to this binding precedent. Therefore, fallacious decisions at the level of the superior courts have the effect of forcing other courts to make similar decisions.

Fourth, it is useful to briefly consider the views about meaning expressed in this judgement. It can be said that this case involved the interpretation of the meaning of a number. Numbers are signs like words, and thus are arbitrary, yet conventional symbols. Although the conventions in relation to numbers are far more settled than those in relation to words, they are still conventions. Therefore, Lord Steyn's statement that 12 January cannot mean 13 January ${ }^{549}$ may not be as self-evident as it seems. It is true that the tenant did not mean 13 January in this instance. Rather, the tenant thought that the clause required notice to be given on 12 January. Still, it may be possible for 12 January to mean 13 January. Meaning is inextricably related to intention. Lord Hoffmann pointed out there is a need to "distinguish between the meaning of words and the question of what would be understood as the meaning of a person who uses words." 550 This distinction is helpful, but it may be clearer to say that the meaning of words is what a speaker uses them to mean. It is possible that a person could refer to '12 January' and mean '13 January', and if this intention was communicated, it should be recognised by the courts. Therefore, the claim that 12 January cannot mean 13 January seems to be based on an erroneous view about meaning. Lord Goff's statement that the "key does not fit the lock, and so the door will not open” ${ }^{551}$ also seems to be based on an erroneous view of meaning: that there should be a fixed relationship between a certain verbal formula and a certain legal result. The whole purpose of language is to convey intention. The analogy of a key and a lock suggests that there is the need of a specific form of language to achieve a certain legal result, and this view of language can lead to the view that the verbal category to which an item can be assigned should determine the legal category to which it should be assigned.

\footnotetext{
548 See text accompanying n 530.

549 See text accompanying n 531.

550 See text accompanying n 534.

551 See text accompanying n 528.
} 


\section{Conclusion}

This section concludes this chapter by addressing the questions regarding judicial interpretation raised at the end of Chapter Two. These answers summarise the main ideas in this chapter. They also show how the central contention of this thesis has been proven. Since this chapter has focused on judicial interpretation which involves categorisation, the answers to these questions focus on this kind of judicial interpretation and the statements made in these answers do not apply to all instances of judicial interpretation. Specifically, they do not apply to instances of judicial interpretation which do not involve the categorisation of a specific item within the legal category designated by the word being interpreted.

1. What are the differences between legal interpretation and ordinary interpretation?

Various minor differences can be noted between legal interpretation and ordinary interpretation. These include that judges are the authoritative interpreters and that legal interpretation takes place in the context of an official legal decision, that intention may need to be presumed where it is not discoverable or did not exist, that the act of interpretation is often delayed and is in the context of a different factual situation from the act of speaking, and that there are various evidentiary restrictions on legal interpretation. Importantly, such differences do not mean that the process of legal interpretation is significantly different from the process of ordinary interpretation.

It is misleading to claim that legal interpretation is concerned with objectively ascertaining meaning whereas ordinary interpretation is concerned with the subjective intentions of speakers. Both kinds of interpretation are necessarily objective. Moreover, in many situations legal interpretation does involve ascertaining the actual intention of speakers.

There are two important differences between legal interpretation and ordinary interpretation. First, the considerations that are relevant to legal interpretation may be different from the ones that are relevant to ordinary interpretation. Because legal interpretation relates to a legal decision regarding the application of the law, considerations related to the law are relevant, for instance, considerations related to the law generally, consideration related to the specific area of law at issue, and legal policy considerations.

Second, legal interpretation is often focused on deciding whether a specific item should fit within a 
legal category whereas ordinary interpretation is focused on discovering a meaning of a word. This means that judges may have to attribute a meaning to a word, rather than discover a meaning. More importantly, this means that the meaning given to the word being interpreted is related to a decision regarding the legal status of the matter before the court, and is not an end in itself.

Having noted these two differences, both legal interpretation and ordinary interpretation involve essentially the same process, and this can be seen clearly when both are viewed in relation to categorisation. Both kinds of interpretation can involve the assignment of an item to a category based on relevant considerations.

2. Should legal interpretation be approached differently from ordinary interpretation? If so, in what way?

The basic processes involved in legal interpretation and ordinary interpretation are similar, but the considerations that need to be taken into account and the focuses of the acts of interpretation are different. A helpful way to approach ordinary interpretation is to view it as the discovery of the meaning a speaker has given the word being interpreted. Therefore, ordinary interpretation is based on considerations indicating the specific meaning being expressed by the speaker and is focused on the discovery of the speaker's meaning. A helpful way to approach legal interpretation can be to view it as an act of categorisation which is based on various relevant legal considerations. Furthermore, the focus of this act of categorisation is on whether the specific item before the court should be included within the legal category designated by the word being interpreted.

3. Are fallacies committed in the interpretation of language ordinarily relevant to legal interpretation?

Fallacies that are committed in ordinary interpretation may be relevant to legal interpretation. For instance, the two fallacies identified in Chapter Three of this thesis (the 'same word' fallacy and the 'different word' fallacy) are relevant to legal interpretation because corresponding fallacies can be committed by judges. Because of the difference in focus between ordinary interpretation and legal interpretation, however, these fallacies should be viewed in relation to the categorisation of a specific item within a certain legal category. Thus, the ordinary language fallacy that involves the assumption 'same word, therefore, same meaning' corresponds to the judicial fallacy that involves the assumption 'same verbal category, therefore, within legal category', and the ordinary language 
fallacy that involves the assumption 'different word, therefore, different meaning' corresponds to the judicial fallacy that involves the assumption 'different verbal category, therefore, outside legal category'.

4. What is the goal of judicial interpretation?

Viewed in relation to categorisation, the goal of judicial interpretation is to correctly categorise the item before the court. The judge needs to determine whether to assign this item to the legal category designated by the word being interpreted. The decision regarding whether to assign a certain item to a legal category should be governed by the legal considerations relevant to this act of categorisation. These include considerations related to the word being interpreted, the legal category designated by this word, items relevant to this act of categorisation, and general legal considerations. ${ }^{552}$ In this chapter, these considerations have been called 'relevant legal considerations'. When an item is assigned to a legal category this has the effect of implementing the law in relation to that category, applying the law to that item, and giving that item a legal status with an attendant legal consequence.

5. What makes an instance of judicial interpretation fallacious?

Judicial interpretation should be based on relevant legal considerations. A consideration is irrelevant when it is not related to the specific act of categorisation before the court. An instance of judicial interpretation is fallacious when it takes into account an irrelevant consideration and it is most likely that a different result would have been reached if that consideration had been omitted, or when it omits a relevant legal consideration and it is most likely that a different result would have been reached if that consideration had been taken into account.

6. What kinds of fallacies are committed in judicial interpretation?

Two specific judicial fallacies have been identified in this chapter. First, the 'same verbal category' fallacy. This occurs when a judge assumes that because an item can be assigned to the verbal category by which the legal category has been designated, it should be assigned to this legal category. Second, the 'different verbal category' fallacy. This occurs when a judge assumes that because an item can be assigned to a different verbal category from the verbal category by which

552 Chart 4.1 sets out these four groups of relevant legal considerations. 
the legal category has been designated, it should not be assigned to this legal category.

When these assumptions regarding the verbal category to which an item can be assigned result in the introduction of irrelevant considerations, and it is most likely that a different result would have been reached if these irrelevant considerations had not been introduced and the relevant legal considerations had been taken into account, the interpretation is fallacious.

7. Why are these fallacies committed in judicial interpretation?

Fallacies are committed in situations where a judge associates the item under consideration with a certain verbal category and does not look beyond this association to the relevant legal considerations. This can occur because of a focus on the discovery of the meaning of the word being interpreted rather than a focus on the correct categorisation of the item before the court.

First, when a judge focuses on the discovery of the meaning of the word being interpreted, this can lead to the introduction of the irrelevant consideration of a meaning the word being interpreted can have and the neglect of the relevant legal considerations. Second, when a judges focuses the word being interpreted rather than the item before the court and whether it should be assigned to the legal category designated by this word, this can cause relevant legal considerations to be misapplied and can introduce irrelevant considerations.

8. What is the consequence of these fallacies?

The consequence of these fallacies is that an item is either wrongly included in or wrongly excluded from the legal category designated by the word being interpreted.

9. How should an instance of interpretation be analysed to see whether it is fallacious?

There are four steps to detect the fallacies identified in this chapter. First, the item to be categorised and the legal category need to be identified. Second, the relevant legal considerations that relate to this act of categorisation need to be elicited. Third, it needs to be determined whether the act of categorisation that has occurred has been made on the basis of an irrelevant consideration regarding the verbal category to which the item can be assigned. Fourth, it needs to be determined whether it is most likely that a different result would have been reached if any irrelevant considerations had 
been omitted and the relevant legal consideration had been introduced.

10. How can judges avoid fallacies?

To avoid fallacies, judges need to pay attention to the relevant legal considerations and avoid irrelevant considerations. They also need to be willing to look beyond the verbal category to which an item can be assigned and determine whether it should be assigned to the legal category at issue. This can be done when judges view judicial interpretation as categorisation based on relevant legal considerations and focus on the correct categorisation of the item before the court.

11. What is the way to arrive at alternative, non-fallacious interpretations when judicial fallacies have been committed?

An alternative, non-fallacious interpretation is reached by making an interpretive decision on the basis of the relevant legal considerations and omitting any irrelevant considerations. Since the fallacies identified in this chapter involve either the wrong inclusion of an item in a legal category or the wrong exclusion of an item from a legal category, the alternative interpretations are clear. For the 'same verbal category' fallacy, the alternative interpretation is that the wrongly included item should be excluded from the legal category. For the 'different verbal category' fallacy, the alternative interpretation is that the wrongly excluded item should be included within the legal category.

This chapter has analysed language in the law and judicial fallacies. It has provided a general definition of fallacious interpretation and has identified two specific fallacies that judges can commit. It has provided a way to detect these fallacies and arrive at alternative, non-fallacious interpretations when they occur. It has also given examples of such fallacies being committed by judges. Furthermore, it has briefly discussed how judges can avoid these fallacies.

The examples of fallacies being committed have been from different jurisdictions, have related to different areas of the law, and have involved the interpretation of different kinds of legal documents. The analysis in this chapter can apply so broadly because it is viewing judicial interpretation as categorisation. Judicial interpretation is governed by different rules in different jurisdictions, but in all jurisdictions it can involve categorisation. Judicial interpretation in different areas of the law is based on different considerations, but in all areas of the law it can involve categorisation. The 
judicial interpretation of different kinds of legal documents is focused on different matters, but the interpretation of all legal documents can involve categorisation. When viewed in relation to categorisation, even judicial interpretation and ordinary interpretation are fundamentally similar. Therefore, viewing judicial interpretation in relation to categorisation provides a helpful way to understand the basic process of judicial interpretation and this understanding can be applied very broadly. 


\section{CHAPTER FIVE}

\section{LAW, LANGUAGE, AND CATEGORISATION}

\section{A Introduction}

This chapter will address the general questions about law and language raised at the end of Chapter Two in light of the analysis in both Chapter Three and Chapter Four. Some of these questions may be dismissed as meaningless, but it is still helpful to address them.

\section{B Law and Categorisation}

This thesis has shown that judicial interpretation often involves categorisation. Although some definitions of the word 'law' were briefly mentioned in Chapter Two, ${ }^{553}$ it has not been necessary to provide a definition of the word 'law' for the purpose of this thesis. It has been seen, however, that judicial interpretation often involves the assignment of items to legal categories. The result of such an assignment is that the law is applied to these items in the sense that they are given a legal status. Furthermore, such assignment means that the law is implemented in the sense that the legal reason for the categories to which the items have been assigned is fulfilled. This implementation of the law can include the implementation of specific laws embodied in statutes, the recognition of legal relationships enshrined in contracts, and the carrying out of legal arrangements set out in wills or other legal documents.

Thus, the law can be viewed as involving a system of legal categories to which items can be assigned by judicial interpretation. Such assignment gives these items a legal status. Although this may not be a comprehensive definition of the word 'law', it is a useful description of an important aspect of the law.

553 See the paragraph accompanying n 26. 
In light of this description of the law, the general questions raised at the end of Chapter Two can be addressed.

1. What is a useful way to describe the nature of the relationship between law and language?

In Chapter Two, various parallels between law and language were noted. ${ }^{554}$ A parallel that was not noted is that both a language and a legal system can be viewed as classificatory systems. Just as a specific language is a classificatory system, it can be said that the law governing a specific jurisdiction is a classificatory system. This is a more basic parallel between law and language than the others which were noted. It shows that there are not merely outward incidental similarities between law and language, but that law and language have a fundamental structural similarity. ${ }^{555}$

The claim that law is language, ${ }^{556}$ therefore, may have some truth to it. The law in a specific jurisdiction is a classificatory system that is used to give items a legal status, just as a language is a classificatory system that is used to give items names. If the claim that law is language means that law functions as a classificatory system similar to language, such a claim is correct.

It can also be said that law uses language as a classificatory system. In a sense, this use of language in the law is similar to other professions such as medicine which have their own vocabulary. Still, there is an important distinction. H L A Hart stated: ${ }^{557}$

The first efforts to define words like 'corporation', 'right' or 'duty' reveal that these do not have the straightforward connection with counterparts in the world of fact which most ordinary words have and to which we appeal in our definition of ordinary words. There is nothing which simply 'corresponds' to these legal words ....

Such a statement is a little misleading. It is arguable that there is something that corresponds to each of these words. This statement, however, reveals an important distinction between the use of language in the law and the use of language in other professions. The use of language as a

\footnotetext{
554 See the paragraph accompanying n 19.

555 Compare the statement by Rotman quoted in $\mathrm{n} 21$.

556 See the quotations in $\mathrm{n} 24$.

557 HLA Hart “Definition and Theory in Jurisprudence” (1954) 70 LQR 37 at 38.
} 
classificatory system in the law is different from the use of a technical vocabulary in other professions because the very existence of legal categories is dependent on the legal system of which those categories are a part. The use of language in the law creates a classificatory system with certain categories which would not exist at all if there were not a legal system to support them. A certain disease would still exist whether or not it was medically recognised, but a crime does not exist if it is not legally recognised. The action that would constitute the crime would still exist, but it would not be a crime. In this sense it can be said that legal categories do not have "counterparts in the world of fact" in the same way that categories created by other professions often do. ${ }^{558}$

2. Why is language important to the law?

Having noted that law is a classificatory system, it is important to point out that law is not merely a classificatory system in addition to language, but is a classificatory system which employs language. Language is important to the law because it provides the law with a medium which makes it possible to categorise items, that is, it provides the law with a system within which legal categories can be expressed. The law uses language as a classificatory system. Language, therefore, makes it possible for items to be legally classified.

3. To what extent does the nature of language determine the nature of the law?

Because law employs language as a classificatory system, the nature of language determines the nature of law in a number of ways. Law inherits various traits of language. For instance, the categorisation errors that are possible in ordinary language interpretation are also possible in legal interpretation. Moreover, these categorisation errors can occur when the categorisation of items in ordinary language is confused with their categorisation in the law. ${ }^{559}$ This is because law uses language to create a system of categorisation, but this system is within the existing system of

\footnotetext{
558 John Searle has drawn a distinction between 'brute facts' and 'institutional facts'. Brute facts include the fact that "Mount Everest has snow and ice near the summit or that hydrogen atoms have one electron, which facts are totally independent of any human opinions. ... Institutional facts are so called because they require human institutions for their existence. In order that a piece of paper should be a five dollar bill, for example, there has to be the human institution of money. Brute facts require no human institutions for their existence.” John R Searle The Construction of Social Reality (The Free Press, New York, 1995) at 2. Therefore, it can be said that the law creates institutional facts, whereas other professions often classify brute facts. Institutional facts, however, can also be created in other areas of society, for instance, in sports (at 1). For instance, whether or not a certain event should be classified as a goal in a certain game depends on the rules of the game being played. These rules are a human institution and thus create institutional facts such as the fact that a certain event constitutes a goal.

559 That is, a judge can think that because an item can be assigned to a certain verbal category it should be assigned to a certain legal category.
} 
categorisation that ordinary language provides and employs the same words. ${ }^{560}$

4. Is the law merely contained in language, or is this language itself the law?

The plain legal language proponent Robert Benson makes the claim that "a law revision commission routinely tells a legislature, 'We have simplified the code you asked us to look at, and changed only the words, not the law',. ${ }^{561}$ Jeffrey Barnes, however, has argued that "in its attempts to change the impact of the law, the plain language project can be usefully analysed as a 'law reform' project."562 The claim that the simplification of legal language changes only the words and not the law relies on an implicit definition of the law as something which is contained in language. The claim that clarifying legal language involves reforming the law may rely on an implicit definition of the law as certain language. To avoid confusion, such implicit definitions need to be made clear. They can be made clear when the law is viewed in relation to categorisation.

In relation to categorisation, the law can either be seen as a system of legal categories that is embodied in specific language or as specific language that embodies a system of legal categories. These two ways of viewing the law are actually saying the same thing in two different ways. Whether the law is defined as the language itself that embodies the legal categories or as legal categories that are embodied in language, it still involves the use of language to embody categories. On the one hand, the categories could not be expressed without the language. On the other hand, the language would be of no effect if it did not express the categories.

Likewise, there is no real difference between the claim that the law is language and the claim that the law is contained in language. On the one hand, the law could not be expressed without the language, so it can be argued that the language itself is the law. On the other hand, the language is of no effect without the law it expresses, so it can be argued that the language contains the law. On either view, however, the law needs to be expressed in language. Therefore, no answer to the

${ }^{560}$ In Chapter Three D it was pointed out that the categorisation that language imposes on thought can either be viewed as restricting thought or as enabling thought, that is, it can either be viewed negatively or positively. Similarly, the categorisation that law imposes on items can be viewed as restrictive or enabling, that is, negatively or positively. In Lon Fuller's words, law can be viewed "as an instrument of constraint to keep people from evil or damaging behaviour ... [or] a framework within which [people] can organize their relations with one another in such a manner as to make possible a peaceful and profitable coexistence" Lon L Fuller "Law as an Instrument of Social Control and Law as a Facilitation of Human Interaction” (1975) 1975 BYU L Rev 89 at 89.

${ }^{561}$ Robert W Benson "The End of Legalese: The Game Is Over" (1984-1985) 13 NYU Rev L \& Soc Change 519 at 563.

562 Jeffrey Barnes “The Continuing Debate About 'Plain Language’ Legislation: A Law Reform Conundrum” (2006) 27 Statute L Rev 83 at 85. 
question of whether the law is merely contained in language or whether this language itself is the law can provide any real insight into the nature of law or its relationship to language. It is thus a meaningless question. A better question to ask would be: 'What effect does language have on the law?'

Diagram 2.1 depicted the relationship between law and language in relation to drafting and judicial interpretation in a preliminary way. This relationship was given more accurately and in more detail in Diagram 4.6 in relation to legal speaking and legal interpretation. Still, the basic question of the relationship between law and language was not addressed clearly by these diagrams. Diagram 5.1, below, revisits the question of the relationship between law and language by viewing this relationship in terms of legal categorisation. 


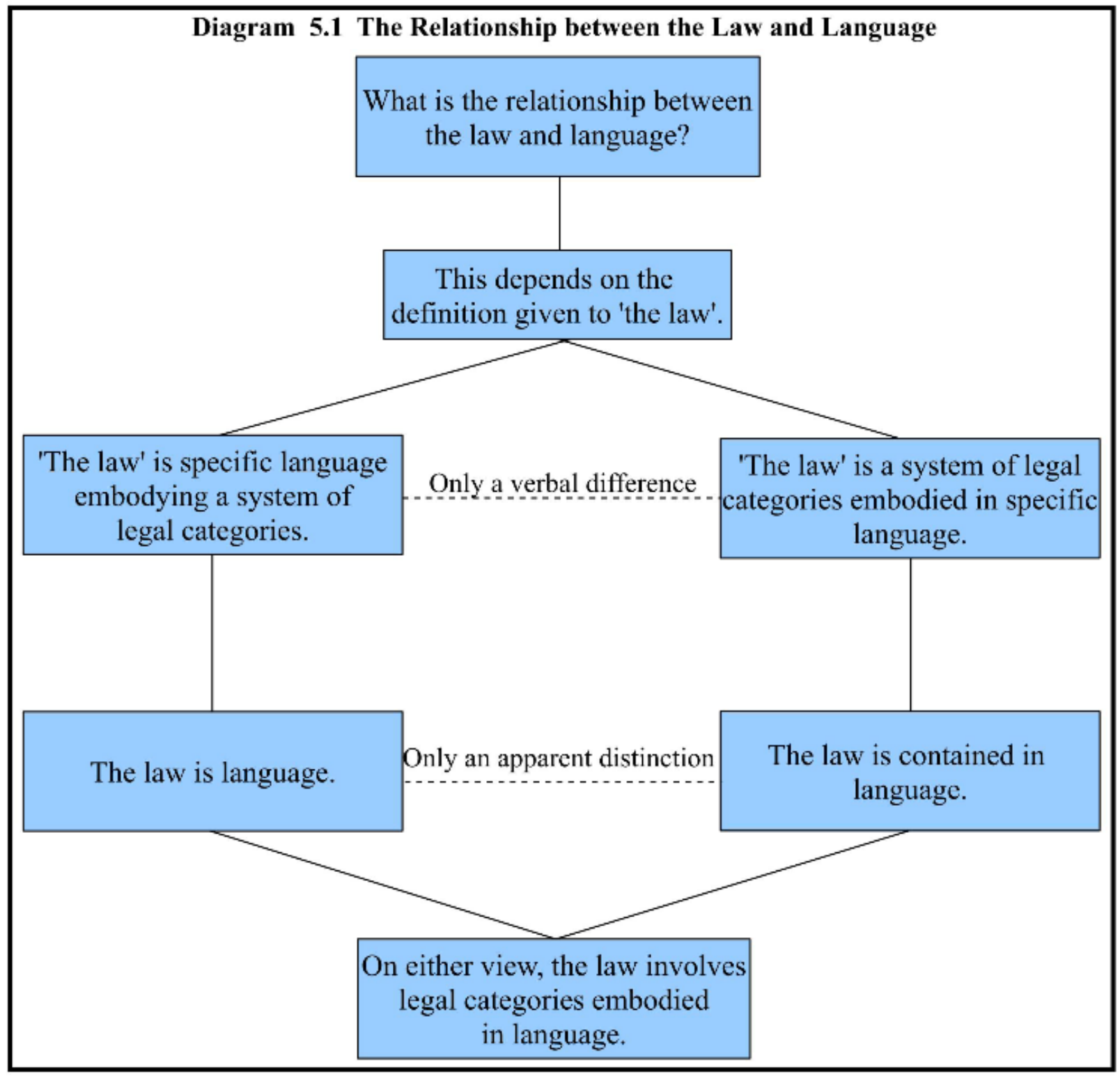

Diagram $5.1^{563}$ shows that when the law is viewed in relation to categorisation it can be seen that the claims that the law is language or that the law is contained in language are really saying the same thing. Such claims, therefore, provide no insight into the nature of the law or its relationship to language. They just illustrate two ways of looking at the relationship between law and language.

To a certain extent, arguments about the law may rely on question-begging definitions. For instance, the claim that simplifying legal language changes only the words and not the law depends on an implicit definition of 'law' as something contained in language. On this definition, the law can be

563 This diagram depicts the relationship between the law and language, whereas Diagram 2.1 depicted the relationship between law and language. The term 'the law' is more specific than the term 'law'. 'The law' relates to a specific legal system, or a specific system of legal categories, whereas 'law' may be thought of as an abstraction that is not related to any particular system of categories. 
distinguished from the language in which it is contained. This, however, is only one way to view the relationship between law and language. Furthermore, the claim that simplifying legal language will change the law may rely on an implicit definition of the law as language. On this definition, the law cannot be distinguished from the language in which it is contained. This again is only one way to view the relationship between law and language. It may be possible to sustain either claim, but to do this is it necessary to see the nature of the relationship between law and language clearly. A good way to see this relationship clearly is to view it in terms of categorisation.

5. If a distinction is drawn between the words of the law and the law, what is the law as opposed to the words of the law?

This question concerns the nature of the 'abstract law' in Diagram 2.1. In Chapter Two it was mentioned that the concept of 'abstract law' is questionable and may create confusion. ${ }^{564}$ There is a certain sense, however, in which the law can be said to exist apart from the words of the law. This can be seen clearly when the law is viewed in relation to categorisation. The law can be viewed as a system of legal categories to which items can be assigned. There are a variety of relevant legal considerations which determine whether an item should be assigned to a legal category. In the sense that these considerations are legally relevant considerations which determine the legal result, and therefore determine what the law is, they can be viewed as the law in relation to this category. These considerations, however, should not be viewed as a "brooding omnipresence in the sky", 565 but rather should just be viewed as a group of considerations which determine whether an item should be assigned to a legal category. Therefore, these relevant legal considerations can be viewed as the abstract law in Diagram 2.1. ${ }^{566}$

Chapter Two mentioned that some theorists have viewed judicial interpretation as the law. ${ }^{567} \mathrm{~A}$ problem with this view was pointed out by Brian Bix. In his introduction to Jerome Frank's Law and the Modern Mind, Bix notes: ${ }^{568}$

One problem with a theory of law that focuses on actual official actions (especially actual judicial

\footnotetext{
564 See text accompanying n 45.

565 See $n 45$.

566 The relevant legal considerations govern interpretation. Therefore, they may relate to more matters than the abstract law in Diagram 2.1 which governs legal drafting. Therefore, it is more accurate to say that only the relevant legal considerations that relate to the drafting of a legal document should be viewed as the abstract law in Diagram 2.1

567 See n 35.

568 Brian Bix in Jerome Frank Law and the Modern Mind (Transaction Publishers, New Brunswick (NJ), 2009) at xiii.
} 
decisions) is that it does not have the resources to explain the idea of 'legal mistake' ... Equating law this closely with actual decisions, and leaving no conceptual room for 'the law' diverging from those [mistaken] decisions, is a more radical conclusion than most judges, lawyers, and legal scholars are willing to swallow.

This is an important point. The law cannot merely be equated with judicial decisions, because judicial decisions may misapply the law. If the claim that judicial interpretation is the law is merely highlighting that judges have a large amount of power, ${ }^{569}$ it may be acceptable, but it is misleading if it is taken as a complete description of the law.

Furthermore, this description of the law does not take into account what judicial decisions are based on. There has to be something prior to judicial decisions on which they are based. Judicial decisions are based on relevant legal considerations. Therefore, these considerations can be viewed as 'abstract law'. It is usually unnecessary, however, to posit the existence of abstract law.

6. Does changing the words of statutes or other legal documents change the law?

The answer to the question depends on how 'the law' is defined. An answer can be given based on a definition of the law as a system of legal categories to which items are assigned on the basis of relevant consideration. To the extent that changing the words of a legal document changes the legal considerations relevant to the legal categories embodied in that document, changing these words may change the law. The meaning of the word being interpreted is an important consideration, often the most important consideration, in legal interpretation. If the word is changed, this meaning can be changed, and thus the relevant legal considerations are changed, and the law may be changed. The law is changed if changing the word results in items being assigned to different legal categories.

This, however, is clearly not the intention of the plain legal language proponents. Therefore, any simplification of the language of the law has to ensure that the meaning of the words remains unchanged. This can be done by providing definitions. Having said this, even if definitions are given, a simplification of the language in which the law is expressed can make the law uncertain and may result in the law being changed when judges interpret these words.

\footnotetext{
${ }^{569}$ See, for instance, Beth Packert's description of Fred Rodell's view that "[b]ecause the words of the Constitution could be twisted to mean nearly anything, those in charge of interpretation had tremendous power." G Beth Packert “The Relentless Realist: Fred Rodell’s Life and Writings” (1984) 1984 U Ill L Rev 823 at 829.
} 
7. When judges determine the meaning of language, do they create the law or do they merely interpret the meaning of the law?

Chapter Two mentioned two basic views in relation to the role of judicial interpretation: that judicial interpretation involves ascertaining the meaning of the law, and that judicial interpretation involves creating the law. Much has been written about this topic, ${ }^{570}$ and the details of this debate are beyond the scope of this discussion. To a certain extent, however, some of the arguments on either side of this debate may depend on the definition given to 'the law'. This again is clarified when judicial interpretation is viewed as categorisation.

Diagram 5.2, below, clarifies the nature of these two views of the role of judicial interpretation by viewing judicial interpretation ${ }^{571}$ as categorisation.

${ }^{570}$ For material written by judges extra-judicially on this topic, see James Reid "The Judge as Law Maker” (1972) 12 JSPTL 22; Ruth McColl “The Art of Judging” (2008) 12 Southern Cross University L Rev 43; Michael Kirby "Judicial activism? A riposte to the counter-reformation” (2004) 24 Aust Bar Rev 219; and Aharon Barak Purposive Interpretation in Law (Princeton University Press, Princeton, 2005).

571 This diagram covers the judicial interpretation of language. It does not relate to judicial decisions regarding the common law, which are sometimes referred to as 'interpreting' the law. See quotation in n 37. 


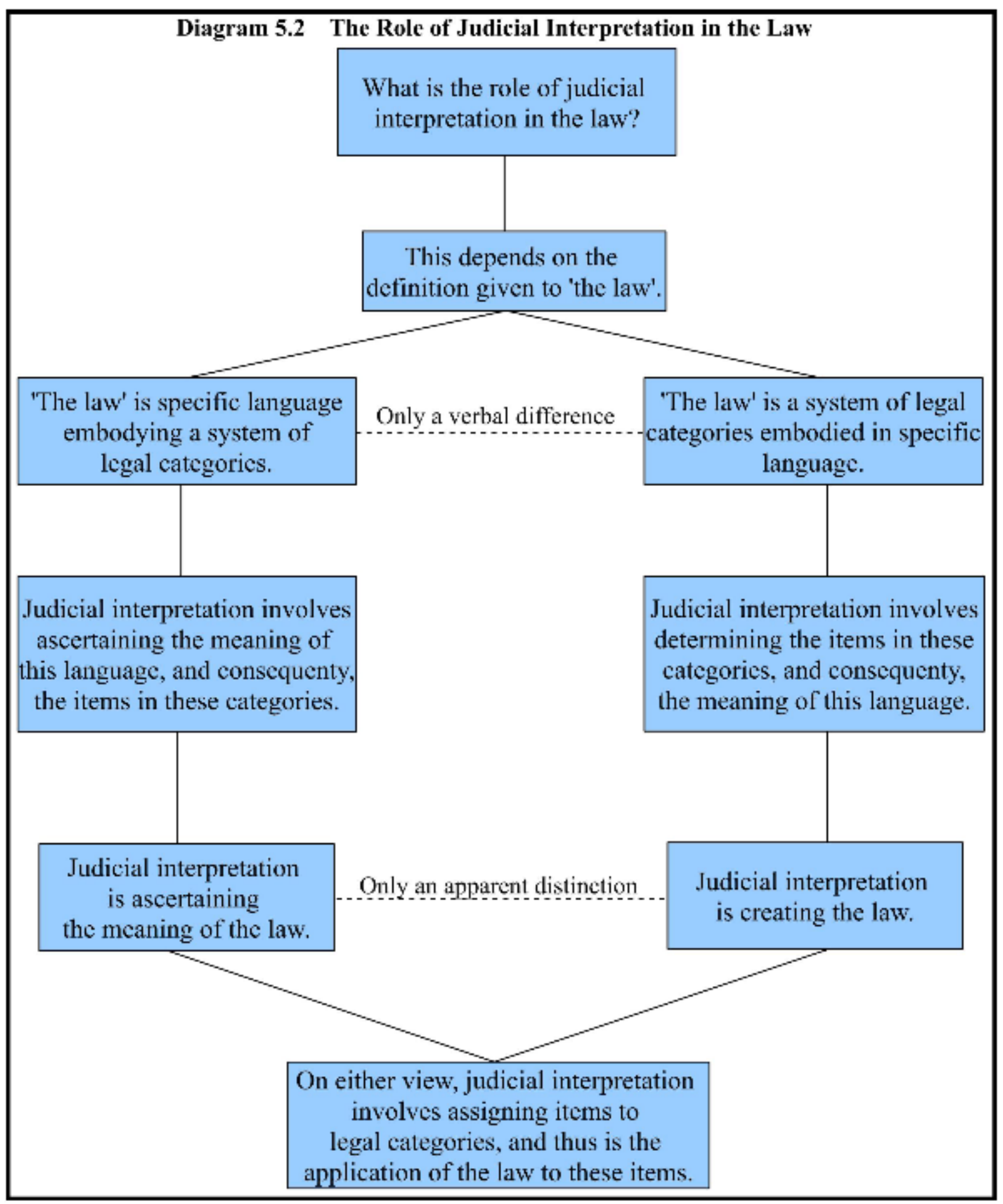

This diagram shows that the two basic views regarding judicial interpretation may involve only an apparent distinction because they rely on a merely verbal difference in the definition given to 'the law'. Often this definition is not stated explicitly but is implicitly assumed.

Even in situations where there is a genuine question at issue - for instance, the issue of how much 
discretion judges should have in interpretation - this issue may be obscured by the way the role of judicial interpretation in the law is described. The issue may be begged by the claim that judges either create the law or merely ascertain the meaning of the law. Arguments can be given in relation to the scope of discretion that should be given to judges. These arguments have not been discussed in this thesis. The point of this section is to show how this issue can be confused by an unreal distinction brought about by a mere verbal difference in the implicit definition given to 'the law'. Merely saying that judges legislate or that judges ascertain the meaning of the law avoids addressing the real issue.

Jerome Frank noted: ${ }^{572}$

[I]t is impossible to anticipate with precision the multitude of particular circumstances which later arise, and which, although not within the literal words of the statute, can be argued to have been within its general scope.

He also noted that "the legislature, not infrequently, uses words that are purposely vague, intending that the courts should work out the meaning as specific cases arise." ${ }^{573}$ When a situation occurs that is possibly within the general scope of a provision, or when the legislature deliberately uses vague words, it is difficult to sustain the claim that judges merely ascertain the meaning of the law. To a certain extent, their task involves the creation of the law. ${ }^{574}$ On the other hand, even in such a situation, the claim that judges merely create the law can be misleading, since they are still engaged in interpretation and should be influenced by legal considerations relevant to this act of interpretation.

\section{E Conclusion}

The discussion in this chapter has shown that the answer to some of the general questions raised in Chapter Two may depend on the definition given to the word 'law'. This chapter has also shown how confusion can arise concerning the relationship between language and the law and the role of

\footnotetext{
${ }^{572}$ Frank, above n 20, at 293-294.

573 Ibid, at 294.

574 TRS Allan notes: "The notion of unqualified parliamentary sovereignty is ultimately grounded ... in an implausible theory of statutory meaning or interpretation. It attributes legal authority to a formally enacted text on the assumption that the words can dictate a literal or 'ordinary' or intended meaning owing little or nothing to judicial construction or evaluation.” TRS Allan "Legislative Supremacy and Legislative Intention: Interpretation, Meaning, and Authority” (2004) 63 Cambridge LJ 685 at 689.
} 
judicial interpretation in the law. This confusion can be dispelled when both the law itself and judicial interpretation are viewed in relation to categorisation. 


\section{CHAPTER SIX}

\section{CONCLUSION}

This thesis has investigated fallacies in judicial interpretation. It has shown that judges commit certain fallacies and has provided a way to detect these fallacies and arrive at alternative, nonfallacious interpretations when they occur.

The focus of this thesis has been on judicial interpretation which involves categorisation. Such categorisation needs to be based on relevant legal considerations. A consideration is irrelevant when it is not related to the specific act of categorisation in which judges are engaged. Relevant considerations include considerations related to the word being interpreted, the legal category designated by that word, items relevant to this act of categorisation, and general legal considerations.

In Chapter One a fallacy in judicial interpretation was defined as an instance of judicial interpretation that is not legally justified and reaches the wrong result. In Chapter Three a more detailed definition of a judicial fallacy was provided. This definition was that an instance of judicial interpretation is fallacious when it takes into account an irrelevant consideration and it is most likely that a different result would have been reached if that consideration had been omitted, or when it omits a relevant legal consideration and it is most likely that a different result would have been reached if that relevant consideration had been taken into account. Such a fallacy is not legally justified because it is not justified by legally relevant considerations. Furthermore, such a fallacy reaches the wrong result because it is most likely that a different result would have been reached if any legally relevant considerations had been introduced and any irrelevant considerations had been omitted.

Based on this general definition of fallacious interpretation, two specific fallacies have been identified: the 'same verbal category' fallacy and the 'different verbal category' fallacy. These fallacies occur when judges make an interpretive decision on the basis of the verbal category to which an item can be assigned rather than on the basis of the relevant legal considerations which determine the legal category to which it should be assigned. These fallacies both involve the introduction of an irrelevant consideration and usually involve the omission of relevant legal 
considerations. This then causes a result to be reached which it is most likely would not have been reached if this irrelevant consideration had been omitted and any relevant considerations had been taken into account.

These two fallacies are detected by assessing whether an instance of interpretation is merely based on the verbal category to which an item can be assigned or whether it is justified by relevant legal considerations. To do this, there is the need to identify the legal category at issue, the item that the judge has either included within this legal category or excluded from this category, and the relevant legal considerations which relate to this act of categorisation. It then needs to be determined whether the reasons that have been given for the act of categorisation that has occurred are relevant considerations. If the categorisation has been based on the irrelevant consideration of the verbal category to which the item can be assigned, and if it is most likely that a different result would have been reached if this irrelevant consideration had been omitted and the relevant legal considerations had been introduced, the decision is fallacious. ${ }^{575}$ Examples have been given of these two fallacies being committed by judges.

Alternative, non-fallacious interpretations are reached by introducing relevant considerations and omitting irrelevant considerations. When this is done, a different result will be reached, that is, the item at issue will be categorised differently. Alternative, non-fallacious interpretations have been provided for the examples that have been given of the fallacies being committed by judges.

Although this thesis is primarily focused on how to critique judicial decisions and detect fallacies, it has also provided a way for judges to avoid fallacies. When engaged in interpretation, judges can avoid fallacies by viewing the act of interpretation as categorisation and focusing on whether the item at issue should be assigned to the legal category designated by the word being interpreted. Whether the item should be assigned to this legal category can be determined by the legal considerations that are relevant to this specific act of categorisation. ${ }^{576}$ Viewing judicial interpretation in relation to categorisation, therefore, provides a helpful way to detect fallacies and a helpful way for judges to avoid fallacies. As shown in Chapter Five, viewing both the law generally and legal interpretation specifically in relation to categorisation also provides a useful way to clarify the relationship between law and language and the role of judicial interpretation in the law. 575 Chart 4.3 sets out the process of detecting fallacies.
576 Chart 4.1 sets out the relevant legal considerations which judges need to take into account when engaged in
interpretation. 
This thesis opened with the epigraph: "The sabbath was made for man, and not man for the sabbath." ${ }^{577}$ Similarly, the law exist to serve society; society does not exist to serve the law. In relation to judicial interpretation which involves categorisation, judges should not primarily focus on ascertaining the meaning of words. Rather, they should focus on whether the item before the court should be assigned to the legal category at issue. That is, they should not start with the legal category, and inflexibly assign items to it based on the apparent meaning of the words designating this category. This is to approach the task from the wrong direction. Rather, they should start with the factual situation before the court and determine how it should be legally classified. To do this, it is helpful to view such instances of judicial interpretation as categorisation based on relevant legal consideration, rather than merely as the discovery of the meaning of the words being interpreted.

577 See text accompanying n 1. 


\section{APPENDIX ONE GLOSSARY}

This glossary collects some important words defined in Chapters Three and Four. The words defined in Chapters Three and Four are grouped separately and are listed alphabetically within each group.

\section{Chapter Three}

Arbitrary: a connection between a word and a thought that it is not natural, intrinsic or necessary.

Convention: an agreed association between a word and a thought.

Fallacy: an unreasonable interpretation where an interpreter arrives at a meaning that is not justified given the relevant considerations indicating the meaning being expressed by the speaker. A fallacy can be committed when speakers either introduce irrelevant considerations or omit relevant considerations.

Ineffable: a thought is ineffable for a speaker when the speaker does not know which word to use to encapsulate that thought; a thing is ineffable for a speaker when a speaker does not know which word to use to describe that thing.

Interpretation: the interpreter objectively ascertaining a speaker's meaning.

Meaning: the thought associated with a word. It is necessary to distinguish between the speaker's meaning, the interpreter's meaning and the general conventional meaning of a word.

Meaningless: a word is meaningless to an interpreter when it does not generate any thought in the interpreter’s mind.

Referent: the thing to which a thought generated by a word refers and, therefore, the thing for which a word stands. 
Speaking: the encapsulation of a speaker's thought in language. 'Speaking' includes any encapsulation of a thought in language, including writing.

\section{Chapter Four}

Because Chapter Four has given stipulative definitions to the words and phrases listed below, the definitions given here are more detailed than the definitions for Chapter Three.

Item: the specific matter before the court which has prompted the instance of interpretation and which needs to be categorised. The court has to decide whether to include this item within the legal category designated by the word being interpreted or to exclude this item from that category. When an item is included within a legal category, this item can be viewed as the referent of the word designating the legal category.

Judicial fallacy: an instance of interpretation that is not legally justified and reaches the wrong result. This means that the interpretation is made based on irrelevant considerations which do not relate to the specific act of categorisation in which the court is engaged rather than relevant legal considerations which do relate to this act of categorisation, and this affects the result reached.

Legal category: a legal category is the category designated by the word being judicially interpreted. For instance, if the word 'vehicle' is used in a certain statutory provision and this word is being interpreted, the legal category is the category designated by this word. The court needs to determine whether to assign the item at issue to this legal category.

Legal ineffability: a thought is legally ineffable for a legal speaker when the speaker does not know which words to use to correctly encapsulate this thought. This means that the legal speaker does not know which words to use to create a legal category with a certain consequence.

Legal interpretation / Judicial interpretation: the process by which judges assign a meaning to a word. The interpretation covered in this thesis involves judges deciding whether to assign the item before the court to the legal category designated by the word being interpreted. Such an assignment needs to be based on relevant legal considerations.

Legal meaninglessness: a word is legally meaningless to a judge when the reason for the existence 
of the legal category which it designates and the kind of items that should be included within this category are unclear to this judge.

Legal speaking: The process by which the language being interpreted by the judiciary comes into being and is given meaning by legal speakers. This involves the creation of legal categories to which items can be assigned by judicial interpretation.

Legal word: the word being judicially interpreted.

Relevant legal consideration: a consideration that is relevant to the assignment of an item to a legal category. A consideration is relevant when it is related to the specific act of categorisation in which the court is engaged. Relevant considerations include considerations related to the word being interpreted, the legal category designated by that word, items relevant to this act of categorisation, and general legal considerations.

Verbal category: the word or words by which a legal category is designated. For instance, the word 'vehicle' may be used in a certain statutory provision to designate a legal category of items to which that provision applies. An item may fit within the verbal category 'vehicle' according to common usage, but may not be an item that should be assigned to this legal category. 


\section{APPENDIX TWO DIAGRAMS}

This appendix collects the diagrams from Chapters Three and Four together.
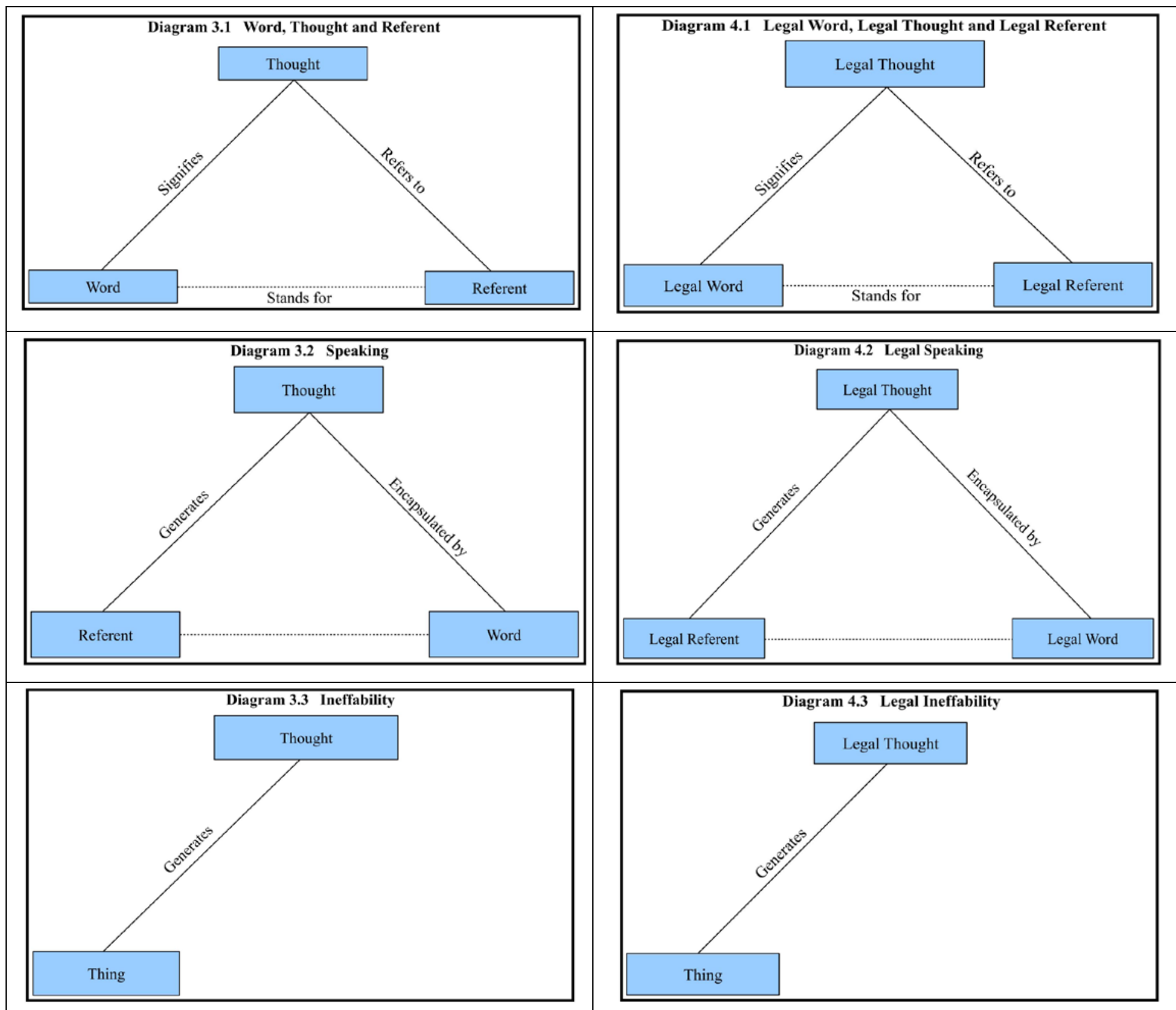

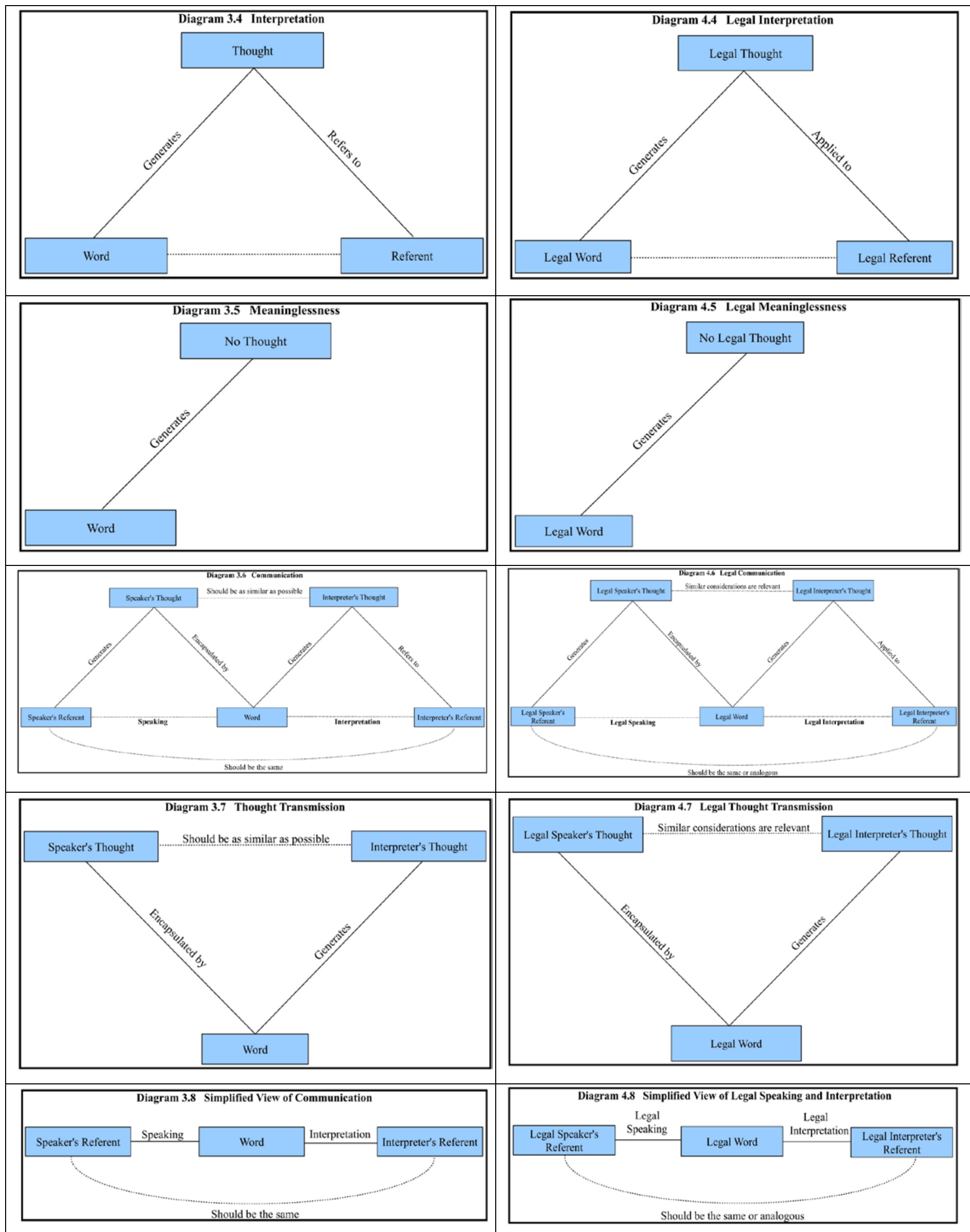

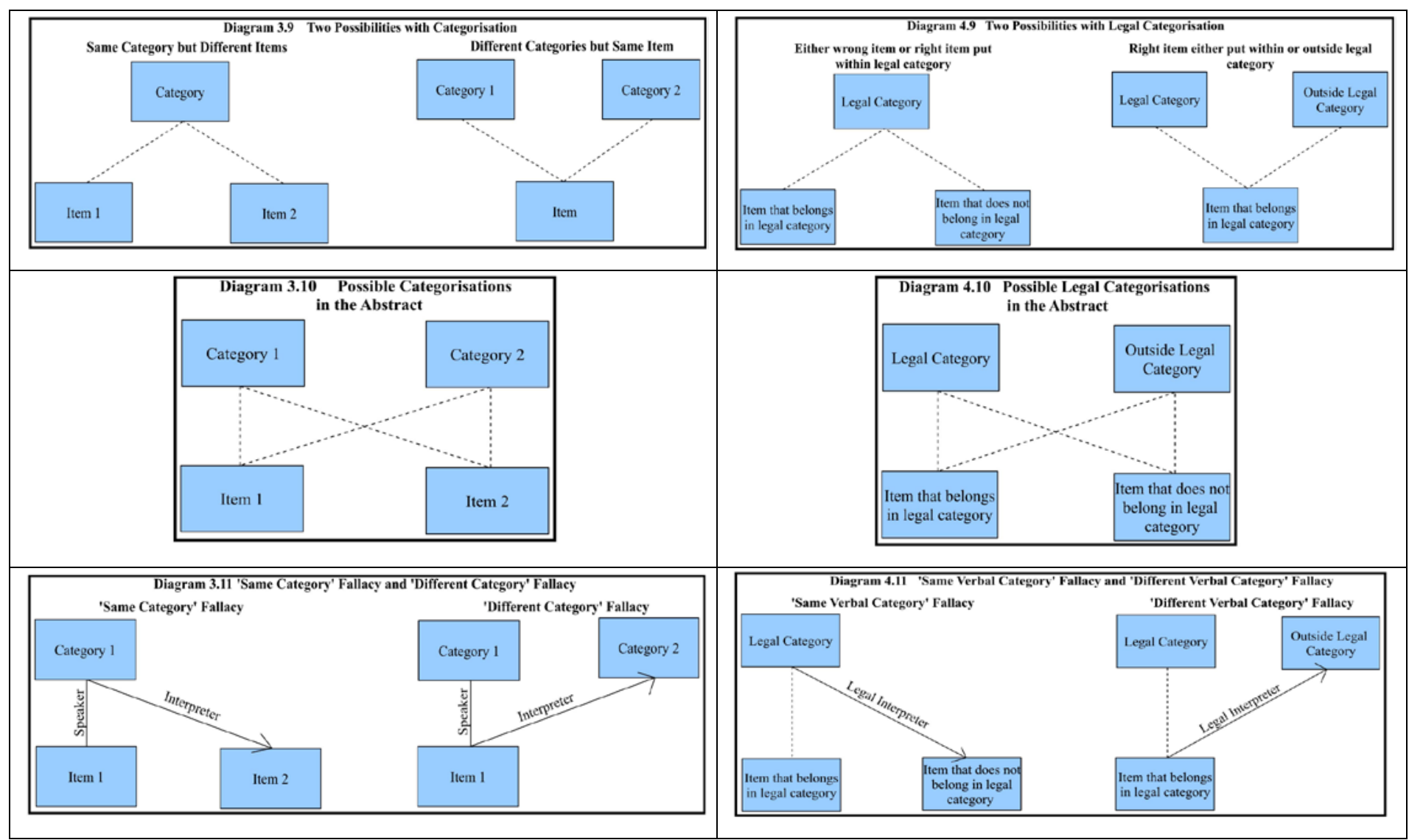


\section{BIBLIOGRAPHY}

\section{A Legislation}

$1 \quad$ New Zealand

Employment Relations Act 2000.

Family Protection Act 1955.

Freshwater Fish Farming Regulations 1983.

$2 \quad$ United Kingdom

Road Traffic Act 1930.

Licensing Act 1872.

$3 \quad$ United States

Code of Laws of the United States of America.

United States Sentencing Commission Guidelines Manual.

B Cases

$1 \quad$ Canada

Haidl v Sacher [1980] 1 WWR 293 (CA).

$2 \quad$ New Zealand

Air Nelson Ltd $v$ The New Zealand Amalgamated Engineering, Printing and Manufacturing Union Incorporated [2010] NZSC 53, [2010] 3 NZLR 433. 
Chartbrook Ltd v Persimmon Homes Ltd [2009] UKHL 38.

Corkery v Carpenter [1951] 1 KB 102.

Donoghue v Stevenson [1932] AC 562 (HL).

Garner v Burr [1951] 1 KB 31.

Investors Compensation Scheme Ltd v West Bromwich Building Society [1998] 1 WLR 896 (HL).

Mannai Investment v Eagle Star Life Assurance [1997] AC 749 (HL).

National Society v Scottish National Society [1915] AC 207 (HL).

Re Rowland [1963] Ch 1 (CA).

$4 \quad$ United States

Caminetti v United States (1917) 242 US 470 (SC).

Lochner v New York (1905) 198 US 45 (SC).

McBoyle v United States (1931) 283 US 25 (SC).

Muscarello v United States (1998) 118 SCt 1911.

Riggs v Palmer (1889) 115 NY 506 (CA).

Sanger v Sanger (2003) 268 Wis2d 846 (CA).

Smith v United States (1993) 113 SCt 2050.

Southern Pacific Co v Jensen (1917) 244 US 205 (SC).

Texas Department of Transportation v Needham (2002) 82 SW3d 314 (SC).

United States v Bass (1971) 404 UC 336 (SC). 
United States v Harris (1992) 294 US AppDC 300 (CA).

Watson v United States (2007) 552 US 74 (SC).

\section{Books}

Aharon Barak Purposive Interpretation in Law (Princeton University Press, Princeton, 2005).

AJ Ayer Language, Truth and Logic (2nd ed, Penguin Books, Harmondsworth, 1971).

Alan Cruse Lexical Semantics (Cambridge University Press, Cambridge, 1986).

Alan Cruse Meaning in Language (2nd ed, Oxford University Press, Oxford, 2004).

Aldous Huxley Words and their Meanings (Jake Zeitlin, Los Angeles, 1940).

Alexander Bryan Johnson A Treatise on Language (Harper \& Brothers, New York, 1836).

Alexander Bryan Johnson The Meaning of Words (D Appleton and Co, New York, 1854).

Alexander Jamieson Grammar of Logic (AH Maltby and Co, New-Haven, 1822).

Alfred Korzybski Science and Sanity (5th ed, Institute of General Semantics, New Jersey, 1994).

Alfred Sidgwick Distinction and the Criticism of Belief (Longmans, Green, and Co, London, 1892).

Alfred Sidgwick Fallacies (D Appleton and Company, New York, 1884).

Alfred Sidgwick The Use of Words in Reasoning (Adam and Charles Black, London, 1901).

AN Whitehead Science and the Modern World (The New American Library of World Literature, Inc, New York, 1948).

AN Whitehead Symbolism (Cambridge University Press, London, 1928).

Anatol Rapoport Semantics (Thomas Y Crowell Company, New York, 1975).

Anne Wagner, Wouter Werner and Deborah Cao Interpretation, Law and the Construction of Meaning (Springer, Dordrecht, 2007). 
Anthony Burgess Language Made Plain (2nd ed, Fontana Paperbacks, London, 1975).

Anthony Weston A Rulebook for Arguments (2nd ed, Hackett Publishing Company, Indianapolis, 1992).

Antony Flew Philosophy (Hooder and Stoughton Limited, London, 1979).

Antony Flew Thinking Straight (Prometheus Books, Buffalo, 1977).

Arthur L Corbin Corbin on Contracts (West Publishing Co, St Paul, 1960).

Barbara Annis Same Words, Different Language (Judy Piatkus (Publishers) Limited, London, 2003).

Benjamin Lee Whorf (John B Carroll (ed)) Language, Thought and Reality (The MIT Press, Cambridge (Mass), 1956).

Bernard S Jackson Making Sense in Law (Deborah Charles Publications, Liverpool, 1995).

Bernard S Jackson Semiotics and Legal Theory (Routledge and Kegan Paul, London, 1985).

BF Skinner Verbal Behavior (Appleton-Century-Crofts, Inc, New York, 1957).

Bill Bryson Notes from a Big Country (Black Swan Books, London, 1999).

Brian Bix Law, Language, and Legal Determinacy (Oxford University Press, Oxford, 1993).

Brian Bix A Dictionary of Legal Theory (Oxford University Press, Oxford, 2004).

Bryan Magee Men of Ideas (British Broadcasting Corporation, London, 1978).

Bryan Magee The Great Philosophers (Oxford University Press, Oxford, 1987).

Charles Dickens The Posthumous Papers of the Pickwick Club (Chapman and Hall, London, 1858).

Charles S Peirce and Victoria Welby (Charles S Hardwick (ed)) Semiotic and Significs (Indiana University Press, Bloomington, 1977).

Charles S Peirce (Morris R Cohen (ed)) Chance, Love and Logic (Kegan Paul, Trench, Truber \& Co Limited, London, 1923). 
Charles W Collier Meaning in Law (Oxford University Press, Oxford, 2009).

Christopher Hutton Language, Meaning and the Law (Edinburgh University Press, Edinburgh, 2009).

Christopher Norris Deconstruction (Methuen, London, 1982).

Christopher Tindale Fallacies and Argument Appraisal (Cambridge University Press, Cambridge, 2007).

CK Ogden and IA Richards The Meaning of Meaning (10th ed, Routledge \& Kegan Paul Limited, London, 1949).

CK Ogden Opposition (Kegan Paul, Trench, Trubner \& Co Limited, London, 1932).

CL Hamblin Fallacies (Methuen \& Co Limited, London, 1970).

CS Lewis Studies in Words (Cambridge University Press, London, 1960).

David Bellos Is That a Fish in Your Ear? (Penguin Books Limited, London, 2011).

David Crystal and Derek Davy Investigating English Style (Longman Group Limited, London, 1969).

David Crystal and Hilary Crystal Words on Words (Penguin Books Limited, London, 2000).

David Crystal How Language Works (Penguin Books Limited, London, 2006).

David Crystal Linguistics (Penguin Books Limited, Harmondsworth, 1971).

David Hackett Fischer Historians’ Fallacies (Harper \& Row, Publishers, New York, 1970).

David Mellinkoff Legal Writing: Sense and Nonsense (Scribners, New York, 1982).

David Mellinkoff The Language of the Law (Little, Brown and Company, Boston, 1963).

David Pears Wittgenstein (Fontana, London, 1971).

Deborah Cameron The Myth of Mars and Venus (Oxford University Press, Oxford, 2007). 
Deborah Cameron Verbal Hygiene (Routledge, London, 1995).

Dennis Lloyd The Idea of Law (Penguin Books Limited, Harmondsworth, 1964).

Dennis Patterson Meaning, Mind and Law (Dartmouth Publishing Company Limited, Aldershot, 2008).

Douglas Walton Fallacies Arising from Ambiguity (Kluwer Academic Publishers, Dordrecht, 1996).

Douglas Walton Fundamentals of Critical Argumentation (Cambridge University Press, New York, 2006).

Douglas Walton Informal Fallacies (John Benjamins Publishing Company, Amsterdam, 1987).

Douglas Walton Informal Logic (2nd ed, Cambridge University Press, New York, 2008).

ED Hirsch The Aims of Interpretation (The University of Chicago Press, Chicago, 1976).

ED Hirsch Validity in Interpretation (Yale University Press, New Haven, 1967).

Edward Sapir Language (Granada Publishing Limited, London, 1978).

EL Piesse (JK Aitken (ed)) The Elements of Drafting (6th ed, The Law Book Company Limited, Sydney, 1981).

Elana Shohamy Language Policy (Routledge, Abingdon, 2006).

Em Griffin A First Look at Communication Theory (McGraw-Hill, New York, 2003).

ER Emmet Learning to Philosophize (Penguin Books Limited, Harmondsworth, 1968).

Ernest Gellner Words and Things (Penguin Books Limited, Harmondsworth, 1968).

Ernest Lepore and Barry C Smith The Oxford Handbook of Philosophy of Language (Clarendon Press, Oxford, 2006).

Erving Goffman Frame Analysis (Northeastern University Press, Boston, 1986).

Evelyn Waugh The Loved One (Penguin Books Limited, Harmondsworth, 1951). 
Ferdinand de Saussure (Roy Harris (trans)) Course in General Linguistics (Open Court Publishing Company, Peru (IL), 1986).

FR Palmer Semantics (2nd ed, Cambridge University Press, Cambridge, 1981).

Francis Lieber Legal and Political Hermeneutics (Charles C Little and James Brown, Boston, 1839).

Fred Rodell Woe Unto You, Lawyers (Pageant Press, New York, 1957).

Frederick Schauer Law and Language (Dartmouth, Aldershot, 1993).

F Waismann (R Harre (ed)) The Principles of Linguistic Philosophy (Macmillan and Co Limited, London, 1965).

GC Thornton Legislative Drafting (4th ed, Butterworths, London, 1996).

Geoffrey Leech Semantics (Penguin Books Limited, Harmondsworth, 1974).

Geoffrey Sampson The 'Language Instinct' Debate (Continuum, London, 2005).

George W Grace The Linguistic Construction of Reality (Croom Helm Publishers Limited, Beckenham, 1987).

George Steiner Real Presences (The University of Chicago Press, Chicago, 1989).

Georgia Lepper Categories in Text and Talk (SAGE Publications, London, 2000).

GHR Parkinson (ed) The Theory of Meaning (Oxford University Press, Oxford, 1968).

Gilbert Harman Reasoning, Meaning and Mind (Clarendon Press, Oxford, 1999).

Gilbert Ryle The Concept of Mind (Penguin Books Limited, Harmondsworth, 1963).

GK Chesterton The Everlasting Man (Ignatius Press, San Francisco, 1993).

Glanville Williams Learning the Law (10th ed, Stevens \& Sons, London, 1978).

GW Turner Stylistics (Penguin Books Limited, Harmondsworth, 1973). 
H Vaihinger The Philosophy of 'As If' (Kegan Paul, Trench, Trubner \& Co Limited, London, 1924).

Heikki ES Mattila (Christopher Goddard trans) Comparative Legal Linguistics (Ashgate Publishing Limited, Aldershot, 2006).

Henry Campbell Black (Joseph R Nolan and Jacqueline M Nolan-Haley (eds)) Black's Law Dictionary (6th ed, West Publishing Co, St Paul (Minn), 1990).

HG Widdowson Discourse Analysis (Oxford University Press, Oxford, 2007).

HLA Hart The Concept of Law (Oxford University Press, Oxford, 1997).

Howard Jackson Words and Their Meaning (Longman Group UK Limited, Harlow, 1988).

Howard Kahane and Nancy Cavender Logic and Contemporary Rhetoric (9th ed, Wadsworth/Thomson Learning, Belmont, 2002).

IA Richards Practical Criticism (Kegan Paul, Trench, Trubner \& Company Limited, London, 1935).

Irving M Copi and Carl Cohen Introduction to Logic (10th ed, Prentice-Hall, Inc, London, 1998).

Isaac Watts Logic (Thomas Tegg, London, 1811).

JA Ernesti Elements of Interpretation (trans Moses Stuart) (Flagg and Gould, Printers, Andover (Mass) 1822).

JA Jolowicz On Civil Procedure (Cambridge University Press, Cambridge, 2000).

JA Simpson and ESC Weiner (eds) The Oxford English Dictionary (2nd ed, Clarendon Press, Oxford, 1989).

James Bradstreet Greenough and George Lyman Kittredge Words and their Ways in English Speech (Macmillian and Co Limited, London, 1914).

James R Hurford and Brendan Heasley Semantics (Cambridge University Press, Cambridge, 1983).

James R Hurford The Origin of Meaning (Oxford University Press, Oxford, 2007). 
Jamie Whyte Crimes Against Logic (McGraw-Hill, New York, 2005).

Jan Nuyts and Eric Pederson (eds) Language and Conceptualization (Cambridge University Press, Cambridge, 1997).

Jan Renkema (ed) Discourse, of Course (John Benjamins Publishing Company, Amsterdam, 2009).

Janet Holmes An Introduction to Sociolinguistics (2nd ed, Pearson Education Limited, Harlow, 2001).

JC Gray The Nature and Sources of the Law (The Columbia University Press, New York, 1909).

Jean Aitchison Linguistics (6th ed, Hodder Headline, London, 2003).

Jennifer Hornsby and Guy Longworth Reading Philosophy of Language (Blackwell Publishing, Malden (Mass), 2006).

Jenny Thomas Meaning in Interaction (Longman, London, 1995).

Jeremy Bentham The Book of Fallacies (John and HL Hunt, London, 1824).

Jerome Bruner Acts of Meaning (Harvard University Press, Cambridge (Mass), 1990).

Jerome Frank Courts on Trial (Princeton University Press, Princeton, 1950).

Jerome Frank Law and the Modern Mind (Transaction Publishers, New Brunswick (NJ), 2009).

Jerome K Jerome The Diary of a Pilgrimage (JW Arrowsmith, Bristol, 1891).

JF Burrows and RI Carter Statute Law in New Zealand (LexisNexis, Wellington, 2009).

Jim Evans Statutory Interpretation (Oxford University Press, Auckland, 1988).

JO Urmson Philosophical Analysis (Oxford University Press, Oxford, 1976).

John B O'Malley Sociology of Meaning (Human Context Books, London, 1972).

John Farrar Introduction to Legal Method (Sweet \& Maxwell, London, 1977).

John Gibbons (ed) Language and the Law (Longman Group UK Limited, Harlow, 1994). 
John Gibbons Forensic Linguistics (Blackwell Publishing Limited, Oxford, 2003).

John Gray Men are from Mars, Women are from Venus (Thorsons, New York, 1993).

John Hospers An Introduction to Philosophical Analysis (4th ed, Routledge, London, 1997).

John L Austin How to Do Things with Words (2nd ed, Harvard University Press, Cambridge (Mass), 1975).

John Locke (John W Yolton (ed)) An Essay Concerning Human Understanding (JM Dent, London, 1993).

John Lyons Chomsky (Fontana, London, 1970).

John Lyons Language, Meaning \& Context (Fontana Paperbacks, Bungay, 1981).

John M Ellis Language, Thought, and Logic (Northwestern University Press, Evanston (IL), 1993).

John Milton (Merritt Y Hughes (ed)) Paradise Lost (The Odyssey Press, Indianapolis, 1962).

John R Searle Intentionality (Cambridge University Press, Cambridge, 1983).

John R Searle Speech Acts (Syndics of the Cambridge University Press, London, 1969).

John R Searle The Construction of Social Reality (The Free Press, New York, 1995).

John V Canfield (ed) Philosophy of Meaning, Knowledge and Value in the Twentieth Century (Routledge, London, 1997).

John Willinsky Empire of Words (Princeton University Press, Princeton, 1994).

John Wilson Language and the Pursuit of Truth (Cambridge University Press, London, 1969).

John Wilson Thinking with Concepts (Cambridge University Press, Cambridge, 1971).

Jonathan Bignell Media Semiotics (2nd ed, Manchester University Press, Manchester, 2002).

Jonathan Culler On Deconstruction (Cornell University Press, New York, 1982). 
Jonathan Culler Structuralist Poetics (Routledge \& Kegan Paul, London, 1975).

Judith N Levi Language and Law (American Bar Association, Chicago, 1994).

Julian Baggini and Peter S Fosl The Philosopher's Toolkit (Blackwell Publishers Limited, Malden (Mass), 2003).

Karl Britton Communication (Kegan Paul, Trench, Trubner \& Co Limited, London, 1939).

Karl N Llewellyn The Bramble Bush (Oxford University Press, New York, 2008).

Karol Janicki Confusing Discourse (Palgrave Macmillan, Basingstoke, 2010).

Keith Allan Linguistic Meaning (Routledge \& Kegan Paul, London, 1986).

Keith Allan Natural Language Semantics (Blackwell Publishers Limited, Oxford, 2001).

Kevin J Vanhoozer Is There a Meaning in This Text? (Zondervan, Grand Rapids, 1998).

Kim Lewison The Interpretation of Contracts (3rd ed, Sweet \& Maxwell, London, 2004).

L Susan Stebbing A Modern Introduction to Logic (Methuen \& Co Limited, London, 1930).

L Susan Stebbing Thinking to Some Purpose (Penguin Books, Harmondsworth, 1939).

Laurence R Horn and Gregory Ward (eds) The Handbook of Pragmatics (Blackwell Publishing, Malden (Mass), 2004).

Laurie Bauer \& Peter Trudgill Language Myths (Penguin Books Limited, London, 1998).

Lawrence M Solan The Language of Judges (The University of Chicago Press, Chicago, 1993).

Leonard Bloomfield Language (Henry Holt and Company, New York, 1933).

Lewis Carroll (Martin Gardner (ed)) The Annotated Alice (Penguin Books Limited, London, 2001).

Lionel Ruby The Art of Making Sense (3rd ed, JB Lippincott Company, Philadelphia, 1974).

Logan Pearsall Smith The English Language (Oxford University Press, London, 1944). 
Lon L Fuller Legal Fictions (Stanford University Press, Stanford, 1967).

Ludwig Wittgenstein (CK Ogden (trans)) Tractatus Logico-Philosophicus (Cosimo Classics, New York, 2010).

Ludwig Wittgenstein (GEM Anscombe (trans)) Philosophical Investigations (2nd ed, Blackwell Publishers Limited, Oxford, 1958).

Madsen Pirie The Book of the Fallacy (Routledge \& Kegan Paul, London, 1985).

MAK Halliday (Jonathan Webster (ed)) Linguistic Studies and Text and Discourse (Continuum, London, 2002).

Margaret Davies Asking the Law Question (The Law Book Company Limited, Sydney, 1994).

Marie McGinn Wittgenstein and the Philosophical Investigations (Routledge, London, 1997).

Marina Yaguello Language through the Looking Glass (Oxford University Press, Oxford, 1998).

Mario Pei Voices of Man (Harper \& Row, Publishers, New York, 1962).

Mark Adler Clarity for Lawyers (2nd ed, The Law Society, London, 2006).

Mark Twain The Adventures of Huckleberry Finn (Penguin Books Limited, London, 1985).

Mark Van Hoecke Law as Communication (Hart Publishing, Oxford, 2002).

Max Black Critical Thinking (Prentice-Hall, Inc, New York, 1946).

Max Black Language and Philosophy (Cornell University Press, Ithaca, New York, 1949).

Max Black The Labyrinth of Language (Penguin Books Limited, Harmondsworth, 1972).

Michael Zander The Law-Making Process (6th ed, Cambridge University Press, Cambridge, 2004).

Michele Asprey Plain Language for Lawyers (The Federation Press, Sydney, 2003).

Monroe C Beardsley Thinking Straight (4th ed, Prentice-Hall, Inc, New Jersey, 1975).

Morris R Cohen Reason and Law (The Free Press, Glencoe (IL), 1950). 
Morton White (ed) The Age of Analysis (The New American Library of World Literature, Inc, New York, 1955).

Nicholas Asher and Alex Lascarides Logics of Conversation (Cambridge University Press, Cambridge, 2003).

Noam Chomsky Language and Mind (Harcourt Brace Jovanovich Incorporated, New York, 1972).

Noam Chomsky Reflections on Language (Fontana Books, Glasgow, 1976).

OR Jones (ed) The Private Language Argument (Macmillan and Co Limited, London, 1971).

Paul Edwards and Arthur Pap (eds) A Modern Introduction to Philosophy (3rd ed, The Free Press, New York, 1973).

Peter Butt and Richard Castle Modern Legal Drafting (Cambridge University Press, Cambridge, 2001).

Peter F Sloss Alice’s Adventures in Jurisprudentia (Borogrove Press, Belvedere (Cal), 1982).

Peter Farb Word Play (Coronet Books, London, 1973).

Peter Goodrich Legal Discourse (St Martin’s Press, New York, 1987).

Peter M Tiersma Legal Language (University of Chicago Press, Chicago, 1999).

PG Wodehouse Stiff Upper Lip, Jeeves (Penguin Books Limited, Harmondsworth, 1966).

RA Waldron Sense and Sense Development (Andre Deutsch, London, 1967).

Randolph Quirk The Use of English (Longmans, Green and Company Limited, 1962).

Randolph Quirk Words at Work (Singapore University Press, Kent Ridge (Singapore), 1986).

Reed Dickerson The Interpretation and Application of Statutes (Little, Brown and Company, Boston, 1975).

Richard A Posner How Judges Think (Harvard University Press, Cambridge (Mass), 2008). 
Richard Chenevix Trench On the Study of Words \& English, Past and Present (JM Dent \& Sons Limited, London, 1927).

Richard Scragg New Zealand's Legal System (Oxford University Press, Oxford, 2005).

Richard Wydick Plain English for Lawyers (Carolina Academic Press, Durham, 1998).

Richmal Crompton Just William’s Luck (George Newnes Limited, London, 1949).

Rita Temmerman Towards New Ways of Terminological Description (John Benjamins Publishing Co, Amsterdam, 2000).

Robert Cockcroft and Susan Cockcroft Persuading People (2nd ed, Palgrave Macmillan, New York, 2005).

Robert H Thouless Straight and Crooked Thinking (2nd ed, Pan Books Limited, London, 1953).

Robert J Stainton Words and Thoughts (Oxford University Press, Oxford, 2006).

Robert M Martin The Meaning of Language (Massachusetts Institute of Technology, Cambridge (Mass), 1987).

Robert W Howard Concepts and Schemata (Cassell Educational, London, 1987).

Roy Harris Communication and Language (Clarendon Press, Oxford, 1978).

Roy Harris The Language Myth (Gerald Duckworth \& Company Limited, London, 1981).

Rudolf Flesch The Art of Plain Talk (Harper and Row, Publishers, New York, 1946).

Rudolf Flesch The Art of Readable Writing (Collier Books, New York, 1962).

Rudolf Flesch How to Write Plain English (Harper \& Row, New York, 1979).

Rupert Crawshay-Williams The Comforts of Unreason (Kegan Paul, Trench, Trubner \& Co Limited, London, 1947).

Rupert Cross (John Bell and George Engle (eds)) Statutory Interpretation (3rd ed, Butterworths, London, 1995). 
Ruth M Kempson Semantic Theory (Cambridge University Press, Cambridge, 1977).

Ruth Rendell Make Death Love Me (Arrow Books, London, 1980).

Ruth Sullivan Statutory Interpretation (2nd ed, Irwin Law Inc, Toronto, 2007).

Sarah Worthington (ed) Commercial Law and Commercial Practice (Hart Publishing, Oxford, 2003).

S Morris Engel Fallacies and Pitfalls of Language (Dover Publications, Inc, New York, 1994).

S Morris Engel With Good Reason (2nd ed, St Martin's Press, New York, 1982).

Sanford Schane Language and the Law (Continuum, London, 2006).

SI Hayakawa Language in Thought and Action (3rd ed, George Allen \& Unwin Limited, London, 1974).

Simeon Potter Language in the Modern World (Penguin Books Limited, Harmondsworth, 1960).

Simeon Potter Our Language (Penguin Books Limited, Harmondsworth, 1966).

Simon Blackburn Spreading the Word (Oxford University Press, Oxford, 1984).

Siobhan Chapman Thinking About Language (Palgrave Macmillan, Basingstoke, Hampshire, 2006).

Sir Ernest Gowers The Complete Plain Words (Penguin Books Limited, Harmondsworth, 1962).

Sir William Dale (ed) British and French Statutory Drafting (Institute of Advanced Legal Studies University of London, 1986).

Sir William Dale Legislative Drafting (Butterworths, London, 1977).

Stanley Fish Is There a Text in This Class? (Harvard University Press, Cambridge (Mass), 1980).

Stephen Edelston Toulmin The Uses of Argument (Cambridge University Press, Cambridge, 1964).

Stephen Potter Anti-Woo (William Heinemann Limited, London, 1965).

Stephen Ullmann Semantics (Basil Blackwell, Oxford, 1962). 
Stephen Ullmann Words and their Use (Frederick Muller Limited, London, 1951).

Steven Pinker The Language Instinct (Penguin Books Limited, London, 1994).

Steven Pinker The Stuff of Thought (Penguin Books Limited, London, 2008).

Steven Pinker Words and Rules (Basic Books, New York, 1999).

Stuart Chase and Marian Tyler Chase Power of Words (Harcourt, Brace \& World, Inc, New York, 1953).

Stuart Chase The Tyranny of Words (6th ed, Methuen \& Company Limited, Great Britain, 1947).

Susanne K Langer Philosophy in a New Key (The New American Library of World Literature, Inc, New York, 1958).

T Edward Damer Attacking Faulty Reasoning (3rd ed, Wadsworth Publishing Company, Belmont, 1995).

TA Rickard Technical Writing (2nd ed, John Wiley \& Sons Inc, London, 1923).

Terence Hawkes Structuralism and Semiotics (Methuen \& Company Limited, London, 1977).

Terry Eagleton Literary Theory (Blackwell Publishing, Oxford, 2008).

Teun A van Dijk Text and Context (Longman, London, 1977).

Thurman Arnold The Symbols of Government (Harcourt, Brace \& World, Inc, New York, 1962).

V Welby Significs and Language (Macmillan and Co Limited, London, 1911).

V Welby What is Meaning? (Macmillan and Co Limited, London, 1903).

Victoria Fromkin and Robert Rodman An Introduction to Language (2nd ed, Holt, Rinehart and Winston, New York, 1978).

Vladimir Nabokov Pnin (William Heinemann Limited, London, 1957).

W Ward Fearnside and William B Holther Fallacy (Prentice-Hall, Inc, Englewood Cliffs (NJ), 
1959).

Walker Percy The Message in the Bottle (Farrar, Straus and Giroux, New York, 1979).

Wallace L Anderson and Norman C Stageberg (eds) Introductory Readings on Language (Holt, Rinehart and Winston, Incorporated, New York, 1967).

Walter Martin The Kingdom of Cults (Bethany House Publishers, Minneapolis, 1977).

Walter Probert Law, Language and Communication (Charles C Thomas, Springfield, 1972).

Wendell Johnson People in Quandaries (Harper \& Brothers Publishers, New York, 1946).

Wendell Johnson Verbal Man (Collier Books, New York, 1965).

Wendell V Harris Interpretive Acts (Clarendon Press, Oxford, 1988).

WH Hudson Far Away and Long Ago (JM Dent \& Sons Limited, London, 1951).

William B Cairns Introduction to Rhetoric (Ginn \& Company, Boston, 1899).

WVO Quine Word and Object (MIT Press, Cambridge (Mass), 1960).

William Blackstone The Commentaries on the Laws of England (Robert Malcolm Kerr (ed)) (4th ed, John Murray, London, 1876).

William Empson Seven Types of Ambiguity (2nd ed, Chatto and Windus, London, 1949).

William N Eskridge, Philip P Frickey and Elizabeth Garrett Legislation and Statutory Interpretation (Foundation Press, New York, 2006).

William R Bishin and Christopher D Stone Law, Language, and Ethics (The Foundation Press, Inc, Mineola, New York, 1972).

Wolfgang B Sperlich Noam Chomsky (Reaktion Books Limited, London, 2006).

Yan Huang Pragmatics (Oxford University Press, Oxford, 2007). 


\section{Articles}

“Looking It Up: Dictionaries and Statutory Interpretation” (1994) 107 Harv L Rev 1437.

AC Gimson "The Transmission of Language” in Randolph Quirk The Use of English (Longmans, Green and Company Limited, 1962) 259.

Adam Kramer “Common Sense Principles of Contract Interpretation (and how we've been using them all along)” (2003) 23 Oxford J Legal Stud 173.

Alan Wolfe "Where (And Whether) to Draw the Line” (1992) 7 Sociological Forum 375.

Alyssa A DiRusso “He Says, She Asks: Gender, Language, and the Law of Precatory Words in Wills” (2007) 22 Wis Women’s LJ 1.

Andrei Marmor “The Immorality of Textualism” (2005) 38 Loy LA L Rev 2063.

Andrew Burrows "Construction and Rectification" in Andrew Burrows and Edwin Peel (eds) Contract Terms (Oxford University Press, Oxford, 2007) 77.

Andrew Jay McClurg "Logical Fallacies and the Supreme Court: A Critical Examination of Justice Rehnquist’s Decisions in Criminal Procedure Cases” (1988) 59 U Colo L Rev 741.

Anna Wierzbicka “'Apples’ Are Not a 'Kind of Fruit': The Semantics of Human Categorization” (1984) 11 American Ethnologist 313

Anthony Mason “The Art of Judging” (2008) 12 Southern Cross University L Rev 33.

AV Nesterov “On Semantic, Pragmatic, and Dialectic Triangles” (2009) 43 Automatic Documentation and Mathematical Linguistics 132.

Barbara Bintliff “Context and Legal Research” (2007) 99 Law Libr J 249.

Bernard S Jackson "Who Enacts Statutes” (1997) 18 Statute L Rev 177.

Brenda Danet “Language in the Legal Process” (1980) 14 Law \& Soc’y Rev 445.

Brian Bix “H.L.A. Hart and the Hermeneutic Turn in Legal Theory” (1999) 52 SMU L Rev 167.

Brian Bix “Michael Moore’s Realist Approach to Law” (1992) 140 U Pa L Rev 1293. 
Brian Hunt "Plain Language in Legislative Drafting: An Achievable Objective or a Laudable Ideal?” (2003) 24 Statute L Rev 112.

Brian Hunt "Plain Language in Legislative Drafting: Is it Really the Answer” (2002) 23 Statute L Rev 24.

Brian J Arnold “The Interpretation of Tax Treaties: Myth and Reality” (2010) 64 Bulletin for International Taxation 2.

Carol M Bast “Lawyers Should Use Plain Language” (1995) 69 Fla Bar J 30.

Charles Alan Wright “Goodbye to Fred Rodell” (1980) 89 Yale LJ 1455.

Charles J Fillmore "Frame Semantics" in Linguistics in the Morning Calm: Selected Papers from SICOL-1981 (Hanshin Publishing Company, Seoul, 1982).

Charles Leslie Stevenson “Persuasive Definitions” (1938) 47 Mind (NS) 331.

Charles W Collier “Speech and Communication in Law and Philosophy” (2006) 12 Legal Theory 1.

Christena Nippert-Eng “Calendars and Keys: The Classification of 'Home' and 'Work”' (1996) 11 Sociological Forum 563.

Christine Mowat “Exploring Meanings of Plain Language” (2004) 52 Clarity 42.

Christopher Hutton "Review of Sanford Schane Language and the Law" (2008) 12 Journal of Sociolinguistics 363.

Christopher Staughton “How Do the Courts Interpret Commercial Contracts?” (1999) 58 CLJ 303.

Christopher W Tindale “Fallacies, Blunders, and Dialogue Shifts: Walton's Contributions to the Fallacy Debate” (1997) 11 Argumentation 341.

Christopher Walshaw “Judicial process: construction or application?” [2010] NZLJ 357.

CJR “Is the Tomato a Fruit or a Vegetable?” (1927) 2 Notre Dame L 123.

Clark D Cunningham and Charles J Fillmore "Using Common Sense: A Linguistic Perspective on Judicial Interpretations of Use a Firearm” (1995) 73 Wash U L Q 1159. 
Clark D Cunningham and others “Plain Meaning and Hard Cases” (1994) 103 Yale LJ 1561.

Daniel CK Chow “Trashing Nihilism” (1990) 65 Tul L Rev 221.

David B Kronenfeld "Issues in the Classification of Kinship Terminologies” (2006) 101 Anthropos 203.

David Burrows “Of Mururoas and Marevas: a Plea for the Liberation of Legal Language (2006) 36 Fam Law 489.

David Crump “Against Plain English: The Case for a Functional Approach to Legal Document Preparation” (2002) 33 Rutgers LJ 713.

David Goddard “The Myth of Subjectivity” (1987) 7 Legal Stud 263.

David Kelly “Legislative Drafting and Plain English” (1986) 10 Adel L Rev 409.

David M Becker “Debunking the Sanctity of Precedent” (1998) Wash U L Q 853.

David Mellinkoff “The Myth of Precision and the Law Dictionary” (1983) 31 UCLA L Rev 423.

DC Dennett “Quining Qualia” in AJ Marcel and E Bisiach (eds) Consciousness in Contemporary Science (Clarendon Press, Oxford, 1988) 42.

Deborah Cameron "When Worlds Collide: Expert and Popular Discourse on Language” (1997) 19 Language Sciences 7.

Dennis Patterson “Against a Theory of Meaning” (1995) 73 Wash U L Q 1153.

Dennis Patterson “Interpretation in Law” (2005) 42 San Diego L Rev 685.

Donald Davidson “Communication and Convention” (1984) 59 Synthese 3.

Donald H Layh "Plain English: Increasing the Power of Our Writing” (1992) 9 Saskatchewan L Rev 1.

Donald Nicholls “My Kingdom for a Horse: The Meaning of Words” (2005) 121 LQR 577.

Doug Surtees “Procedure 'B' is for Bayda” (2007) 70 Sack L Rev 259. 
Douglas Walton “Alfred Sidgwick: A Little-Known Precursor of Informal Logic and Argumentation” (2000) 14 Argumentation 175.

DW McLauchlan “Common Intention and Contract Interpretation” [2011] LMCLQ 30.

DW McLauchlan “Contract Interpretation: What Is It About” (2009) 31 Sydney L Rev 5.

DW McLauchlan “Interpretation and Rectification: Lord Hoffmann's Last Stand” [2009] NZ Law Review 431.

DW McLauchlan “Objectivity in Contract” (2005) 24 U QLJ 479.

DW McLauchlan “The New Law of Contract Interpretation” (2000) 19 NZULR 147.

DW McLauchlan “The Plain Meaning Rule of Contractual Interpretation” (1996) 2 NZBLQ 80.

Dwight Bolinger “Truth Is a Linguistic Question” (1973) 49 Language 539.

E Allan Farnsworth "Meaning in the Law of Contracts” (1967) 76 Yale LJ 939.

Edgardo Rotman "The Inherent Problems of Legal Translation: Theoretical Aspects” (1995) 6 Ind Int'l \& Comp L Rev 187.

Edward B Duffy “Practicing Law and General Semantics” (1958) 9 W Res L Rev 119.

Edward H Levi “An Introduction to Legal Reasoning” (1948) 15 U Chi L Rev 501.

Edwin W Patterson “Logic in the Law” (1942) 90 U Pa L Rev 875.

Elizabeth Fajans and Mary R Falk “Against the Tyranny of Paraphrase: Talking Back to Texts” (1993) 78 Cornell L Rev 163.

Ellen P Aprill “The Law of the Word: Dictionary Shopping in the Supreme Court”(1998) 30 Ariz St LJ 275.

Eviatar Zerubavel “Lumping and Splitting: Notes on Social Classification” (1996) 11 Sociological Forum 421.

Ewan McKendrick “The Interpretation of Contracts: Lord Hoffmann’s Re-Statement” in Sarah 
Worthington (ed) Commercial Law and Commercial Practice (Hart Publishing, Oxford, 2003).

Felix S Cohen “Field Theory and Judicial Logic” (1950) 59 Yale LJ 238.

Felix S Cohen “Transcendental Nonsense and the Functional Approach” (1935) 35 Colum L Rev 809.

Frank Maher “Words, Words, Words” (1984) 14 Melb U L Rev 468.

Frank L Schiavo “Does the Use of 'Request,' 'Wish,' or 'Desire' Create a Precatory Trust or Not?” (2006) 40 Real Prop Probate \& Trust J 647.

Franklin Fearing “Words, Words, Words” (1947) 2 Hollywood Quarterly 312.

Fred Rodell “Goodbye to Law Reviews - Revisited” (1962) 48 Va L Rev 280.

Fred Rodell “Goodbye to Law Reviews” (1936) 23 Va L Rev 38.

Frederick Schauer “The Authority of Legal Scholarship” (1991) 139 U Pa L Rev 1003.

G Beth Packert “The Relentless Realist: Fred Rodell's Life and Writings” (1984) 1984 U Ill L Rev 823.

Gary S Lawson "Linguistics and Legal Epistemology: Why the Law Pays Less Attention to Linguists than it Should” (1995) 73 Wash U L Q 995.

George D Gopen “The State of Legal Writing: Res Ipsa Loquitur” (1987) 86 Mich L Rev 333.

George Lakoff "Categories” in Linguistics in the Morning Calm: Selected Papers from SICOL-1981 (Hanshin Publishing Company, Seoul, 1982).

George Orwell "Politics and the English Language" in The Collected Essays, Journalism and Letters of George Orwell (Penguin Books Limited, Harmondsworth, 1970) Vol 4156.

Gerard McMeel "Language and the Law Revisited: An Intellectual History of Contractual Interpretation” (2005) 34 Comm L World Rev 256.

Glanville Williams “Language and the Law” (1945) 61 Law Q Rev 71.

Glanville Williams “The Meaning of Literal Interpretation” (1981) 131 NLJ 1128. 
Gottlob Frege “Sense and Reference” (1948) 57 Philosophical Review 209.

Harold J Krent “The Failed Promise of Regulatory Variables” (1995) 73 Wash U L Q 1117.

Herbert Morris “Verbal Disputes and the Legal Philosophy of John Austin” (1960) 7 UCLA L Rev 27.

Hilary Putnam “Meaning and Reference” (1973) 70 Journal of Philosophy 699.

HLA Hart “Definition and Theory in Jurisprudence” (1954) 70 LQR 87 at 88.

Howard Kahane “Thomason on Natural Kinds” (1969) 3 Noûs 409.

HP Grice “Logic and Conversation” in Peter Cole and Jerry L Morgan (eds) Syntax and Semantics (Academic Press, New York, 1975) 41.

HP Grice “Meaning” (1957) 66 Philosophical Review 377.

HP Grice “Utterer's Meaning, Sentence-Meaning, and Word-Meaning” (1968) 4 Foundations of Language 225.

Hugh Collins "Objectivity and Contextualism in Interpretation” in Sarah Worthington (ed) Commercial Law and Commercial Practice (Hart Publishing, Oxford, 2003) 189

James Boyd White "Law as Language: Reading Law and Reading Literature” (1982) 60 Tex L Rev 415.

James Boyd White "Law As Rhetoric, Rhetoric As Law: The Arts of Cultural and Communal Life" (1985) 52 U Chi L Rev 684.

James D Gordon III “How Not to Succeed in Law School” (1991) 100 Yale LJ 1679.

James Farr "Francis Lieber and the Interpretation of American Political Science" (1990) 52 Journal of Politics 1027.

James Reid “The Judge as Law Maker” (1972) 12 JSPTL 22.

JC Cooley “Review of Lionel Ruby Logic” (1953) 50 Journal of Philosophy 619. 
Jeffrey Barnes “The Continuing Debate About 'Plain Language' Legislation: A Law Reform Conundrum” (2006) 27 Statute L Rev 83.

Jerome Frank “What Courts Do in Fact” (1931-1932) 26 Ill L Rev 645.

Jerome Frank “Words and Music: Some Remarks on Statutory Interpretation” (1947) 47 Colum L Rev 1259.

Jim Chen “Law as a Species of Language Acquisition” (1995) 73 Wash U L Q 1263.

Jim Evans “Sketch of a Theory of Statutory Interpretation” [2005] NZ L Rev 449.

JJ Spigelman “From Text to Context” (2007) 81 Australian Law Journal 322.

JJ Spigelman “The poet’s rich resource: Issues in statutory interpretation” (2001) 21 Aust Bar Rev 224.

JJ Spigelman “Words, Words, Words” (2007) 81 Australian Law Journal 601.

Johan Steyn “Contract Law: Fulfilling the Reasonable Expectations of Honest Men” (1997) 113 LQR 433.

Johan Steyn “Does Legal Formalism Hold Sway in England?” (1996) 49 CLP 43.

Johan Steyn "Interpretation: Legal Texts and their Landscape" in Basil S Markesinis (ed) The Coming Together of the Common Law and the Civil Law (Hart Publishing, Oxford, 2000) 79.

Johan Steyn “Pepper v Hart; A Re-examination” (2001) 21 Oxford J Legal Stud 59.

Johan Steyn "The Intractable Problem of The Interpretation of Legal Texts” (2003) 25 Sydney L Rev 5.

Johan Steyn “Written Contracts: To What Extent May Evidence Control Language?” (1988) 41 CLP 23.

John Dewey “Logical Method and Law” (1924) 33 Philosophical Review 560.

John Dewey “The Historic Background of Corporate Legal Personality” (1926) 35 Yale LJ 655.

John Dewey "The Influence of Darwinism on Philosophy” in Martin Gardner (ed) The Sacred 
Beetle (Oxford University Press, Oxford, 1985).

John E Nowak “Professor Rodell, The Burger Court, and Public Opinion” (1994) 1 Const Comment 107.

John M Ellis “What Does Deconstruction Contribute to Theory of Criticism?” (1988) 19 New Literary History 259.

John R Searle “How to Derive 'Ought’ From 'Is”” (1964) 73 Philosophical Review 43.

John R Searle “Meaning and Speech Acts” (1962) 71 Philosophical Review 423.

John W Hager “Let’s Simplify Legal Language” (1959) 32 Rocky Mntn L Rev 74.

John Willis “Statute Interpretation in a Nutshell” (1938) 16 Can Bar Rev 1.

Joseph C Smith “Law, Language, and Philosophy” (1968) 3 U Brit Colum L Rev 59.

Joseph Kimble “Answering the Critics of Plain Language” (1994-1995) 5 Scribes J of Leg Writing 51.

Judith N Levi and others "Northwestern University/Washington University Law and Linguistics Conference-Proceedings” (1995) 73 Wash U L Q 800.

Judith N Levi "Introduction: What is Meaning in a Legal Text: A First Dialogue for Law and Linguistics” (1995) 73 Wash U L Q 771.

Kenneth MacCorquodale “On Chomsky’s Review of Skinner’s Verbal Behavior” (1970) 13 Journal of the Experimental Analysis of Behavior 83.

Kent Greenawalt "Nature of Rules and the Meaning of Meaning” (1997) 72 Notre Dame L Rev 1449.

Kent Greenwalt “The Language of Law and More Probable Than Not: Some Brief Thoughts” (1995) 73 Wash U L Q 989.

Kerry S Robichaux "A Prolegomenon to a Hermeneutic of the Bible According to the Intrinsic Being of God” (1999) 4(3) Affirmation \& Critique 3.

L Susan Stebbing "Review of AN Whitehead Process and Reality” (1930) 39 Mind (NS) 466. 
Larry A DiMatteo “A Theory of Interpretation in the Realm of Idealism” (2006) 5 DePaul Bus \& Comm LJ 17.

Larry Alexander “Fancy Theories of Interpretation Aren’t” (1995) 73 Wash U L Q 1081.

Laurence R Horn "Vehicles of Meaning: Unconventional Semantics and Unbearable Interpretations” (1995) 73 Wash U L Q 1145.

Lawrence A Cunningham "Hermeneutics and Contract Default Rules: An Essay on Lieber and Corbin” (1995) 16 Cardozo L Rev 2225.

Lawrence M Friedman “Law and Its Language” (1964) 33 Geo Wash L Rev 563.

Lawrence M Solan “Can the Legal System Use Experts on Meaning” (1999) 66 Tenn L Rev 1167.

Lawrence M Solan "Judicial Decisions and Linguistics Analysis: Is There a Linguist in the Court” (1995) 73 Wash U L Q 1069.

Lawrence M Solan “New Textualists' New Text, The Symposium: Theories of Statutory Interpretation” (2005) 38 Loy LA L Rev 2027.

Lawrence M Solan “When Judges Use the Dictionary” (1993) 68 Am Speech 50.

Lawrence M Solan "Why Laws Work Pretty Well, but Not Great: Words and Rules in Legal Interpretation” (2001) 26 Law \& Soc Inquiry 243.

Layman E Allen "Symbolic Logic: A Razor-Edged Tool for Drafting and Interpreting Legal Documents” (1957) 66 Yale LJ 833.

Leonard Hoffmann “The Intolerable Wrestle with Words and Meanings” (1997) 56 S African LJ 656.

Lera Boroditsky and Jesse Prinz "What Thought Are Made Of” in Gün R Semin and Eliot R Smith (eds) Embodied Grounding (Cambridge University Press, Cambridge, 2008) 98.

Lera Boroditsky, Lauren A Schmidt, and Webb Phillips “Sex, Syntax, and Semantics” in Dedre Gentner and Susan Goldin-Meadow (eds) Language in Mind (The MIT Press, Cambridge (Mass), 2003) 61. 
Lera Boroditsky “How language shapes thought” (February, 2011) Scientific American 63.

Lon L Fuller "Law as an Instrument of Social Control and Law as a Facilitation of Human Interaction” (1975) 1975 BYU L Rev 89.

Maimon Schwarzschild "Mad Dogmas and Englishmen: How Other People Interpret and Why" in J Goldsworthy and T Campbell (eds) Legal Interpretation in Democratic States (Ashgate Publishing Company, Aldershot, 2002) 93.

Margaret M Bryant “Language and the Law” (1949) 24 American Speech 201.

Margaret O’Toole “Lawyer's response to language constructing law” in John Gibbons (ed) Language and the Law (Longman Group UK Limited, Harlow, 1994) 188.

Mark G Kelman “Trashing” (1984) 36 Stan L Rev 293.

Martin Gardner “Art, Propaganda, and Propaganda Art” in Order and Surprise (Oxford University Press, Oxford, 1984) 29.

Matthew H Kramer "False Conclusions from True Premises: Warnings to Legal Theorists” (1994) 14 Oxford J Legal Stud 111.

Matthew Krygier "Julius Stone: Leeways of Choice, Legal Tradition and the Declaratory Theory of Law” (1986) 9 UNSWLJ 26.

Max Black “Linguistic Relativity: The Views of Benjamin Lee Whorf” (1959) 68 Philosophical Review 228.

Max Black “Meaning and Intention: An Examination of Grice's Views” (1973) 4 New Literary History 257.

Max Black “Some Objections to Ogden and Richards' Theory of Interpretation” (1942) 39 Journal of Philosophy 281.

Meyer Elkin “The Language of Family Law is the Language of Criminal Law” (1975) 13 Family Court Review iii.

MH Abrams "How to do things with texts” (1979) 46 Partisan Review 566.

Michael L Geis “The Meaning of Meaning in the Law” (1995) 73 Wash U L Q 1125. 
Michael Pantazakos “Form of Ambiguity: Law, Literature, and the Meaning of Meaning” (1998) 10 Cardozo Stud L \& Literature 199.

Michael S Moore “A Natural Law Theory of Interpretation” (1985) 58 S Cal L Rev 277.

Michael S Moore “Plain Meaning and Linguistics--A Case Study” (1995) 73 Wash U L Q 1253.

Michael S Moore “The Interpretive Turn in Modern Theory: A Turn for the Worse?” (1989) 41 Stan L Rev 871.

Michael S Moore “The Semantics of Judging” (1981) 54 S Cal L Rev 151.

Michael Toolan “A Few Words on Telementation” (1997) 19 Language Sciences 79.

Monroe C Beardsley “Modes of Interpretation” (1971) 32 Journal of the History of Ideas 143.

Moritz Schlick “Meaning and Verification” (1936) 45 Philosophical Review 339.

Nachman Ben-Yehuda "Review of Eviatar Zerubavel The Fine Line: Making Distinctions in Everyday Life” (1993) 22 Contemporary Sociology 114.

Neil Duxbury "In the Twilight of Legal Realism: Fred Rodell and the Limits of Legal Critique" (1991) 11 Oxford J Legal Stud 354.

Nicole Isaacson “The 'Fetus-Infant': Changing Classifications of 'In Utero' Development in Medical Texts” (1996) 11 Sociological Forum 457.

Noam Chomsky "Review of BF Skinner Verbal Behavior (1959) 35 Language 26.

Oliver Wendell Holmes “The Path of the Law” (1897) 1 Boston L School Mag 1.

Oliver Wendell Holmes “The Theory of Legal Interpretation” (1899) 12 Harv L Rev 417.

Owen M Fiss “Objectivity and Interpretation” (1982) 34 Stan L Rev 739.

Pamela Blewitt "Understanding Categorical Hierarchies: The Earliest Levels of Skill” (1994) 65 Child Development 1279.

Paul M Postal “Advances in Linguistic Rhetoric” (1988) 6 Natural Language \& Linguistic Theory 
Paul Ricoeur "Metaphor and the Main Problem of Hermeneutics” (1974) 6 New Literary History 95.

Paula Johnson “Interpretation Games” (1979) 41 College English 136.

Peter Butt “Modern Legal Drafting” (2002) 23 Statute L Rev 12.

Peter Goodrich "Rhetoric as Jurisprudence: An Introduction to the Politics of Legal Language" (1984) 4 Oxford J Legal Stud 88.

Peter Goodrich “The Role of Linguistics in Legal Analysis” (1984) 47 MLR 523.

Peter M Tiersma "The Ambiguity of Interpretation: Distinguishing Interpretation from Construction” (1995) 73 Wash U L Q 1095.

Peter M Tiersma "The Language of Offer and Acceptance: Speech Acts and the Question of Intent” (1986) 74 Cal L Rev 189.

PG Wodehouse "Jeeves in the Springtime” in The World of Jeeves (Herbert Jenkins Limited, 1967, London) 19.

Philip A Joseph "Parliament, the Courts and the Collaborative Enterprise” (2004) 15 KCLJ 321 at 338.

Philip P Frickey “Faithful Interpretation” (1995) 73 Wash U L Q 1085.

Philip P Frickey "From the Big Sleep to the Big Heat: The Revival of Theory in Statutory Interpretation” (1992) 77 Minn L Rev 241.

Philip P Frickey "Revisiting the Revival of Theory in Statutory Interpretation: A Lecture in Honor of Irving Younger” (1999) 84 Minn. L Rev 199.

Philip Thomas “Legal Skills and the Use of Ambiguity” (1991) 42 N Ir Legal Q 14.

Pintip Hompluem Dunn "How Judges Overrule: Speech Act Theory and the Doctrine of Stare Decisis” (2003) 113 Yale LJ 493.

PW Bridgman “Operational Analysis” (1938) 5 Philosophy of Science 114. 
Ray J Aiken “Let’s Not Oversimplify Legal Language” (1960) 32 Rocky Mntn L Rev 358.

Reed Dickerson “Referential Meaning: The Static Aspects” (1969) 10 Jurimetrics J 58.

Richard A Posner "Pragmatism versus Purposivism in First Amendment Analysis” (2002) 54 Stan L Rev 737.

Richard A Posner “The Jurisprudence of Skepticism” (1988) 86 Mich L Rev 827.

Richard Calnan "Construction of Commercial Contracts: A Practitioner's Perspective” in Andrew Burrows and Edwin Peel (eds) Contract Terms (Oxford University Press, Oxford, 2007) 17.

Richard Hyland “A Defense of Legal Writing” (1986) 134 U Pa L Rev 599.

Richard V Barndt “Language and Logic in the Law” (1964) 43 Tex L Rev 86.

Rita L Marker and Wesley J Smith “The Art of Verbal Engineering” (1996) 35 Duq L Rev 81.

Robert Chaim "Slouching into the Vernacular: In Defense of Plain Language and Plain Meaning” (1998) 22 Legal Stud F 393.

Robert Goff “Commercial contracts and the Commercial Court” [1984] LMCLQ 382.

Robert K Rasmussen “Why Linguistics” (1995) 73 Wash U L Q 1047.

Robert Rodman "Linguistics and the Law: How Knowledge of, or Ignorance of, Elementary Linguistics May Affect the Dispensing of Justice” (2002) 9 Forensic Linguistics 92.

Robert W Benson “The End of Legalese: The Game Is Over” (1984-1985) 13 NYU Rev L \& Soc Change 519.

Robert W Benson “Up a Statute with Gun and Camera: Isolating Linguistic and Logical Structures in the Analysis of Legislative Language” (1985) 8 Seton Hall Legis J 279.

Robert V Wells “The Nature of Meaning: The Role of the Trial Lawyer in Creating and Shaping Meaning” (2008) 32 Am J Trial Advoc 297.

Ronald Dworkin “Law as Interpretation” (1982) 60 Tex L Rev 527. 
Roscoe Pound “Mechanical Jurisprudence” (1908) 8 Colum L Rev 605.

Ruth McColl “The Art of Judging” (2008) 12 Southern Cross University L Rev 43.

Ruth Sullivan “Some Implications of Plain Language Drafting” (2001) 22 Statute L Rev 175.

Ruth Sullivan “Statutory Interpretation in a New Nutshell” (2003) 82 Can Bar Rev 51.

Ruth Sullivan “The Promise of Plain Language Drafting” (2001) 47 McGill LJ 97.

Sanford Schane “The Corporation is a Person: The Language of Legal Fiction” (1987) 61 Tul L Rev 563.

SI Hayakawa “Semantics, Law and Priestly-Minded Men” (1958) 9 W Res L Rev 176.

Stephen B Cohen “Words! Words! Words!: Teaching the Language of Tax” (2005) 55 J L Educ 600.

Stephen F Ross “The Limited Relevance of Plain Meaning” (1995) 73 Wash U L Q 1057.

Steven Stark “Why Lawyers Can’t Write” (1984) 97 Harvard L Rev 1389.

Steven Wisotsky "How to interpret statutes - or not: the phantom of plain meaning” (2009) 83 Florida Bar Journal 43.

Susan Krongold “Writing Laws: Making Them Easier to Understand” (1992) 24 Ottawa L Rev 495.

Susan Sontag “Against Interpretation” in Susan Sontage Against Interpretation and Other Essays (Farrar, Strauss \& Giroux, New York, 1966) 4.

Tamar Rosenblum and Steven A Pinker "Word Magic Revisited: Monolingual and Bilingual Children's Understanding of the Word-Object Relationship” (1983) 54 Child Development 773.

Terrill Pollman and Judith M Stinson “IRLAFARC! Surveying the Language of Legal Writing” (2004) 56 Me L Rev 239.

TRS Allan "Legislative Supremacy and Legislative Intention: Interpretation, Meaning, and Authority” (2004) 63 Cambridge LJ 685.

Michael Kirby “Judicial activism? A riposte to the counter-reformation” (2004) 24 Aust Bar Rev 219. 
Michael Kirby "Towards a Grand Theory of Interpretation: The Case of Statutes and Contracts" (2003) 24 Stat L Rev 95.

Urban A Lavery “Language of the Law” (1921) 7 ABAJ 277.

Walter J Ong “The Power and Mystery of Words” (1972) Saint Louis University Magazine 4.

Walter Probert “Language of Law - Preface” (1958) 9 W Res L Rev 115.

Walter Probert "Law and Persuasion: The Language Behavior of Lawyers” (1959) 108 U Pa L Rev 35.

Walter Probert “Law, Logic and Communication” (1958) 9 W Res L Rev 129.

Walter Probert “Why Not Teach Semantics in Law School” (1957) 10 J Legal Educ 208.

Walter Probert "Words Consciousness: Law and the Control of Language” (1972) 23 Case W Res L Rev 374.

Walter V Schaefer “Language of Law_Foreword” (1958) 9 W Res L Rev 117.

Wayne Schiess “What Plain English Really Is” (2003-2004) 9 Scribes J Leg Writing 43.

William D Popkin “Law and Linguistics: Is There Common Ground” 73 Wash U L Q 1043.

William K Wimsatt and Monroe C Beardsley “The Intentional Fallacy” (1946) 54 Sewanee Review 468.

William N Eskridge and Judith N Levi “Regulatory Variable and Statutory Interpretation” (1995) 73 Wash U L Q 1103.

William N Eskridge and Philip P Frickey “Statutory Interpretation as Practical Reasoning” (1990) 42 Stan L Rev 321.

William S Brewbaker III “Found Law, Made Law and Creation: Reconsidering Blackstone’s Declaratory Theory” (2006-2007) 22 J L \& Religion 255.

William T Allen and Galya Levy "The Uses of Ambiguity in Commercial Contracts: On Facilitating Re-Bargaining” in Sarah Worthington (ed) Commercial Law and Commercial Practice (Hart 
Publishing, Oxford, 2003) 163.

WVO Quine “Two Dogmas of Empiricism” (1951) 60 Philosophical Review 20.

Yon Mayley "The language of the law" in John Gibbons (ed) Language and the Law (Longman Group UK Limited, Harlow, 1994) 11.

Zechariah Chafee “The Disorderly Conduct of Words” (1941) 41 Colum L Rev 381.

\section{E Internet Material}

Timothy Endicott "Law and Language” (2010) (Edward N Zalta (ed)) Stanford Encyclopedia of Philosophy <www.plato.standford.edu $>$. 